\title{
Biodiesel from Tall Oil Fatty Acids and Physico Thermal Properties of Tropical Tree Fruit Oils as Thermal Energy Storage Systems
}

\author{
Gideon Sackey Lawer-Yolar
}

Follow this and additional works at: https://researchrepository.wvu.edu/etd

\footnotetext{
Recommended Citation

Lawer-Yolar, Gideon Sackey, "Biodiesel from Tall Oil Fatty Acids and Physico Thermal Properties of Tropical Tree Fruit Oils as Thermal Energy Storage Systems" (2015). Graduate Theses, Dissertations, and Problem Reports. 6044.

https://researchrepository.wvu.edu/etd/6044

This Dissertation is protected by copyright and/or related rights. It has been brought to you by the The Research Repository @ WVU with permission from the rights-holder(s). You are free to use this Dissertation in any way that is permitted by the copyright and related rights legislation that applies to your use. For other uses you must obtain permission from the rights-holder(s) directly, unless additional rights are indicated by a Creative Commons license in the record and/ or on the work itself. This Dissertation has been accepted for inclusion in WVU Graduate Theses, Dissertations, and Problem Reports collection by an authorized administrator of The Research Repository @ WVU. For more information, please contact researchrepository@mail.wvu.edu.
} 
Biodiesel from Tall Oil Fatty Acids and Physico Thermal Properties of Tropical Tree Fruit Oils as Thermal Energy Storage Systems

Gideon Sackey Lawer-Yolar

Dissertation submitted to the

Davis College of Agriculture, Natural Resources and Design

at West Virginia University

in partial fulfillment of the requirements for the degree of

Doctor of Philosophy

In

Forest Resources Science

Ben Dawson-Andoh, Ph.D., Chair

Eugene Felton, Ph.D.

Gregory Dahle, Ph.D.

John Renton, Ph.D.

Ben Spong, Ph.D.

Department of Wood Science and Technology

West Virginia University

Morgantown, West Virginia

2015

Keywords: TOFA, Latent Heat, Solar Energy, Allanblackia Oil, Shea Butter, Palm Kernel Oil, DSC, TGA, FTIR, Thermal cycling

Copyright 2015 Gideon Sackey Lawer-Yolar 


\section{ABSTRACT \\ Biodiesel from Tall Oil Fatty Acids and Physico Thermal Properties of Tropical Tree Fruit Oils as Thermal Energy Storage Systems}

\section{Gideon Sackey Lawer-Yolar}

Research into biodiesel as a substitute for petroleum diesel has been ongoing since the energy crisis of the 1970's. The concern for the effect on the use of edible vegetable oils as feedstock has increased. Tall oil fatty acids have been considered as a non-food substitute and various works have been done on it. In this study, sulfuric acid and Amberlyst BD 20 were used as homogeneous and heterogeneous catalysts respectively in the production of biodiesel from Tall oil fatty acids in a batch reactor. The treatment conditions for the homogeneous catalysis varied the factors of fatty acid to methanol molar ratio, the temperature, the catalyst concentration and the time of the reaction. Fourier transform infrared (FTIR) spectroscopy was used to monitor the reaction in real time to show when conversion of reactants to products is complete. Gas chromatography showed the fatty acids present in the oil sample. The major fatty acids present are oleic and linoleic acid. Acid value, the kinematic viscosity, and specific gravity were all determined. The heterogeneous catalysis kept the temperature of the reaction constant within 75$80^{\circ} \mathrm{C}$. The molar ratio, catalyst concentration and time of reaction were varied. Results showed that the homogeneous catalysis gave a higher yield that the heterogeneous catalysis. The acid value was for optimum production of the heterogeneous catalysis was lower than the homogeneous catalysis. Also the solid catalyst was recycled 4 times without losing its activity.

The storage of energy is as important as the source of the energy itself. Research into thermal energy storage systems has been ongoing but most of the research has focused on fossil fuel sources as the feedstock. This study therefore evaluated fruit oils and their synthesized products as feedstock for use as phase change materials (PCMs) in latent heat storage in thermal energy storage systems. Seeds of Allanblackia were processed into oil and also oils from shea butter and palm kernel oil were purchased commercially and further processed. Differential scanning calorimetry (DSC) was used to determine the enthalpy values as well as the temperatures at melting and crystallization. Thermo-gravimetric analysis (TGA) was used to determine stability 
of the samples within the temperature of interest. Fourier transform infrared spectroscopy (FTIR) spectra were taken to determine the chemical stability of the samples. Thermal cycling of the samples for 1000 times was used to evaluate the stability and reliability of the sample after continuous use of the sample over a very long period. Results showed that Allanblackia oil gave a high enthalpy value of $80.53 \mathrm{~J} / \mathrm{g}$ at a melting point of $34.74^{\circ} \mathrm{C}$. Allanblackia oil was chemically stable but showed a slight oxidative instability around $37^{\circ} \mathrm{C}$. However, Allanblackia oil did not decompose after 1000 thermal cycles, and can therefore be considered suitable for use as a PCM. The oils from shea butter and palm kernel are all unsuitable for use as PCMs because their enthalpy values are not latent energies. The fatty acids produced from the oils showed that Allanblackia fatty acids gave the highest latent heat values that are thermally stable and reliable within the desired temperature of interest, as well as chemically stable for use as a PCM for thermal energy storage. The fatty acids from shea butter and palm kernel oil did not show latent heat properties and therefore could not be considered as PCMs for thermal energy storage systems. The methyl esters produced from all the oils did not show potential for their use as PCMs for thermal energy storage systems but the Allanblackia butyl ester and shea butter butyl ester are capable of being considered for thermal energy storage systems. They are thermally stable and reliable within the desired temperature of interest, and also chemically stable. The butyl ester of palm kernel is unsuitable for use as a PCM for thermal energy storage system since it is chemically unstable. 


\section{DEDICATION}

A special dedication goes to my wife for the love, support, encouragement, understanding and sacrifices

To my four boys, Nathan, Moses, Paul and Kwasi, for their attachment and obedience even in times of difficulty and absence during my whole study

To family and friends within and without for your constant support and encouragement

All mentors and counsellors, as well as those who have supported us in diverse ways materially, financially and morally without whose help and guidance this achievement would never have been possible 


\section{ACKNOWLEDGEMENT}

My special thanks go to the Almighty God who has led us thus far on this way without whose hand nothing could have been achieved

I would like to acknowledge the entire membership of my doctoral dissertation committee for their special time spent in discussions and comments in the whole duration of this research and the writing of the dissertation

I am especially grateful to Miss Susan Slider of the Animal and Nutrition Department of the Davis College of Agriculture, Forestry and Design for the wonderful work done with my GC work and also Dr. Daniel Panacionne for allowing me to use his Thermal Programmer

I am also grateful to Mr. Albert Taylor of the Chemistry Department at West Virginia University for the assistance given to me for the use of the FTIR machine in the department

I cannot sign off without mentioning my colleagues Emmanuel Atta-Obeng, Kofi Nkansah, Bibu George, Charlie Collins as well as all the lecturers in the Department of Wood Science and Technology

Finally, I will like to specially thank Dr. Ben Dawson-Andoh, my major advisor and mentor for guiding, teaching, helping me not only in my research but also on a personal level to make this journey possible

Mention should also be made of Dr. Jim Armstrong, who worked with me on wood anatomy and identification. Also I am grateful to Jennifer McIntosh, Attorney David Fryson, Asuntina Levelle, my family and friends, the Division of Forestry and Natural Resources, and all the wonderful people who in diverse ways have contributed to make my studies at West Virginia University a great success

I could not have done this without your collective efforts!!!! 


\section{TABLE OF CONTENTS}

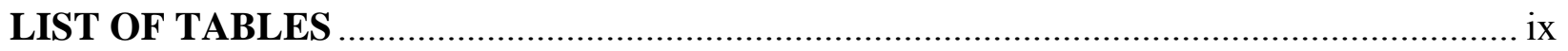

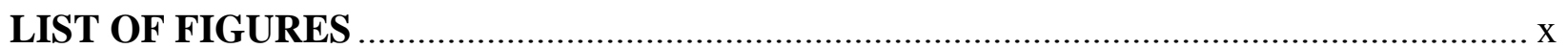

1 STRUCTURE OF DISSERTATION, INTRODUCTION AND OBJECTIVES ............... 1

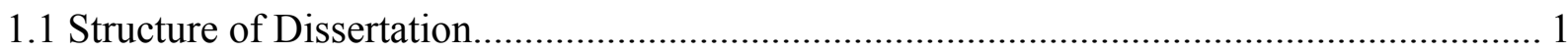

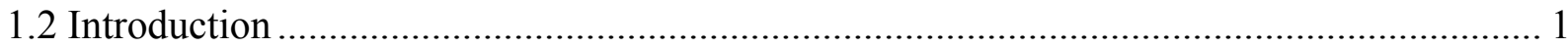

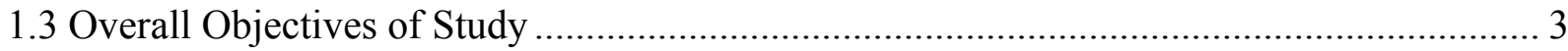

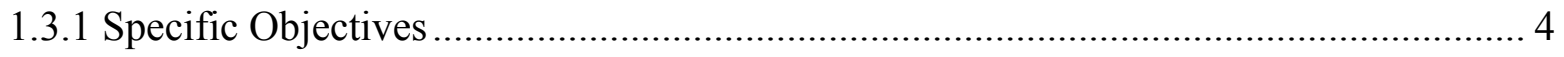

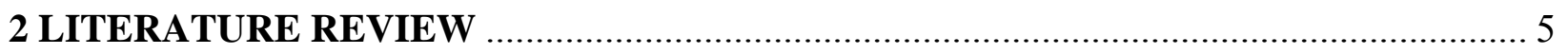

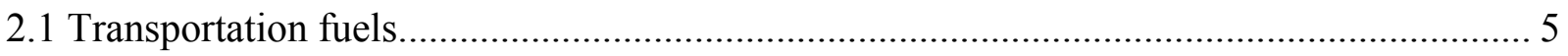

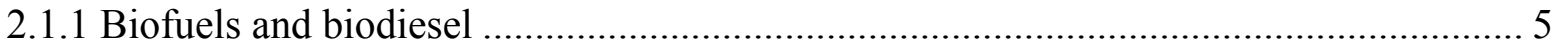

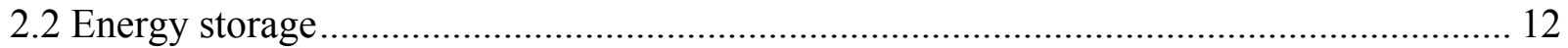

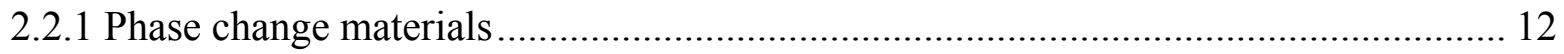

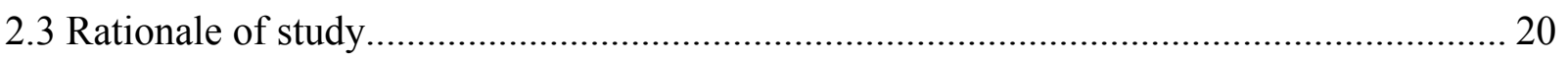

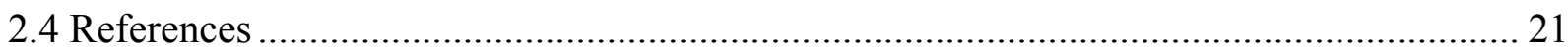

3 Biodiesel Production from Tall Oil Fatty Acids via Homogeneous and heterogeneous

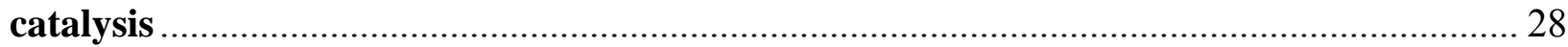

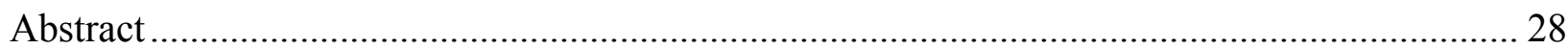

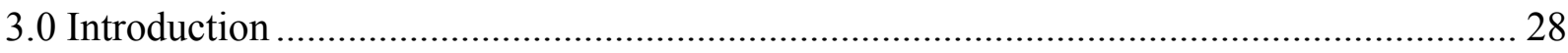

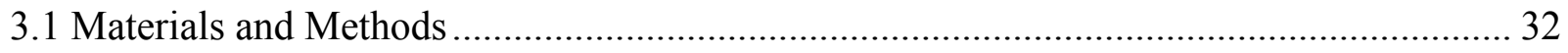

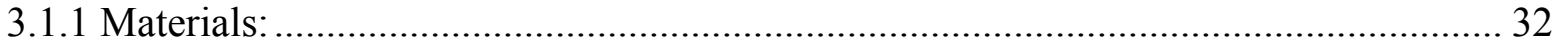

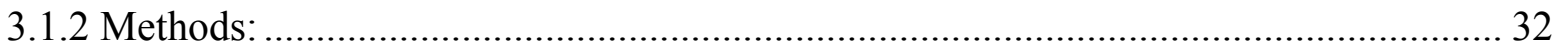

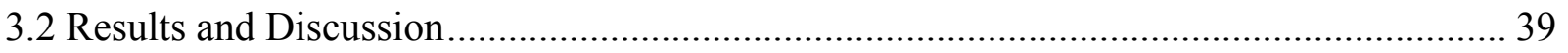

3.2.1 Statistical analysis for homogeneous catalysis ................................................ 41

3.2.2 Chemical properties of TOFA and TOME ..................................................... 42

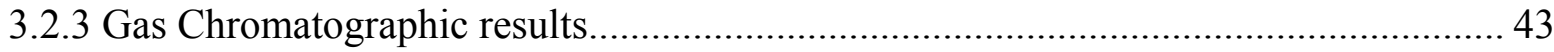

3.2.4 The FTIR spectra of TOFA and biodiesel produced by the homogeneous catalysis of

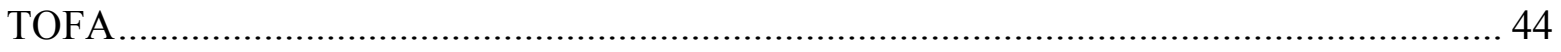

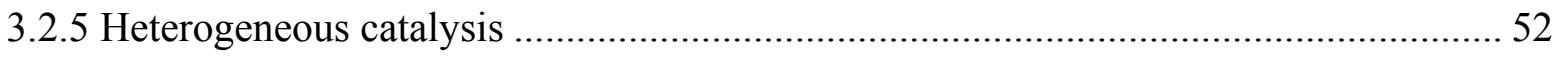

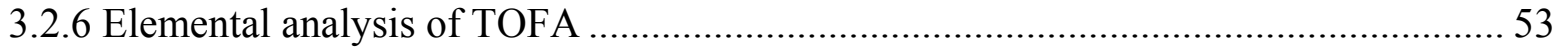

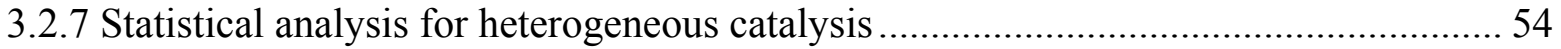

3.2.8 FTIR Spectra for the heterogeneous catalysis .................................................... 57

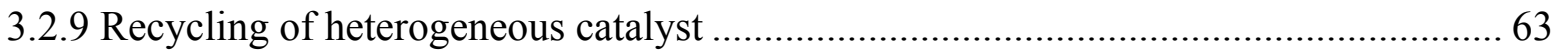




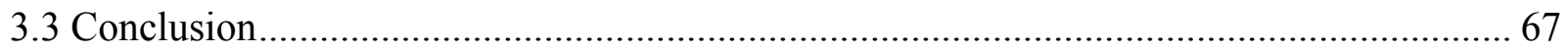

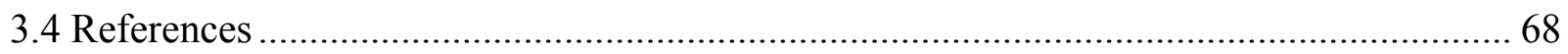

4 Phase Change Materials for Thermal Energy Storage: Evaluation of Tropical Tree Fruit

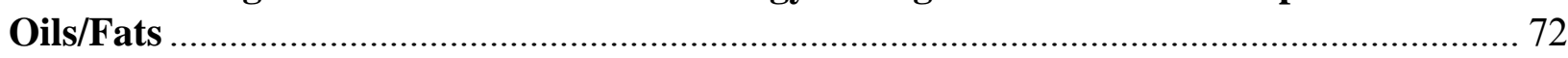

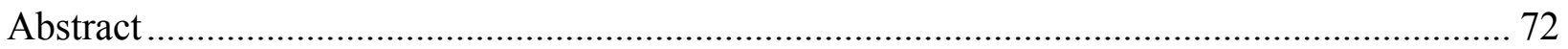

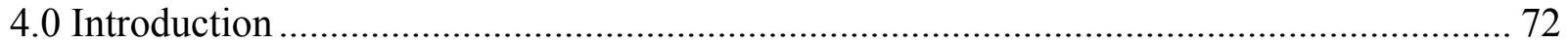

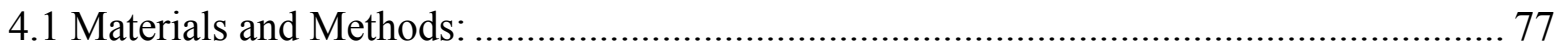

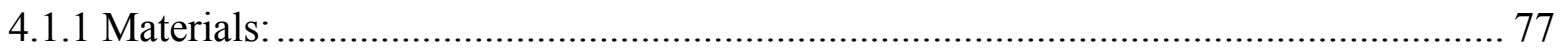

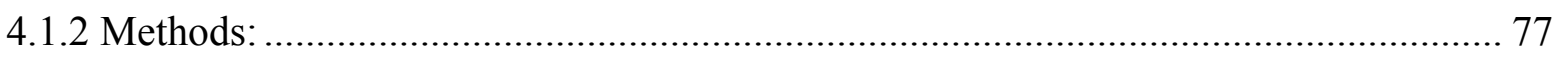

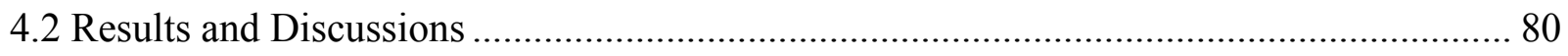

4.2.1 Optimum yield of oil extraction from Allanblackia ............................................ 80

4.2.2 Differential scanning calorimetric (DSC) analysis of oil samples ........................... 82

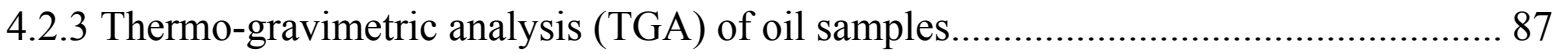

4.2.4 Fourier transform mid-infrared (FTIR) spectroscopy of the raw oil samples ............ 91

4.2.5 Thermo-physical and chemical characteristics of oils after Thermal Cycling ............ 97

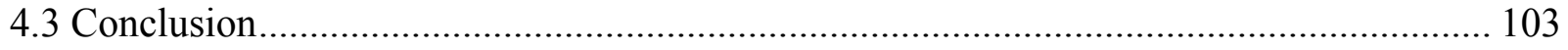

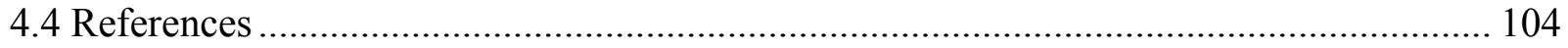

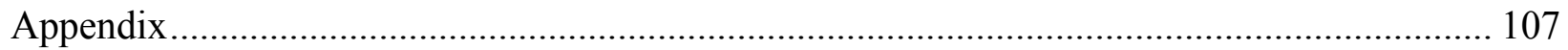

5 Phase Change Materials for Thermal Energy Storage: Evaluation of Fatty Acids from

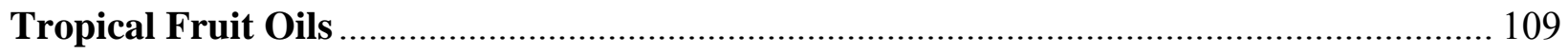

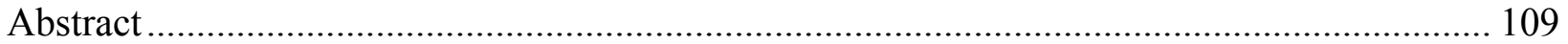

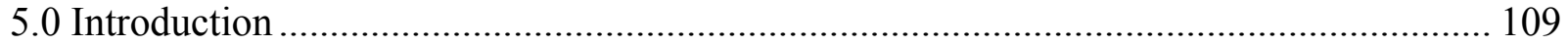

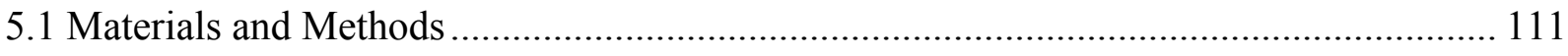

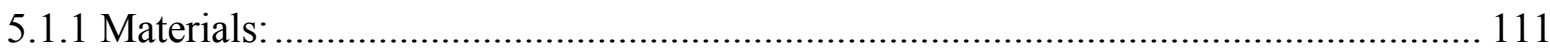

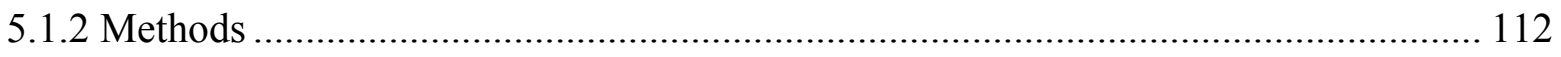

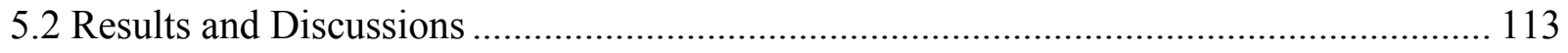

5.2.1 Differential scanning calorimetric (DSC) analysis of fatty acids........................... 113

5.2.2 DSC profile of Thermally Cycled fatty acids ........................................................ 119

5.2.3 Thermo-gravimetric analysis (TGA) of fatty acids ............................................ 125

5.2.4 Thermo-gravimetric analysis of fatty acids after Thermal Cycling ........................ 129

5.2.5 Fourier transform infrared (FTIR) spectroscopy of fatty acids ............................. 131

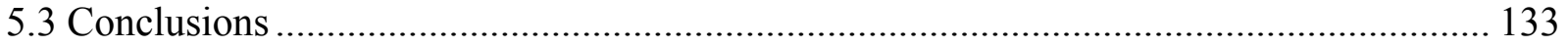

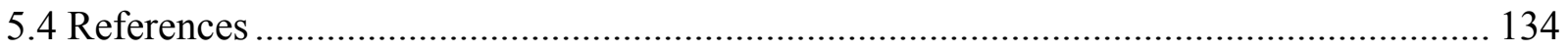


6 Evaluation of methyl and butyl esters of Tropical fruit oils as Phase Change Materials for

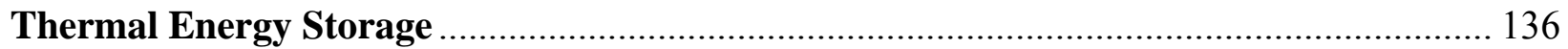

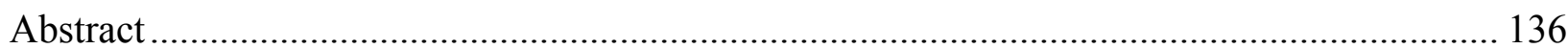

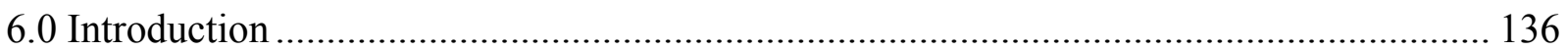

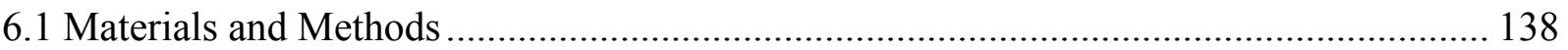

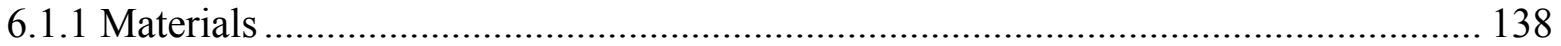

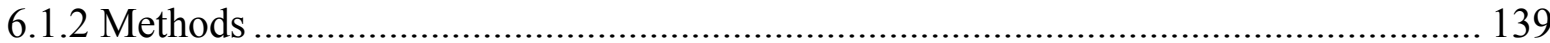

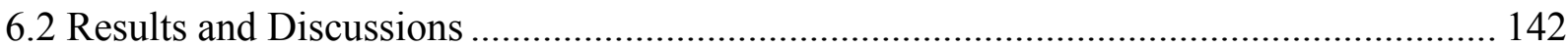

6.2.1 Differential scanning calorimetric (DSC) analysis of methyl and butyl esters produced from oils of Allanblackia, shea butter and palm kernel................................................... 142

6.2.2 Thermo-gravimetric analysis (TGA) of esters produced from the oils of Allanblackia

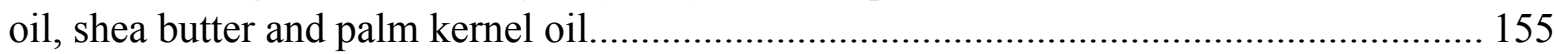

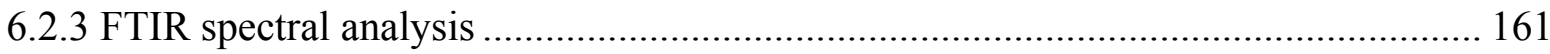

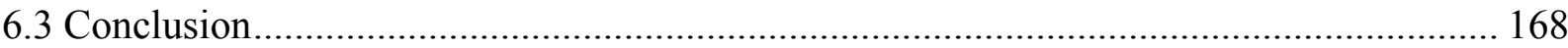

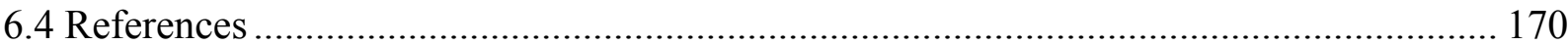

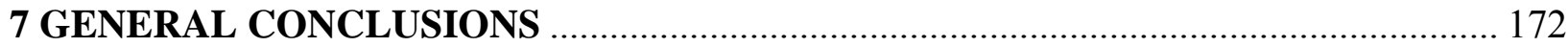

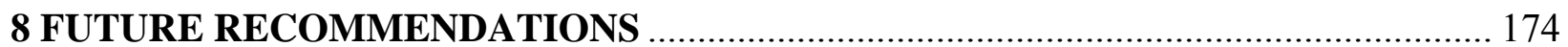




\section{LIST OF TABLES}

Table 2.1: Table showing the composition of a typical TOFA 8

Table 3.1: Microwave digestion program 33

Table 3.2: Range of sample weight for acid value determination 35

Table 3.3: Biodiesel yield from Tall oil fatty acids (TOFA) using a homogeneous catalyst 38

Table 3.4: Chemical properties of TOFA and TOME 41

Table 3.5: Fatty acid composition for TOFA using GC 42

Table 3.6: Results of biodiesel production via heterogeneous catalysis 51

Table 3.7: Results of elemental analysis $\quad 52$

Table 3.8: Results of recycling of catalyst for treatment HetBD_H3 63

Table 4.1: Results of Allanblackia oil extraction 80

Table 4.2: FTIR spectra of oil samples $\quad 91$

Table 4.3: Fatty acid characteristics of Allanblackia oil, shea butter and palm kernel oil 95

Table 4.4: Table showing the DSC profile of the oil samples before and after Thermal $\begin{array}{ll}\text { Cycling } & 97\end{array}$

Table 4.5: TGA profile of the oil samples before and after Thermal Cycling 99

Table 5.1: DSC profile of oils and their fatty acids $\quad 120$

Table 6.1: Table showing the thermal degradation of the esters of Allanblackia, shea

butter and palm kernel oil 155

Table 6.2: Table showing observed peaks in FTIR Spectra of esters of oil samples 160 


\section{LIST OF FIGURES}

Figure 2.1: Abietic acid, pimaric acid and oleic acid present in Tall Oil

Figure 2.2: Schematic view of a lightweight wall. The PCM micro-capsules are integrated into the interior plaster (Sharma et al., 2009)

Figure 2.3: The Guineo-Congolian forest zone, original forest cover in light green, and the strip of evergreen forests along the Gulf of Guinea in dark green, believed to be the habitat of Allanblackia spp. (Rompaey, 2003)

Figure 2.4: Allanblackia flowering, Allanblackia fruit on the tree, and Allablackia seeds being dried in air (Buss and Tissari, 2010)

Figure 2.5: A mature shea butter tree, flowering tree, nuts and the processed butter (www.google.com)

Figure 2.6: The palm tree, palm fruit with its kernel and the processed palm kernel oil

Figure 3.1: A graph of \%Yield against ratio, temperature, catalyst concentration and time of reaction

Figure 3.2: GC spectra of biodiesel produced from TOFA

Figure 3.3: FTIR spectra of Tall oil fatty acids (TOFA)

Figure 3.4: FTIR spectra of Tall oil methyl ester (TOME)

Figure 3.5: FTIR spectra of Tall oil methyl ester (TOME)

Figure 3.6: Overlaid FTIR spectra of TOME 16, 17 \& 18

Figure 3.7: FTIR spectra of TOME 1, 2 \& 3

Figure 3.8: FTIR spectra of TOME treatments 34,35 and 36

Figure 3.9: FTIR spectra of TOME treatments $13,14 \& 15$

Figure 3.10: FTIR spectra showing TOME 7, 8 \& 9

Figure 3.11: FTIR spectra of TOME 40, 41 and 42

Figure 3.12: The response surface graph showing ratio and catalyst concentration against $\%$ Yield

Figure 3.13: The response surface graph showing ratio and catalyst concentration against acid value 
Figure 3.14: A Graph of \%Yield against Acid Value 56

Figure 3.15: FTIR spectra of biodiesel production treatment HetBD_H18 56

Figure 3.16: FTIR spectra of biodiesel production treatment HetBD_H16 57

Figure 3.17: FTIR spectra of biodiesel production treatment HetBD_H13 57

Figure 3.18: FTIR spectra of biodiesel production treatment HetBD_H3 58

Figure 3.19: Full Range FTIR spectra for TOFA, and four different treatments for the

$\begin{array}{lr}\text { Production of biodiesel } & 59\end{array}$

Figure 3.20: FTIR spectra of TOFA and four other treatments within the wavenumber range of 3375 and $2425 \mathrm{~cm}^{-1} \quad 59$

Figure 3.21: FTIR spectra of TOFA and four treatments within the range of 2000-830 $\mathrm{cm}^{-1} \quad 60$

Figure 3.22: FTIR spectra of TOFA and four treatments within the wavenumber range of $1800-1600 \mathrm{~cm}^{-1}$

Figure 3.23: A graph showing the means comparison of \%Yield using the Tukey-Kramer HSD procedure.

Figure 3.24: A graph showing the means comparison of acid value using the Tukey-Kramer HSD procedure

Figure 3.25: The split FTIR spectra of the recycled catalyst treatments

Figure 3.26: The overlaid FTIR spectra of the biodiesel from recycled catalyst within the $1803-1680 \mathrm{~cm}^{-1}$ range

Figure 3.27: The overlaid FTIR spectra of biodiesel from recycled catalyst in the range of $1226-1103 \mathrm{~cm}^{-1}$

Figure 4.1: Solvent extraction of Allanblackia oil from seeds (Soxhlet Apparatus) 78

Figure 4.2: The DSC curve of Allanblackia oil extract $\quad 81$

Figure 4.3: The DSC curve of shea butter 83

Figure 4.4: The DSC curve of palm kernel oil $\quad 85$

Figure 4.5: The heating and cooling curves of Allanblackia oil, shea butter and palm kernel oil overlaid on each other 
Figure 4.6: The TGA curve of Allanblackia $\quad 87$

$\begin{array}{lr}\text { Figure 4.7: The TGA curve of shea butter } & 88\end{array}$

Figure 4.8: The TGA curve of palm kernel oil 89

Figure 4.9: Overlay of the TGA curves of Allanblackia, shea butter and palm kernel oil 90

Figure 4.10: The split spectra of Allanblackia, palm kernel oil and shea butter 93

Figure 4.11: FTIR spectra of oils within the region $2800 \mathrm{~cm}^{-1}$ and $3051 \mathrm{~cm}^{-1} \quad 93$

Figure 4.12: FTIR spectra of oil around $1743 \mathrm{~cm}^{-1} \quad 94$

Figure 4.13: FTIR spectra of oils in the $700 \mathrm{~cm}^{-1}$ and $1371 \mathrm{~cm}^{-1}$ region 94

Figure 4.14: Overlay curve of Allanblackia before cycling and after Thermal Cycling 98

Figure 4.15: The overlay curve of shea butter before and after Thermal Cycling 98

Figure 4.16: Overlay DSC curve of palm kernel oil before cycling and after Thermal

$\begin{array}{ll}\text { Cycling } & 98\end{array}$

Figure 4.17: The overlay curve of all the samples shown before and after thermal Cycling

Figure 4.18: The combined spectra of Allanblackia oil and thermally cycled Allanblackia oil within $1300-687 \mathrm{~cm}^{-1}$ region

Figure 4.19: The spectra of shea butter and thermally cycled shea butter within $1557-600 \mathrm{~cm}^{-1}$

Figure 4.20: The palm kernel and thermally cycled palm kernel oil within 1601-581 $\mathrm{cm}^{-1} \quad 102$

$\begin{array}{ll}\text { Figure A1. A cylindrical shell with PCM storage } & 106\end{array}$

Figure A2. Detailed cross-sectional view of the cylindrical heat storage tank combined with PCM

Figure 5.1: The DSC thermogram of fatty acids from Allanblackia oil (AllanFA) 113

Figure 5.2: The DSC overlaid thermograms of Allanblackia oil and Allanblackia fatty acid 114

Figure 5.3: The DSC thermogram of the fatty acid of shea butter (SheaFA) 115

Figure 5.4: The DSC thermogram of the overlaid shea butter and its fatty acid 116

Figure 5.5: The DSC thermogram of the fatty acid of palm kernel oil (PalmFA) 116 
Figure 5.6: The overlaid thermograms of palm kernel oil and its fatty acid

Figure 5.7: DSC thermograms of overlaid AllanFA, SheaFA and PalmFA 118

Figure 5.8: The DSC thermogram of AllanFA after Thermal Cycling

Figure 5.9: Overlaid DSC thermograms of Allanblackia, Allanblackia fatty acid, thermally cycled Allanblackia and thermally cycled Allanblackia fatty acid

Figure 5.10: The DSC thermogram of the fatty acid of shea butter after Thermal Cycling

Figure 5.11: Overlaid DSC curves of non- and thermally cycled shea butter and SheaFA

Figure 5.12: DSC tharmograms of the fatty acid of palm kernel oil after thermal cycling

Figure 5.13: Overlaid DSC curves of non- and thermally cycled palm kernel oil and PalmFA

Figure 5.14: TGA thermogram of AllanFA

Figure 5.15: TGA thermogram of SheaFA

Figure 5.16: TGA thermogram of PalmFA

Figure 5.17: TGA thermogram of the overlaid AllanFA, SheaFA, and PalmFA

Figure 5.18: TGA curve of the overlaid Allanblackia, AllanFA, TC Allanblackia, and TC AllanFA (Data from earlier paper on the use of fruit seed oils as PCMs)

Figure 5.19: TGA curve of the overlaid Shea Butter, SheaFA, TC Shea Butter, and TC SheaFA (Data from earlier paper on the use of fruit seed oils as PCMs)

Figure 5.20: TGA curve of the overlaid Palm Kernel, PalmFA, TC Palm Kernel, and TC PalmFA (Data from earlier paper on the use of fruit seed oils as PCMs)

Figure 5.21: FTIR spectra of the overlaid curves of AllanFA and Thermally Cycled AllanFA

Figure 5.22: FTIR Spectra of the overlaid curves of SheaFA and Thermally Cycled SheaFA

Figure 5.23: The FTIR Spectra of the Overlaid curve of PalmFA and Thermally Cycled PalmFA 
Figure 6.1: The DSC curve of Allanblackia methyl ester

Figure 6.2: The DSC curve of Allanblackia butyl ester

Figure 6.3: The DSC curve of shea butter methyl ester

Figure 6.4: The DSC curve of shea butter butyl ester

Figure 6.5: The DSC curve of palm kernel oil methyl ester

Figure 6.6: The DSC curve of palm kernel oil butyl ester

Figure 6.7: The DSC curve of Thermally Cycled (TC) Allanblackia methyl ester

Figure 6.8: The DSC curve of Thermally Cycled (TC) Allanblackia butyl ester

Figure 6.9: The DSC curve of Thermally Cycled (TC) shea butter methyl ester

Figure 6.10: The DSC curve of Thermally Cycled (TC) shea butter butyl ester

Figure 6.11: The DSC curve of Thermally Cycled (TC) palm kernel methyl ester

Figure 6.12: The DSC curve of Thermally Cycled (TC) palm kernel butyl ester

Figure 6.13: The overlaid curve of the methyl and butyl esters of Allanblackia and their thermally cycled products

Figure 6.14: The overlaid curve of the methyl and butyl esters of shea butter and their thermally cycled products

Figure 6.15: The overlaid curve of the methyl and butyl esters of palm kernel and their thermally cycled products

Figure 6.16: The overlaid TGA curves of the esters of Allanblackia and their thermally cycled products

Figure 6.17: The overlaid TGA curves of the esters of shea butter and their thermally cycled products

Figure 6.18: The overlaid TGA curves of the esters of palm kernel oil and their thermally cycled products

Figure 6.19: The overlaid curves of the methyl esters of Allanblackia, shea butter 
and palm kernel oil

Figure 6.20: The overlaid TGA curves of the butyl esters of Allanblackia, shea butter and palm kernel oil

Figure 6.21: The overlaid FTIR curves of the esters of Allanblackia oil and their thermally cycled products within the wavenumber region of 3051 and $2820 \mathrm{~cm}^{-1}$

Figure 6.22: The overlaid FTIR curves of non- and thermally cycled the esters of Allanblackia oil in the 1815 and $1612 \mathrm{~cm}^{-1}$ region

Figure 6.23: The overlaid FTIR spectra of non- and thermally cycled the esters of Allanblackia oil in the 1450 and $640 \mathrm{~cm}^{-1}$ region

Figure 6.24: The overlaid FTIR curves of non- and thermally cycled esters of shea butter in the 4000 and $650 \mathrm{~cm}^{-1}$ region

Figure 6.25: The overlaid FTIR curves of non- and thermally cycled esters of shea butter in the 3300 and $2623 \mathrm{~cm}^{-1}$ region

Figure 6.26: The overlaid FTIR spectra of non- and thermally cycled the esters of shea butter in 1804 and $1666 \mathrm{~cm}^{-1}$ region

Figure 6.27: The overlaid FTIR spectra of non- and thermally cycled esters of shea in 1483 and $650 \mathrm{~cm}^{-1}$ region

Figure 6.28: The overlaid FTIR curves of non- and thermally cycled esters of palm kernel oil in 3461 and $2634 \mathrm{~cm}^{-1}$ region

Figure 6.29: The overlaid FTIR curves of non- and thermally cycled esters of palm kernel oil in 1489 and $901 \mathrm{~cm}^{-1}$ region 


\section{STRUCTURE OF DISSERTATION, INTRODUCTION AND OBJECTIVES}

\subsection{Structure of Dissertation}

This dissertation contains eight chapters. Chapter one contains the structure of the dissertation, the introduction as well as the objectives of this work.

Chapter two is the literature review of the whole work.

Chapter's three to six contains four unpublished papers of the results of the whole work in this dissertation. Chapter three (Paper I) examined the production of biodiesel from Tall oil fatty acids using sulfuric acid as a homogeneous catalyst and Amberlyst BD20 from Rom and Haas (Dow chemicals) as a heterogeneous (solid) catalyst. The use of FTIR spectra was used to monitor the reaction process in the production and the optimum reaction process was determined.

Chapters four to six examined the use of the oils/fats of Allanblackia, shea butter and palm kernel and the synthesized products from them as phase change materials (PCMs) for thermal energy storage systems. The study in these chapters employed the use of differential scanning calorimetry (DSC), thermo-gravimetric analysis (TGA), thermal cycling and Fourier transformed mid-infrared spectroscopy (FTIR) as analysis tools. Chapter four (Paper II) looked at the raw oils, chapter five (Paper III) looked at the hydrolyzed fatty acids from the raw oils and chapter six (Paper IV) examined the methyl and butyl esters produced from the oils.

The general conclusions and the future recommendations of this thesis are presented in chapters seven and eight respectively.

\subsection{Introduction}

Until the later part of year 2014, the prices of petroleum products continued to climb, and greenhouse gases continued to be released with its attendant effect on global warming and the negative impact on the environment. With this trend, there is the need to harness other forms of energy. This is where renewable energy comes in. The storage of energy is also as important as the energy source. Energy storage becomes important due to the variation or imbalance in the supply and consumption of energy with time (Lane, 1983). Energy is used for domestic purposes in heating of homes, cooking, washing, lighting, powering the computer and television, etc. In 
addition to the domestic uses of energy, energy is used in transportation, industrial uses and electricity generation.

Transportation fuel has relied on fossil energy sources in the form of gasoline and diesel for cars, trucks, tractors, rail transport, etc. Concern for the environment, health, dependence on imports of petroleum products with its attendant political connotations as well as the positive impact on agriculture have all contributed to the need to harness renewable energy which will positively impact the environment (Howell and Jobe, 2005). Agricultural products like corn have been used in the production of ethanol as a substitute and also as a blend for gasoline. Vegetable oils have been researched into as possible feedstock for biodiesel as a substitute and blend for diesel (Meher et al., 2006).

Sources of energy have been varied, ranging from wood, coal, natural gas, electricity, solar, petroleum, uranium, etc. The concern for the continued availability of energy for the present and future generation has called for research into renewable energy such as solar, wind, and biomass. Solar energy as an important natural direct energy source which is renewable, does not destroy the earth's environment. Due to the mismatch in supply and demand, energy storage, especially thermal energy storage coupled with storage technologies have become very important. The need for energy conservation as well as the development of renewable sources of energy requires a lot of prominence. Energy can be stored as sensible heat, latent heat or thermochemical heat. In sensible heat storage, heat is transferred to the storage medium with an increase in temperature. Energy storage density is small because the volume involved is high. Latent heat storage occurs with transfer of heat occurring at almost a constant temperature or with small changes in temperature with its attendant volume very small compared with that of sensible heat storage. Thermochemical energy storage is said to occur when chemical bonds are broken or formed in a reversible reaction. Of particular concern in this study will be latent heat storage. Latent heat storage involves the use of phase change materials (PCMs). There is a change of physical state of the medium from one phase to another with attendant absorption or release of energy. The energy absorbed is stored and later used. The change of phase can occur from solid to solid, or solid to liquid, or solid to gas, or liquid to gas, or vice versa. Various feedstock have been considered for use as PCMs for latent heat storage. These feedstock are categorized into organic, inorganic and eutectic mixtures. The organic PCMs are divided into paraffin and non-paraffin 
(Sharma and Sagara, 2005). Some of the non-paraffin organic PCMs are fatty acids like stearic acids, palmitic acids, etc. (Sharma and Sagara, 2005). There are no reported cases of the use of non-paraffin organic PCMs from renewable energy sources. There is therefore the need to find sources of feedstock for PCMs from renewable energy sources.

The first part of this study focusses on the use of Tall oil fatty acids (TOFA), which is a byproduct of the pulping industry as a feedstock for biodiesel. Production of biodiesel was by the batch process using homogeneous and heterogeneous catalysis. The production process was monitored by FTIR and the biodiesel produced was however, characterized using ASTM standards.

The second part of the study looks at latent heat energy and the PCMs considered, changed phase from solid to liquid and liquid to solid. The energy involved during the process as well as the temperatures involved were determined using DSC. The thermal stability and reliability of the PCMs were determined by TGA and DSC after prolonged use. A Thermal recycler was used to recycle the process over a 1000 cycles. The chemical stability of the PCMs were determined using FTIR before and after the thermal cycling process.

This study therefore evaluates natural oils that have characteristics of PCMs to ascertain their eligibility or otherwise for use as PCMs, as alternatives to the feedstock from fossil fuel sources. The natural oils considered are Allanblackia (Allanblackia parviflora), shea butter (Vitellaria paradoxa) and palm kernel oil derived from the oil palm (Elaeis guineensis) tree. Apart from the natural oils, their hydrolysis products as well as their synthesized methyl and butyl esters were similarly evaluated.

\subsection{Overall Objectives of Study}

The overall research objectives of this study are:

1. Evaluation of a non-food feed stock for biodiesel production

2. Evaluation of a new heterogeneous catalyst for biodiesel production

3. Determination of the chemical and physico-thermal properties of three tropical seed oils for potential use in a thermal energy storage system 


\subsubsection{Specific Objectives}

This study consists of two specific objectives:

(1) Production of biodiesel from Tall oil fatty acids (TOFA) by homogeneous and heterogeneous catalysis. Two tasks are identified:

o Determination of optimum yields of biodiesel from Tall Oil fatty acid by homogenous catalysis

o Determination of optimum yields of biodiesel from Tall oil fatty acid by heterogeneous catalysis

and,

(2) Determination of physico-thermal properties of Allanblackia seed oil, shea butter and palm kernel oil and their hydrolysis product and esters. 


\section{LITERATURE REVIEW}

\subsection{Transportation Fuels}

For 700 million years, green plants contributed to the formation of soil, oil, natural gas, and coal. As the human population increases, so too does the consumption of oil and fossil energy. In 2006, Pimentel and Patzek noted that if this trend continues unabated, humans will consume most of these precious resources within the next few hundred years. It has been estimated also that at the current rate of consumption of known petroleum reserves, the resource will be depleted in less than 50 years (Demirbas, 2007). The uncertainty surrounding the future supply of fossil fuels has driven worldwide research into other forms of reliable energy resources to replace fossil fuels (Shafiee and Topal, 2009). The US accounts for about a quarter of the world's total fossil fuel use with only about 4.5 percent of the world's population. About 90 percent of US oil has been mined between 1850 and 2000 (Pimentel and Patzek, 2006). The transportation sector is the major consumer of petroleum products like gasoline, diesel, compressed natural gas (CNG), liquefied petroleum gas (LPG) and biofuels.

\subsubsection{Biofuels and Biodiesel}

To be considered a viable alternative fuel, biofuels must provide a net energy gain, be economically competitive, and have environmental benefits and be available without negatively impacting food. Biomass has been considered as an attractive renewable energy feedstock with a potential for sustainable development as well as a positive environmental properties resulting in no net carbon dioxide release into the atmosphere and a very low sulfur content (Ozcimen and Karaosmanoglu, 2004). The most widely used liquid biofuel is ethanol. It is derived from cellulosic biomass, starches or sugars by fermentation. Biodiesel is an alternative to petro-diesel. Biodiesel is mono-alkyl esters of fatty acids, most often obtained from vegetable or plant oils, or animal fats. Rudolph Diesel first used vegetable oil in the form of peanut oil to power his diesel 
engine in the Paris Exhibition in 1900. In the 1930s and 1940s, vegetable oils were used as diesel fuel for the diesel engine (Knothe, 2001). There were however, some setbacks with the use of raw vegetable oils as diesel fuels. These are depositions in the combustion chamber, injector tips coking, and deterioration of lubricating oil resulting in piston rings sticking in the engine, and consequent polymerization and oxidation of vegetable oils due to prolonged usage of the oil (Canakci and Sanli, 2008). These engine problems were due to the high viscosities of the vegetable oils or animal fats which have higher molecular weights than petro-diesels. Chemical processes were therefore employed to reduce the high viscosities of these oils. These are dilution, microemulsion, pyrolysis (thermal cracking), and transesterification (Ramadhas et al., 2004). Biofuels have advantage over petro-diesel. Biodiesel, as well, have some advantages over ethanol biofuel as well as fossil fuels. According to Hill et al. (2006), ethanol yields $25 \%$ of energy invested in it while biodiesel yields $93 \%$ more. They also discovered that biodiesel releases $1 \%, 8.3 \%$ and $13 \%$ of agricultural nitrogen, phosphorus and pesticide pollutants respectively, for any net energy gain. Ethanol reduces greenhouse gas emissions by $12 \%$ with respect to fossil fuels while biodiesel reduces it by $41 \%$ (Hill et al., 2006). Biodiesel fuels are biodegradable; are devoid of aromatics and sulfur; have reduced particulate and toxic emissions; and higher cetane index than diesel (Encinar et al., 2005; Knothe et al., 2005; Canakci and Van Gerpen, 2001). Biodiesel have high flash points (Encinar et al., 2002) and this makes its storage and transportation safe. Biodiesels sequester carbon dioxide from the atmosphere and thereby reduce global warming by the use of plant or vegetable oils as feedstock (Schumacher et al., 1995; Noureddini et al., 1998; Clark et al., 1984).

\subsubsection{Tall Oil Fatty Acids (TOFA)}

Tall oil is a mixture of acidic compounds found in pine trees (Pinus spp) and is produced as a byproduct in the pulping process in the paper making industry. It is composed of resin acids, fatty acids and unsaponifiables, also known as neutrals. The resin acids are mixtures of organic acids produced as a result of the oxidation and polymerization of terpenes found mainly in softwoods, especially pines. The main constituent of resin acids in tall oil is abietic acid, and there are also small amounts of pimaric acid present. In the case of the fatty acids, the main constituents are palmitic acid, oleic acid and linoleic acid. The unsaponifiables are neutral compounds that 
include hydrocarbons, higher alcohols and sterols. The unsaponifiables do not form soap when saponified (Wansbrough, 1987).

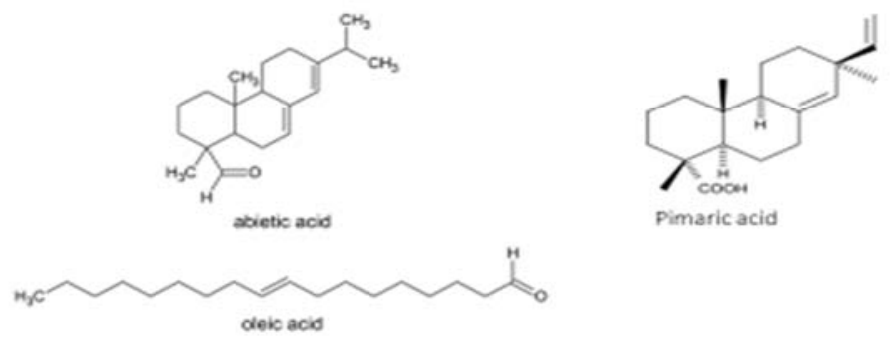

Figure 2.1: Abietic acid, pimaric acid and oleic acid present in Tall oil (Wansbrough, 1987).

\subsection{Production of Tall Oil Fatty Acids}

Tall oil fatty acids (TOFA) is obtained by the fractional distillation of Crude Tall Oil (CTO). The major components contained in the CTO are $30-40 \%$ by weight resin acids (or rosin) related to mainly abietic acid, $35-50 \%$ fatty acids related mainly to oleic and linoleic acids, and about $10-$ $20 \%$ neutral matter, in which the main component is $\beta$-sitosterol (Bokis et al., 1999). The fatty acids from Tall oil and their derivatives are all complex mixtures and they are obtained from a natural product, being mainly the pine trees. Each pine tree has a different mixture of the fatty acids and even climate and local conditions can vary the mix of fatty acids in a particular species. Therefore, the chemical composition of the Tall oil can vary with the age, pine species, geographical location of the tree and the pulping process (Keskin et al., 2010). The fatty acids in the Tall oil are derived from glycerol esters that exist in the pine trees. During the pulping process, chips from wood used in the pulping process are cooked in alkaline solution which is termed the white liquor. The resin acids and fatty acids from the glycerol esters are saponified in the process to sodium salts which form the Tall oil soaps. When the cooking is done, the black liquor which is the spent liquor contains the sodium salts (soap) of the acids (resin and fatty 
acids) as well as neutral compounds. When the liquor is evaporated, the soap is floated on the top and these are subsequently skimmed off from the spent pulping liquor and then acidified with sulfuric acid to form the CTO (McSweeney, 1987).

The formed CTO is then fractionally distilled at high temperatures under vacuum to obtain the TOFA as one of the several fractionation products which come off as the second fractionation product. The TOFA contain at least $90 \%$ fatty acids (oleic and linoleic) and about $2 \%$ rosin (Bokis et al., 1999). The largest use of TOFA has been in dimer acids, which are subsequently used in coatings, printing inks, surfactants, liquid soaps and adhesives (HPV Chemical Challenge Program, 2001). Tall oil fatty acids have been shown to be biodegradable and several different commercial mixtures of TOFA which may be branched or linear have been shown to degrade at $41-98.4 \%$ over a period of 28 days in standard Organization of Economic Cooperation and Development (OECD) ready biodegradation tests (US EPA Hazard Characterization Document, 2012).

Table 2.1: Table showing the composition of a typical TOFA.

\section{Composition of a Typical Tall Oil Fatty Acid}

\section{Common}

Name

Palmitic acid

Stearic acid

Oleic acid $48 \%$

Linoleic acid $35 \%$
Chemical Structure $\mathrm{CH}_{3}\left(\mathrm{CH}_{2}\right){ }_{14} \mathrm{COOH}$

$\mathrm{CH}_{3}\left(\mathrm{CH}_{2}\right){ }_{16} \mathrm{COOH}$

$\mathrm{CH}_{3}\left(\mathrm{CH}_{2}\right)_{7} \mathrm{CH}=\mathrm{CH}\left(\mathrm{CH}_{2}\right)_{7} \mathrm{COOH}$

$\mathrm{CH}_{3}\left(\mathrm{CH}_{2}\right)_{4} \mathrm{CH}=\mathrm{CH}-\mathrm{CH}_{2} \mathrm{CH}=\mathrm{CH}\left(\mathrm{CH}_{2}\right)_{7} \mathrm{COOH}$
Percent

Composition

Conjugated linoleic acid ${ }^{\mathrm{a}} \quad \mathrm{CH}_{3}\left(\mathrm{CH}_{2}\right) \times \mathrm{CH}=\mathrm{CHCH}=\mathrm{CH}-\left(\mathrm{CH}_{2}\right) \mathrm{YCOOH} \quad 7 \%$

$\begin{array}{ll}\text { Other acids }^{b} & 4 \%\end{array}$

Unsaponifiable matter $\quad 2 \%$

a: $\mathrm{x}$ usually 4 or 5 ; y usually 7 or 8 ; but $\mathrm{x}+\mathrm{y}=12$

b: 5,9,12-octadecatrienoic acid; linolenic acid; 5,11,14-eicosatrenoic acid; cis,cis-5,9octadecadienoic acid; eicosadienoic acid; elaidic acid; cis-11 octadecanoic acid; C-20, C-22, C24 saturated acids.

Source: HPV Chemical Challenge Program, 2001. (Association and others, 2001) 


\subsection{Biodiesel Production from Tall Oil Fatty Acids}

Tall oil fatty acids, being non-edible fatty acids because they contain other impurities such as sulfuric acid, have been considered for use as feedstock in biodiesel production and several researchers have worked on it in producing biodiesel. Pisarello et al. (2007) used TOFA as feedstock to produce biodiesel with sulfuric acid as a homogeneous catalyst and solid niobic acid $\left(\mathrm{Nb}_{2} \mathrm{O}_{3} . \mathrm{nH}_{2} \mathrm{O}\right)$ as a heterogeneous catalyst. In their experiment, the homogeneous catalyst loading was 0.18 and $0.5 \% \mathrm{v} / \mathrm{v}$ with methanol/fatty acid mole ratio ranging from $2: 1,3: 1,8: 1$ and 40:1 at a constant temperature of $60^{\circ} \mathrm{C}$. The heterogeneous catalyst reaction conditions used temperatures of $130^{\circ} \mathrm{C}$ and $180^{\circ} \mathrm{C}$ in a pressurized stainless steel reactor. The homogeneous catalyst gave the highest conversion of $98.4 \%$ with acidity reduction from 96.5 to 1.55 for the highest mole ratio of 40:1 occurring within a time of 3 minutes. Increase in molar ratio increased recovery and decreased acidity as well as decreased time of equilibrium attainment. For the heterogeneous catalyst, the acidity dropped to 8.06 with a conversion of $91.6 \%$. The best ester yield occurred at $180^{\circ} \mathrm{C}$ with a molar ratio of $3: 1$ and a catalyst loading of $12 \mathrm{wt} . \%$. They therefore concluded that TOFA can be used to produce biodiesel using a homogeneous catalyst at atmospheric pressure but the heterogeneous catalyst needed a higher pressure for biodiesel production. Similarly, Ramos et al. (2008) using TOFA with sulfuric acid and niobium powder as homogeneous and heterogeneous catalysts respectively in biodiesel production, showed that the steady state of reaction was achieved in less than $1 \mathrm{hr}$ when the homogeneous catalyst used a methanol/fatty acid mole ratio of $8: 1$, catalyst loading of $0.5 \% \mathrm{v} / \mathrm{v}$ for the acid number to decrease from 96.55 to $0.45 \mathrm{~g}$ of oleic acid per $100 \mathrm{~g}$ of TOFA. With the heterogeneous catalyst, the best ester yield occurred at a temperature of $155^{\circ} \mathrm{C}$ using a methanol/fatty acid mole ratio of 2.5:1, catalyst loading of $12 \mathrm{wt} \%$ and a reaction time of $2 \mathrm{hrs}$, where the acid number dropped from 96.55 to $6.71 \mathrm{~g}$ of oleic acid per 100g of TOFA in one reaction step. Keskin et al. (2010) performed emission tests on biodiesels prepared from TOFA and resinic acids and found no significant difference in specific fuel consumption for fuel blends while there were significant reduction in carbon monoxide and smoke levels. The $\mathrm{NO}_{\mathrm{x}}$ levels did increase while $\mathrm{CO}_{2}$ levels showed no significant increase with the fuel blends. White et al. (2011) used supercritical 
methanol at high temperature and pressure to convert TOFA to biodiesel in the absence of a catalyst. They used pressure of 4.2 $\mathrm{MPa}$ and $6.6 \mathrm{MPa}$ to obtain yields of $81 \%$ and $75 \%$ respectively and noted that pressures did not affect yield but was rather heavily dependent on temperature, time of reaction and molar ratio. A low molar ratio of 5:1 gave comparable conversions. The supercritical methanol method however, require high capital cost due to the high temperature and pressure requirements even though total manufacturing cost seems lower than that of the alkali-catalyzed method due to a higher purity glycerol formation and the absence of the cost of a catalyst or solvent (Lim et al., 2009).

\subsection{Catalysts}

Traditionally, the biodiesel production process is a catalyzed reversible reaction process, and hence catalysts are required to start the biodiesel production process. Alkali and acid catalysts have been used for producing the biodiesel (Lim et al., 2009; White et al., 2011). In the transesterification process, alkali metal alkoxides have been the most effective catalysts. Sodium alkoxide are most effective, however, $\mathrm{KOH}$ and $\mathrm{NaOH}$ are also used. Transmethylation occurs about 4000 times faster if an alkaline catalyst is used in place of acid catalyst (Formo, 1954). Alkaline catalysts have the added advantage of being less corrosive to industrial equipment than acidic catalysts. Pure vegetable oils use alkali catalysts in a transesterification reaction whereas feedstock with high Free Fatty acids (FFAs) use acid catalysts because of the formation of soap that causes emulsions in the biodiesel resulting in difficulty in separation and ultimately lower yields when alkali catalysts are used (Abidin et al., 2012). The acid catalysts convert both triglycerides and FFAs using tranesterification and esterification reactions respectively (Abidin et al., 2012) but their reactions are much slower. In order to use TOFA as a feedstock in biodiesel production, an acid catalyst is required since it contains mainly free fatty acids.

\subsection{Homogeneous and Heterogeneous Catalysts}

Catalysts, whether acid or alkaline, can be grouped into two types. These are homogeneous (liquid) and heterogeneous (solid) catalysts. Ma et al. (1998), studied the effect of sodium hydroxide and sodium methoxide on the yield of biodiesel production from beef tallow and concluded that sodium hydroxide is a more effective catalyst and can be used at a lower 
concentration of $0.3 \% \mathrm{w} / \mathrm{w}$ than sodium methoxide at a little higher concentration of $0.5 \% \mathrm{w} / \mathrm{w}$. It was demonstrated that a $1 \%$ potassium hydroxide at a temperature of $25^{\circ} \mathrm{C}$ and molar ratio of $6: 1$ gave the best yield and viscosities for the methanolysis of soybean oil in 30 mins (Tomasevic and Marinkovic, 2003). Even though there is a high conversion of triglycerides to methyl esters using alkaline catalysts, in a short reaction time, certain drawbacks are encountered. These are difficulty in glycerol recovery, the need for the acid or glycerol to be removed from the product, treatment of the alkaline waste water, the interference of FFA and water in the reaction, and the reaction is energy intensive (Meher et al., 2006). Homogeneous alkaline catalysts require the oil or feedstock to be refined for a good conversion. It is therefore required that base catalyzed tranesterification need feedstock to have FFA values as low as possible (in the range of between $0.5 \mathrm{wt} . \%$ and $2 \mathrm{wt} . \%$ ), since the FFA will result in soap formation as well as water which will deactivate the catalyst.

\subsection{High Free Fatty Acid Feedstock}

For feedstock with high FFA, homogeneous catalysts used in the biodiesel production process have been sulfuric acid and hydrochloric acid because they are effective and soluble in methanol, insensitive to the FFA, and they can catalyze both esterification and transesterification reactions (Kulkarni and Dalai, 2006; Jacobson et al., 2008), and hence give a high yield of biodiesel. However, like any homogeneous acid catalysts, their reactions are slow even with a high methanol to oil ratio. These mineral acid catalysts are also corrosive to the equipment with attendant environmental problems, high temperatures and also generate large amount of salt due to neutralization (Jacobson et al., 2008). It is therefore not commercially attractive. Solid or heterogeneous acid catalysts could eliminate these problems and give the advantage of reusability, better separation, less corrosiveness and reduced negative environmental impact (Noshadi et al., 2012). The best heterogeneous catalyst must have several qualities such as catalyzing both transesterification and esterification reactions, it must not be deactivated by water, it should be stable, it should not leach, it should have high selectivity and be active at low temperatures (Di Serio et al., 2008). 


\subsection{Energy Storage}

There are three types of thermal energy storage systems. These are sensible heat storage (SHS), latent heat storage (LHS) and thermochemical heat storage (THS). In the SHS process, the transfer of heat to the storage medium is attended by an increase in temperature, i.e., a sensor can detect the temperature increase. The ratio of the stored heat to the temperature rise is called heat capacity of the storage medium. Examples of sensible heat storage are stones, brick and liquids like water as storage material. The SHS uses the heat capacity of the storage medium. It is accompanied by appreciable change in volume. And, energy storage density is lower. In contrast, LHS method occurs without change in temperature of storage medium. Therefore, materials that exhibit change in phase (solid to solid; solid to liquid; liquid to solid; liquid to gas) upon heating or cooling are excellent candidates. Phase change such as melting is accompanied by small volume change (less than 10\%). Here, the thermal energy storage density is high. The third type of thermal energy storage is the thermo-chemical heat storage which relies on the energy absorbed or released in breaking and forming of molecular bonds in a completely reversible chemical reaction (Lane, 1983).

\subsubsection{Phase Change Materials}

The study proposed here is focused on LH using phase change materials (Garg et al., 1985). When phase change materials are heated, they absorb heat (enthalpy; heat of melting) and changes from solid to liquid (i.e. they undergo a change in phase). During phase change, the temperature of the PCM stays constant. The reverse of this process is accompanied by the release of absorbed latent heat at a constant temperature and change in phase (e.g. liquid to solid). This property of PCMs has important applications in thermal energy storage such as solar energy (e.g. solar water heating) (Sharma and Sagara, 2005). In this situation, solar energy can be collected during the day and used in the night when the sun is no longer available. 


\subsubsection{Applications of PCMs for Thermal Energy Storage Systems}

PCMs have wide applications and uses in latent heat storage systems for solar engineering, solar water heating, and spacecraft thermal control applications. Before the 1980s, PCMs have been considered for buildings and have been implemented in Trombe walls, wallboards, shutters, under-floor heating systems and ceiling boards as part of buildings for heating and cooling applications (Sharma et al., 2009). Prakash et al. (1985) used a layer of PCM to line the bottom of a solar heater. Heat is absorbed during the sunshine hours and released during off sunshine hours. They concluded that water heaters with PCMs at the bottom are more suitable for hot water requirements during off-sunshine hours, and that PCM storage without night insulation is as effective as conventional water heaters with night insulation.

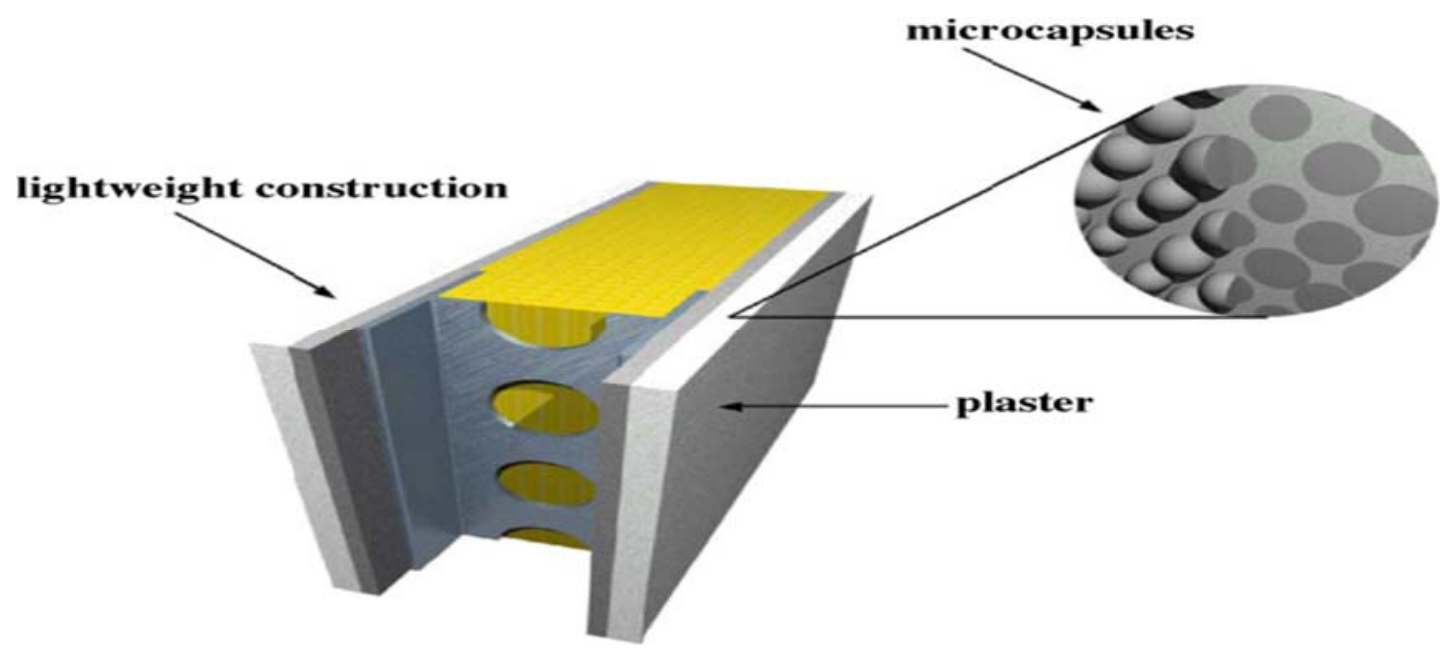

Fig. 2.2: Schematic view of a lightweight wall. The PCM micro-capsules are integrated into the interior plaster. (Sharma et al., 2009).

\subsubsection{Properties of PCMs}

Physical and thermal properties of PCMs which enable them to be used in thermal energy storage include: (1) melting temperature in desired operating range, (2) high latent heat of fusion per unit volume, (3) high specific heat, high thermal conductivity in both the solid and liquid state, (4) small volume changes on transformation of phase, (5) congruent melting of PCM for a constant storage capacity of material for every freezing/melting cycle, (6) chemical stability, high nucleation to avoid super-cooling of liquid phase, (7) not degraded after several 
melting/freezing cycles, (8) non-corrosive, non-toxic, (9) non-flammable, readily available and (10) cheap (Garg et al., 1985).

Three main types of PCMs are recognized: (i) organic, (ii) inorganic and (iii) eutectic mixtures. Organic phase change materials include saturated hydrocarbons (paraffin), alcohols, glycols, fatty acids and esters of fatty acids. Inorganic PCMs are salt hydrates (e.g. hydrated calcium chloride $\mathrm{CaCl}_{2} \cdot 6 \mathrm{H}_{2} \mathrm{O}$, hydrated sodium sulfate, $\mathrm{Na}_{2} \mathrm{SO}_{4} \cdot 10 \mathrm{H}_{2} \mathrm{O}$ ) (Lane, 1983). Eutectic mixtures are not pure compounds but are mixtures of two or more substances whose melting point is lower than that for any other mixtures of the same substances (Science/Chemistry/Eutectic Mixtures, 2013). They include naphthalene and benzoic acid mixture; aluminum chloride $\left(\mathrm{AlCl}_{3}\right)$ and sodium chloride $(\mathrm{NaCl})$ mixture.

Phase change materials per se do not transfer heat. In latent heat storage systems, heat transfer mediums (heat exchangers) are used to transfer heat from their sources to the PCMs, and from the PCMs to their final destination. Different methods have been employed to improve the transfer of heat in this process. Two such methods are the use of finned surfaces embedded into the heat storage medium and the use of a matrix structure with a high heat of conductivity into the heat storage medium, or the impregnation of a heat storage medium into a porous matrix structure (Kenisarin and Mahkamov, 2007). Natural or vegetable oils and fats undergo a process of polymorphism when melted. Polymorphism is a phenomenon whereby the same chemical substance exists in more than one crystalline form (Berger and Akehurst, 1966). Polymorphic forms can therefore undergo transition to other forms at different temperatures.

\subsubsection{Feedstock for Thermal Energy Storage}

The materials needed for use as PCMs for latent energy considerations must conveniently be a solid that is made to change phase to a liquid or gas. But since the change into the gaseous phase involves a large container volume, it is the solid to liquid that is economically feasible. This study will therefore evaluate three types of potential organic PCMs obtained from tropical forest trees. These potential PCMs are solids at room temperature and changes into the liquid phase on heating to melt and also crystallize upon cooling. They are Allanblackia (Allanblackia parviflora), shea butter (Vitellaria paradoxa) and palm kernel oil derived from the oil palm (Elaeis guineensis) tree. 


\subsection{Allanblackia}

Allanblackia is an oil seed-bearing fruit tree found growing in the rainforest of West Africa subregion ranging from Sierra Leone through Ghana, Nigeria, Cameroon and Gabon in West Africa and Democratic Republic of Congo, Tanzania and Uganda in Central and East Africa respectively (Figure 2.3). There are nine species of Allanblackia with an unknown species found in Fernando Po. These species of Allanblackia are A. floribunda (Nigeria to D. R. Congo), A. gabonensis (Cameroon and Gabon), A. kimbiliensis (D. R. Congo and Uganda), A. kisonghi (D. R. Congo), A. marienii (D. R. Congo), A. parviflora (Sierra Leone to Ghana), A. stanerana (Cameroon, D. R. Congo and Angola), A. stuhlmannii (Tanzania), and A. ulugurensis (Tanzania).The tenth species which is the imperfectly known species is A. monticola found in Fernando Po (Rompaey, 2003). In Ghana, it is found in cocoa growing areas as well as forest areas of the Eastern, Ashanti, Western and Central Regions (Irvine, 1961). Studies have shown that a species of Allanblackia, Allanblackia parviflora A. Chev. (Clusiaceae Lindley) is the primary species in Ghana (Peprah et al., 2009; Rompaey, 2003). Allanblackia belongs to the Guttiferae family of the subfamily Clusiodeae. It is a medium sized tree that grows to a height of about $40 \mathrm{~m}$ with a cylindrical bole having a diameter at breast height around $50 \mathrm{~cm}$ (Peprah et al., 2009). Oil production from a tree can be an average of about $12 \mathrm{~kg} /$ tree from a net seed weight of $35 \mathrm{~kg}$ (Figure 2.4) where harvesting is once a year. Wilfred et al. (2010) reported yields of 48.60 and $67.59 \%$ respectively from manual press expeller and solvent extraction of seeds of Allanblackia floribunda seeds. Allanblackia floribunda contain $6.0 \%$ water, $3.6 \%$ crude protein, 3.1\% crude fiber, $2.2 \%$ ash $20.7 \%$ carbohydrate and $64.4 \%$ oil (FAO, 2013). This high oil content of Allanblackia seeds makes it a very good candidate for oil extraction for food, fuel and industrial uses. The oil of Allanblackia is a solid at room temperature and melts between $42-$ $44^{\circ} \mathrm{C}$. Locally, oil extracted from Allanblackia seeds is used for preparing traditional medicines, cooking, timber and production of soap on a small scale. Unilever Ghana Limited is funding an ongoing research on the reproductive biology, genetics and establishment of Allanblackia "farms" in Ghana (Novella Partnership, 2008). The oil obtained from Allanblackia is a solid white or yellow fat. Unilever has identified other commercial uses of Allanblackia oil as a cosmetic product and also as a margarine spread. The high melting point of the oil gives it a major advantage over other similar oils, because it does not need any modification such as 
fractionation, hardening or hydrogenation (Ofori et al., 2015). With the increasing demand for Allanblackia surpassing the present availability and supply, there is the need to increase its cultivation to supplement the wild picking from the forest.

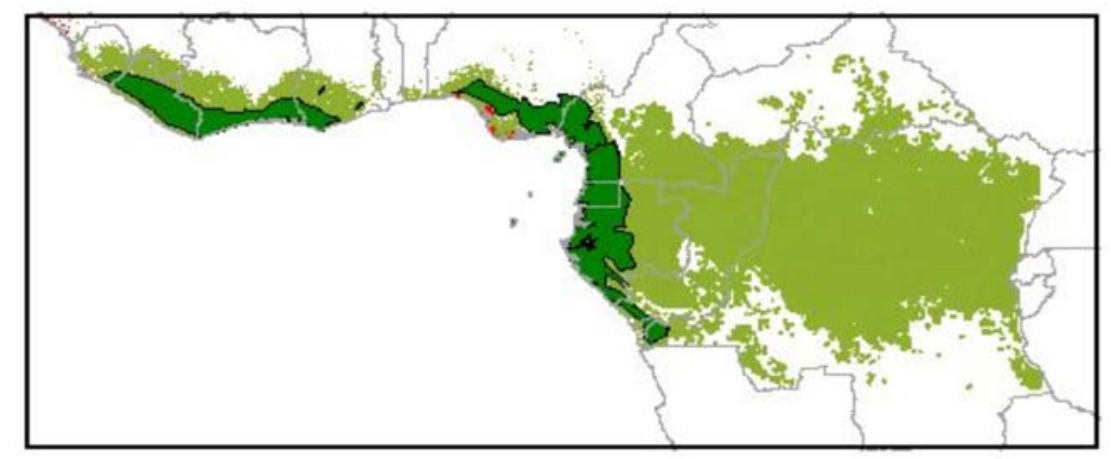

Figure 2.3: The Guineo-Congolian forest zone, original forest cover in light green, and the strip of evergreen forests along the Gulf of Guinea in dark green, believed to be the habitat of Allanblackia spp. (Rompaey, 2003).

Again, with the dangers of plantation creation, which will result in a monoculture with its attendant negative effect on biodiversity conservation, on-farm cultivation of Allanblackia mixed with other crops and trees, is proposed. The Allanblackia tree is therefore being domesticated for oil extraction, and rural communities are being encouraged to contribute to this work, which will greatly impact these communities socio-economically (Ofori et al., 2015). There are however some bottlenecks to the domestication and cultivation of the plant. These bottlenecks are due to the plant being a diocey and hence there is uncertainty to the proportion of males and females until flowering. However, the slow seed germination, whereby it takes $50 \%$ of seeds to germinate in 3 months and $75 \%$ to germinate in 10 months greatly affects domestication of the plant (Ofori et al., 2011). Also, it took the first flowering to be observed after 6 years (Ofori and Peprah, 2011). 


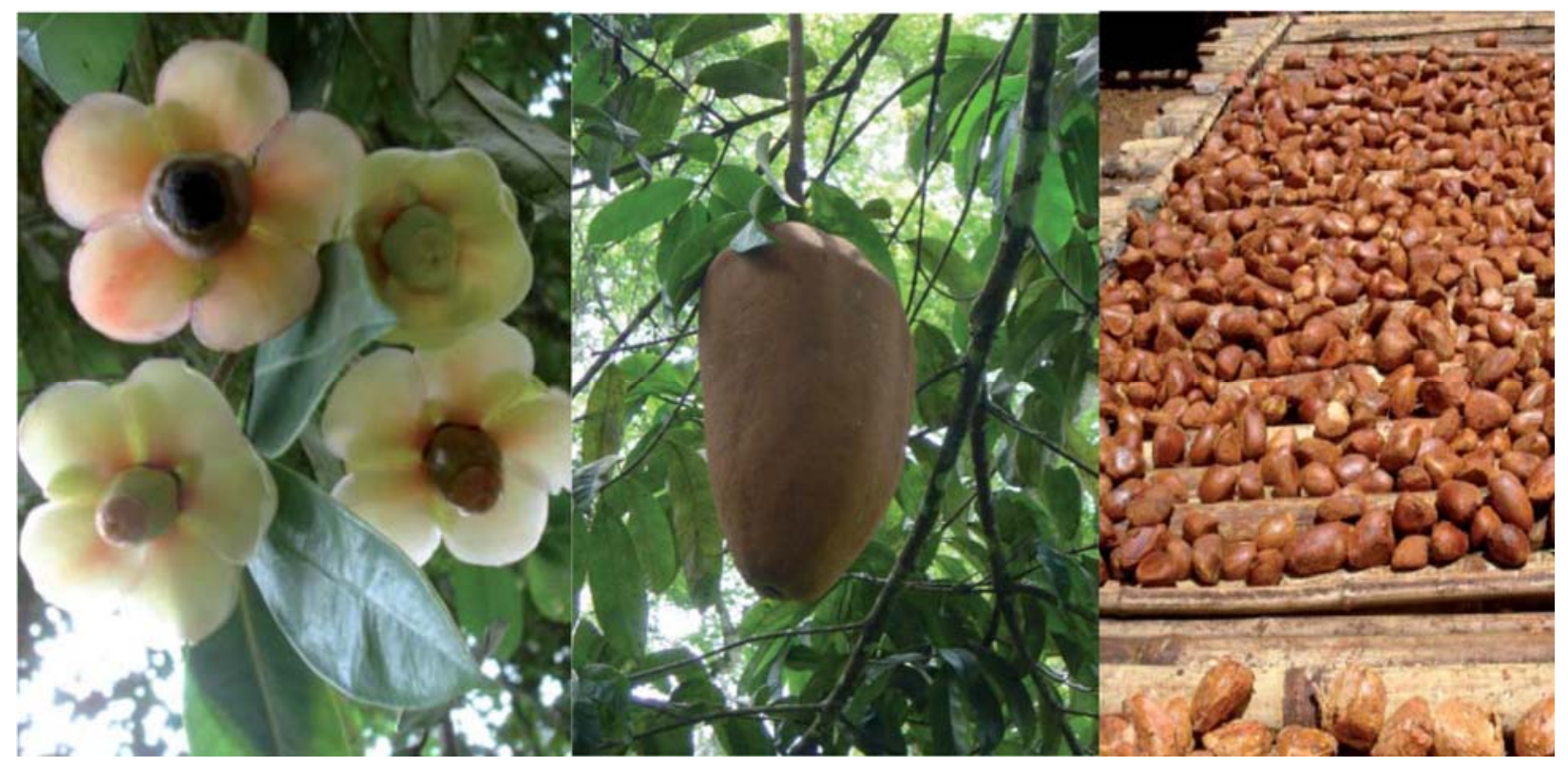

Fig. 2.4: Allanblackia flowering, Allanblackia fruit on the tree, and Allablackia seeds being dried in air (Buss and Tissari, 2010).

Research efforts have however, led to solving these bottlenecks whereby a shorter flowering time can been achieved and flowers have been found in one to two years after grafting (Ofori et al., 2008). Allanblackia oil consists of these fatty acids, stearic acid (saturated fatty acid, 45-58\%), oleic acid (unsaturated fatty acid, 40-51\%). Other minor fatty acids found in Allanblackia oil are lauric acid $(<1 \%)$, myristic acid $(<1 \%)$, palmitic acid $(<2 \%)$, palmitoleic acid $(<1 \%)$, linoleic acid $(<1 \%)$, $\gamma$-linoleic $(<1 \%)$, arachidic acid $(<1 \%)$ and free fatty acids (max. $0.1 \%)$. Three major triglycerides are found in Allanblackia oil, and they are stearic-oleic-stearic $(\sim 70 \%)$, stearicoleic-oleic ( 23\%), and oleic-oleic-oleic ( 4\%) (Tetens, 2007-European Food Safety Authority, 2007; Hermann, 2009). The advantage of Allanblackia oil as a fat at room temperature, makes it a potential candidate for use as a PCM for latent energy storage. Allanblackia will be coevaluated with two other tropical savannah tree seed oils, shea butter and palm kernel oil for their potential use as a phase change material for latent energy storage.

\subsection{Shea Butter}


Shea butter is produced from the nuts of the shea butter tree (Vitellaria paradoxa) which are found growing mainly in the West and Central Africa region. The tree is widely spread across Africa covering about 15,000 km in the Savannah belt from Senegal in West Africa through Sudan in the east to the foothills of Ethiopia's mountains. It can be found spreading out in 19 African countries from Senegal, Sierra Leone, Guinea, Guinea Bissau, Cote D'Ivoire, Ghana, Burkina Faso, Mali, Niger, Togo, Benin, Nigeria, Cameroun, Congo D. R., Central African Republic, Chad, Sudan, Uganda and Ethiopia. The average tree height is about 15 meters, and has an average diameter of 1.75 meters with many lateral branches (Figure 2.5). It has a thick bark that makes it highly fire resistant (Dogbevi, 2007). In Ghana, the tree is mainly found in the Northern, Upper East and Upper West Regions, with sparse cover in the Brong Ahafo, Ashanti, Eastern and Volta Regions. The tree grows in the wild and can take up to 50 years to mature and live up to about 200 years (Dogbevi, 2007). The tree bears a greenish-yellow ellipsoid spherical fruit once a year, and is harvested by wild picking when the mature fruit falls from the tree (Quansah, S., 2012). The processing of shea butter is traditionally achieved by various steps. It starts first with the removal of the seeds from the ripe fruit. The seeds are air-dried for about 4-5 days in order to achieve a moisture content of around 6-7\%. The nuts are de-husked to remove the shell cover. The nuts are roasted and ground into a fine powder and mixed with warm water. The resulting mixture is stirred continuously to form a paste and then left to stand. The oil formed collects on top of the mixture and it is skimmed off (http://www.berniceagyekwena.wordpress.com). This skimmed oil is the shea butter, and it is a solid at room temperature. Shea butter has various uses which include healing burns, sores, scars, dermatitis, psoriasis, dandruff, stretch marks, personal care products like lotions, cosmetic products, moisturizers for the skin, lips, hair, etc. ( http://www.vitaminstuff.com).

Variations in the fatty acid profile and 18 physico-chemical composition of shea butter has been reported. Fatty acid profile and its composition for shea butter from Uganda are as follows: palmitic, stearic, oleic, linoleic and arachidic fatty acids. These range between $6.52-8.12 \%$, $28.65-30.94 \%, 55.54-57.63 \%, 6.18-7.79 \%$ and $0.65-0.90 \%$, respectively. The fat content of shea butter is between $41-54 \%$ (Okullo et al., 2010). Shea butter is being co-evaluated with the other fats/oil as a potential PCM for thermal energy storage material because it is a solid at room temperature and can undergo a phase change during melting and crystallization. 


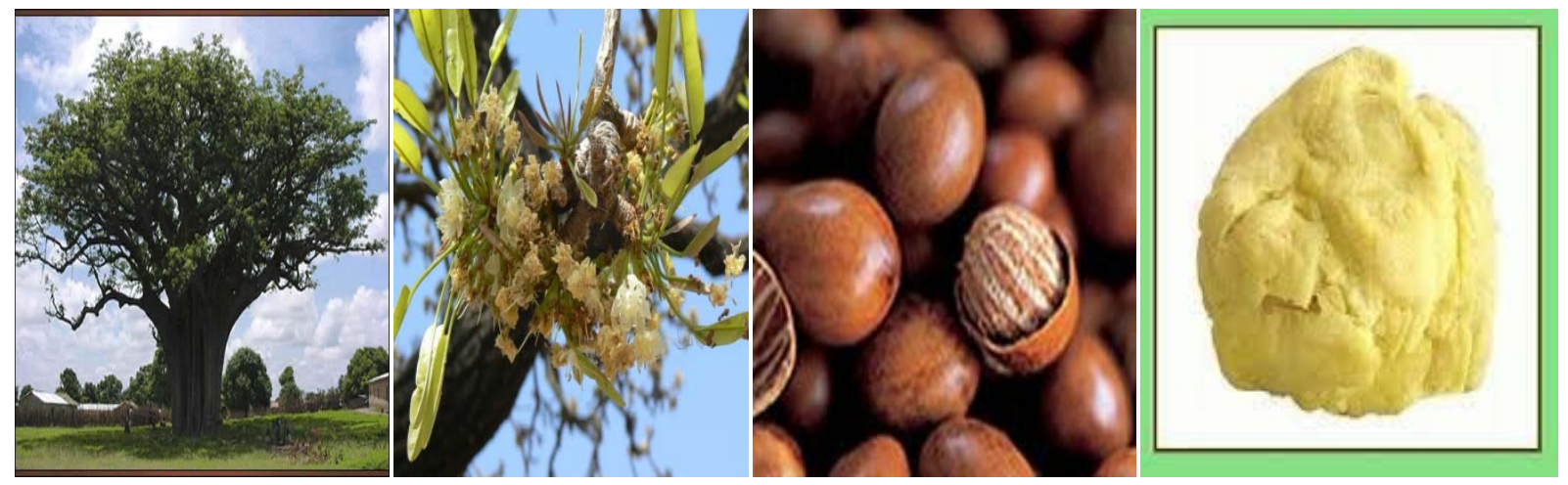

Fig. 2.5: A mature shea butter tree, flowering tree, nuts and the processed butter (www.google.com).

\subsection{Palm kernel oil}

Oil palm (Elaeis guineensis) originated from the tropical rainforest of West Africa. It runs through Sierra Leone, Liberia, Cote D’Ivoire, Ghana, Togo, Nigeria, Cameroun, and also in the equatorial regions of Congo and Angola (Poku, 2002). The fruit was exported to the Americas during the $14^{\text {th }}$ and $17^{\text {th }}$ centuries, from where they were sent to the Far East, where they have become viable and have thrived very well. It is now a major commercial product and large plantations have been set up for commercial ventures. The plantations of oil palm have however, resulted in the deforestation of large tracks of forest lands especially in Asia. It has been reported by Wood (1990), that Malaysia belongs to 14 countries with annual deforestation rate of more than 250,000 hectares. Forests have been converted into oil palm plantations and these have affected the environment and biodiversity negatively. The oil palm industry have however positively impacted the economic lives of the citizens. Pletcher in 1991 has shown how Malaysian oil palm industry has improved the economic life of poorer citizens by supporting half a million people. The fruit of the palm oil is made up of an outer exocarp which forms the outer skin, followed by a mesocarp which is the pulp that contains the palm oil in a fibrous matrix. At the center of the fruit is the shell (endocarp) which contains the kernel whose oil is different from the palm oil. Palm nut is a by-product of palm oil extraction. Cracking the nut produces the kernel (Figure 2.6), which also contains a different kind of oil capable of being used as a substitute for cocoa butter (Poku, 2002). Palm kernel oil is therefore extracted from the kernel of the palm fruit. Palm kernel oil is a saturated fat and it is a semi-solid to solid at room 
temperature. Palm kernel oil contains the fatty acid chain ranging from C6 to C18. The fatty acids present in Malaysian palm kernel are lauric, myristic, palmitic, and oleic with lauric being the dominant acid with a composition of $48 \%$. This oil is therefore designated as lauric oil. Palm kernel oil crystallizes in the beta form at a temperature of $0-25^{\circ} \mathrm{C}$ (Chong and Siew, 1994). The total composition is given as follows: C6 (0.3\%), C8 (4.4\%), C10 (3.7\%), C12 (48.3\%), C14 (15.6\%), C16 (7.8\%), C18 (2.0\%), C18:1 (15.1\%), C18:2 (2.7\%) and others (0.2\%) (Chong and Siew, 1994). The unsaturated fats present are oleic and linoleic. Palm kernel oil has various uses in food as well as in industry. Rashid et al. (2014) utilized the shell of palm kernel as a reducing agent for low grade iron ore. This process also caused a reduction in carbon dioxide emissions. Other uses of the palm kernel oil are in washing powders, personal care products like lotions, cosmetic products, moisturizers for the skin, lips, hair, nails, antioxidants and medicines, food, soaps, cooking, and solid waste fuel for firing boilers during processing (Poku, 2002;

hudsonandknight.co.za).
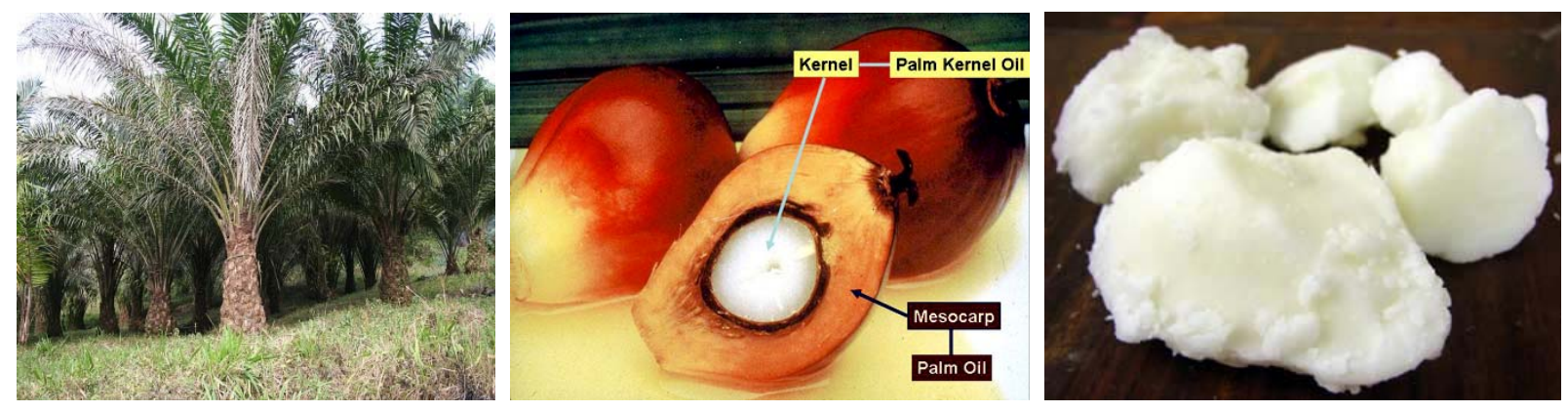

Fig. 2.6: The palm tree, palm fruit with its kernel and the processed palm kernel oil.(www.google.com)

\subsection{Rationale of study}

Vegetable oils used as feed stocks for biodiesel production competes with their use as food. The use of vegetable oils as biodiesel feed stock has become a major global issue especially in emerging economies. To-date, biodiesel is more expensive than diesel because of the use of vegetable oils as feed stock. The cost of vegetable oils represents approximately $60-80 \%$ of its total production cost of biodiesel (Demirbas, 2002). Vegetable oils are not used directly as fuel in internal combustion engines because of its high viscosity. Transesterification is the most common process used to reduce the viscosity of vegetable oils. In this process, an alcohol from 
the glyceride is displaced by another alcohol in the presence of a catalyst to give smaller molecular weight esters with physical properties similar to diesel (Quick et al., 1983). Glycerin is the by-product of this process. Glycerin can be used to make soap (or any one of 1,600 other products) (Demirbas, 2002).

The overall transesterification reaction with a base catalyst is shown below:

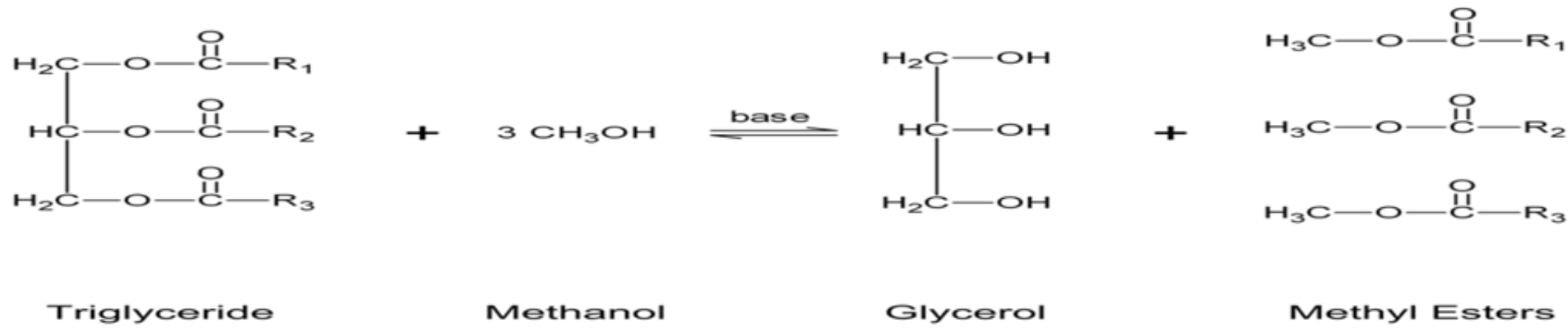

where $R_{1}, R_{2}$, and $R_{3}$ are alkyl groups of long chain fatty acids.

Source: ww2.mackblackwell.org

Fatty acids can be directly esterified with an alcohol to produce an ester (biodiesel) using an acid catalyst:

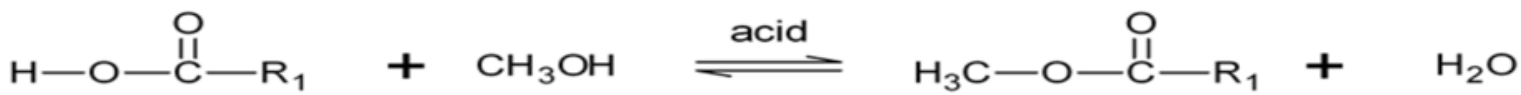

Free Fatty Acid Methanol Methyl Ester Water

Source: ww2.mackblackwell.org

The reaction of the fatty acids with the methanol here is a direct esterification process since it does not contain the triglycerides in the vegetable oils, and hence does not undergo a transesterification reaction.

\subsection{References}

“Palm Kernel Oil” hudsonandknight.co.za. Hudson \& Knight. Accessed April 2014. 
Abd Rashid, R.Z., Mohd Salleh, H., Ani, M.H., Yunus, N.A., Akiyama, T., and Purwanto, H. (2014). Reduction of low grade iron ore pellet using palm kernel shell. Renewable Energy 63, $617-623$.

Abidin, S.Z., Haigh, K.F., and Saha, B. (2012). Esterification of free fatty acids in used cooking oil using ion-exchange resins as catalysts: An efficient pretreatment method for biodiesel feedstock. Industrial \& Engineering Chemistry Research 51, 14653-14664.

Association, P.C., and others (2001). HPV test plans and robust summaries for tall oil and related substances and tall oil fatty acids and related substances. Atlanta, Ga: Pine Chemicals Association.

Berger, K.G., and Akehurst, E.E. (1966). Some applications of differential thermal analysis to oils and fats. International Journal of Food Science \& Technology 1, 237-247.

Bokis, C.P., Chen, C.-C., and Orbey, H. (1999). A segment contribution method for the vapor pressure of tall-oil chemicals. Fluid Phase Equilibria 155, 193-203.

Buss, C., and Tissari, J. (2010). Allanblackia-an ingredient for poverty reduction? Rural 213 , $37-39$.

Canakci, M., and Sanli, H. (2008). Biodiesel production from various feedstocks and their effects on the fuel properties. Journal of Industrial Microbiology \& Biotechnology 35, 431-441.

Canakci, M., and Van Gerpen, J. (2001). Biodiesel production from oils and fats with high free fatty acids. Transactions-American Society of Agricultural Engineers 44, 1429-1436.

Center for History and New Media Zotero Quick Start Guide.

Chong, C.L., and Siew, W.L. (1994). Chemical and physical properties of palm kernel oil. In Proceedings of the World Conference on Lauric Oils: Sources. Processing and Applications, pp. 79-83.

Clark, S.J., Wagner, L., Schrock, M.D., and Piennaar, P.G. (1984). Methyl and ethyl soybean esters as renewable fuels for diesel engines. J Am Oil Chem Soc 61, 1632-1638.

Demirbaş, A. (2002). Biodiesel from vegetable oils via transesterification in supercritical methanol. Energy Conversion and Management 43, 2349-2356. 
Demirbas, A. (2007). Progress and recent trends in biofuels. Progress in Energy and Combustion Science 33, 1-18.

Di Serio, M., Tesser, R., Pengmei, L., and Santacesaria, E. (2007). Heterogeneous catalysts for biodiesel production. Energy \& Fuels 22, 207-217.

Dogbevi, E.K. (2007). The Shea Tree Has Economic and Environmental Values for Ghana.

Encinar, J.M., Gonzalez, J.F., and Rodríguez-Reinares, A. (2005). Biodiesel from used frying oil. Variables affecting the yields and characteristics of the biodiesel. Industrial \& Engineering Chemistry Research 44, 5491-5499.

Encinar, J.M., Gonzalez, J.F., Rodriguez, J.J., and Tejedor, A. (2002). Biodiesel Fuels from Vegetable Oils: Transesterification of Cynara c ardunculus L. Oils with Ethanol. Energy \& Fuels $16,443-450$.

Formo, M.W. (1954). Ester reactions of fatty materials. Journal of the American Oil Chemists Society $31,548-559$.

Garg, H.P., Mullick, S.C., and Bhargava, A.K. (1985). Solar thermal energy storage (Springer Science \& Business Media).

Hermann, M. (2009). The impact of the European Novel Food Regulation on trade and food innovation based on traditional plant foods from developing countries. Food Policy 34, 499-507. Hill, J., Nelson, E., Tilman, D., Polasky, S., and Tiffany, D. (2006). Environmental, economic, and energetic costs and benefits of biodiesel and ethanol biofuels. Proceedings of the National Academy of Sciences 103, 11206-11210.

Howell, S., and Jobe, J. (2005). Current status of biodiesel in the United States. The Biodiesel Handbook 183-193.

http://berniceagyekwena.wordpress.com/2011/01/04/the-sheanut-tree-the-wonder-tree/. Accessed 04/05/2014.

https://www.google.com/search?q=The+shea + nut + tree\&biw $=1024 \& b i h=677 \&$ tbm $=$ isch\&imgil $=$ YKLVAASQ7CZcFM\%253A\%253Bhttps. Accessed 04/05/2014.

Irvine, F.R., and others (1961). Woody plants of Ghana with special reference to their uses.

Woody Plants of Ghana with Special Reference to Their Uses. 
Jacobson, K., Gopinath, R., Meher, L.C., and Dalai, A.K. (2008). Solid acid catalyzed biodiesel production from waste cooking oil. Applied Catalysis B: Environmental 85, 86-91.

Kenisarin, M., and Mahkamov, K. (2007). Solar energy storage using phase change materials. Renewable and Sustainable Energy Reviews 11, 1913-1965.

Keskin, A., Yaşar, A., Gürü, M., and Altıparmak, D. (2010). Usage of methyl ester of tall oil fatty acids and resinic acids as alternative diesel fuel. Energy Conversion and Management 51, 2863-2868.

Knothe, G. (2001). Historical perspectives on vegetable oil-based diesel fuels. Inform 12, $1103-$ 1107.

Knothe, G., and Steidley, K.R. (2005). Lubricity of components of biodiesel and petrodiesel. The origin of biodiesel lubricity. Energy \& Fuels 19, 1192-1200.

Kulkarni, M.G., and Dalai, A.K. (2006). Waste cooking oil an economical source for biodiesel: a review. Industrial \& Engineering Chemistry Research 45, 2901-2913.

Lane, G.A. (1983). Solar heat storage: latent heat materials.

Lim, Y., Lee, H., Lee, Y.-W., and Han, C. (2009). Design and economic analysis of the process for biodiesel fuel production from transesterificated rapeseed oil using supercritical methanol. Industrial \& Engineering Chemistry Research 48, 5370-5378.

Ma, F., Clements, L.D., and Hanna, M. (1998). The effects of catalyst, free fatty acids, and water on transecterification of beef tallow.

McSweeney, E.E., Arlt, H.G., and Russell, J. (1987). Tall Oil and Its Uses-II (Pulp Chemicals Association New York, NY).

Meher, L.C., Vidya Sagar, D., and Naik, S.N. (2006). Technical aspects of biodiesel production by transesterification - a review. Renewable and Sustainable Energy Reviews 10, 248-268.

Noshadi, I., Amin, N.A.S., and Parnas, R.S. (2012). Continuous production of biodiesel from waste cooking oil in a reactive distillation column catalyzed by solid heteropolyacid: optimization using response surface methodology (RSM). Fuel 94, 156-164. 
Noureddini, H., Harkey, D., and Medikonduru, V. (1998). A continuous process for the conversion of vegetable oils into methyl esters of fatty acids. Journal of the American Oil Chemists' Society 75, 1775-1783.

Ofori, D. A. and Peprah, T. 2011. Domestication of Allanblackia parviflora in Ghana. Report to ICRAF - January 2010-March 2011, 10.

Ofori, D.A., Asomaning, J.M., Peprah, T., Agyeman, V.K., Anjarwalla, P., Tchoundjeu, Z., and Mowo, J. (2015). ADDRESSING CONSTRAINTS IN PROPAGATION OF Allanblackia spp. THROUGH SEED SECTIONING AND AIR LAYERING. Journal of Experimental Biology 3, 1.

Ofori, D.A., Peprah, T., Henneh, S., Von Berg, J.B., Tchoundjeu, Z., Jamnadass, R., and Simons, A.J. (2008). Utility of grafting in tree domestication programme with special reference to Allanblackia parviflora A. Chev. Ghana Journal of Forestry 23, 42-48.

Okullo, J.B.L., Omujal, F., Agea, J.G., Vuzi, P.C., Namutebi, A., Okello, J.B.A., and Nyanzi, S.A. (2010). Physico-Chemical characteristics of shea butter (Vitellaria paradoxa CF Gaertn.) oil from the Shea district of Uganda. African Journal of Food, Agriculture, Nutrition and Development 10.

Özçimen, D., and Karaosmanoğlu, F. (2004). Production and characterization of bio-oil and biochar from rapeseed cake. Renewable Energy 29, 779-787.

Peprah, T., Ofori, D.A., Siaw, D., Addo-Danso, S.D., Cobbinah, J.R., Simons, A.J., and Jamnadass, R. (2009a). Reproductive biology and characterization of Allanblackia parviflora A. Chev. in Ghana. Genetic Resources and Crop Evolution 56, 1037-1044.

Peprah, T., Ofori, D.A., Siaw, D., Addo-Danso, S.D., Cobbinah, J.R., Simons, A.J., and Jamnadass, R. (2009b). Reproductive biology and characterization of Allanblackia parviflora A. Chev. in Ghana. Genetic Resources and Crop Evolution 56, 1037-1044.

Pimentel, D., and Patzek, T. (2006). Green plants, fossil fuels, and now biofuels. Bioscience 56, $875-875$.

Pisarello, L. Ma., Cordeiro, C. S., and Querini, C. A., 2007. Biodiesel from Tall Oil Fatty acids using Homogeneous and Heterogeneous Catalysts. 
Pletcher, J. (1991). Regulation with growth: the political economy of palm oil in Malaysia. World Development 19, 623-636.

Poku, K. (2002). Small-scale palm oil processing in Africa (Food \& Agriculture Org.).

Prakash, J., Garg, H.P., and Datta, G. (1985). A solar water heater with a built-in latent heat storage. Energy Conversion and Management 25, 51-56.

Quansah, S. (2012). Life cycle analysis of shea butter biodiesel using GREET software.

Quick, G.R., P.J. Woodmore and B.T. Wilson, (1983). Vegetable Oil as Diesel Fuel. USDA, Agric. Rev. Man., ARM-NC-28, 138.

Ramadhas, A.S., Jayaraj, S., and Muraleedharan, C. (2004). Use of vegetable oils as IC engine fuels - a review. Renewable Energy 29, 727-742.

Ramos, L. P., Cordeiro, S., Pissarelo, Ma. L., and Querini, C. A., 2008. Biodiesel from Tall Oil Fatty Acids Using Homogeneous and Heterogeneous Catalysts. V CONGRESO IBEROAMERICANO DE INVESTIGACION EN CELULOSA Y PAPEL 2008.

Schumacher, L.G., Borgelt, S.C., and Hires, W.G. (1995). Fueling a diesel engine with methylester soybean oil. Applied Engineering in Agriculture (USA).

Shafiee, S., and Topal, E. (2009). When will fossil fuel reserves be diminished? Energy Policy 37, 181-189.

Sharma, A., Tyagi, V.V., Chen, C.R., and Buddhi, D. (2009). Review on thermal energy storage with phase change materials and applications. Renewable and Sustainable Energy Reviews 13, 318-345.

Sharma, S.D., and Sagara, K. (2005). Latent heat storage materials and systems: a review. International Journal of Green Energy 2, 1-56.

Shrestha, R.B., and Akangaamkum, A.D. (2008). Novella partnership, a partnership for poverty reduction through sustainable enterprise development based on Allanblackia. SNV Ghana 20. Tetens, I. (2007). Opinion of the Scientific Panel on Dietetic Products, Nutrition and Allergies on a request from the Commission related to the safety of Allanblackia seed oil for use in yellow fat and cream based spreads: Request N ${ }^{\circ}$ EFSA-Q-2007-059 (European Food Safety Authority). 
Tomasevic, A.V., and Siler-Marinkovic, S.S. (2003). Methanolysis of used frying oil. Fuel Processing Technology 81, 1-6.

US Environmental Protection Agency Hazard Characterization Document, (2012). ScreeningLevel Hazard Characterization Sponsored Chemical. Tall Oil Fatty Acids, Compounds with Triethanolamine (CASRN 68132-46-7).

Van Rompaey, R. (2003). Distribution and ecology of Allanblackia spp. Clusiaceae) in African Rain Forests, with Special Attention to the Development of a Wild Picking System of the Fruits. ECOSYN Consulting, Wageningen and Unilever Research Laboratories, Vlaardingen.

Wansbrough, H. (1987). Written as a combination of two articles from edition one by P.J. Hooker and L.E. Fotherby (1977 Chemistry 100 students) and by Malcolm Rough, Senior Process Engineer, KRTA Ltd. respectively, with updated information provided by Stuart Cooney (Eka Chemicals) and with reference to: Grant, Roger and Grant, Claire; Grant and Hockh's Chemical Dictionary (5th ed.); McGraw-Hill Book Company; 1987.

White, K., Lorenz, N., Potts, T., Roy Penney, W., Babcock, R., Hardison, A., Canuel, E.A., and Hestekin, J.A. (2011). Production of biodiesel fuel from tall oil fatty acids via high temperature methanol reaction. Fuel 90, 3193-3199.

Wilfred, S., Adubofuor, J., and Oldham, J.H. (2010). Optimum conditions for expression of oil from Allanblackia floribunda seeds and assessing the quality and stability of pressed and solvent extracted oil. African Journal of Food Science 4, 563-570.

Wood, W.B. (1990). Tropical deforestation: balancing regional development demands and global environmental concerns. Global Environmental Change 1, 23-41.

ww2.mackblackwell.org www.fao.org/docrep/003/x6877E/x6877E09.htm. Accessed 03/10/2013. 


\title{
3 Biodiesel Production from Tall Oil Fatty Acids via homogeneous and heterogeneous catalysis
}

\begin{abstract}
A homogeneous catalyst, sulfuric acid, and a heterogeneous acid, Amberlyst BD 20 from Dow Chemicals were used to produce biodiesel from Tall oil fatty acids (TOFA) using a batch reactor. Mid-infrared (FTIR) was used to monitor the reaction to determine when the reaction has gone to completion. Results indicated a higher percentage yield of 94.72 for the homogeneous catalysis while the heterogeneous catalysis showed a lower optimization percentage yield of 93.12. FTIR spectra showed that the homogeneous catalysis gave more complete reaction toward production formation in a shorter time than the heterogeneous catalysis which took a longer time. The heterogeneous catalyst, Amberlyst BD 20, gave a higher percentage yield as well as a lower acid value from the second recycling because the reactants were not fully in contact with the catalyst during the first recycling. The catalyst did not show a reduction in catalytic activity even after recycling for four times. However, the optimum acid value was within that for ASTM standards for biodiesel. Gas chromatographic data showed that the major fatty acids present in the TOFA are oleic acid (C18:1n9) and linoleic acid (C18:2n6). The kinematic viscosity was within the ASTM standards for biodiesel.
\end{abstract}

\subsection{Introduction}

For the greater part of the 20th and $21^{\text {st }}$ centuries, petroleum-based fuels and products have been relatively cheap. During this period, transportation of industrial goods and services have been effected primarily by diesel powered trucks, trains and other vehicle (Howell and Jobe, 2005), and oil needed to produce diesel fuel has been imported into the US. This increasing dependence on foreign oil has necessitated the search and development of alternative fuels such as biodiesel (Howell and Jobe, 2005).

A major source of alternative fuel is oil from plant origin like vegetable oils and seeds from trees (Meher et al., 2006). Vegetable oils were first used to power diesel engine by its inventor Rudolf Diesel in 1900 (Pinto et al., 2005). Vegetable oils and animal fats have in recent times been considered as viable feed stocks for biodiesel production due to the fact that they have similar properties as petro-diesel. The advantage of biodiesel over petro-diesel include high cetane 
value, high flash points, higher lubricity, biodegradability, low environmental footprint. Over 350 oil bearing seed plants have been identified as potential alternative sources for producing biodiesel. Among these are sunflower, safflower, soybean, cottonseed, rapeseed and peanut oils (Goering et al., 1982; Pryor, et al., 1983). Other targeted sources for biodiesel production are waste cooking oils, animal fat, and algae. Biodiesel has the potential to positively impact agriculture and improve the economies of rural communities (Meher et al., 2006). Additionally, biodiesel can be used in compression ignition engines without modification to the engine (Howell and Jobe, 2005).

Several methods have been used to produce biodiesels from renewable sources. They include pyrolysis, emulsification, blending, and transesterification. Commercially, the common process for biodiesel production is transesterification. The latter process involves reaction of a triglyceride (ester of glycerol) of the oil with an alcohol in the presence of a catalyst to obtain another ester (biodiesel). Methanol the commonly used alcohol produces fatty acid methyl ester (FAME). Traditionally, biodiesel production process is a catalyzed reversible reaction process and alkalis and acids have been used as catalysts (Lim et al., 2009; White et al., 2011). The overall transesterification reaction with a base (alkali) catalyst is shown below:

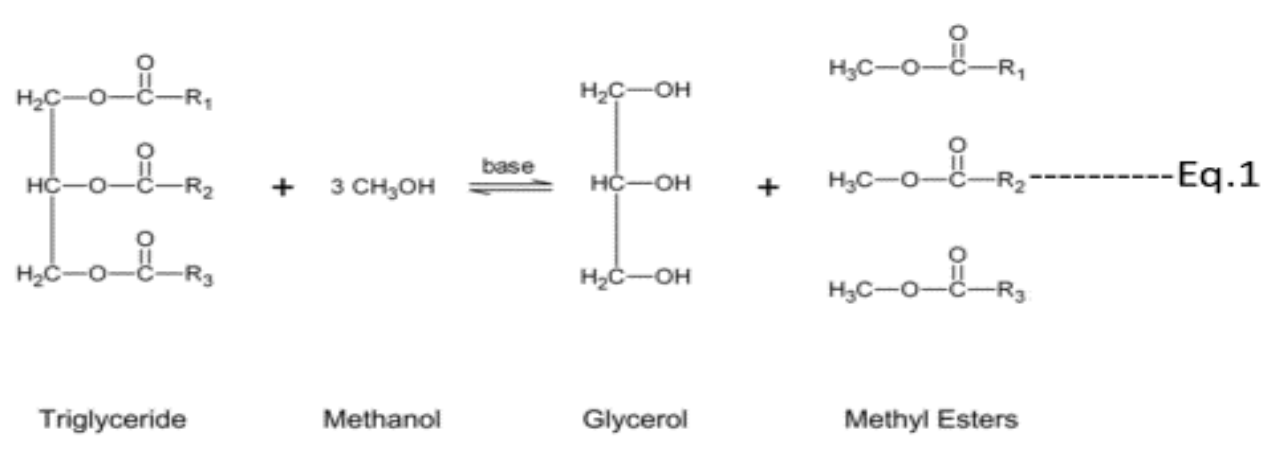

where $\mathrm{R}_{1}, \mathrm{R}_{2}$, and $\mathrm{R}_{3}$ are alkyl groups of long chain fatty acids.

Source: ww2.mackblackwell.org 
Biodiesel can also be produced from fatty acids by direct esterification. Tall oil, a by-product of Kraft pulping of pine is further processed to produce Tall oil fatty acids (TOFA). The TOFA consists of resin acids, fatty acids and unsaponifiables (neutrals). Resin acids are mixtures of organic acids produced via oxidation and polymerization of terpenes present in softwoods like pines. In Tall oil, the major component of resin acids is abietic acid and small amounts of pimaric acid. Fatty acids present in Tall oil are palmitic acid, oleic acid and linoleic acid. Unsaponifiable components of Tall oil are neutral compounds that include hydrocarbons, higher alcohols and sterols. Unsaponifiables do not form soap when saponified (Wansbrough, 1987). Tall oil fatty acids is a fractionation product from the distillation of crude Tall oil. Tall oil fatty acids represent a potential feedstock for biodiesel production. As mentioned earlier, biodiesel production from TOFA involves the reaction of TOFA with methanol. Biodiesel feedstock with high free fatty acids (FFAs) use acid catalysts instead of basic (alkali) catalysts because the latter results in the formation of soaps (Abidin et al., 2012).

Production of biodiesel (fatty acid methyl ester) from TOFA is illustrated below:

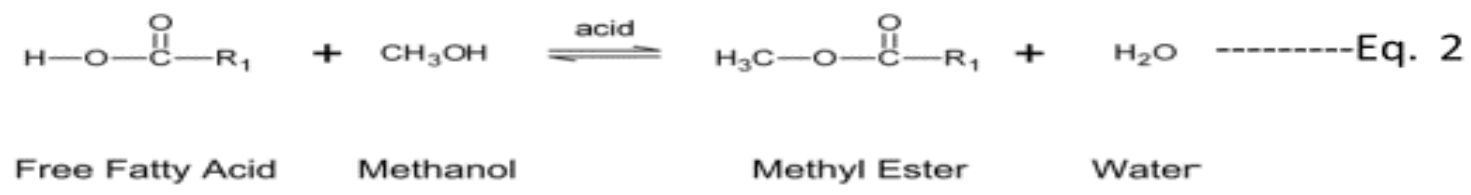

Source: ww2.mackblackwell.org

Production of biodiesel from TOFA have been reported. Pisarello et al. (2007) produced biodiesel from TOFA using sulfuric acid (homogeneous catalyst) and solid niobic acid $\left(\mathrm{Nb}_{2} \mathrm{O}_{3} . \mathrm{nH}_{2} \mathrm{O}\right.$, heterogeneous catalysts). The homogeneous catalyst loading was 0.18 and $0.5 \%$ 
(volume/volume, $\mathrm{v} / \mathrm{v}$ ) with methanol/fatty acid mole ratio ranging from 2:1, 3:1, 8:1 and 40:1 at a constant temperature of $60^{\circ} \mathrm{C}$. The heterogeneous catalyst used reaction temperatures of $130^{\circ} \mathrm{C}$ and $180^{\circ} \mathrm{C}$ in a pressurized stainless steel reactor. The homogeneous catalyst gave the highest yield of $98.4 \%$ with acidity reduction from 96.5 to 1.55 for the highest mole ratio of $40: 1$ occurring within a time of 3 minutes. Increase in molar ratio increased recovery and decreased acidity as well as decreased time of equilibrium attainment. For the heterogeneous catalyst production, the acidity dropped to 8.06 with a conversion of $91.6 \%$. The best ester yield occurred at $180^{\circ} \mathrm{C}$ with a molar ratio of $3: 1$ and a catalyst loading of $12 \mathrm{wt} . \%$. Therefore, it was concluded that TOFA can be used to produce biodiesel via a homogeneous catalyst at atmospheric pressure. However, heterogeneous catalysis required higher pressure. Similarly, Ramos et al. (2008) demonstrated that when production of biodiesel from TOFA is catalyzed with sulfuric acid (homogeneous catalyst) and niobium powder (heterogeneous catalyst), a steady state of reaction was achieved in less than 1 hour for homogeneous catalysis and a methanol/fatty acid mole ratio of $8: 1$, catalyst loading of $0.5 \% \mathrm{v} / \mathrm{v}$ for the acid number to decrease from 96.55 to $0.45 \mathrm{~g}$ of oleic acid per $100 \mathrm{~g}$ of TOFA. For heterogeneous catalysis, the best biodiesel yield occurred at a temperature of $155^{\circ} \mathrm{C}$ using a methanol/fatty acid mole ratio of $2.5: 1$, catalyst loading of $12 \%$ (weight/volume, w/v) and a reaction time of $2 \mathrm{hrs}$. Also, acid number dropped from 96.55 to $6.71 \mathrm{~g}$ of oleic acid per $100 \mathrm{~g}$ of TOFA in one reaction step. Keskin et al. (2010) performed emission tests on biodiesels prepared from TOFA and resinic acids and found no significant difference in specific fuel consumption for fuel blends while there were significant reduction in carbon monoxide and smoke levels. The nitric oxide $\left(\mathrm{NO}_{\mathrm{x}}\right)$ levels did increase while carbon dioxide $\left(\mathrm{CO}_{2}\right)$ levels showed no significant increase with the fuel blends. White et al. (2011) used supercritical methanol method at high temperature and pressure to convert TOFA to biodiesel in the absence of a catalyst. Yields of $81 \%$ and $75 \%$ at pressures of $4.2 \mathrm{MPa}$ and 6.6 MPa respectively were obtained. However, the yields obtained were more dependent on temperature, time of reaction and molar ratio and less on pressures. A low molar ratio of 5:1 gave comparable conversions. However, the supercritical methanol method however requires a high capital outlay due to the high temperature and pressure requirements even though total manufacturing cost seems lower than that of the alkali-catalyzed method due to a higher purity glycerol formation and the absence of the cost of a catalyst or solvent (Lim et al., 2009). 
A new heterogeneous catalyst for the biodiesel production, Amberlyst BD 20, has been reported by Rohm and Haas (Dow Chemicals). Park et al. (2010), tested the catalytic potency of two catalysts Amberlyst BD 15 and Amberlyst BD 20 for high FFA oils with 50 and 99.8 wt. \% and found out that Amberlyst BD 15 activity decreased with recycling due to water poisoning whereas Amberlyst BD 20 activity was not affected by the water production.

Herein, we report the results of a study that evaluated biodiesel production using both a homogeneous catalyst, sulfuric acid, and a heterogeneous catalyst, Amberlyst BD 20 resin. Optimum conditions for both processes were also determined.

\subsection{Materials and Methods}

\subsubsection{Materials:}

Tall Oil Fatty Acid (TOFA) was provided ex-gratia by Georgia Pacific Company (Atlanta, GA. USA). Methanol ( $\left.\mathrm{CH}_{3} \mathrm{OH}\right)$, ACS grade (Fisher Scientific, NJ., USA), A PerkinElmer Spectrum 100 FTIR (Waltham, Massachusetts, U.S.A.) with an ATR spectrometer, Ambersep ${ }^{\mathrm{TM}}$ BD19 (Midcontinental Chemical Co., Olathe, KS, USA), Amberlyst ${ }^{\mathrm{TM}}$ BD20 (Midcontinental Chemical Co., Olathe, KS, USA), Buchi Rotavapor, R-210/215 (Flawil, Switzerland), anhydrous sodium sulfate $\left(\mathrm{Na}_{2} \mathrm{SO}_{4}\right.$ ) (Acros Organics, NJ USA), potassium acid phthalate, $0.05 \mathrm{~N}$ (Alfa Aesar, Ward Hill, MA, USA), barium hydroxide (Fisher Scientific, Nazareth, PA, USA), phenolphthalein indicator (Allied Chemical Corporation, Morristown, NJ, USA), isopropyl alcohol (Acros Organics, NJ, USA), Toluene (Fisher Scientific, Fair Lawn, NJ, USA), MarsXpress Microwave Digester (CEM Corporation, Matthews, NC, USA), Touch Mixer Mechanical Shaker Model 231 (Fisher scientific, NJ, USA), Sorvall RC-5B Refrigerated Superspeed Centrifuge (Dupont Instruments, Chadds Ford, PA, USA), Specific Gravity Bottles (Kimble Glass Inc., Vineland, NJ USA), Thermometer with a range of -20 to $102^{\circ} \mathrm{C}$ with 0.2 subdivisions (H-B Instrument Co., Collegeville, PA USA), Water Bath.

\subsubsection{Methods:}

\subsubsection{Homogeneous Biodiesel Production}

The experimental design was a randomized full factorial design. The experimental conditions were: (1) ratio of the methanol to oil (TOFA) levels as 6:1 and 15:1; (2) temperature levels of 
$55^{\circ} \mathrm{C}$ and $75^{\circ} \mathrm{C}$; (3) catalyst levels at $0.5 \% \mathrm{w} / \mathrm{w}$ and $2 \% \mathrm{w} / \mathrm{w}$ of oil; (4) time of reaction levels of 30 minutes and 60 minutes. Each treatment was replicated three times.

Approximately $40 \mathrm{~g}$ of TOFA was weighed into $125 \mathrm{ml}$ conical flasks. Varying the mole ratio of oil to methanol from 6:1 and 15:1, equivalent amount of methanol was weighed into a $250 \mathrm{ml}$ conical flask and sulfuric acid catalyst added. The catalyst-methanol mixture was then added to the TOFA and stirred at a constant temperature in a water bath at 1,000 rpm under reflux using a magnetic stirrer. The reaction starts when the reaction mixture attains the target temperature. At the end of the reaction period, the reaction mixture was poured into a separating funnel. Over a period of time, two phases developed. The heavier (bottom) water phase was collected first by gravity and the upper biodiesel phase (methyl ester) was washed with warm water several times to remove suspended impurities, unreacted methanol, catalyst and any soap formed.

The washed reaction mixture (biodiesel) was then filtered through a bed of anhydrous sodium sulfate to remove all water and then stored in a refrigerator at $6^{\circ} \mathrm{C}$ until use.

\subsubsection{Analysis of Biodiesel using Mid-Infrared (FTIR) Spectroscopy}

The functional group chemistry of biodiesel was determined via mid-infrared spectroscopy (Fourier transform infrared spectra, FTIR) using a PerkinElmer Spectrum 100 FTIR spectrometer fitted with a Universal Sampling Accessory. Measurement was recorded in Transmittance mode and the range was between $4000 \mathrm{~cm}^{-1}$ and $600 \mathrm{~cm}^{-1}$. Four scans were taken per each measurement. Biodiesel sample (about $0.1 \mathrm{~mL}$ ) was dropped on the diamond ATR probe aperture, and spectra were recorded at a resolution of $8 \mathrm{~cm}^{-1}$ using 4 scans under 1 minute against air as the background. In the analysis of the FTIR spectra, emphasis was placed on the functional groups of the ester in the biodiesel. The conversion of the starting material (TOFA) to the biodiesel (ester or FAME, Tall oil methyl ester - TOME) is defined by the shape of the peaks in the carbonyl region of the spectrum.

\subsubsection{Analysis of Biodiesel using Gas Chromatography method}

The fatty acid methyl ester (FAME, biodiesel) content of the reaction mixture was determined by capillary gas chromatography (GC). The GC was a Varian CP-3800 gas chromatograph equipped with FID (flame ionization detector) and Varian 8400 auto-sampler. The column was a wall- 
coated open tubular (WCOT) fused silica capillary column of $100 \mathrm{~m}$ length with a $0.25 \mathrm{~mm}$ inside diameter (CP-Sil 88 for FAME; (Varian/Agilent Technologies, Santa Clara, CA, USA). The carrier gas was nitrogen and the split ratio was 10:1. The chromatographic separation conditions were: initial oven temperature, $140^{\circ} \mathrm{C}$; this was held for $6 \mathrm{~min}$, then ramped at $4^{\circ} \mathrm{C} / \mathrm{min}$ to $225^{\circ} \mathrm{C}$ and held for $15 \mathrm{~min}$. Injector temperature was $270^{\circ} \mathrm{C}$ and the detector temperature reached $300^{\circ} \mathrm{C}$. Fatty acid methyl ester (FAME's) identification was based on comparison of retention times of standard FAME (Supleco quantitative standard FAME 37). The GC used the Integrator: Star GC Workstation version 6 software (Varian) for analysis.

\subsubsection{Elemental analysis of biodiesel}

Microwave digestion was carried out prior to elemental analysis of TOFA using Inductively Coupled Plasma Optical Emission Spectroscopy (ICP-OES). About $0.5 \mathrm{~g}$ of TOFA was weighed into vessels of the MarsXpress microwave digester and $10 \mathrm{ml}$ of concentrated $\mathrm{HNO}_{3}$ was added to it and then pre-digested with caps open for 15 minutes under a hood. The vessels were then capped and inserted into the vessel holder and put in the microwave digester and run according to the digestion program below:

Table 3.1: Microwave digestion program

\begin{tabular}{|l|l|l|l|l|l|}
\hline \multirow{2}{*}{ Stage } & \multicolumn{2}{|l|}{ Power } & $\begin{array}{l}\text { Ramp } \\
\text { Time } / \text { mins }\end{array}$ & Temperature $/{ }^{\circ} \mathrm{C}$ & $\begin{array}{l}\text { Hold } \\
\text { Time } / \mathrm{mins}\end{array}$ \\
\cline { 2 - 6 } & Level & $\%$ & 20 & 200 & 20 \\
\hline 1 & $1600 \mathrm{~W}$ & 90 & 20 & \\
\hline
\end{tabular}

After digestion, the vessels were removed and allowed to cool. The resulting mixture from the digestion was poured into $100 \mathrm{ml}$ beakers and the solutions were made up to $50 \mathrm{ml}$ with deionized water in $50 \mathrm{ml}$ volumetric flasks. The solutions were then poured into $50 \mathrm{ml}$ vials and the elemental composition of the biodiesel determined by ICP-OES.

\subsubsection{Physical and Chemical Characterization of Biodiesel 3.1.2.5.1 Kinematic Viscosity}

The kinematic viscosity of TOFA and TOME were determined according to ASTM D445-12 and ASTM D446-07. The Ubbelholde Capillary Viscometers of sizes 100 and 200 were used for the 
determination. The size 200 with a viscosity range of 20-100 cSt was used for the determination of the TOFA while the size 100 with a viscosity range of 3-15 cSt was used for the determination of the TOME.

\subsection{Water Content Determination}

Water Content of the biodiesel was determined according to ASTM D2709-96 (reapproved 2011). $100 \mathrm{ml}$ samples were measured into cone-shaped centrifuge tubes and kept at a room temperature of $25^{\circ} \mathrm{C}$ for sample to equilibrate to the laboratory temperature. The samples were then shaken on a Touch Mixer mechanical shaker for 10 minutes. Sample tubes were filled and placed in trunnion cups opposite to one another and whirled at $2500 \mathrm{rpm}$ for 10 minutes. The volume of water that settled at the bottom of the sample tubes were measured after the centrifuging period.

\subsection{Determination of Acid Value}

The acid value of the biodiesel produced was determined as per AOCS Official Method Cd 3a63 (Revised 1987, Reapproved 1989).

(a) $0.1 \mathrm{M} \mathrm{KOH}$ was accurately standardized and made carbonate free. $6 \mathrm{~g}$ of reagent grade $\mathrm{KOH}$ was added to water and made up to $1 \mathrm{~L}$ in a $2 \mathrm{~L}$ Erlenmeyer flask. The solution was boiled for 10 minutes with stirring and $2 \mathrm{~g}$ of reagent grade barium hydroxide $\left(\mathrm{Ba}(\mathrm{HO})_{2}\right)$ was added to it. The resulting mixture was boiled for an additional 5-10 minutes. It was then cooled, stoppered in a glass bottle and allowed to stand for several hours. Solution was filtered through sintered glass funnel and stored in an alkali resistant bottle protected from carbon dioxide $\left(\mathrm{CO}_{2}\right)$. It was then standardized by titration with a primary standard grade potassium acid phthalate $(0.05 \mathrm{M})$, using phenolphthalein as indicator.

(b) A solvent mixture consisting of equal parts by volume of isopropyl alcohol and toluene was prepared and the mixture gave a sharp distinct end point with the phenolphthalein indicator in a titration.

(c) Phenolphthalein indicator solution of $1 \%(\mathrm{w} / \mathrm{v})$ in isopropyl alcohol was also prepared.

(d) The indicator solution was added to the required amount of solvent in the ratio of $2 \mathrm{ml}$ to 125 $\mathrm{ml}$ and neutralized with the $0.1 \mathrm{M} \mathrm{KOH}$ to a faint permanent color. 
The amount of sample used was determined according to the Table 3.2 below:

Table 3.2: Range of sample weight for acid value determination.

\begin{tabular}{|l|l|l|}
\hline Acid Value & $\begin{array}{l}\text { Wt. of Sample } \\
( \pm 10 \%) / \mathrm{g}\end{array}$ & $\begin{array}{l}\text { Weighing Accuracy } \\
\mathrm{g}\end{array}$ \\
\hline $0-1$ & 20 & 0.05 \\
\hline $1-4$ & 10 & 0.02 \\
\hline $4-15$ & 2.5 & 0.01 \\
\hline $15-75$ & 0.5 & 0.001 \\
\hline 75 and above & 0.1 & 0.0002 \\
\hline
\end{tabular}

A given amount of the well mixed liquid sample was weighed into an Erlenmeyer flask and 125 $\mathrm{ml}$ of the neutralized solvent was added to it and dissolved in the solvent and warmed for complete dissolution of the sample in the solvent. Resulting solution was titrated against the standard $0.1 \mathrm{M} \mathrm{KOH}$ solution to the first permanent pink color of the same intensity as that of the neutralized solvent before it was added to the sample. The color persisted for 30 minutes. Calculations:

The acid value, $\mathrm{mg} \mathrm{KOH} / \mathrm{g}$ of sample is given by

\{(A-B) X N X 56.1\}/W

Where, $\mathrm{A}=\mathrm{ml}$ of standard alkali used in titration

$\mathrm{B}=\mathrm{ml}$ of standard alkali used in titrating the blank

$\mathrm{N}=$ Normality or Molarity of standard alkali

$\mathrm{W}=$ Weight of sample in grams.

\subsection{Specific gravity of TOFA and biodiesel}

The method for determining the specific gravity of TOFA and the biodiesel from TOFA was done according to ASTM D5355-95 (reapproved 2006). The specific gravity bottles were cleaned and dried thoroughly, and then weighed. They were then filled with boiled and cooled de-ionized water at $20-23^{\circ} \mathrm{C}$. The bottles were filled to overflowing by being held on its side. The stopper was inserted and then immersed in the water bath at a temperature of $25 \pm 0.2^{\circ} \mathrm{C}$. The entire bulb was completely covered with water and held at the specified temperature for 30 
minutes. Any water that exuded from the side opening was removed. The bottle was then taken from the bath and wiped completely dry and weighed with its contents. The weight of the water was then calculated.

\subsection{Specific gravity at $25 / 25^{\circ} \mathrm{C}$}

The oil sample was melted and filtered through a filter paper. The sample was then cooled to a temperature between 20 and $23^{\circ} \mathrm{C}$ and filled to overflowing by holding it on its side. The stopper was inserted and immersed into it, and then held in the water bath at a temperature of $25 \pm 0.2^{\circ} \mathrm{C}$ for 30 minutes. Any excess oil exuding from bottle was wiped clean and thoroughly dried. The bottle and its contents were weighed and the specific gravity calculated according to the formula:

Specific Gravity = Weight of Bottle and Oil - Weight of Bottle

\section{Weight of Water at $25^{\circ} \mathrm{C}$}

\subsection{Specific gravity at $60 / 25^{\circ} \mathrm{C}$}

The oil sample was melted and filtered through a filter paper. The oil was then poured into the specific gravity bottle at a temperature of $56-58^{\circ} \mathrm{C}$ to overflowing, while holding the bottle on its side. The bottle was then stoppered and immersed and held in the water bath at $60 \pm 0.2^{\circ} \mathrm{C}$ for 30 minutes. The bottle was then wiped clean of excess oil and dried thoroughly. The contents were then weighed and the specific gravity calculated according to the formula:

Specific Gravity = (F)/W[1 + (0.000025 X 35) $]$

Where $\mathrm{F}=$ Weight of Oil at $60^{\circ} \mathrm{C}$

$$
\mathrm{W}=\text { Weight of Oil at } 25^{\circ} \mathrm{C} \text {. }
$$

\subsubsection{Drying of Ambersep BD19 wet resin}

Ambersep BD 19 wet resin needed to be dried before use. The wet Ambersep BD19 resin was measured into a graduated cylinder and made into a slurry with de-ionized water. A glass column was used as a reactor and filled a quarter full with water. The slurry of Ambersep BD19 was slowly poured into the reactor containing the de-ionized water while tapping the side to ensure 
good settling or packing. The reactor was then sealed and dried under vacuum. Dry methanol was then flowed through the reactor from the top of the column. This shifts the Ambersep BD19 wetness from water to methanol. Five volumes of methanol were passed through the reactor to ensure complete dryness (Ambersep BD19 Oil Purification Technology, 2010).

\subsection{Purification using Ambersep BD 19 dry resin prior to use in the heterogeneous catalysis process}

The TOFA requires purification before use in the heterogeneous catalyzed conversion to biodiesel. A given volume of methanol-dried Ambersep BD19 was measured into a graduated cylinder and slowly poured into a glass column reactor while gently tapping the side to ensure good settling and packing. The reactor was then sealed and enough oil was poured unto the Ambersep BD19 resin to completely saturate it, keeping approximately, one inch headspace above the resin in the reactor. The oil containing reactor was kept in a water bath at $60^{\circ} \mathrm{C}$ for a minimum of one hour. The oil was drained under vacuum from the reactor to be used for the esterification process (Ambersep BD19 Oil Purification Technology, 2010).

\subsubsection{Drying of Amberlyst BD20 wet resin catalyst}

The Amberlyst BD20 which was received in a wet form was measured into a graduated cylinder and made into a slurry with de-ionized water. A glass column was used as a reactor and filled a quarter full with water. The slurry of Amberlyst BD20 was slowly poured into the reactor containing the de-ionized water while tapping the side to ensure good settling or packing. The reactor was then sealed. The catalyst was then dried under vacuum while at the same time pouring an equal volume of dry methanol to replace the water that is being removed. Dry methanol was thereafter flowed through the reactor from the top of the column. This shifts the Amberlyst BD20 wetness from water to methanol. Five (5) volumes of methanol were passed through the reactor to ensure complete dryness (Amberlyst BD20 FFA Esterification, 2010).

\subsubsection{Heterogeneous conversion of TOFA to biodiesel via heterogeneous catalysis}

A Central Composite (CCD) and Response Surface Methodology (RSM) design of experiment was used. Data emanating from this study was analyzed statistically using the JMP Statistical Software, JMP Pro 11. The factors were: (1) methanol:oil molar ratio with 2 levels (15:1 and 
$20: 1)$; (2) catalyst concentration with 2 levels (10\% and 20\%); and (3) time of reaction with 2 level ( $4 \mathrm{hrs}$ and $8 \mathrm{hrs}$ ). The temperature of the reaction was kept constant at $75-80^{\circ} \mathrm{C}$.

Esterification process was carried out in a water bath at a constant temperature range of $75-80^{\circ} \mathrm{C}$. About $40 \mathrm{~g}$ of TOFA was measured into a conical flask and dry Amberlyst BD20 resin catalyst was added to it. This mixture was heated in the water bath to the required temperature of the reaction. When the reaction temperature has been attained, methanol was added to the oil and catalyst and then refluxed with water for the required time of the reaction while stirring at a rate of $800 \mathrm{rpm}$. The catalyst was filtered from the reaction mixture after completion of the reaction. The mixture was heated in a Buchi Rotavapor under vacuum to separate unreacted methanol, residual water and any impurities from the biodiesel. The resultant biodiesel solution was poured into a separating funnel and the heavier water portion separated from the biodiesel. The biodiesel was then passed through a bed of anhydrous sodium sulfate $\left(\mathrm{Na}_{2} \mathrm{SO}_{4}\right)$ to remove any remaining water. The biodiesel yield was determined by measuring the weight of the product obtained.

\subsection{Results and Discussion}

The yield of biodiesel produced via homogeneous catalysis of TOFA is shown in Table 3.3. Conversion of TOFA to TOME is attended by a drop in the kinematic viscosity of $20.614 \mathrm{cSt}$ to $5.216 \mathrm{cSt}$, respectively (Table 3.4). This is within the ASTM standard level of 1.9-6.0 cSt (ASTM D445). Tall Oil Fatty Acid feedstock used for biodiesel production is a mixture of fatty acids obtained via fractional distillation of Crude Tall Oil (CTO).

Table 3.3: Biodiesel yield from Tall oil fatty acids (TOFA) using a homogeneous catalyst.

\begin{tabular}{|l|l|l|l|l|l|l|}
\hline No. & Sample & Ratio & Temperature $/{ }^{\circ} \mathrm{C}$ & Catalyst Con. $/ \%$ & Time/mins & Yield/\% \\
\hline 1 & Tome 16 & $6: 1$ & 75 & 2 & 30 & 84.47 \\
\hline 2 & Tome 25 & $15: 1$ & 55 & 2 & 60 & 93.93 \\
\hline 3 & Tome 28 & $6: 1$ & 75 & 0.5 & 30 & 91.19 \\
\hline 4 & Tome 31 & $6: 1$ & 55 & 0.5 & 60 & 91.34 \\
\hline 5 & Tome 10 & $15: 1$ & 55 & 2 & 30 & 88.86 \\
\hline 6 & Tome 13 & $6: 1$ & 75 & 0.5 & 60 & 86.42 \\
\hline 7 & Tome 34 & $15: 1$ & 55 & 0.5 & 30 & 89.77 \\
\hline 8 & Tome 1 & $6: 1$ & 55 & 0.5 & 30 & 92.85 \\
\hline 9 & Tome 4 & $6: 1$ & 55 & 2 & 60 & 66.56 \\
\hline
\end{tabular}




\begin{tabular}{|c|c|c|c|c|c|c|}
\hline 10 & Tome 7 & $15: 1$ & 55 & 0.5 & 60 & 91.03 \\
\hline 11 & Tome 37 & $6: 1$ & 55 & 2 & 30 & 88.24 \\
\hline 12 & Tome 17 & $6: 1$ & 75 & 2 & 30 & 86.97 \\
\hline 13 & Tome 40 & $15: 1$ & 75 & 0.5 & 60 & 94.99 \\
\hline 14 & Tome 19 & $15: 1$ & 75 & 0.5 & 30 & 85.28 \\
\hline 15 & Tome 26 & $15: 1$ & 55 & 2 & 60 & 93.73 \\
\hline 16 & Tome 14 & $6: 1$ & 75 & 0.5 & 60 & 79.03 \\
\hline 17 & Tome 32 & $6: 1$ & 55 & 0.5 & 60 & 93.88 \\
\hline 18 & Tome 8 & $15: 1$ & 55 & 0.5 & 60 & 95.32 \\
\hline 19 & Tome 43 & $6: 1$ & 75 & 2 & 60 & 60.00 \\
\hline 20 & Tome 11 & $15: 1$ & 55 & 2 & 30 & 80.35 \\
\hline 21 & Tome 35 & $15: 1$ & 55 & 0.5 & 30 & 93.11 \\
\hline 22 & Tome 20 & $15: 1$ & 75 & 0.5 & 30 & 85.16 \\
\hline 23 & Tome 22 & $15: 1$ & 75 & 2 & 60 & 80.48 \\
\hline 24 & Tome 46 & $15: 1$ & 75 & 2 & 30 & 94.70 \\
\hline 25 & Tome 47 & $15: 1$ & 75 & 2 & 30 & 92.11 \\
\hline 26 & Tome 44 & $6: 1$ & 75 & 2 & 60 & 60.00 \\
\hline 27 & Tome 48 & $15: 1$ & 75 & 2 & 30 & 93.16 \\
\hline 28 & Tome 41 & $15: 1$ & 75 & 0.5 & 60 & 94.48 \\
\hline 29 & Tome 15 & $6: 1$ & 75 & 0.5 & 60 & 85.28 \\
\hline 30 & Tome 38 & $6: 1$ & 55 & 2 & 30 & 86.02 \\
\hline 31 & Tome 45 & $6: 1$ & 75 & 2 & 60 & 60.00 \\
\hline 32 & Tome 36 & $15: 1$ & 55 & 0.5 & 30 & 91.29 \\
\hline 33 & Tome 2 & $6: 1$ & 55 & 0.5 & 30 & 93.64 \\
\hline 34 & Tome 23 & $15: 1$ & 75 & 2 & 60 & 84.31 \\
\hline 35 & Tome 9 & $15: 1$ & 55 & 0.5 & 60 & 89.26 \\
\hline 36 & Tome 3 & $6: 1$ & 55 & 0.5 & 30 & 90.10 \\
\hline 37 & Tome 18 & $6: 1$ & 75 & 2 & 30 & 85.75 \\
\hline 38 & Tome 21 & $15: 1$ & 75 & 0.5 & 30 & 85.38 \\
\hline 39 & Tome 5 & $6: 1$ & 55 & 2 & 60 & 74.09 \\
\hline 40 & Tome 42 & $15: 1$ & 75 & 0.5 & 60 & 94.68 \\
\hline 41 & Tome 33 & $6: 1$ & 55 & 0.5 & 60 & 92.51 \\
\hline 42 & Tome 29 & $6: 1$ & 75 & 0.5 & 30 & 85.84 \\
\hline 43 & Tome 30 & $6: 1$ & 75 & 0.5 & 30 & 91.94 \\
\hline 44 & Tome 27 & $15: 1$ & 55 & 2 & 60 & 94.00 \\
\hline 45 & Tome 24 & $15: 1$ & 75 & 2 & 60 & 88.39 \\
\hline
\end{tabular}




\begin{tabular}{|l|l|l|l|l|l|l|}
\hline 46 & Tome 39 & $6: 1$ & 55 & 2 & 30 & 86.76 \\
\hline 47 & Tome 12 & $15: 1$ & 55 & 2 & 30 & 88.61 \\
\hline 48 & Tome 6 & $6: 1$ & 55 & 2 & 60 & 87.04 \\
\hline
\end{tabular}

\subsubsection{Statistical analysis for homogeneous catalysis}

Statistical analysis of the homogeneously catalyzed biodiesel production was performed using JMP statistical software, JMP Pro 11. From the 2x2x2x2 factorial ANOVA followed by Tukey's HSD multiple comparison procedure, the model is significant with $\mathrm{p}<0.0001$ at $\alpha=0.05$ level. The $\mathrm{R}^{2}$ value was 0.9 while the adjusted $\mathrm{R}^{2}$ value was 0.85 . The mean of the response was $86.71 \%$. All the fixed factors were not significant. However, some interactions were significant. These are catalyst concentration and time interactions $(\mathrm{p}=0.0076)$ : ratio, temperature and time interactions ( $p=0.040)$; ratio, catalyst concentration and time interactions $(p=0.002)$; ratio, temperature and time interactions $(\mathrm{p}=0.011)$; and ratio, temperature, catalyst concentration and time interactions $(p=0.036)$. With all factors and levels considered for the whole model, the treatment with highest mean $(94.72 \%)$ has the treatment conditions of ratio $(15: 1)$, temperature $\left(75^{\circ} \mathrm{C}\right)$, catalyst concentration $(0.5 \%)$ and a time of reaction (60 mins), represented as Tome 40 , 41 and 42 . This treatment is significantly different from the treatment with the mean $(83.57 \%)$ which has the conditions of ratio $(6: 1)$, temperature $\left(75^{\circ} \mathrm{C}\right)$, catalyst concentration $(0.5 \%)$ and time of reaction (60 mins). The treatment with highest mean $(94.72 \%)$ is also significantly different from treatment with a mean yield (75.89\%) having the treatment conditions of ratio $(6: 1)$, temperature $\left(55^{\circ} \mathrm{C}\right)$, catalyst concentration $(2 \%)$ and reaction time (60 mins). The same highest mean treatment is again significantly different from the treatment with a mean of $60 \%$ having treatment conditions of ratio $(6: 1)$, temperature $\left(75^{\circ} \mathrm{C}\right)$, catalyst concentration $(2 \%)$ and reaction time of 60 mins (figure 3.1). 


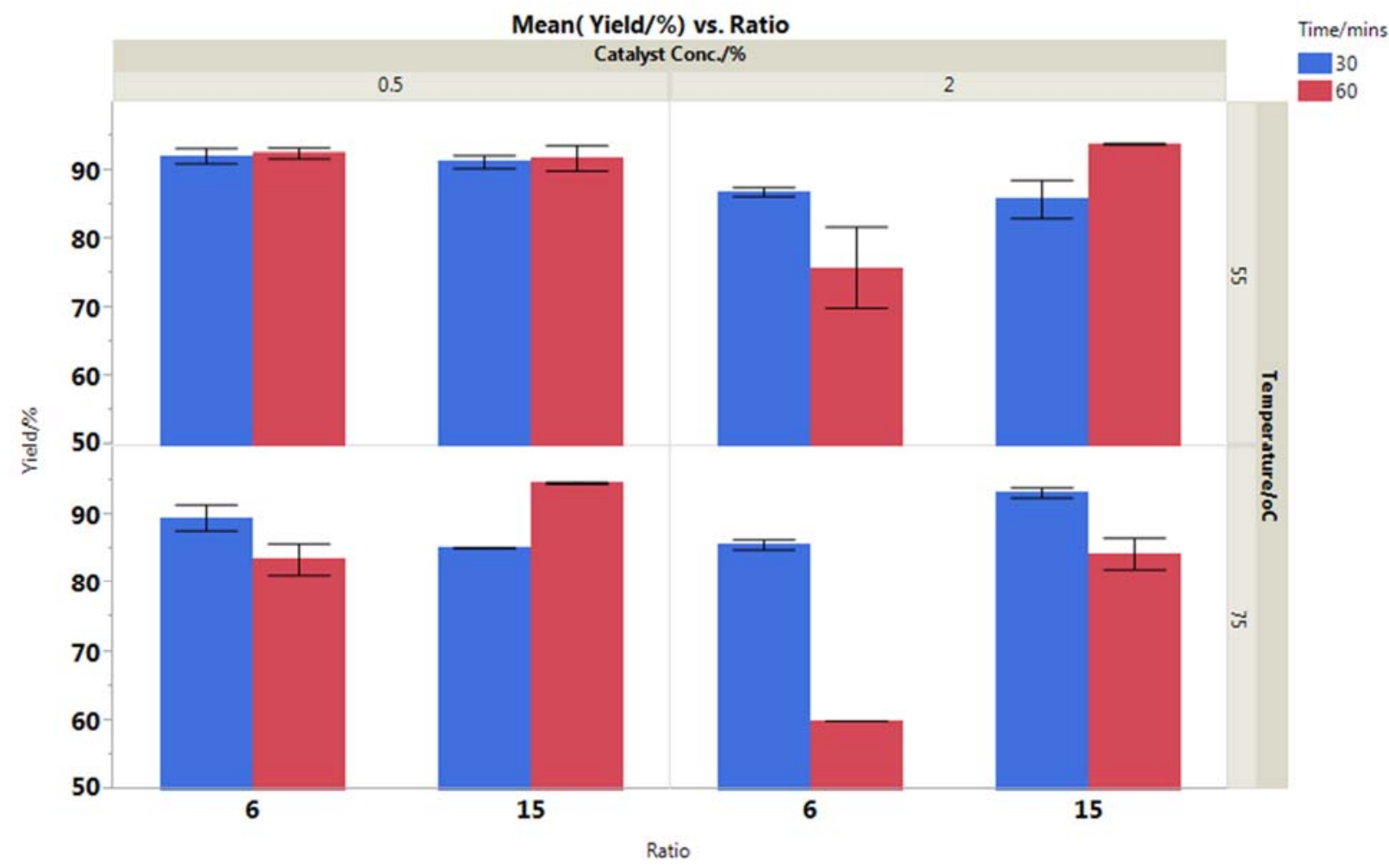

Fig. 3.1: A graph of \%Yield against ratio, temperature, catalyst concentration and time of reaction

\subsubsection{Chemical properties of TOFA and TOME}

Table 3.4: Chemical properties of TOFA and TOME

\begin{tabular}{|l|l|l|l|}
\hline FUEL PROPERTIES & $\begin{array}{l}\text { TOFA (Mean } \\
\pm \text { SD) }\end{array}$ & $\begin{array}{l}\text { TOME } \\
(\text { Mean } \pm \text { SD) }\end{array}$ & TEST METHOD \\
\hline Kinematic Viscosity/cSt. & $20.614 \pm 0.059$ & $5.216 \pm 0.016$ & ASTM D445 \\
\hline $\begin{array}{l}\text { Specific Gravity } \\
@ 25 / 25^{\circ} \mathrm{C}\end{array}$ & $0.904 \pm 0.000$ & $0.972 \pm 0.000$ & ASTM D5355-95 \\
\hline $\begin{array}{l}\text { Specific Gravity } \\
\text { a60/25ㄷ }\end{array}$ & $0.889 \pm 0.000$ & $0.971 \pm 0.000$ & ASTM D5355-95 \\
\hline Water Content/v/v & - & 0.000 & ASTM D2709 \\
\hline $\begin{array}{l}\text { Acid Value/mg/g of oleic } \\
\text { acid }\end{array}$ & $113.180 \pm 0.010$ & $4.240 \pm 0.120$ & $\begin{array}{l}\text { ASTM D664/AOCS Cd } \\
\text { 3a-63 }\end{array}$ \\
\hline
\end{tabular}




\subsubsection{Gas chromatographic results}

The GC data (Table 3.5) and the chromatogram of the biodiesel (Figure 3.1) produced from TOFA show that the dominant fatty acids are oleic acid (C18:1 cis-9; 57.72\%), and linoleic acid (C18:2 cis-9, 12; 35.41\%). Other minor components present were pentadecenoic acid (C15:1 cis-10; 1.41\%), palmitoleic acid (C16:1 cis-9; 0.87\%), and arachidic acid (C20:0; 2.61\%). Several other fatty acids were present at less than $0.5 \%$. The total composition of all these minor fatty acids were approximately $1.98 \%$. This agreed with results reported earlier by Bokis et al. (1999).

Table 3.5: Fatty acid composition for TOME using GC

\begin{tabular}{|l|l|}
\hline Fatty Acids & Percent Composition \\
\hline C15:1(cis-10) & 1.41 \\
\hline C16:1(cis-9) & 0.87 \\
\hline C18:1(cis-9) & 57.72 \\
\hline C18:2(cis-9,12) & 35.41 \\
\hline C20:0 & 2.61 \\
\hline $\begin{array}{l}\text { Other Minor Fatty } \\
\text { Acids }(<0.5 \%)\end{array}$ & 1.98 \\
\hline
\end{tabular}

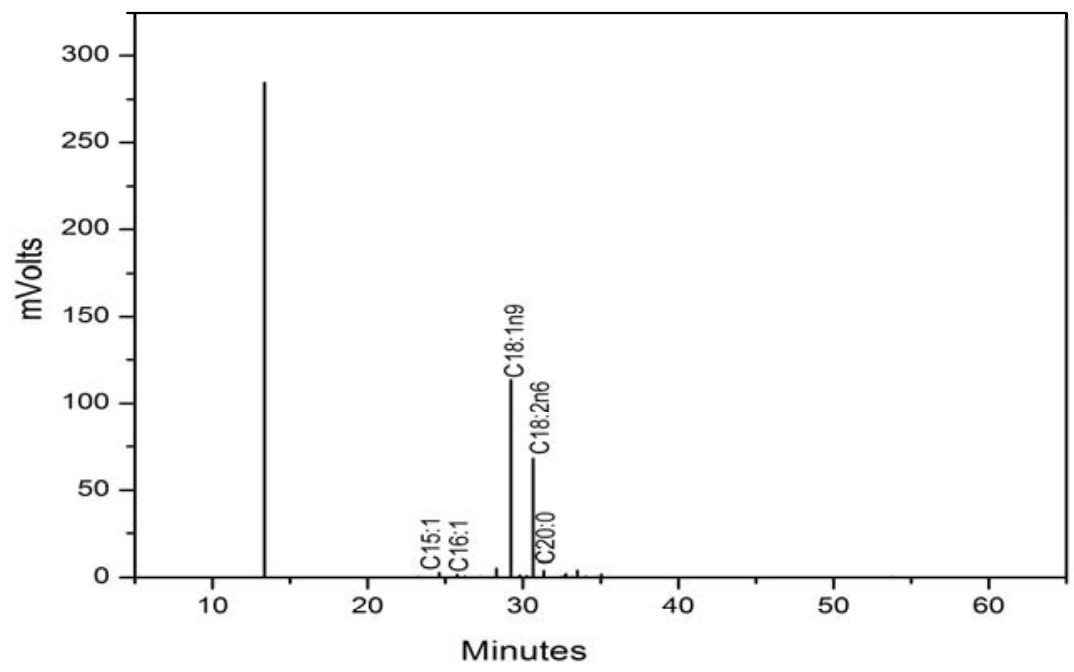

Figure 3.2: GC chromatogram of biodiesel produced from TOFA 
3.2.4 The FTIR Spectra of TOFA and biodiesel produced by the homogeneous catalysis of TOFA

The FTIR spectra (range, $4000 \mathrm{~cm}^{-1}-600 \mathrm{~cm}^{-1}$ ) of the biodiesel (FAME) and Tall oil fatty acids (TOFA) are shown in Figures 3.3 and 3.4 respectively. Intense sharp peaks at $2923 \mathrm{~cm}^{-1}$ and $2854 \mathrm{~cm}^{-1}$ were representative of aliphatic antisymmetric $\mathrm{CH}_{2}$ stretching and aliphatic symmetrical $\mathrm{CH}_{2}$ stretching vibrations respectively. The high intensity of these peaks was indicative of saturated oil. However, the small peak at the shoulder of the intense antisymmetric $\mathrm{CH}_{2}$ peak at $3007 \mathrm{~cm}^{-1}$ represented unsaturation due to olefenic double bonds. The shoulder at 3005-3007 $\mathrm{cm}^{-1}$ was due to olefenic cis double bonds (Guillen and Cabo, 1999; Canakci and Sanli, 2008). High proportions of linolenic or linoleic acyl groups exhibit a higher frequency (Arnold and Hartung, 1971) than those with oleic acyl groups. The intensity $(I)$ ratio of the band at $3007 \mathrm{~cm}^{-1}$ and $2854 \mathrm{~cm}^{-1}$ was a measure of the degree of unsaturation (Arnold and Hartung, 1971). The higher the intensity ratio, the higher the level of unsaturation. The absorption peak at $1741 \mathrm{~cm}^{-1}$ was due to the ester carbonyl $(\mathrm{C}=\mathrm{O})$ as aliphatic esters usually appear at the 1750 $1735 \mathrm{~cm}^{-1}$ region (Silverstein et al., 2005). For $\alpha, \beta$-unsaturated esters, the peaks appear in the region $1730-1715 \mathrm{~cm}^{-1}$. The absence of a peak in this region was indicative of the fact that there was no $\alpha, \beta$ - unsaturated ester present and hence no conjugation nor a cyclic compound. This was in agreement with the GC data showing that the fatty acids present were long chain carboxylic acids. 


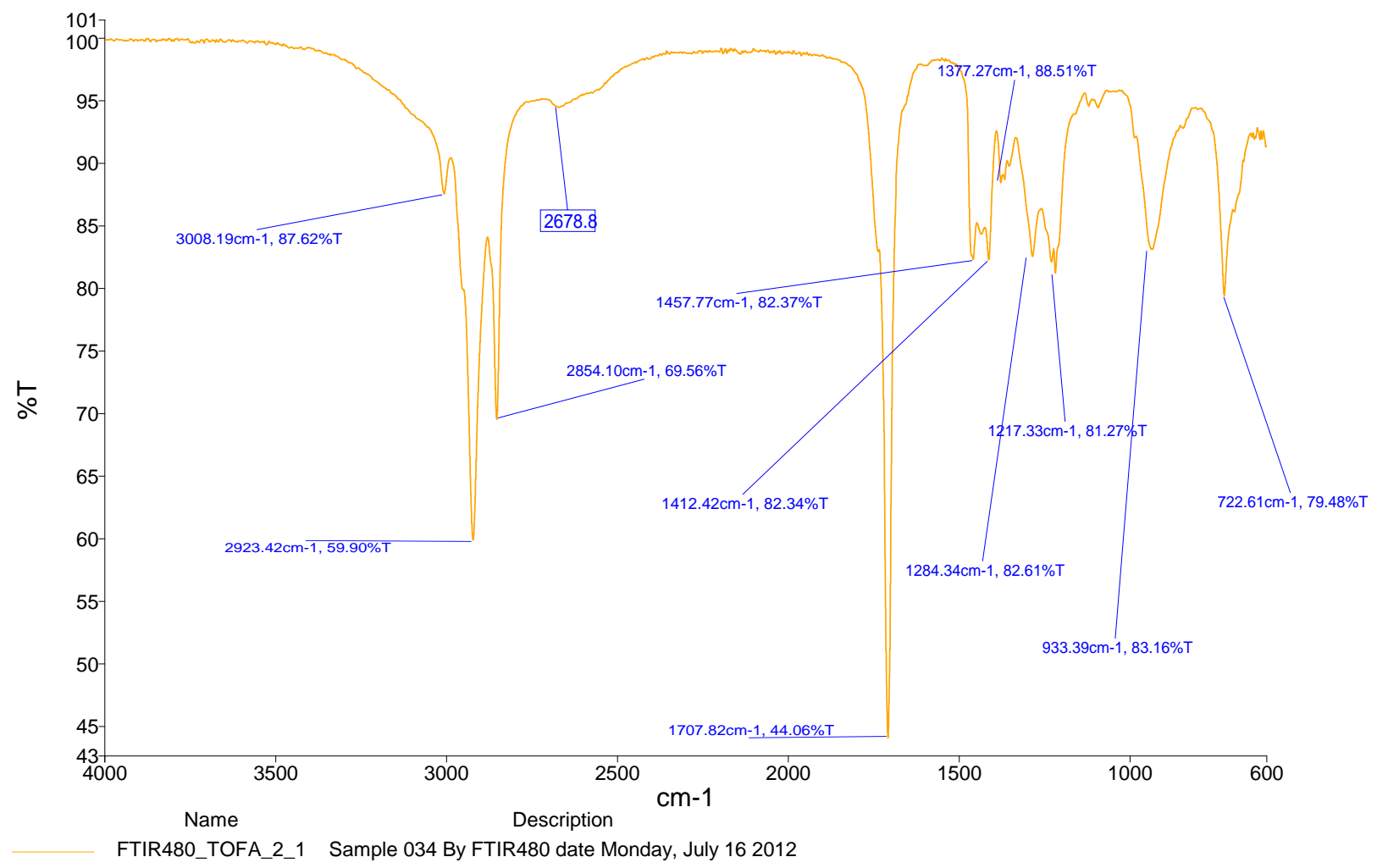

Figure 3.3: FTIR spectra of Tall oil fatty acids (TOFA)

The intense peak at $1707-1709 \mathrm{~cm}^{-1}$ could be attributed to carboxylic acid dimers which occur between 1720 and $1706 \mathrm{~cm}^{-1}$ due to hydrogen bonding (Dahlberg et al., 1997). However, the absence of a very broad $\mathrm{OH}$ band observed around the $3300 \mathrm{~cm}^{-1}$ region was indicative that a carboxylic acid dimer was most likely not present. Also, the absences of specific shoulder bands higher than $1750 \mathrm{~cm}^{-1}$ and lower than $1720 \mathrm{~cm}^{-1}$, indicated that the oils had been converted into esters (biodiesel) in the TOME spectra, and there were no carboxylic acid dimers, even though there may be some interferences from the acid spectra. This spectra confirms the presence of an 
ester.

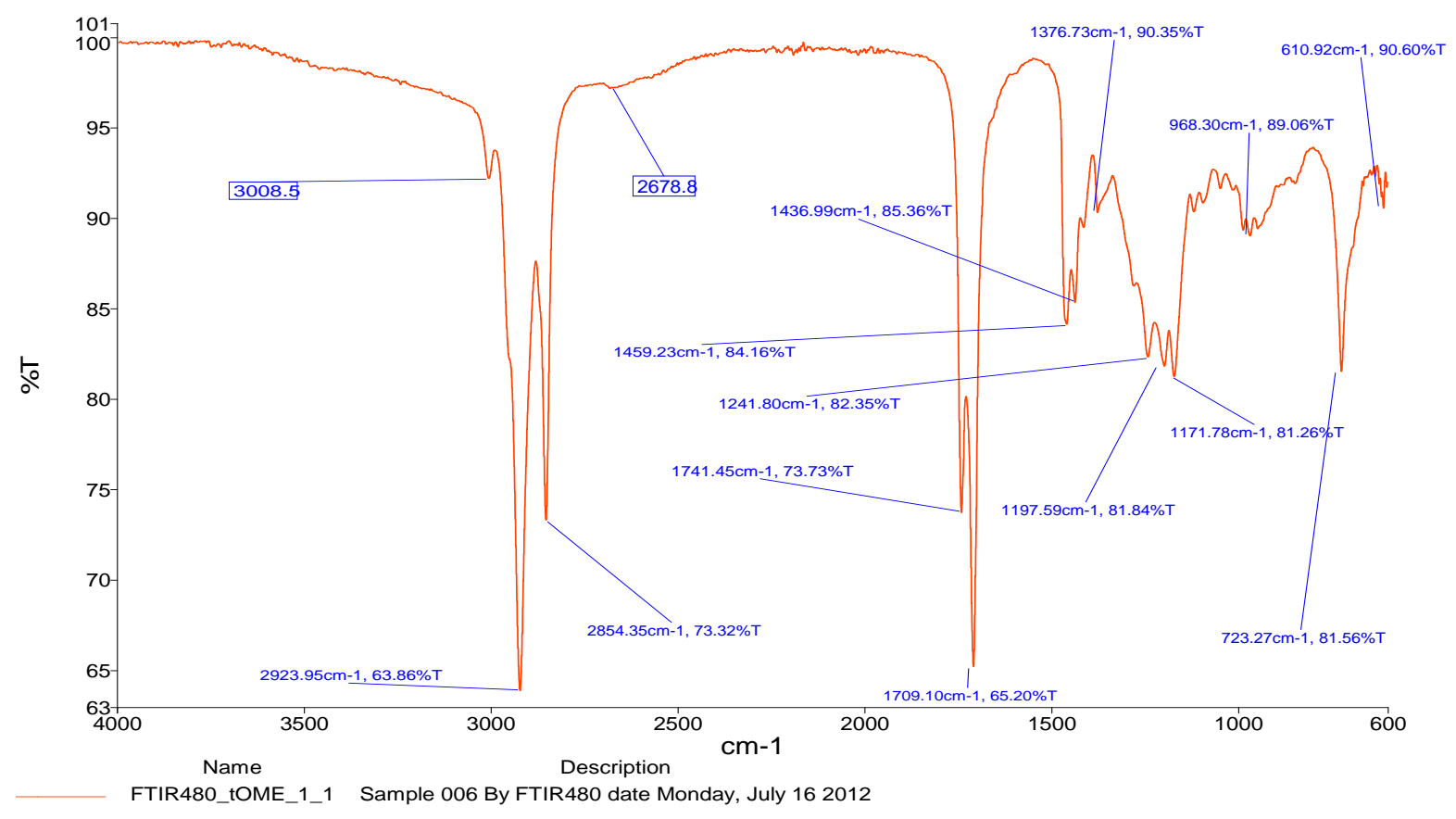

Figure 3.4: FTIR spectra of Tall oil methyl ester (TOME)

Absorption peaks at 1434 and $1459 \mathrm{~cm}^{-1}$ were attributed to asymmetric $\mathrm{CH}_{3}$ and $\mathrm{CH}_{2}$ bending vibrations of the ester. The bands at $1171,1197 \mathrm{~cm}^{-1}$ were ascribed to $\mathrm{C}-\mathrm{O}-\mathrm{C}$ and $\mathrm{O}-\mathrm{CH}_{3}$ stretching vibration of a terminal methoxy group of the ester (biodiesel) respectively (Mahamuni and Adewuyi, 2009; Praptijanto et al., 2010). This terminal methoxy group confirmed the presence of a methyl ester and hence a fatty acid methyl ester (biodiesel, FAME).

The absorption band at $968 \mathrm{~cm}^{-1}$ was assigned to isolated trans double bonds vibrational mode (Guillen and Cabo, 1999). The sharp peak at $723 \mathrm{~cm}^{-1}$ was attributed to C-H rocking vibration due to long chain alkanes. The spectra in Figures 3.5 to 3.11 represent biodiesel conversion at various stages of production. The single sharp peak observed in Figure 3.5 at $1741 \mathrm{~cm}^{-1}$ was due to an ester carbonyl $\mathrm{C}=\mathrm{O}$ peak. Here, it was a single peak indicating a higher purity of this sample compared with the spectra of the sample in Figure 3.3 which had some acid $\mathrm{C}=\mathrm{O}$ peak at $1709 \mathrm{~cm}^{-1}$.

The FTIR spectra was used to monitor the extent of methyl ester (biodiesel) production by monitoring appearance and disappearance/diminishing of certain absorption peaks as well as other peaks diminishing or disappearing. The formation of an ester from the fatty acids (TOFA) 
in a reversible reaction indicated that the reaction had gone more in the direction of biodiesel production (methyl ester). Certain peaks/regions in the FTIR spectra revealed the extent of biodiesel production. The broad absorption in the $3300-2500 \mathrm{~cm}^{-1}$ region for TOFA was attributed to $-\mathrm{OH}$ stretching (Harwood and Claridge, 1997; Silverstein et al., 2005). As the reaction continued with increasing formation of the ester, the broadness of this region began to flatten and disappear completely at the point of total conversion (Figure 3.5).

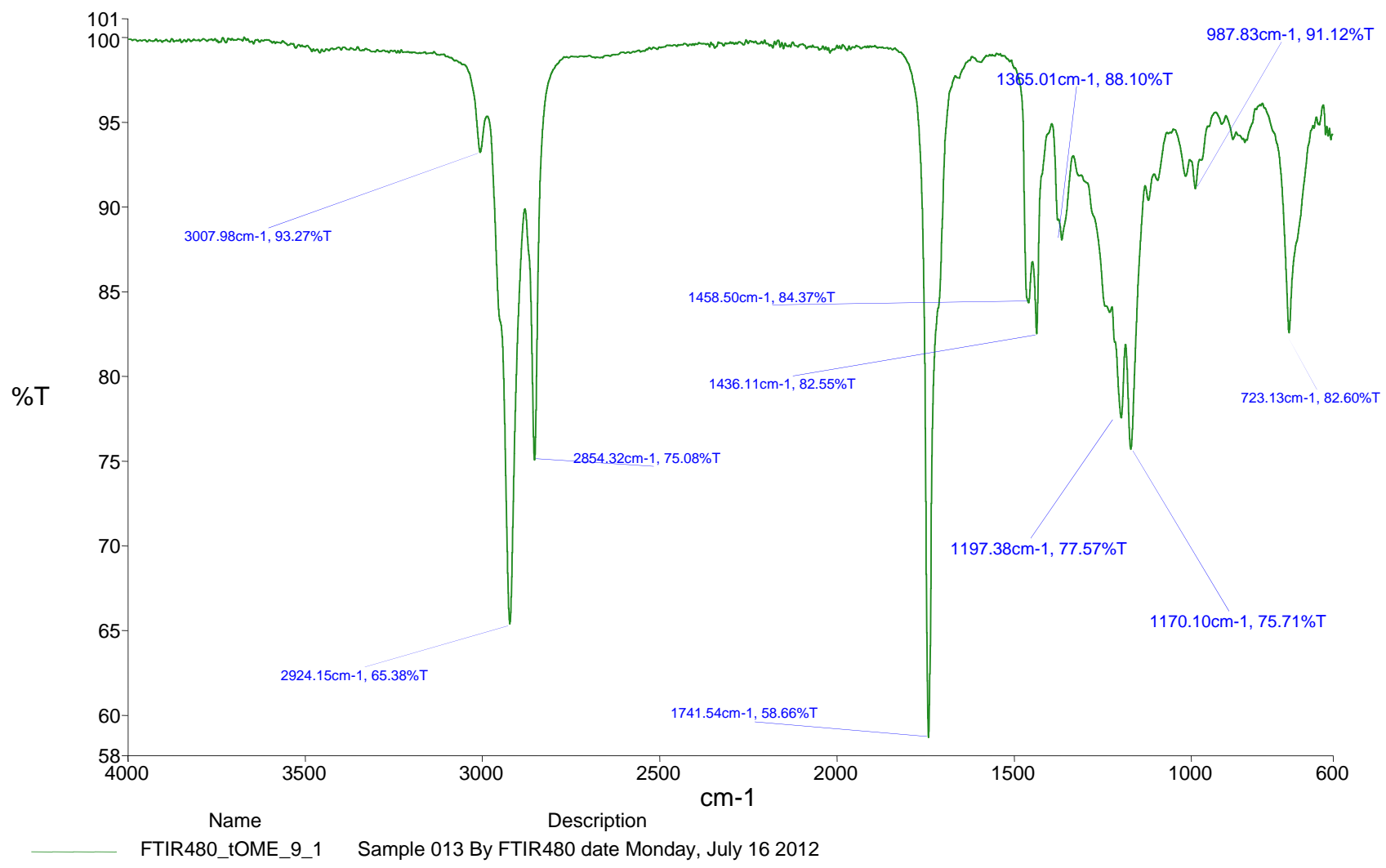

Figure 3.5: FTIR spectra of Tall oil methyl ester (TOME)

For the production of Tall oil fatty acids to methyl esters (TOME), the main absorption peaks of the carbonyl $\mathrm{C}=\mathrm{O}$ functional groups appeared at different positions for the acid and the ester. These absorption peaks are prominent and very important in monitoring the reaction process. The acid carbonyl peak occurred at $1707-1712 \mathrm{~cm}^{-1}$ while the ester carbonyl peak appeared around 1741-1742 $\mathrm{cm}^{-1}$. For a high conversion to the ester formation, the ester carbonyl peak appeared at $1741 \mathrm{~cm}^{-1}$. Other peaks used for identification were $1197 \mathrm{~cm}^{-1}$ due to $\mathrm{O}-\mathrm{CH}_{3}$ 
stretching vibration and $1171 \mathrm{~cm}^{-1}$ due to C-O-C stretching vibration. The medium sharp peaks at $1284 \mathrm{~cm}^{-1}$ and $1217 \mathrm{~cm}^{-1}$ observed for TOFA are due to C-O stretching band (1320-1210 $\left.\mathrm{cm}^{-1}\right)$ of carboxylic acids due to interaction between $\mathrm{C}-\mathrm{O}$ stretching and in-plane $\mathrm{C}-\mathrm{O}-\mathrm{H}$ bending vibrations. These were absent in the ester spectra. There was also a peak at $1241-1244 \mathrm{~cm}^{-1}$ attributed to the ester band but absent in the carboxylic acid band. The peak at $1412 \mathrm{~cm}^{-1}$ for the TOFA was due to the $\mathrm{C}-\mathrm{O}-\mathrm{H}$ bending vibration (moderate intensity). A peak observed around 930-940 $\mathrm{cm}^{-1}$ was due to O-H out of plane bending vibration (Silverstein et al., 2005). For TOFA (Figure 3.3), absorption peaks due to acid $-\mathrm{OH}$ and $\mathrm{C}=\mathrm{O}$ as well as $\mathrm{C}-\mathrm{OH}$ bonds were more prominent.

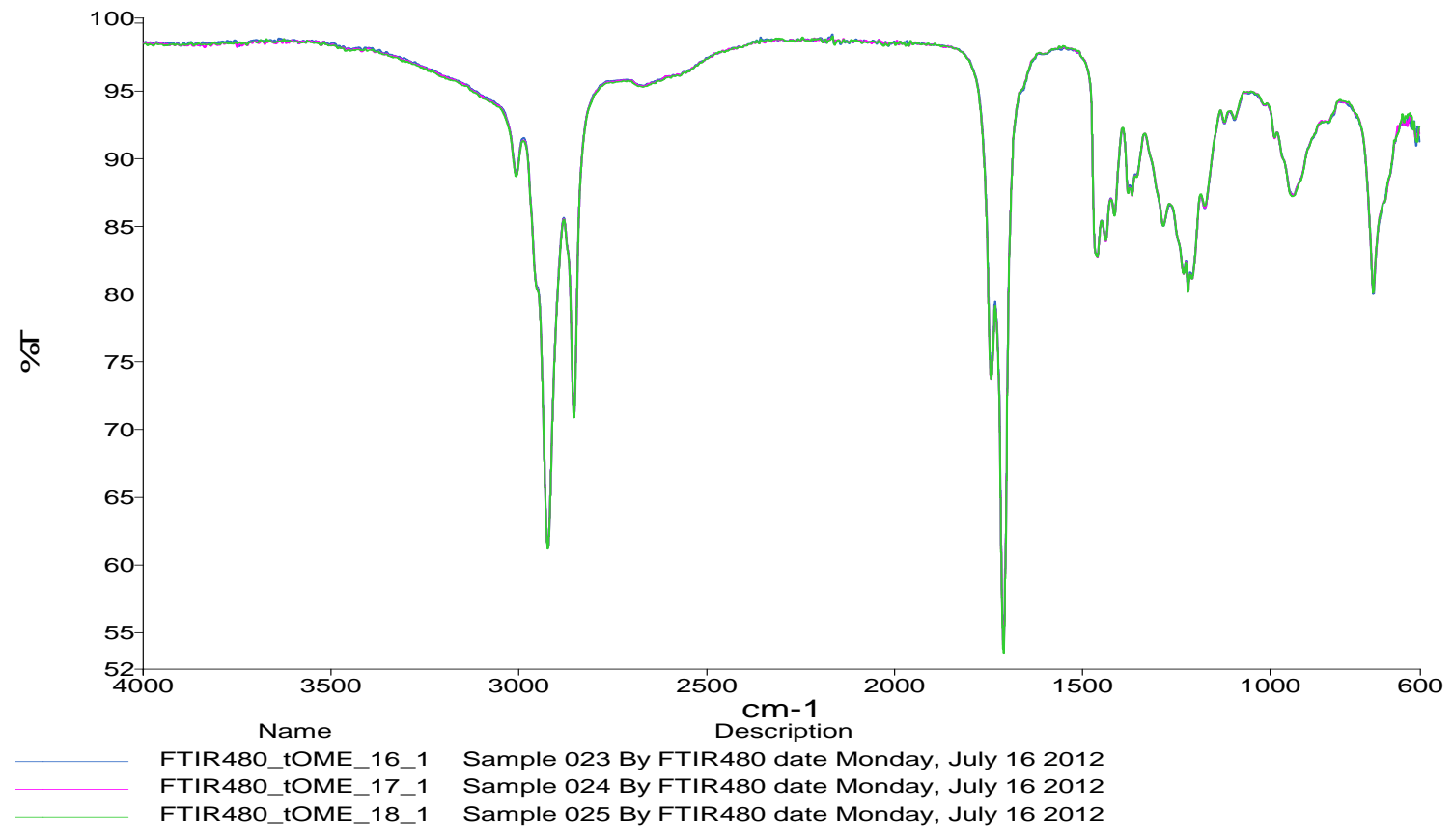

Figure 3.6: Overlaid FTIR spectra of TOME 16, $17 \& 18$ 


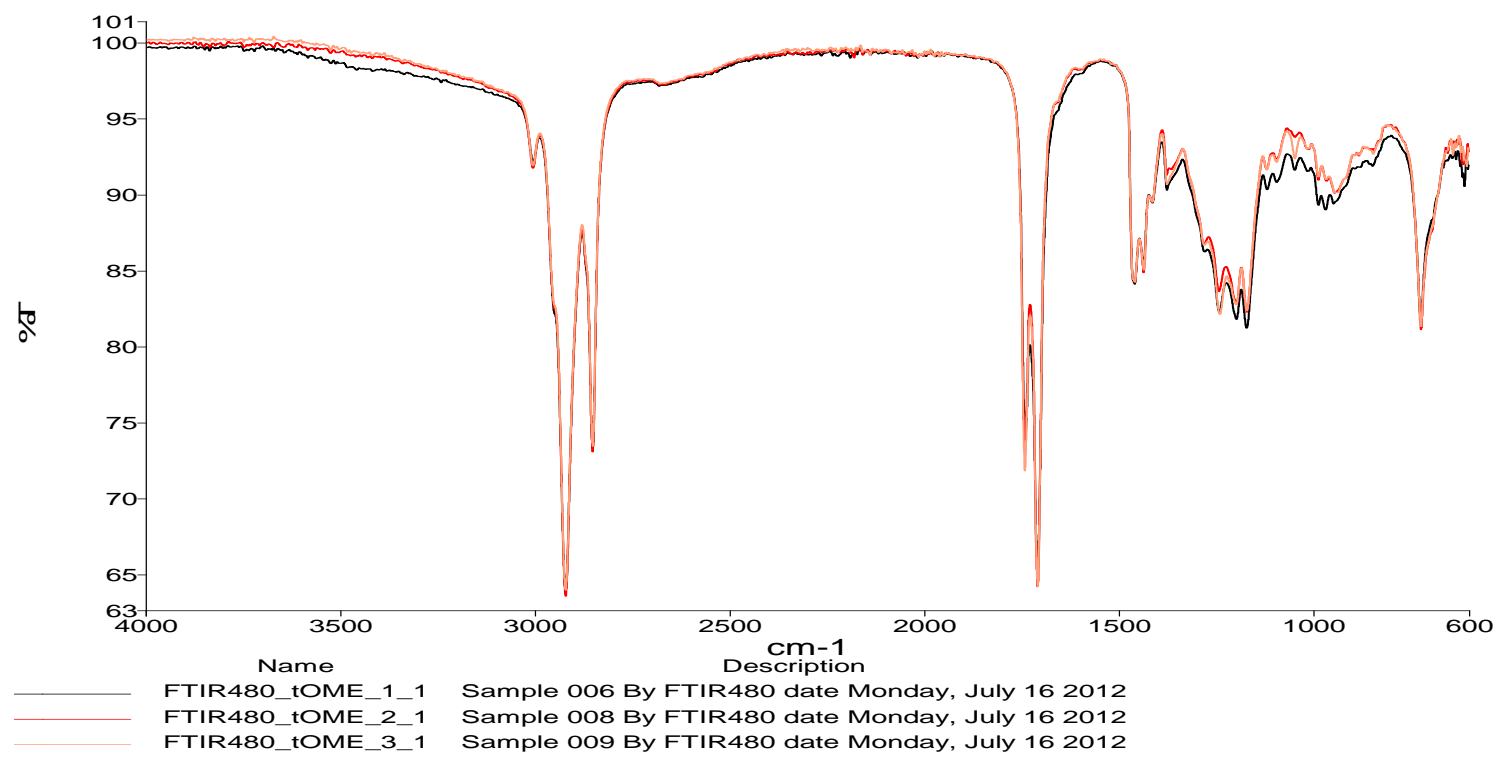

Figure 3.7: Overlaid FTIR spectra of TOME 1, $2 \& 3$

Figure 3.6 and Table 3.6 showed a gradual progression from the acid to the ester as the reaction proceeded. The average intensity of the acid peak was still high and the ester carbonyl started to appear. The absorption peak was broad above the $3000 \mathrm{~cm}^{-1}$ wavenumber region as is also shown in the TOFA spectra. The average intensity ratio of the acid carbonyl decreased (Figure 3.7) while there was a slight increase for the ester carbonyl. In Figure 3.7, the spectra showed a further decrease in the acid carbonyl peak and intensity ratio while the ester carbonyl one increased in the opposite direction. The broadness of the absorption region beyond $3000 \mathrm{~cm}^{-1}$ disappeared due to the decrease in the acid content $(-\mathrm{OH}$ functional group of the carboxyl moiety) of the biodiesel produced. 


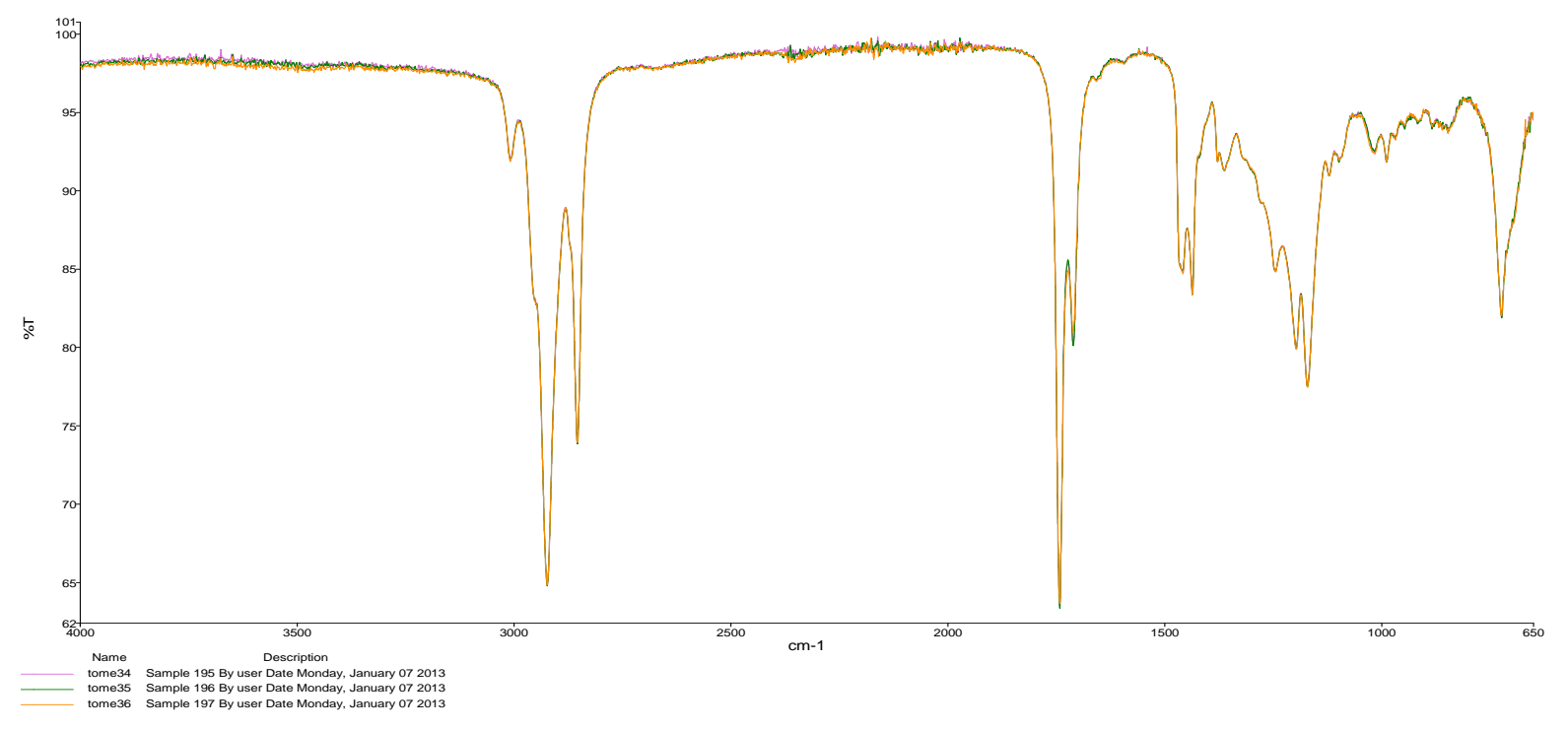

Figure 3.8: FTIR spectra of TOME treatments 34, 35 and 36.

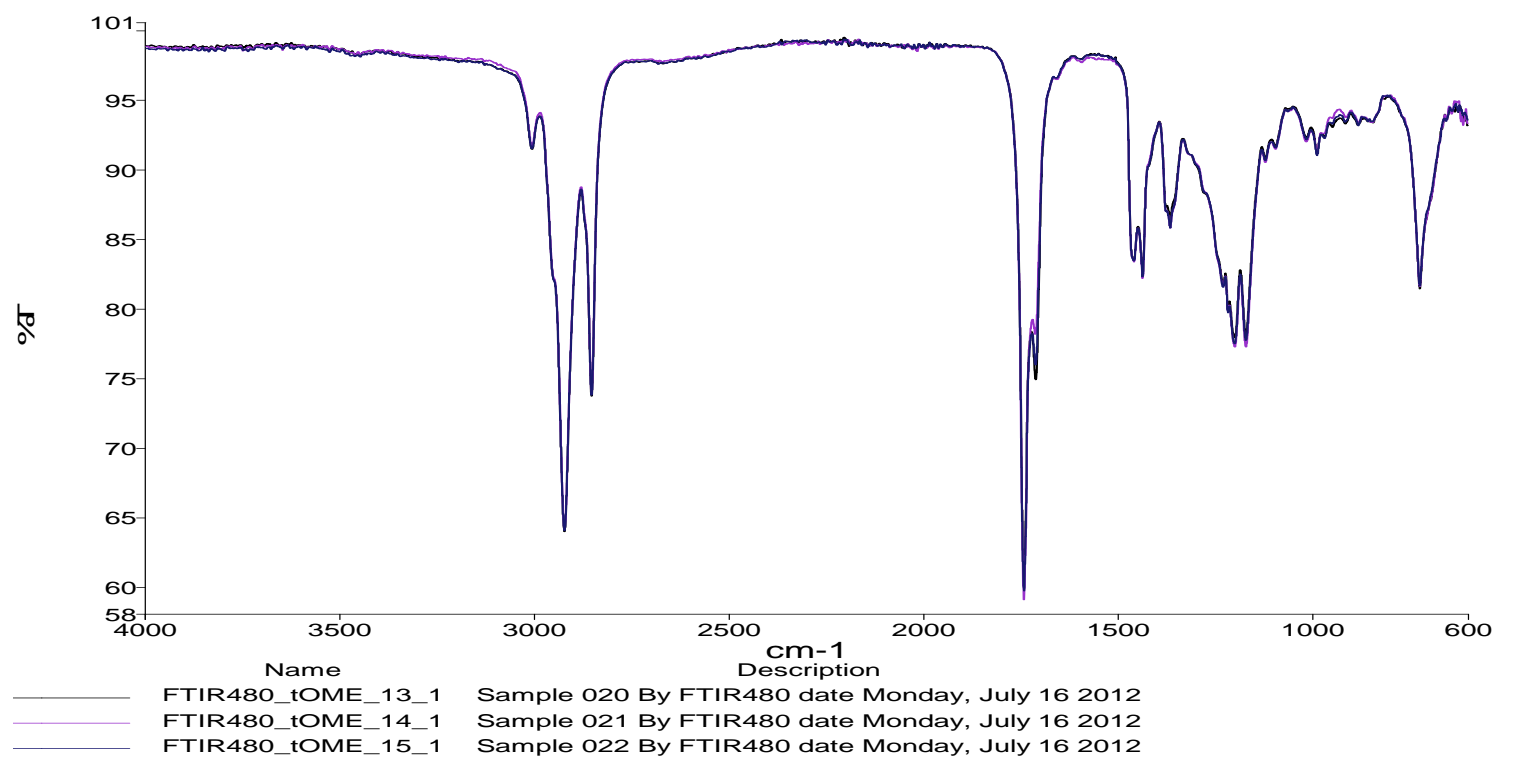

Figure 3.9: FTIR spectra of TOME treatments $13,14 \& 15$

Further decrease in the acid carbonyl peak with the attendant shoulder peak (Figure 3.9) was observed. Additionally, the intensity of the carbonyl absorption further increased as was reflected in the ratio of the absorption peak intensities. The spectra also showed the disappearance of the absorption region beyond $3000 \mathrm{~cm}^{-1}$. 
The FTIR spectra in Figure 3.10 showed complete disappearance of the acid carbonyl peak with a small unresolved peak. In the FITR spectra shown in Figure 3.11, a total disappearance of the acid carbonyl peak and its replacement by the ester carbonyl peak was observed.

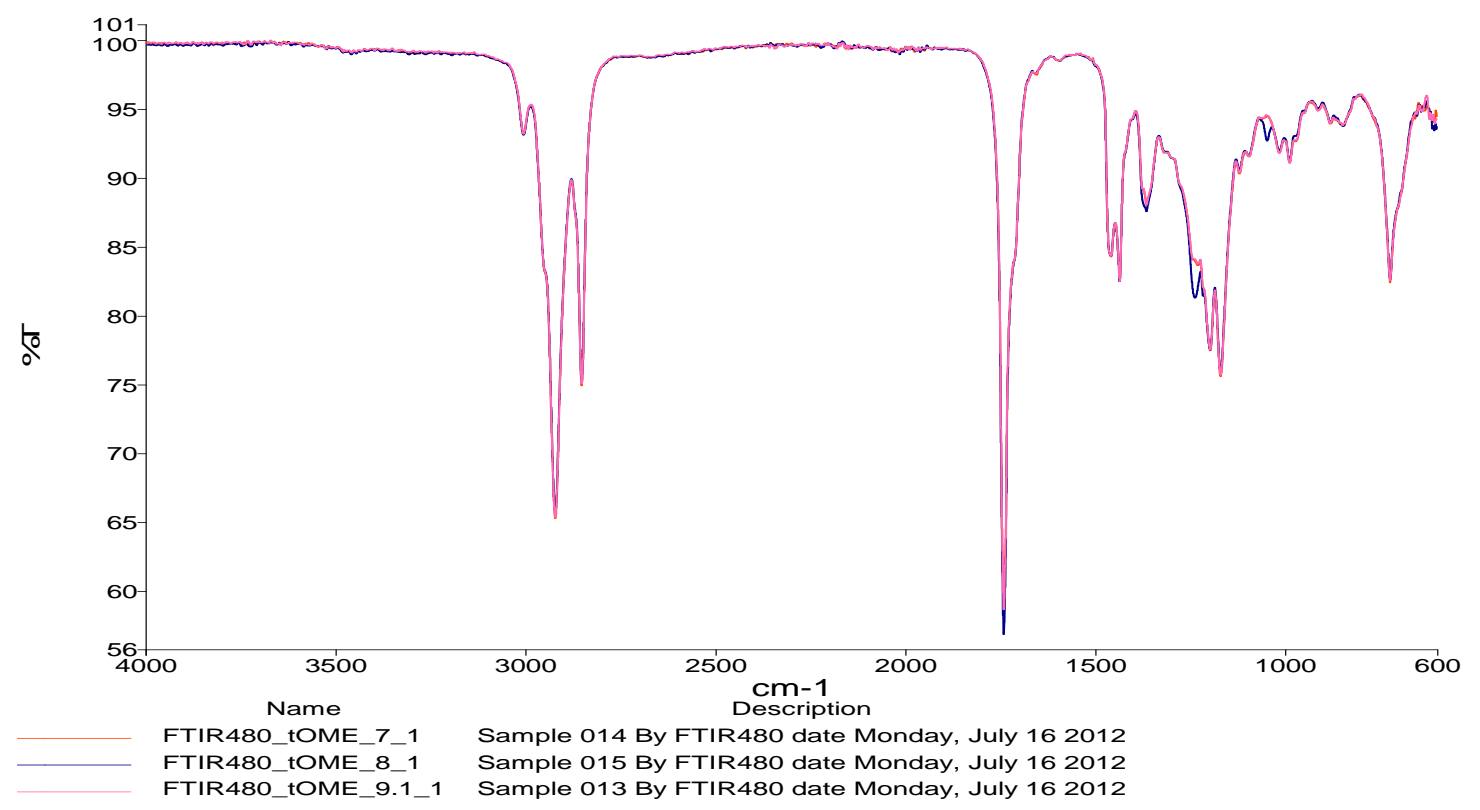

Figure 3.10: FTIR spectra showing TOME treatments $7,8 \& 9$.

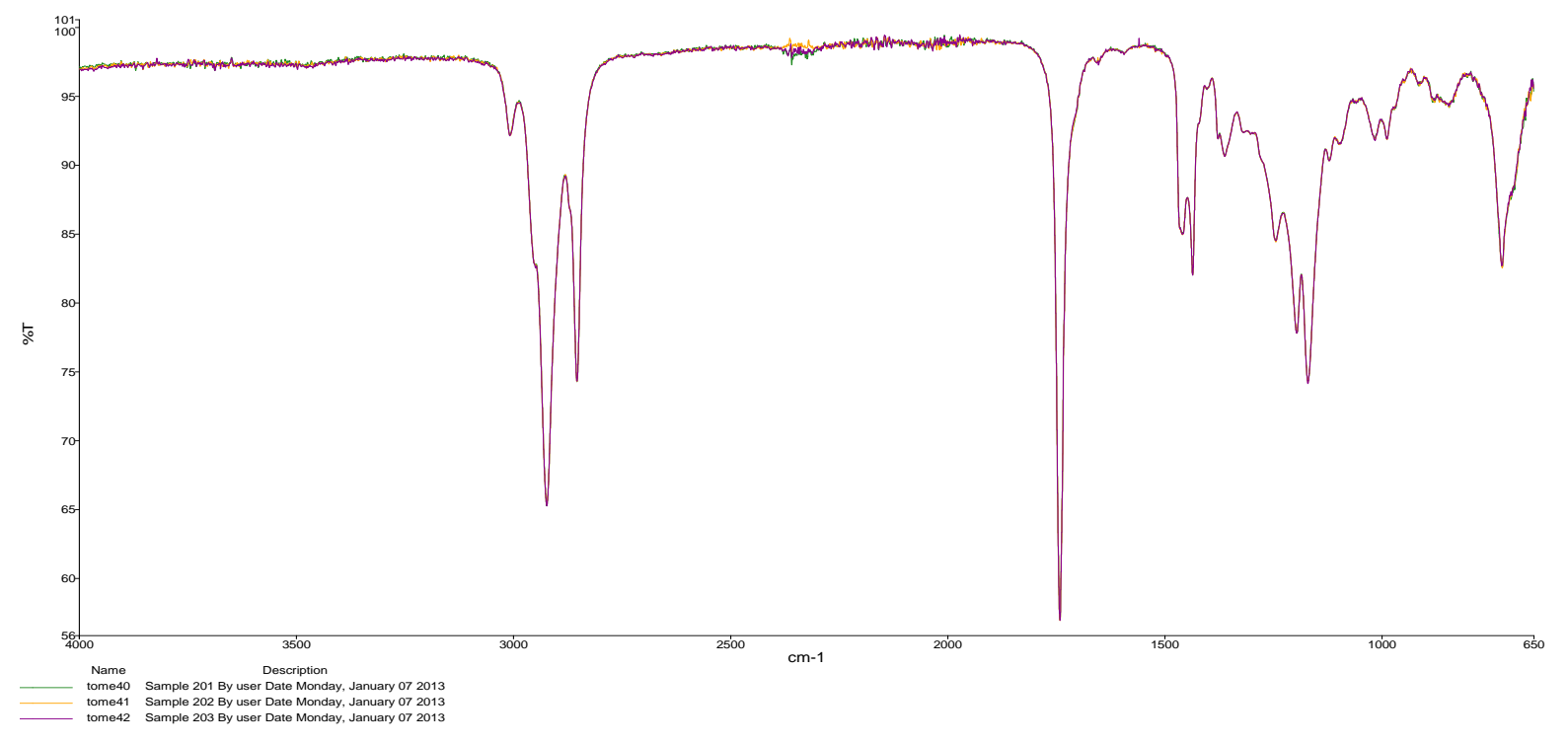

Figure 3.11: FTIR spectra of TOME treatments 40,41 and 42. 


\subsubsection{Heterogeneous catalysis}

Table 3.6: Results of biodiesel production via heterogeneous catalysis

\begin{tabular}{|c|c|c|c|c|c|c|c|c|}
\hline Expt.\# & Oil Wt./g & $\underline{\text { Ratio }}$ & $\begin{array}{l}\underline{\mathrm{MeOH}} \\
\underline{\mathrm{vol} . / \mathrm{ml}}\end{array}$ & $\begin{array}{l}\text { Cat. } \\
\text { Wt./g }\end{array}$ & $\underline{T i m e / h r s}$ & Yield/g & \%Yield & $\begin{array}{l}\underline{\text { Acid }} \\
\text { Value }\end{array}$ \\
\hline 1 & 40 & 17.5 & 29.47 & 2.64 & 3 & 31.53 & 78.82 & 29.49 \\
\hline 2 & 40 & 15 & 25.26 & 8 & 2 & 32.11 & 80.27 & 21.83 \\
\hline 3 & 40 & 20 & 33.68 & 8 & 4 & 34.75 & 86.88 & 12.65 \\
\hline 4 & 40 & 21.7 & 36.54 & 6 & 3 & 32.75 & 81.88 & 18.53 \\
\hline 5 & 40 & 17.5 & 29.47 & 6 & 1.3 & 30.70 & 76.75 & 30.58 \\
\hline 6 & 40 & 17.5 & 29.47 & 6 & 3 & 31.51 & 78.77 & 25.34 \\
\hline 7 & 40 & 20 & 33.68 & 8 & 4 & 34.20 & 85.49 & 13.59 \\
\hline 8 & 40 & 21.7 & 36.54 & 6 & 3 & 32.38 & 80.96 & 21.37 \\
\hline 9 & 40 & 15 & 25.26 & 4 & 2 & 31.94 & 79.84 & 26.43 \\
\hline 10 & 40 & 17.5 & 29.47 & 6 & 4.7 & 31.24 & 78.10 & 28.58 \\
\hline 11 & 40 & 20 & 33.68 & 4 & 2 & 32.25 & 80.62 & 24.93 \\
\hline 12 & 40 & 20 & 33.68 & 4 & 2 & 32.16 & 80.39 & 25.54 \\
\hline 13 & 40 & 17.5 & 29.47 & 6 & 3 & 30.87 & 77.17 & 28.08 \\
\hline 14 & 40 & 15 & 25.26 & 8 & 2 & 30.62 & 76.56 & 26.05 \\
\hline 15 & 40 & 20 & 33.68 & 8 & 2 & 31.59 & 78.97 & 28.83 \\
\hline 16 & 40 & 17.5 & 29.47 & 6 & 3 & 30.48 & 76.21 & 31.53 \\
\hline 17 & 40 & 17.5 & 29.47 & 6 & 1.3 & 28.68 & 71.69 & $\begin{array}{l}45.18 \\
\end{array}$ \\
\hline 18 & 40 & 20 & 33.68 & 8 & 2 & 30.51 & 76.27 & 36.76 \\
\hline 19 & 40 & 17.5 & 29.47 & 9.36 & 3 & 31.19 & 77.99 & 34.04 \\
\hline 20 & 40 & 15 & 25.26 & 8 & 4 & 30.96 & 77.40 & 22.03 \\
\hline 21 & 40 & 17.5 & 29.47 & 2.64 & 3 & 30.66 & 76.65 & 41.03 \\
\hline 22 & 40 & 15 & 25.26 & 4 & 4 & 31.46 & 78.64 & 49.94 \\
\hline 23 & 40 & 17.5 & 29.47 & 9.36 & 3 & 30.51 & 76.28 & 33.65 \\
\hline 24 & 40 & 15 & 25.26 & 8 & 4 & 30.34 & 75.84 & 34.98 \\
\hline 25 & 40 & 20 & 33.68 & 4 & 4 & 31.27 & 78.17 & 49.02 \\
\hline 26 & 40 & 15 & 25.26 & 4 & 4 & 31.71 & 79.28 & 47.16 \\
\hline 27 & 40 & 13.3 & 22.4 & 6 & 3 & 30.08 & 75.20 & 44.36 \\
\hline 28 & 40 & 15 & 25.26 & 4 & 2 & 30.92 & 77.30 & 33.74 \\
\hline 29 & 40 & 20 & 33.68 & 4 & 4 & 31.05 & 77.63 & 51.37 \\
\hline 30 & 40 & 17.5 & 29.47 & 6 & 4.7 & 30.07 & 75.19 & 35.84 \\
\hline 31 & 40 & 13.3 & 22.4 & 6 & 3 & 31.59 & 78.97 & 44.18 \\
\hline TOFA & 40 & & & & & & & 113.18 \\
\hline
\end{tabular}


Results of heterogeneous catalysis (solid catalyst Amberlyst BD-20) of TOFA including percentage yield and acid values are shown in Table 3.6.

\subsubsection{Elemental analysis of TOFA}

Results of the elemental analysis of TOFA are shown in Table 3.7. Sodium and calcium exhibited the highest concentration. However, these concentrations were less than the minimum concentration $(10 \mathrm{mg} / \mathrm{L})$ of impurities in the oil sample that will deactivate the catalyst (Amberlyst BD20 FFA Esterification, 2010).

Table 3.7: Results of elemental analysis

\begin{tabular}{|l|l|}
\hline Element & $\begin{array}{l}\text { Amount in Sample } \\
\{\mathrm{mg} / \mathrm{L}(\text { Mean } \pm \text { SD })\}\end{array}$ \\
\hline $\mathrm{Al}$ & $2.29 \pm 0.73$ \\
\hline $\mathrm{Fe}$ & $2.42 \pm 3.20$ \\
\hline $\mathrm{Mg}$ & $0.45 \pm 0.34$ \\
\hline $\mathrm{Ca}$ & $5.25 \pm 0.68$ \\
\hline $\mathrm{K}$ & 0 \\
\hline $\mathrm{Na}$ & $5.97 \pm 4.54$ \\
\hline $\mathrm{Cu}$ & 0 \\
\hline $\mathrm{Zn}$ & $0.63 \pm 0.14$ \\
\hline $\mathrm{P}$ & - \\
\hline
\end{tabular}

It is important to remove from oil feedstock impurities such as salts, phosphorus compounds and proteins before their use in biodiesel production. They negatively affect the production process (www.amberlyst.com). Impurities such as proteins, phospholipids, metal ions (sodium, potassium etc.) cause the catalyst to lose their activity. The biodiesel feedstock used in this study was purified using Ambersep BD 19 to preclude any deactivation of the catalyst. This purification process ensured the removal of the metal ions and other impurities that may impede the conversion process. Figures 3.17 to Figure 3.20 show gradual shift in intensity of absorption from acid carbonyl peaks to ester carbonyl peaks. Ester carbonyl peaks form and become 
prominent with reaction moving towards the products (biodiesel) while peaks due to the acid carbonyl gradually decrease accordingly. In effect, the extent of biodiesel formation can be monitored using the spectra formed from mid-infrared (FTIR). Figure 3.21 to Figure 3.24 shows the combination spectra of the TOFA and the 4 other treatments at various wavenumber regions.

\subsubsection{Statistical analysis for heterogeneous catalysis}

Results of statistical analysis via the Central Composite Design (CCD) and the Response Surface Methodology (RSM) gave a $\mathrm{R}^{2}$ value of 0.53 , with the adjusted $\mathrm{R}^{2}$ value of 0.33 . This indicated that other factors not in the model affected biodiesel yield. Analysis of Variance (ANOVA) showed that the model was significant $(p=0.03)$ at a significant level of $p=0.05$. The only factor that was significant was the methanol:oil ratio with a p-value of 0.01 . Catalyst concentration and time of reaction were all not significant at $\mathrm{p}=0.05$ significant level. Likewise, all the square terms as well as the interaction terms were insignificant. The regression equation for \%Yield is given by:

$\%$ Yield $=66.16+0.5 *$ Ratio, $R^{2}=0.53$

The highest biodiesel yield was given by a ratio of methanol:oil at 15.5:1, a catalyst concentration of $6.4 \mathrm{~g}$ weight of Amberlyst BD20 representing (16\% of oil weight) and time of reaction of 3.4 hours. The solution was a Saddle Point with a \% Yield of 76.79. Maximizing the model to predict a higher biodiesel \%Yield was given by a ratio of methanol:oil to be 20.8:1 and a catalyst concentration of $9.36 \mathrm{~g}$, representing ( $23.4 \%$ of the oil weight ), and a time of reaction of 4.7 hours. This maximization produced a percentage biodiesel yield of 90.24 . 


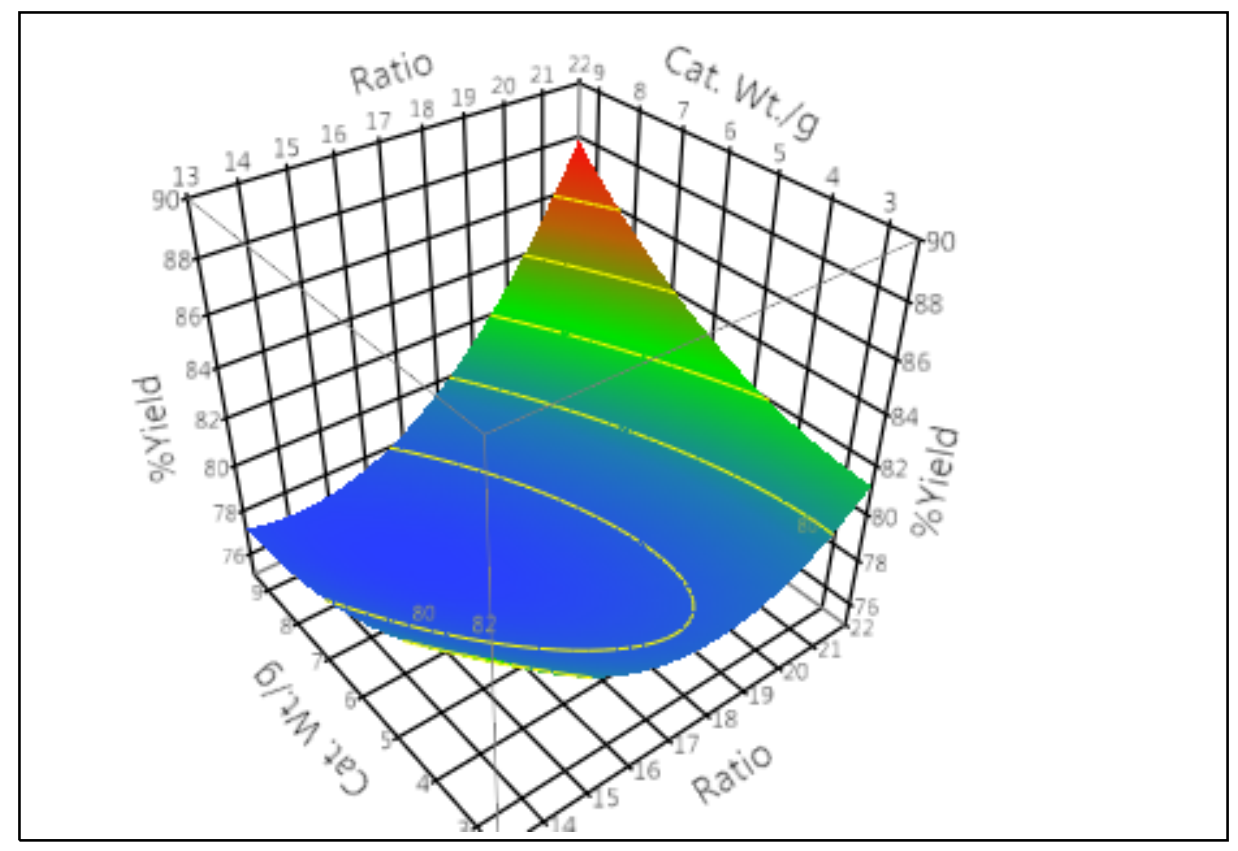

Figure 3.12: The response surface graph showing ratio and catalyst concentration against \%Yield For Acid Value, the $\mathrm{R}^{2}$ value was 0.58 with the adjusted $\mathrm{R}^{2}$ value of 0.41 . ANOVA gave a $\mathrm{p}$ value of 0.01 , which was significant at $\mathrm{p}=0.05$. Also, methanol:oil ratio was significant $(\mathrm{p}=0.03)$, and catalyst concentration was also significant $(\mathrm{p}=0.01)$. All the squared terms were insignificant. However, the interaction between catalyst concentration and time gave a p-value of 0.002 at $\alpha=0.05$ significant level. Time of reaction was not significant $(p=0.39)$ and hence the interaction term was left out of the model to give the following regression equation:

Acid Value $=63.28-1.48 *$ Ratio $-2.13 *$ Catalyst Conc., $\mathbf{R}^{2}=0.58$

The combination for the acid value occurred at a ratio of methanol:oil of 20.2:1, catalyst concentration of $4.89 \mathrm{~g}$ (representing $12.23 \%$ of the oil weight), and time of reaction of $2.12 \mathrm{hrs}$. This solution was a saddle point and a predicted acid value of 27.21. Minimizing the model in order to predict the smallest acid value yielded a methanol:oil ratio of $21.4: 1$, a catalyst concentration of $8.22 \mathrm{~g}$ (representing $20.6 \%$ of oil weight), and a time of reaction of 4.7 hours. Minimization produced an acid value of $14.1 \mathrm{mg} \mathrm{KOH} / \mathrm{g}$ oleic acid. 


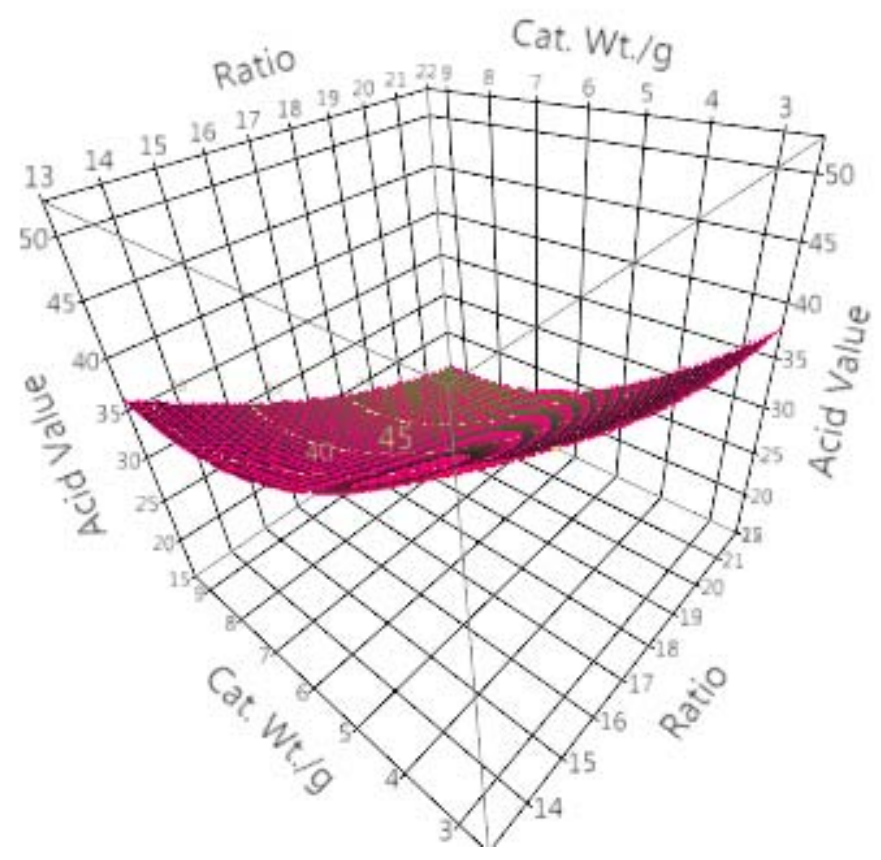

Figure 3.13: Response surface graph showing ratio and catalyst concentration against acid value.

Using the response surface with multiple responses (where the \%Yield is maximized and the acid value minimized), the optimum response occurs with a \%Yield of 93.12 and an acid value of $0.51 \mathrm{mg} \mathrm{KOH} / \mathrm{g}$ oleic acid with methanol:oil ratio of $21.7: 1$, catalyst concentration of $9.36 \mathrm{~g}$ $(23.4 \%)$ and a time of reaction of 4.7 hours. A graph of percentage biodiesel yield versus the acid value is shown in Figure 3.18, and is linear with an $\mathrm{R}^{2}$ value of 0.39 and the Adjusted $\mathrm{R}^{2}$ value being 0.37 . The model is significant with a p-value of 0.0002 . The linear equation is given by: 


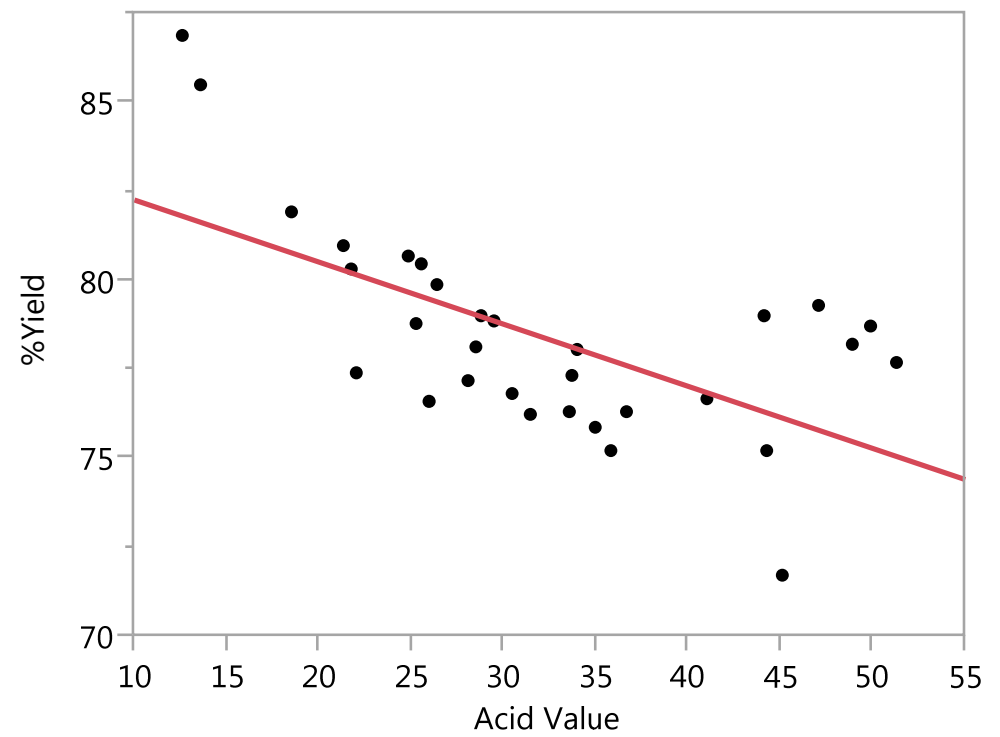

Figure 3.14: A graph of \%Yield against acid value

\subsubsection{FTIR spectra for the heterogeneous catalysis}

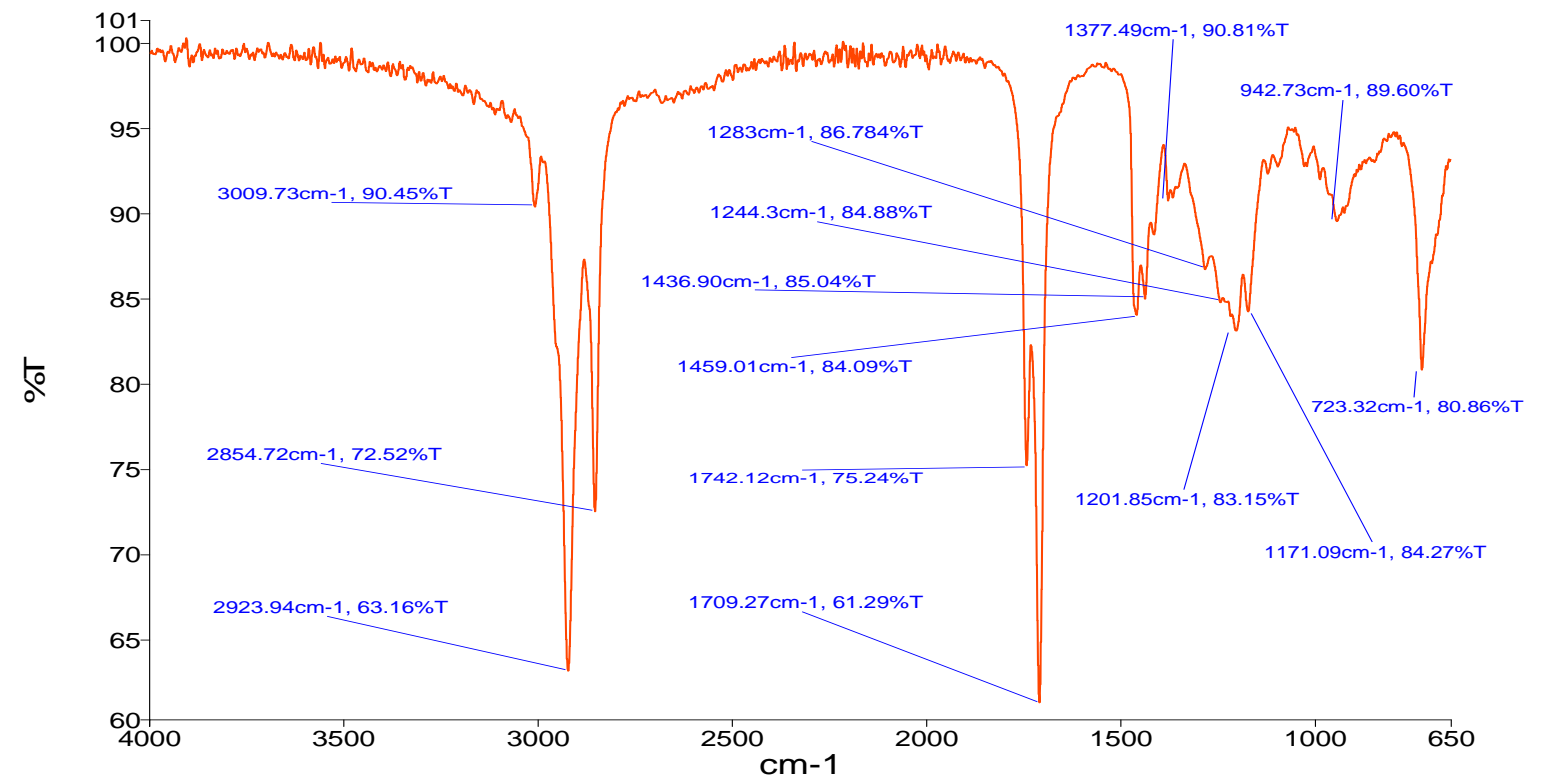

Figure 3.15: FTIR spectra of biodiesel production treatment HetBD_H18

The FTIR spectra in Figures 3.3 and 3.15 show a gradual appearance of the ester carbonyl absorption peak from the initial acid carbonyl peak. This indicated the commencement of the biodiesel reaction and its shift in the reversible reaction towards ester formation. Figure 3.16 
showed a further reduction in the absorption peak of the acid carbonyl but an increase in the ester carbonyl absorption peak (Figure 3.15). Both the acid carbonyl peak and the ester carbonyl (Figure 3.16) gave almost the same peak intensity.

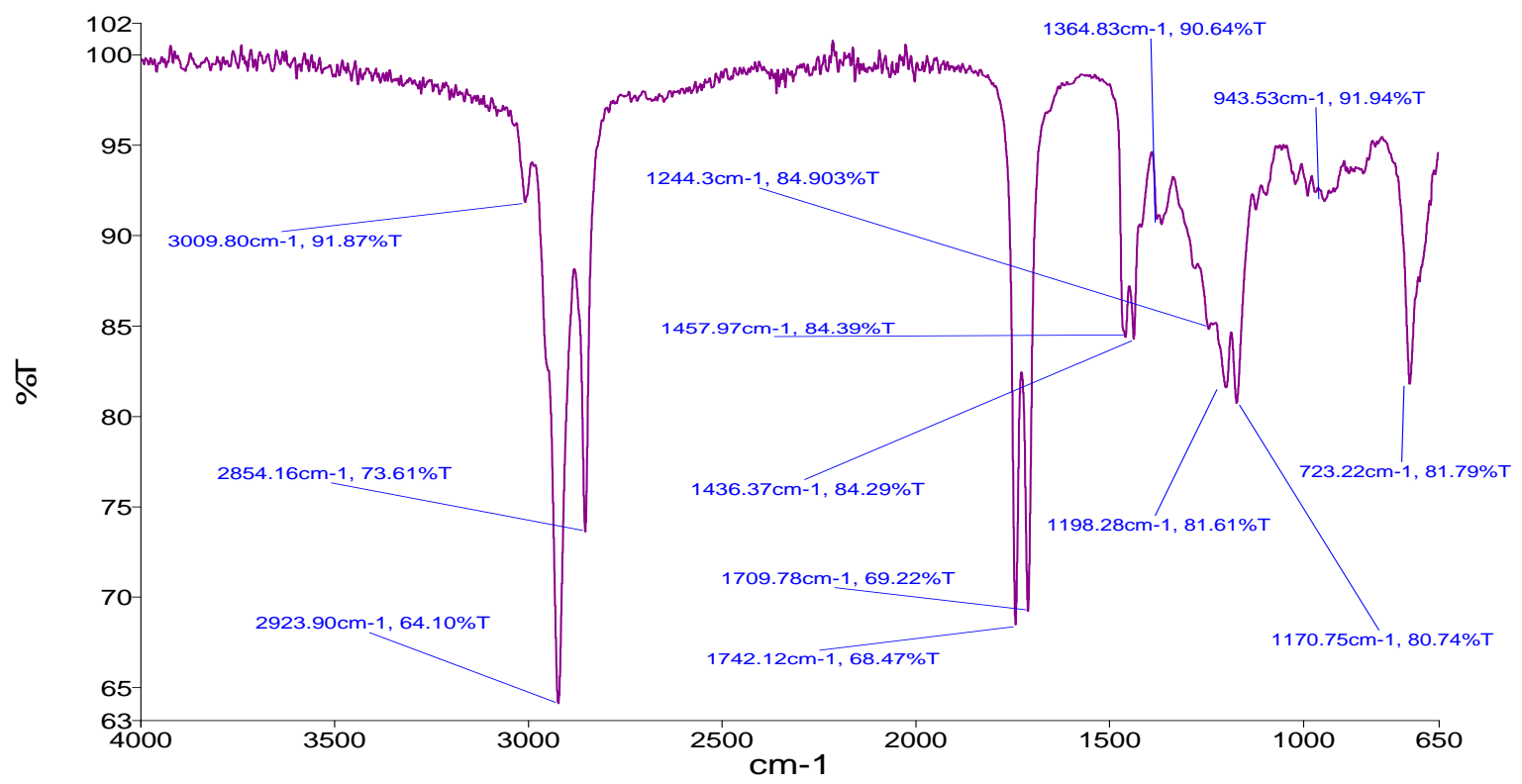

Figure 3.16: FTIR spectra of biodiesel production treatment HetBD_H16

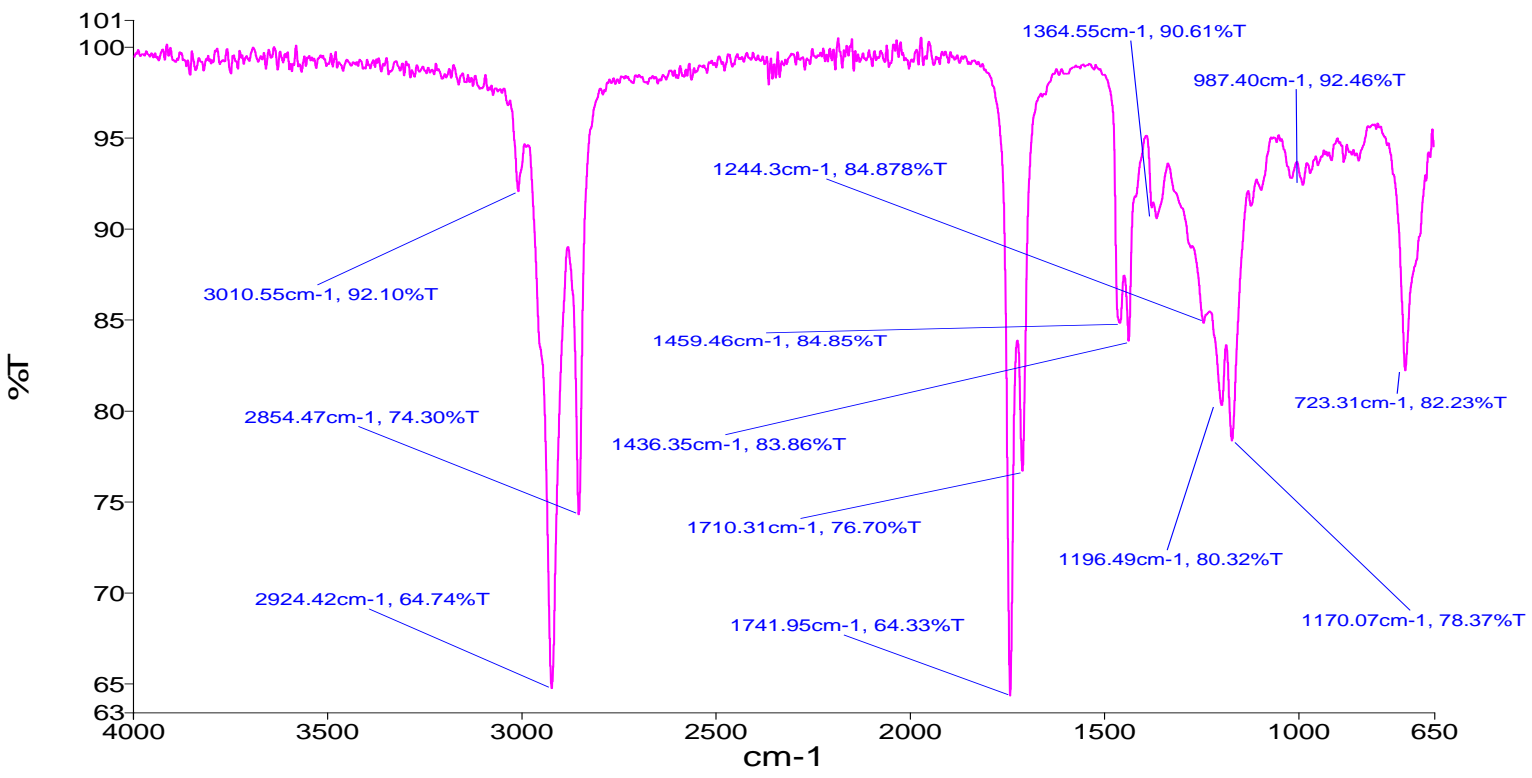

Figure 3.17: FTIR spectra of biodiesel production treatment HetBD_H13

The FTIR spectra in Figure 3.17 showed that the intensity of the ester carbonyl absorption peak increased more than that of the acid carbonyl functional group. Thus as the intensity of acid 
carbonyl peak is reduced (Figure 3.16), that of the ester carbonyl absorption peak is increased. This demonstrated the reversible nature of the reaction as borne out by the FTIR spectra. The spectra in Figure 18 showed the almost complete elimination of the acid carbonyl absorption peak while the ester carbonyl peak intensity increased. Elimination of the acid peak was confirmed by the flatness of the absorption region beyond the $3000 \mathrm{~cm}^{-1}$ region. This confirmed the complete removal of the $-\mathrm{OH}$ functional group of the carboxylic acid moiety.

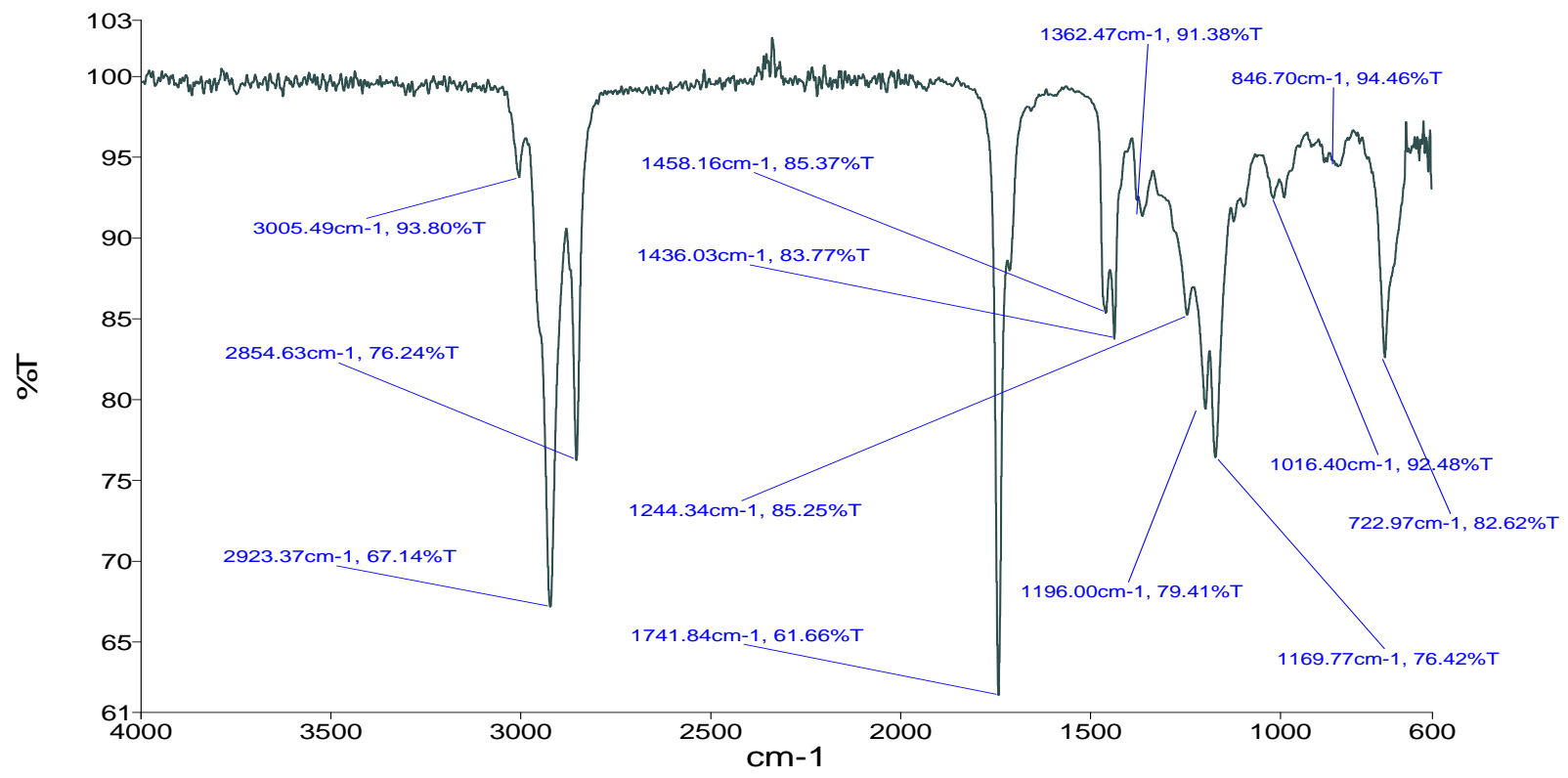

Figure 3.18: FTIR spectra of biodiesel production treatment HetBD_H3 


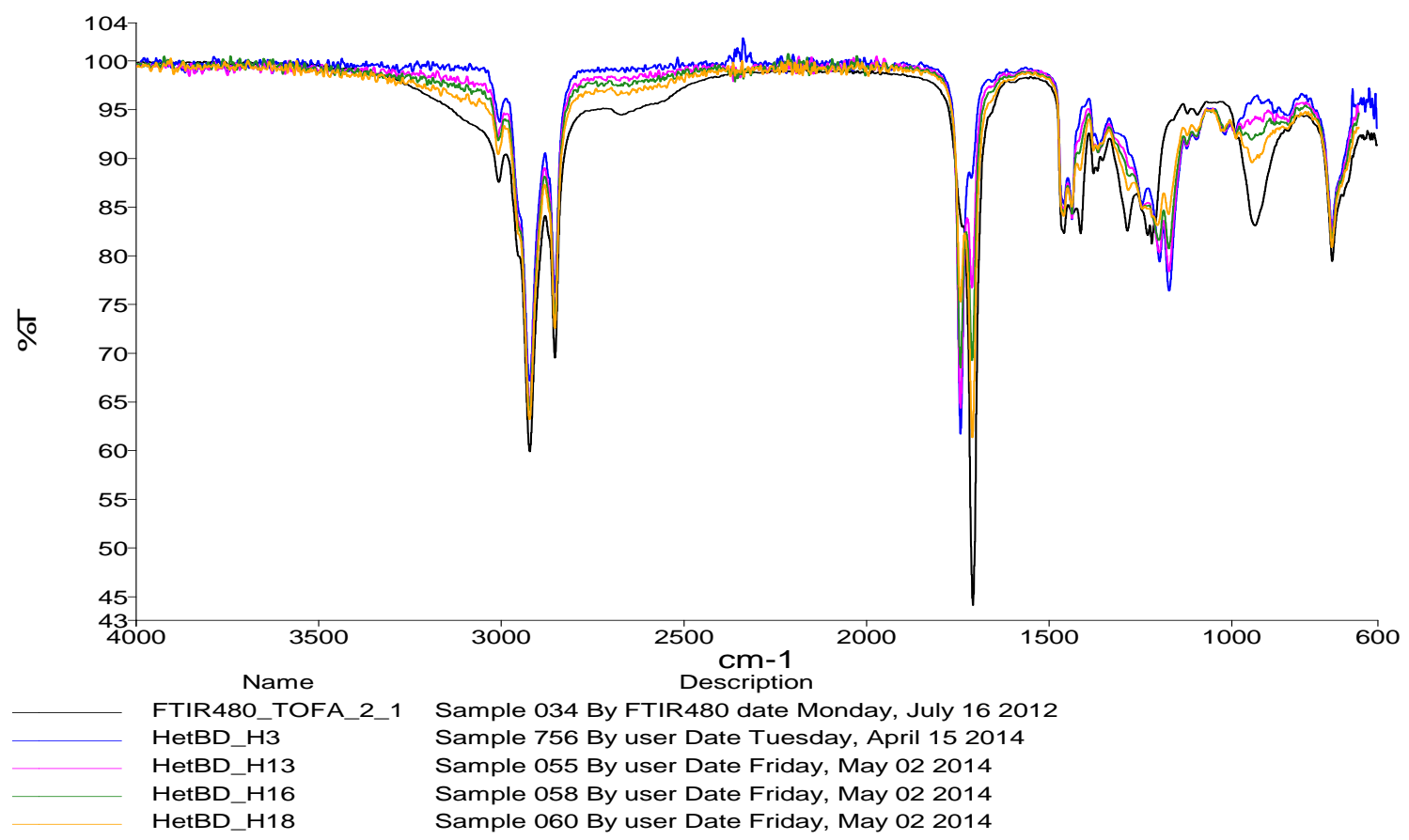

Figure 3.19: Full range FTIR spectra for TOFA and four different treatments for the production of biodiesel.

Figure 3.19 showed the overlay of spectra of the various conditions of the biodiesel production process and the gradual elimination of carboxylic acid functional group and their replacement by ester functional groups. Thus, this spectra reflected the reversibility of the reaction process.

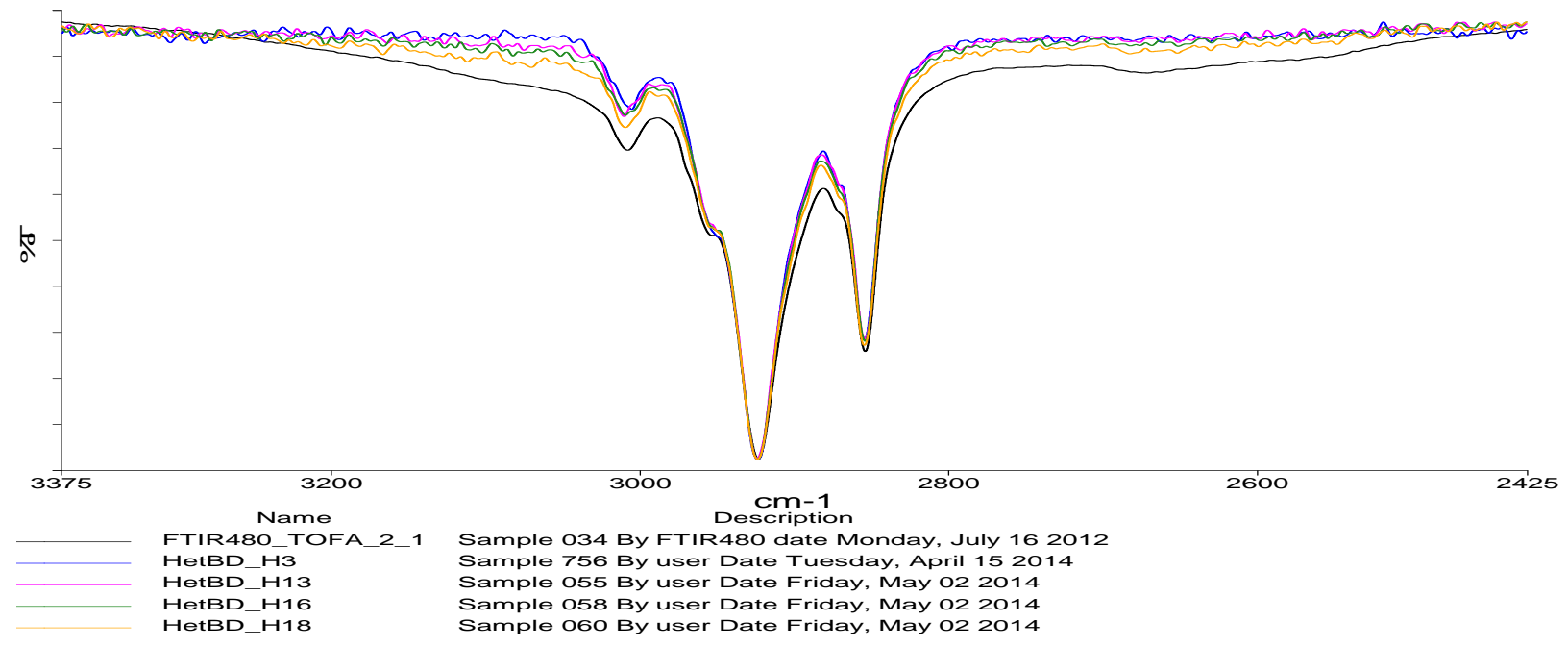

Figure 3.20: FTIR spectra of TOFA and four other treatments within the wavenumber range of 3375 and $2425 \mathrm{~cm}^{-1}$ 
The FTIR spectra in Figure 3.20 showed the nature of the absorption peaks between 3375 and $2425 \mathrm{~cm}^{-1}$ region. In this spectra, the TOFA FTIR spectra curve showed a lowered intensity and was also broad when compared to other treatments. The HetBD_H3 FTIR spectra curve showed the complete removal of the broadness and flattening of the absorption band in this region due to the elimination of the $-\mathrm{OH}$ acid functional group.

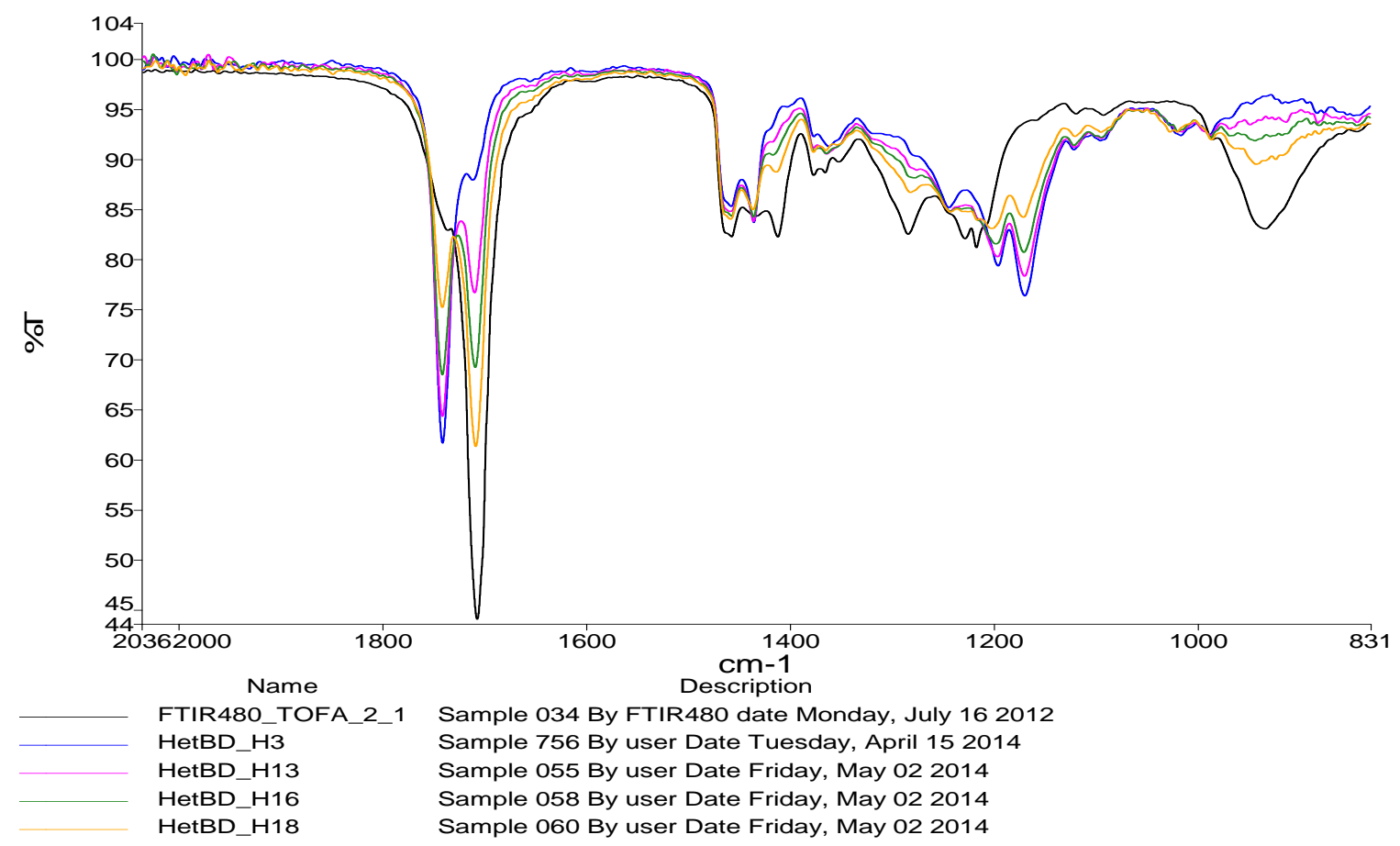

Figure 3.21: FTIR spectra of TOFA and four treatments within the range of $2000-830 \mathrm{~cm}^{-1}$. 


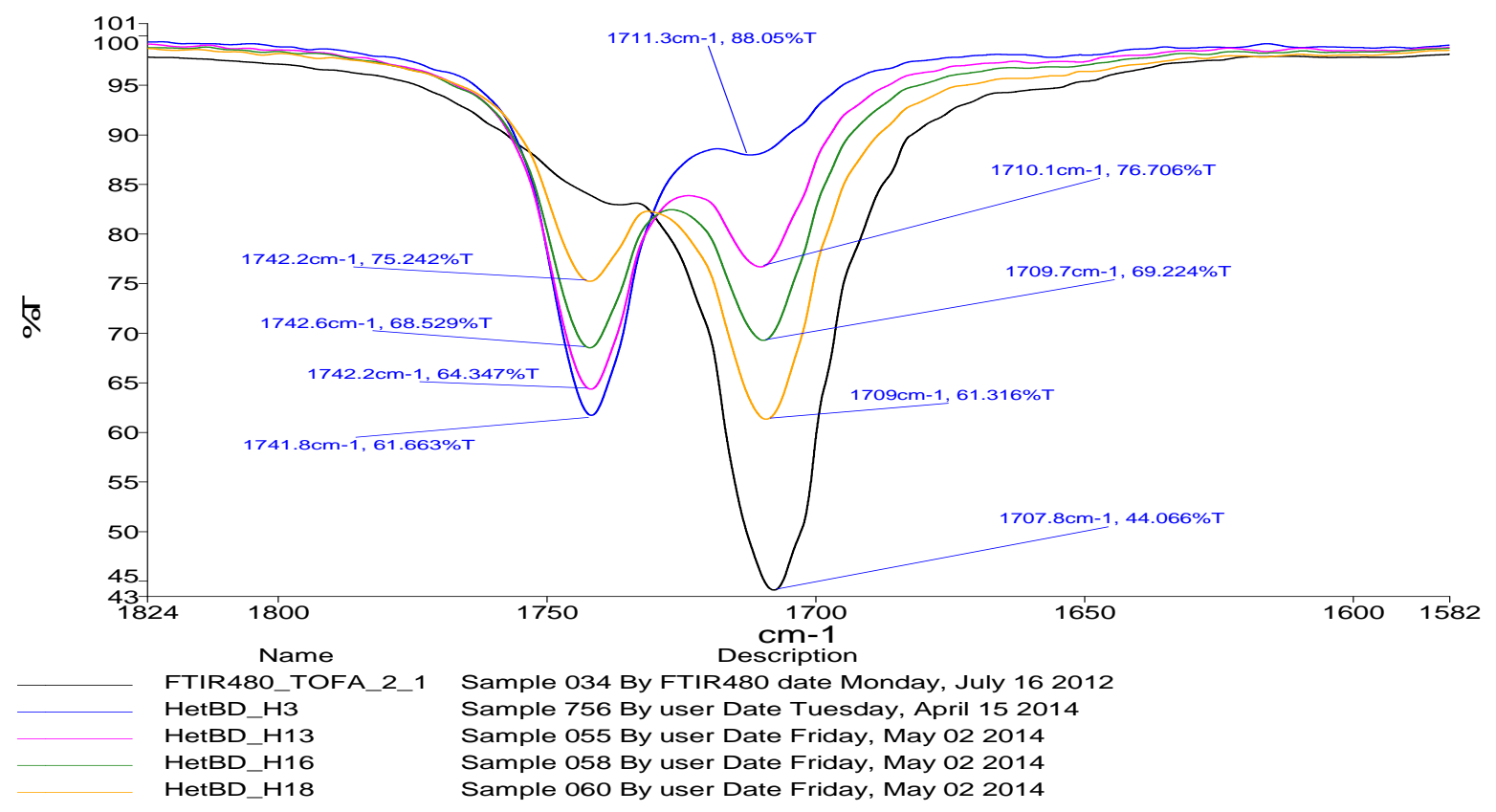

Figure 3.22: FTIR spectra of TOFA and four treatments within the wavenumber range of 1800$1600 \mathrm{~cm}^{-1}$

The shape of the absorption band (Figures 3.21 and 3.22) indicated that TOFA had the highest intensity of the acid carbonyl (44\%T) absorption peak followed by HetBD_H18 (61\%T), HetBD_H16 (69\%T), HetBD_H13 (76\%T) and finally HetBD_H3 (88\%T) in that order. This trend is reversed in the ester carbonyl peak at 1741-1742 $\mathrm{cm}^{-1}$. The treatment HetBD_H3 had the highest intensity with 61\% T while the smallest was HetBD_H18 with75\%T. The treatment HetBD_H3 and HetBD_H7 were replicates with a treatment condition of methanol to oil mole ratio of $20: 1$, catalyst concentration of $20 \%$, the time of reaction of 4 hours within a temperature range of $75-80^{\circ} \mathrm{C}$.

Results of the heterogeneous catalysis showed that H3 (HetBD_H3) and H7 (HetBD_H7) treatments had the lowest acid value of 12.65 and 13.59 respectively. The percent biodiesel yields were $86.88 \%$ and $85.49 \%$ for $\mathrm{H} 3$ and $\mathrm{H} 7$ respectively with an average of $86.18 \%$. However, statistical optimization of the process gave a molar ratio of methanol:oil as 21.7:1, a catalyst concentration of $23.40 \%$ (of the weight of oil), and a reaction time of $4.7 \mathrm{hrs}$ and a biodiesel percentage yield of 93.12. The acid values of the treatments HetBD_H3 and HetBD_H7 had the lowest values that were consistent with the carbonyl absorption peaks (from the FTIR spectra). The FTIR spectra in Figure 3.18 confirmed the near disappearance of the acid 
carbonyl absorption peak and its replacement by the ester carbonyl absorption peak. Therefore FTIR characterization of the biodiesel production process showed that the treatment conditions of HetBD_H3 and HetBD_H7 were close to the optimum conditions. However, the model predicted that the optimum conditions gave a $93.12 \%$ biodiesel yield by methanol:oil molar ratio of $21.7: 1$, catalyst concentration of $23.40 \%$ and time of reaction of 4.7 hours using the heterogeneous catalyst Amberlyst BD 20 while minimizing the acid value to give a very low value of 0.51 , which is within the ASTM standard for acid value for biodiesel.

\subsubsection{Recycling of heterogeneous catalyst}

The effects of recycling of the catalyst in the heterogeneous catalyzed biodiesel production process are presented in Table 3.8 and Figures 3.23-3.27. The ability to recycle catalyst and retain catalytic activity could reduce the overall cost of production of biodiesel. The percentage biodiesel yield increased after the first reaction. Similarly, the acid value had the highest value (14.53) after the first cycle, and the value subsequently decreased to attain the lowest value of 9.72 after the fourth cycle. This phenomenon whereby the activity of the catalyst increased to the maximum before becoming stable is ascribed to its swelling (Lopez et al. 2005). Park et al. (2010) also reported that the catalytic activity of Amberlyst BD 20 increased from the second cycle. This observation was ascribed to the time required by the catalyst to get in contact with the reactants. Consequently, the activity of the first reaction cycle is retarded. The results also indicated that the catalyst could be recycled even to the fourth cycle without decrease in activity of the catalyst. This is consistent with the work of Telebian-Kiakalaieh et al. (2013), Park et al. (2010) and Jacobson et al. (2008). 
Table 3.8: Results of recycling of catalyst for treatment HetBD_H3

\begin{tabular}{|c|c|c|c|c|c|}
\hline Recycle & $\frac{\text { Biodiesel }}{\text { Wt./g }}$ & \%Yield & $\frac{\text { \%Yield }}{\text { (Mean } \pm \text { SD) }}$ & $\frac{\text { Acid }}{\text { Value }}$ & $\frac{\text { Acid Value }}{\text { (Mean } \pm \text { SD) }}$ \\
\hline RA-1 & 32.5987 & 81.4968 & \multirow[t]{3}{*}{$82.77 \pm 1.10$} & 14.82 & \multirow[t]{3}{*}{$14.53 \pm 0.49$} \\
\hline RA-2 & 33.405 & 83.5124 & & 13.96 & \\
\hline RA-3 & 33.3149 & 83.2873 & & 14.81 & \\
\hline RB-1 & 35.2328 & 88.0821 & \multirow[t]{3}{*}{$88.26 \pm 0.45$} & 9.96 & \multirow[t]{3}{*}{$10.03 \pm 0.06$} \\
\hline RB-2 & 35.17 & 87.9251 & & 10.05 & \\
\hline RB-3 & 35.5067 & 88.7668 & & 10.08 & \\
\hline $\mathrm{RC}-1$ & 34.7686 & 86.9214 & \multirow[t]{3}{*}{$86.77 \pm 0.49$} & 10.33 & \multirow[t]{3}{*}{$10.52 \pm 0.18$} \\
\hline $\mathrm{RC}-2$ & 34.4902 & 86.2254 & & 10.68 & \\
\hline $\mathrm{RC}-3$ & 34.8656 & 87.1641 & & 10.55 & \\
\hline RD-1 & 35.1826 & 87.9564 & \multirow[t]{3}{*}{$88.0235 \pm 0.26$} & 9.78 & \multirow[t]{3}{*}{$9.72 \pm 0.18$} \\
\hline RD-2 & 35.3262 & 88.3155 & & 9.86 & \\
\hline RD-3 & 35.1194 & 87.7986 & & 9.52 & \\
\hline
\end{tabular}

\section{Oneway Analysis of \%Yield By Trt}

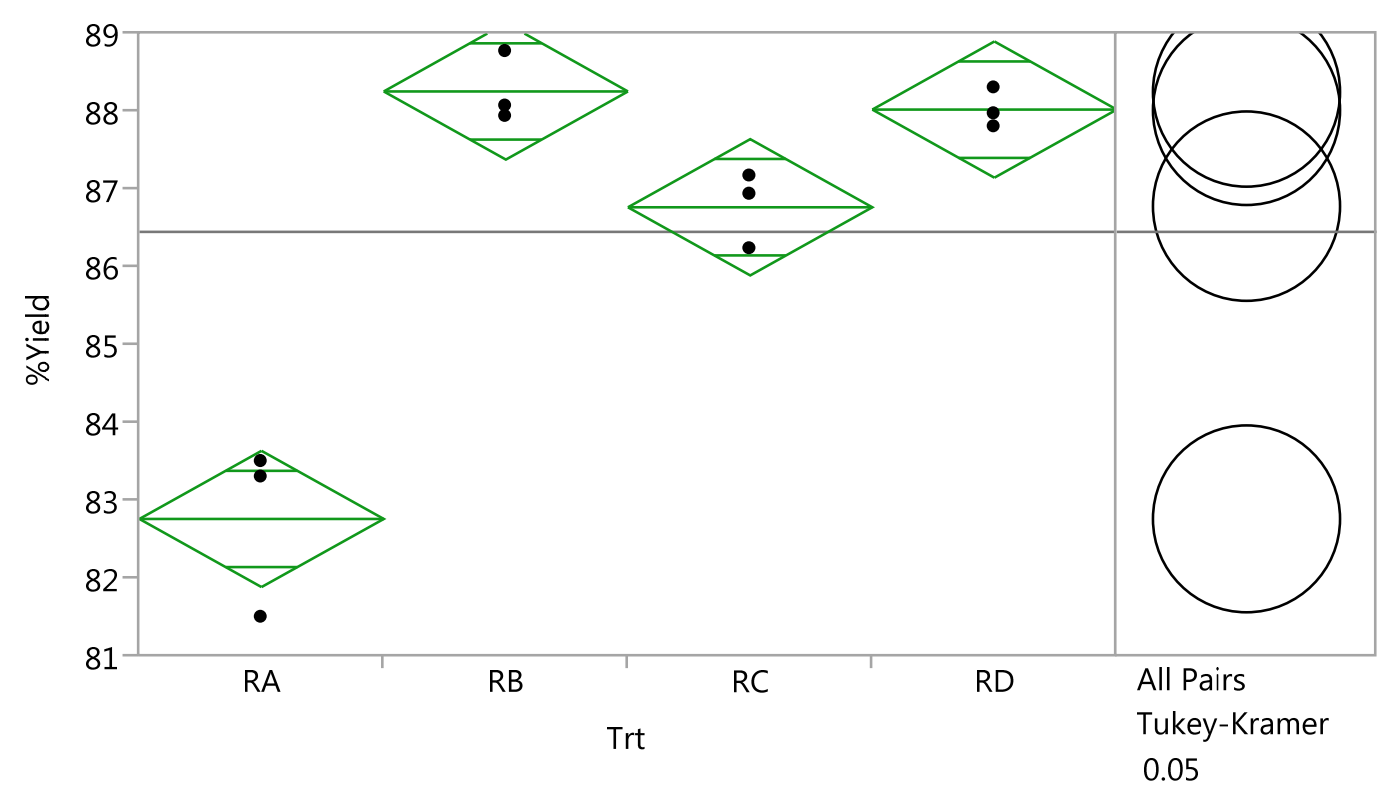

Figure 3.23: A graph showing the means comparison of \%Yield using the Tukey-Kramer HSD procedure.

A one way ANOVA and comparison of mean difference on \%Yield by recycling gives an $\mathrm{R}^{2}$ value of 0.94 . This shows a high correlation between the factors. The model is significant $(\mathrm{p}<0.0001)$ at 0.05 significant level. By the Tukey-Kramer HSD mean comparison method, the first cycle (RA) is significantly different from the second recycle $(R B)$ with $(p<0.0001)$; $R A$ is 
significantly different from the third recycle $(\mathrm{RC})$ with ( $\mathrm{p}=0.0003)$; $\mathrm{RA}$ is significantly different from the fourth recycle $(\mathrm{RD})$ with $(\mathrm{p}<0.0001)$. There were no significant differences between $\mathrm{RB}$ and $\mathrm{RC}$ nor $\mathrm{RB}$ and $\mathrm{RD}$ nor $\mathrm{RC}$ and $\mathrm{RD}$ (Figure 3.23). The largest mean \%Yield (88.26) is however for RB.

\section{Oneway Analysis of Acid Value By Trt}

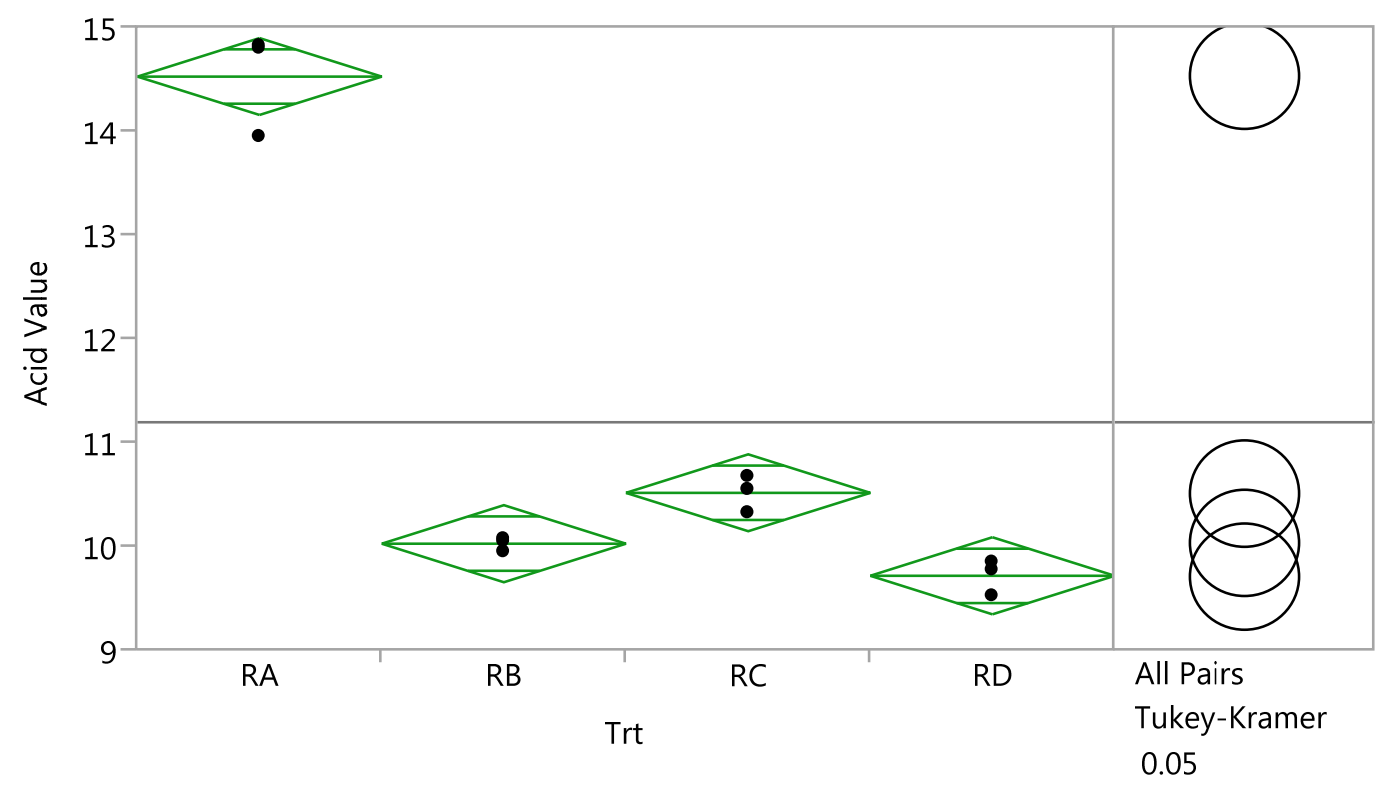

Figure 3.24: A graph showing the means comparison of acid value using the Tukey-Kramer HSD procedure.

A one way ANOVA and comparison of mean difference on acid value by recycling gives an $\mathrm{R}^{2}$ value of 0.99 . This shows a high correlation between the factors. The model is significant $(p<0.0001)$ at $\alpha=0.05$ significant level. By the Tukey-Kramer HSD mean comparison method, the first cycle (RA) is significantly different from the second recycle (RB) with $(p<0.0001)$; RA is significantly different from the third recycle $(\mathrm{RC})$ with ( $<<0.0001)$; $\mathrm{RA}$ is significantly different from the fourth recycle $(\mathrm{RD})$ with $(\mathrm{p}<0.0001)$; and $\mathrm{RC}$ is significantly different from $\mathrm{RD}(\mathrm{p}=0.0322)$. There were no significant differences between $\mathrm{RB}$ and $\mathrm{RC}$ nor for $\mathrm{RB}$ and $\mathrm{RD}$ (figure 3.24). The lowest mean acid value (9.72) is however for $\mathrm{RD}$. 


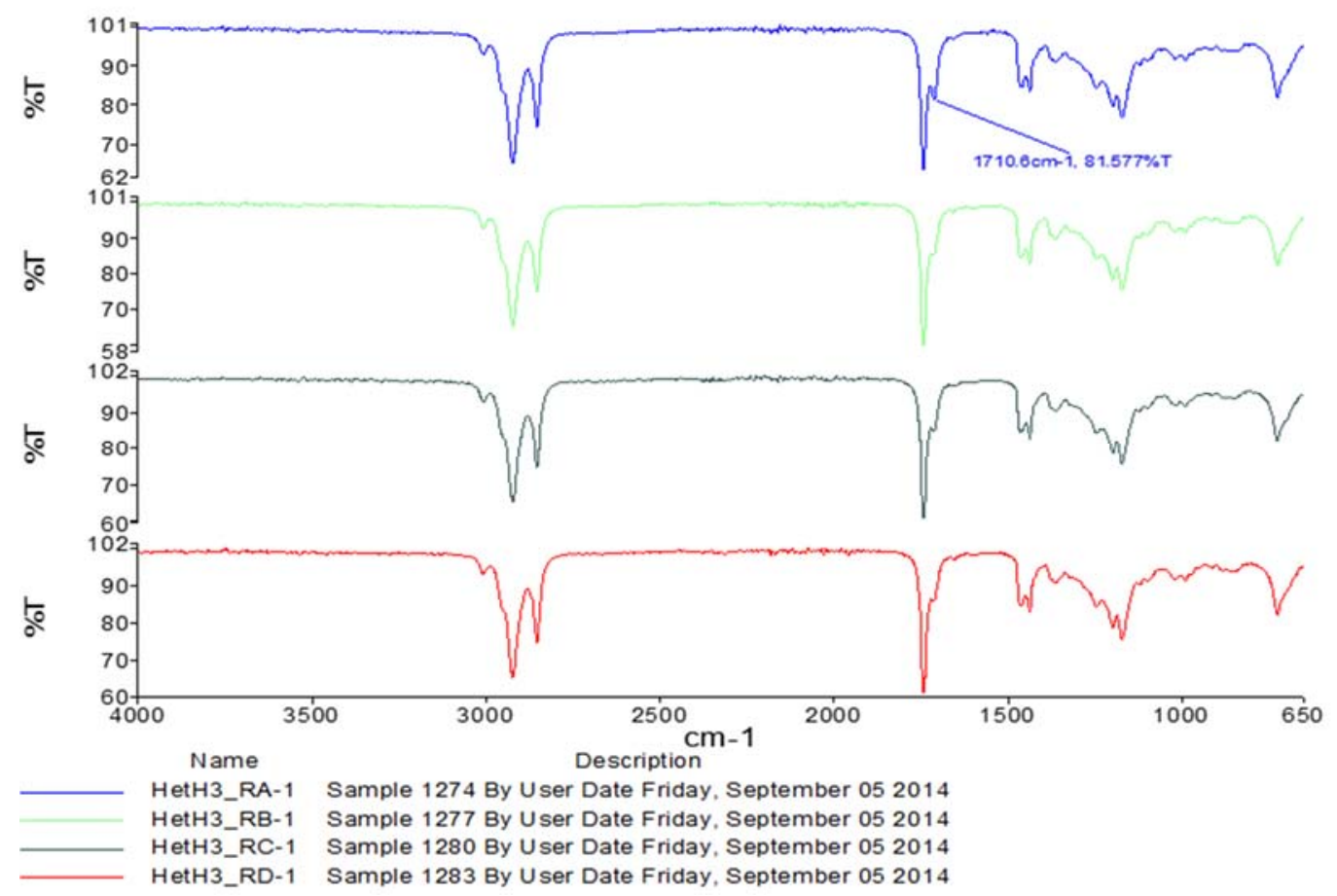

Fig. 3.25: The split FTIR spectra of the recycled catalyst treatments

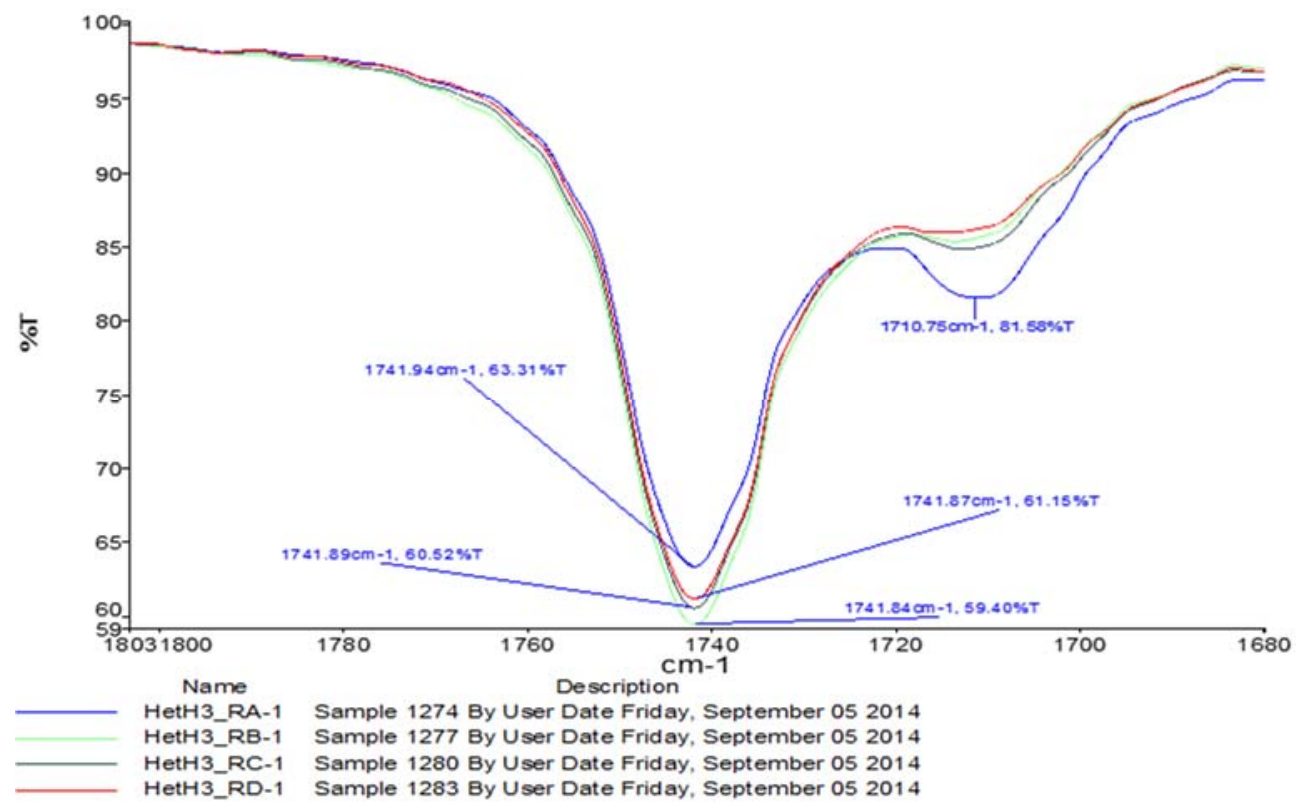

Fig. 3.26: The overlaid FTIR spectra of the biodiesel from recycled catalyst within the 1803$1680 \mathrm{~cm}^{-1}$ range 


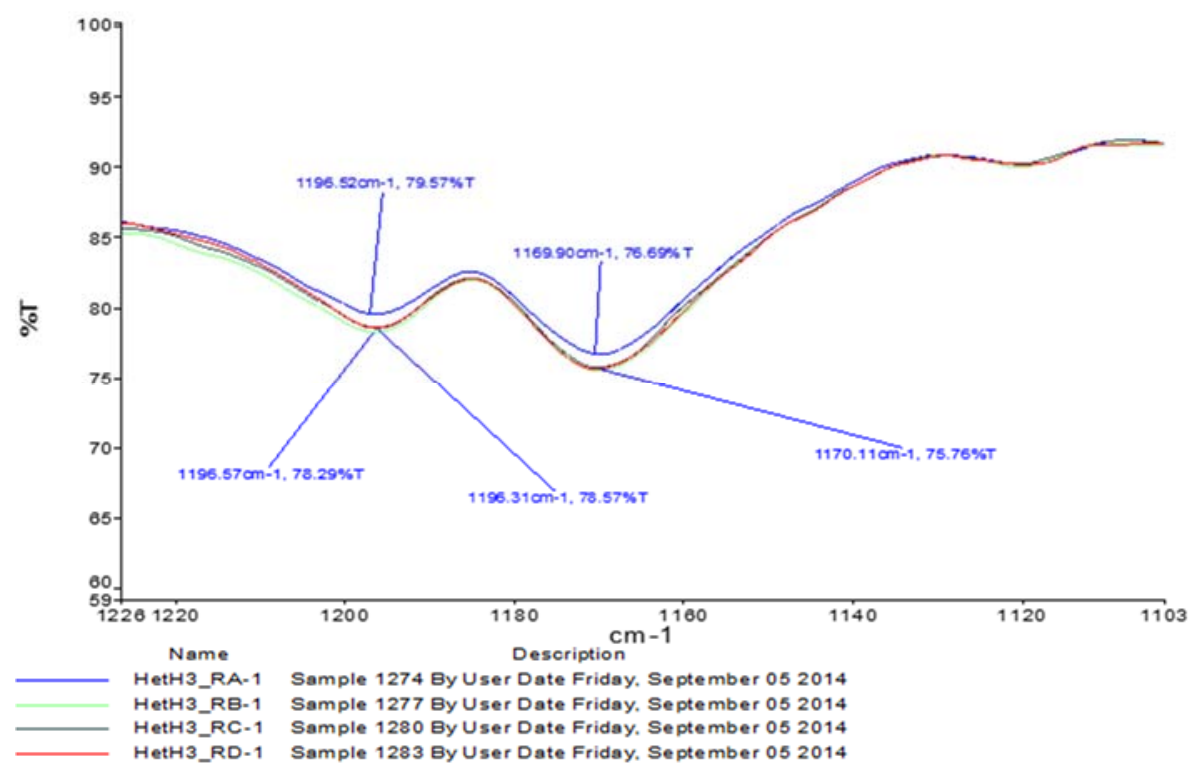

Fig. 3.27: The overlaid FTIR spectra of biodiesel from recycled catalyst in the range of 1226$1103 \mathrm{~cm}^{-1}$

The FTIR spectra of all the cycles show that the first cycle had the highest acid carbonyl peak while the recycling reduces that peak while increasing the ester carbonyl peak. The highest activity is shown by the second cycle and it slightly decreases towards the fourth cycle but still potent in its activity.

\subsection{Conclusion}

Infrared spectroscopy was used to monitor progress of production of biodiesel from Tall oil fatty acids using homogeneous (sulfuric acid) and heterogeneous (Amberlyst BD 20) catalysts respectively. For homogeneous catalysis, the treatment with the highest yield $(94.72 \%)$ was exhibited by the reaction conditions with: methanol to oil molar ratio of $15: 1$ at $75^{\circ} \mathrm{C}$ and a catalyst concentration of $0.5 \%$ and a reaction time of 60 minutes. This was confirmed by the FTIR spectra which showed total conversion of the fatty acid into FAME (biodiesel). The acid value was reduced from $113.18 \pm 0.01 \mathrm{mg} \mathrm{KOH} / \mathrm{g}$ oleic for the TOFA to $4.24 \pm 0.12 \mathrm{mg} \mathrm{KOH} / \mathrm{g}$ oleic acid for the biodiesel. This acid value is too high above the ASTM standard value of $0.8 \mathrm{mg}$ $\mathrm{KOH} / \mathrm{g}$ oleic acid. Kinematic viscosity was reduced from a value of $20.614 \pm 0.059 \mathrm{~mm}^{2} / \mathrm{s}$ for the TOFA to $5.216 \pm 0.016 \mathrm{~mm}^{2} / \mathrm{s}$ for the biodiesel which is within the ASTM standard value of 1.9$6.0 \mathrm{~mm}^{2} / \mathrm{s}$. For heterogeneous catalysis, the predicted optimum conditions while maximizing 
\%Yield and minimizing acid value is 93.12 for biodiesel production were methanol:oil molar ratio of $21.7: 1$ at a catalyst concentration of $23.4 \%(9.36 \mathrm{~g})$ of the oil and a reaction time of 4.7 hours at a constant temperature of $75-80^{\circ} \mathrm{C}$. The predicted acid value for the heterogeneous catalysis was $0.51 \mathrm{mg} \mathrm{KOH} / \mathrm{g}$ of oleic acid. This predicted acid value for the optimum yield of biodiesel from heterogeneous catalysis meets the ASTM standards $(0.8 \mathrm{mg} \mathrm{KOH} / \mathrm{g}$ oleic acid) for biodiesel. The major fatty acids present in the TOFA are oleic and linoleic acids. The biodiesel produced from the homogeneous catalysis was higher than that of the heterogeneous catalysis. However, the heterogeneous catalysts could be recycled for about four times without losing its catalytic activity. FTIR spectra was in agreement with the yield data showing a better conversion of biodiesel for the homogeneous catalysis than the heterogeneous catalysis.

\subsection{References}

Abidin, S.Z., Haigh, K.F., and Saha, B. (2012). Esterification of free fatty acids in used cooking oil using ion-exchange resins as catalysts: An efficient pretreatment method for biodiesel feedstock. Industrial \& Engineering Chemistry Research 51, 14653-14664.

Amberlyst ${ }^{\mathrm{TM}}$ BD20 FFA Esterification (2010). Lab Evaluation Guidelines. Rohm and Haas Biodiesel Technology. DOW Advanced Materials.

Ambersep ${ }^{\mathrm{TM}}$ BD19 Oil Purification Technology (2010). Lab Evaluation Guidelines. Biodiesel Technology. DOW Advanced Materials.

AOCS Official Method Cd 3a-63 (Revised 1987, Reapproved 1989)

Arnold, R.G., and Hartung, T.E. (1971). Infrared spectroscopic determination of degree of unsaturation of fats and oils. Journal of Food Science 36, 166-168.

ASTM D2709-96 (reapproved 2011)

ASTM D5355-95 (reapproved 2006)

Bokis, C.P., Chen, C.-C., and Orbey, H. (1999). A segment contribution method for the vapor pressure of tall-oil chemicals. Fluid Phase Equilibria 155, 193-203. 
Canakci, M., and Sanli, H. (2008). Biodiesel production from various feedstocks and their effects on the fuel properties. Journal of Industrial Microbiology \& Biotechnology 35, 431-441.

Dahlberg, D.B., Lee, S.M., Wenger, S.J., and Vargo, J.A. (1997). Classification of vegetable oils by FT-IR. Applied Spectroscopy 51, 1118-1124.

Goering, C.E., Daugherty, M.J., Heakin, A.J., Pryde, E.H., and Schwab, A.W. (1982). Fuel properties of eleven vegetable oils. ASAE Tech. Pap.;(United States) 25.

Guillén, M.D., and Cabo, N. (1999). Usefulness of the frequency data of the Fourier transform infrared spectra to evaluate the degree of oxidation of edible oils. Journal of Agricultural and Food Chemistry 47, 709-719.

Harwood, L.M., and Claridge, T.D. (1997). Introduction to organic spectroscopy (Oxford University Press New York).

Howell, S., and Jobe, J. (2005). Current status of biodiesel in the United States. The Biodiesel Handbook 183-193.

Jacobson, K., Gopinath, R., Meher, L.C., and Dalai, A.K. (2008). Solid acid catalyzed biodiesel production from waste cooking oil. Applied Catalysis B: Environmental 85, 86-91.

Keskin, A., Yaşar, A., Gürü, M., and Altıparmak, D. (2010). Usage of methyl ester of tall oil fatty acids and resinic acids as alternative diesel fuel. Energy Conversion and Management 51, 2863-2868.

Lim, Y., Lee, H., Lee, Y.-W., and Han, C. (2009). Design and economic analysis of the process for biodiesel fuel production from transesterificated rapeseed oil using supercritical methanol. Industrial \& Engineering Chemistry Research 48, 5370-5378.

López, D.E., Goodwin, J.G., Bruce, D.A., and Lotero, E. (2005). Transesterification of triacetin with methanol on solid acid and base catalysts. Applied Catalysis A: General 295, 97-105.

Mahamuni, N.N., and Adewuyi, Y.G. (2009). Fourier transform infrared spectroscopy (FTIR) method to monitor soy biodiesel and soybean oil in transesterification reactions, petrodieselbiodiesel blends, and blend adulteration with soy oil. Energy \& Fuels 23, 3773-3782. 
Meher, L.C., Sagar, D.V., and Naik, S.N. (2006). Technical aspects of biodiesel production by transesterification - a review. Renewable and Sustainable Energy Reviews 10, 248-268.

Park, J.-Y., Kim, D.-K., and Lee, J.-S. (2010). Esterification of free fatty acids using watertolerable Amberlyst as a heterogeneous catalyst. Bioresource Technology 101, S62-S65.

Pinto, A.C., Guarieiro, L.L., Rezende, M.J., Ribeiro, N.M., Torres, E.A., Lopes, W.A., Pereira, P.A. de P., and Andrade, J.B. de (2005). Biodiesel: an overview. Journal of the Brazilian Chemical Society 16, 1313-1330.

Pisarello, L. Ma., Cordeiro, C. S., and Querini, C. A. (2007). Biodiesel from Tall Oil Fatty acids using Homogeneous and Heterogeneous Catalysts.

Praptijanto, A., Sebayang, D., Agustian, E., and Untoro, P. (2011). Rapid monitoring of fatty acid methyl ester in sonochemistry transesterification process using attenuated total reflection.

Pryor, R.W., Hanna, M.A., Schinstock, J.L., and Bashford, L.L. (1983). Soybean oil fuel in a small diesel engine. Transactions of the ASAE [American Society of Agricultural Engineers].

Ramos, L. P., Cordeiro, S., Pissarelo, Ma. L., and Querini, C. A. (2008). Biodiesel from Tall Oil Fatty Acids Using Homogeneous and Heterogeneous Catalysts. V CONGRESO IBEROAMERICANO DE INVESTIGACION EN CELULOSA Y PAPEL 2008.

Silverstein, R., and Webster, F. (2006). Spectrometric identification of organic compounds (John Wiley \& Sons).

Talebian-Kiakalaieh, A., Amin, N.A.S., Zarei, A., and Noshadi, I. (2013). Transesterification of waste cooking oil by heteropoly acid (HPA) catalyst: optimization and kinetic model. Applied Energy 102, 283-292.

Wansbrough, H. (1987). Written as a combination of two articles from edition one by P.J. Hooker and L.E. Fotherby (1977 Chemistry 100 students) and by Malcolm Rough, Senior Process Engineer, KRTA Ltd. respectively, with updated information provided by Stuart Cooney (Eka Chemicals) and with reference to: Grant, Roger and Grant, Claire; Grant and Hockh's Chemical Dictionary (5th ed.); McGraw-Hill Book Company. 
White, K., Lorenz, N., Potts, T., Penney, W.R., Babcock, R., Hardison, A., Canuel, E.A., and Hestekin, J.A. (2011). Production of biodiesel fuel from tall oil fatty acids via high temperature methanol reaction. Fuel 90, 3193-3199.

ww2.mackblackwell.org. Accessed 03/10/2013. 


\title{
4 Phase Change Materials for Thermal Energy Storage: Evaluation of Tropical Tree Fruit Oils/Fats
}

\begin{abstract}
Oils from the natural tropical fruits of Allanblackia (Allanblackia parviflora), shea butter (Vitellaria paradoxa) and palm kernel oil derived from the oil palm (Elaeis guineensis) tree have been considered as potential sources for use as phase change materials (PCMs) for thermal energy storage materials using thermo-physical and chemical characterization methods. Oils were extracted by soxhlet extraction with hexane as the extraction solvent. The optimum yield obtained for extraction of oil from Allanblackia seeds was $70.36 \%$ using an extraction condition of $0.25 \mathrm{~mm}$ mesh size and a time of 4 hours. The results of the differential scanning calorimetry (DSC) method showed that all the oils were polymorphic and hence gave multiple melting/freezing profile over a wide range. Allanblackia oil showed latent heat property for both melting and freezing cycles with high latent heat of energy $(80.53 \mathrm{~J} / \mathrm{g})$ and also gave the highest melting point profile $\left(34.74^{\circ} \mathrm{C}\right.$ peak temperature). The Thermo-gravimetric analysis (TGA) results showed that all the oil samples were thermally stable and did not degrade within the temperature of interest even though Allanblackia oil showed an increase in weight around $37^{\circ} \mathrm{C}$ indicating oxidative instability. The results showed that even with Allanblackia having a slight oxidative instability (reduced intensities of peaks), infrared spectra showed that all samples were relatively chemically stable and did not degrade or decompose after 1000 thermal cycles. Of the three fats/oils studied, Allanblackia oil therefore has the potential for use as a PCM for thermal energy storage while the other oils did not produce latent heat enthalpies.
\end{abstract}

\subsection{Introduction}

Thermal energy storage (TES) is one of the key technologies for energy conservation because of its capability to store energy for later use (Dincer and Rosen, 2002). It is best suited for heating and cooling applications. Although an ancient technology (e.g. harvesting ice and storing for later use), its significant impact on modern technology is only recent. Many energy sources in nature are intermittent and the mis-match in their supply and demand can be corrected using TES to ensure good performance and reliability (Farid, et al., 2004; Dincer and Rosen, 2002). Energy 
storage systems may be short-term or long-term and five forms are recognized: mechanical, chemical, biological, magnetic and thermal (Dincer and Rosen, 2002).

In this study, only thermal energy storage is considered. Three major types of TES are recognized: (1) sensible heat storage (SHS), (2) thermochemical storage (TCS) and (3) latent heat storage (LHS). Some materials used in TES may exhibit phase change. There are two types of phase change: (1) solid-liquid-gas phase change and (2) crystal structural (solid-solid) phase change (Chou, 2008). Only the phase change characterized by solid $\leftrightarrow$ liquid conversion accompanied by absorption of heat (solid melts to liquid phase) or release of heat (liquid solidifies) is considered in this study. This process is characterized by (latent) heat of fusion heat required to convert a unit mass of solid at its melting point to liquid without an increase in temperature (e.g. conversion of ice to liquid). This process occurs at the melting point. The process is "latent" because the introduced heat cannot be observed since the temperature remains constant (Wikepedia).

When a material is heated, its temperature rises and when it is cooled its temperature falls. The increase or decrease in heat attending this process is called Sensible Heat (SH) (Dincer and Rosen, 2002). Thus, in this system, energy is stored by changing the temperature of the storage medium (Berea, 2006). Consequently, the key thermal property of SH is the Specific Heat Capacity (SHC) which is the ratio of the stored heat to the temperature rise (the amount of energy stored by unit mass per degree). The SHS do not exhibit phase change. Examples of SHS are the heating of water in solar heating system to store heat (liquid-based system) and a rock bed for air-based systems (Farid et al., 2004). Water has a SH of $4.186 \mathrm{~kJ} / \mathrm{kg}{ }^{\circ} \mathrm{C}$. Thermochemical storage is characterized by a chemical reaction, usually a reversible thermal decomposition reactions where the energy is stored in the products indefinitely at room temperature with no loss of heat capacity (Berea, 2006). When energy is required, the products recombine in an exothermic chemical reaction to release heat. Examples of thermochemical storage systems include ammonium sulfate $\left(\left(\mathrm{NH}_{4}\right)_{2} \mathrm{SO}_{4}\right)$ and calcium hydroxide $\left(\mathrm{Ca}(\mathrm{OH})_{2}\right)$. In LHS, energy is absorbed (when the storage medium changes from solid to liquid; e.g. melts) or heat is released (when the storage medium transitions from liquid to solid; i.e. solidifies). Hence, these energy storage systems exhibit phase change (solid $\rightarrow$ liquid or liquid $\rightarrow$ solid). These materials are therefore characterized by latent heat of melting/crystallization and their melting 
point(s). Also, the energy is delivered over a constant temperature. This makes these storage materials very attractive for smaller and lighter storage devices with low storage losses such as packaging materials, clothing, blankets, gloves, astronaut space suits and footwear (Berera, 2006).

Physical and thermal properties of PCMs which facilitates their use in thermal energy storage include: (1) melting temperature in desired operating range, (2) high latent heat of fusion per unit volume, (3) high specific heat, (high thermal conductivity in both the solid and liquid state), (4) small volume changes on transformation of phase, (5) congruent melting of PCM for a constant storage capacity of material for every freezing/melting cycle, (6) thermal stability, high nucleation to avoid super-cooling of liquid phase, (7) not degraded after several melting/freezing cycles, (8) non-corrosive, non-toxic, (9) non-flammable, readily available and (10) cheap (Garg et al., 1985). Since this study was a "Proof-of-Concept" to evaluate the candidacy of these fruit oils as PCMs for TES, only factors 1,2,6, and 7 described above were considered. The tropical tree fruit oils have been reported as non-corrosive, non-toxic (8), non-flammable, readily available (9) and low cost (10) (Tetens, 2007; RPT 223-FDA, 2004; Mukherjee and Mitra, 2009).

Some oils and fatty acids have been used as PCMs (Chaudari et al., 2013). To-date, these materials have been derived from fossil sources. However, oils and fatty acids can also be obtained from plant resources. In the past decade, it has been reported that fruits of some tropical trees may contain oils of economic importance (Louppe and Grubben, 2008). Traditionally, the major forest products of tropical forests, like their temperate counterparts are woody materials such as logs, lumber, pulp, paper, wood composites. etc. (Abbiw, 1990). This view has resulted in the overexploitation and destruction of many tropical forests. An alternate paradigm to the use of the tropical forest is the concept of non-wood forest products. The tropical forest besides protecting game and wildlife provides a source of food, cash crops; contains undescribed plant species of unknown potential; curative herbs, seeds, etc. The tropical forest is "nature's pharmacy". "The paradox of the forest is that where it occurs, man's tendency is to destroy it, and where it does not occur the tendency is to create. Directly and indirectly, it serves a multiplicity of purposes" (Abbiw 1990). 
Tropical tree species such as Allanblackia spp. which has previously been considered an excellent timber material (Abbiw 1990) because of its natural durability has other potential economic uses. This tree has nine species; grows in West and East Africa and bears fruits which contain oil seeds. Allanblackia oil consists of these fatty acids, stearic acid (saturated fatty acid, 45-58\%), oleic acid (unsaturated fatty acid, 40-51\%). Other minor fatty acids found in Allanblackia oil are lauric acid $(<1 \%)$, myristic acid $(<1 \%)$, palmitic acid $(<2 \%)$, palmitoleic acid $(<1 \%)$, linoleic acid $(<1 \%), \gamma$-linoleic $(<1 \%)$, arachidic acid $(<1 \%)$ and free fatty acids (max. 0.1\%). Three major triglycerides are found in Allanblackia oil, and they are stearic-oleicstearic $(\sim 70 \%)$, stearic-oleic-oleic ( 23\%), and oleic-oleic-oleic ( $4 \%)$ (Tetens, 2007 ; Hermann, M., 2009).

Two other oil-seed bearing tree species which are found in West and/or Central Africa are the shea butter tree and the oil palm tree. Shea butter tree (Vitellaria paradoxa) bears a greenishyellow ellipsoid spherical fruit which is harvested and processed into shea butter. The oil has the following fatty acid profile: palmitic, stearic, oleic, linoleic and arachidic fatty acids. These range between $6.52-8.12 \%, 28.65-30.94 \%, 55.54-57.63 \%, 6.18-7.79 \%$ and $0.65-0.90 \%$, respectively. The fat content of shea butter is between 41-54\% (Okullo et al., 2010). Shea butter is being co-evaluated with the other fats/oil as a potential PCM for thermal energy storage material because it is a solid at room temperature and can undergo a phase change during melting and crystallization. Oil palm tree (Elaeis guineensis) is cultivated commercially in West Africa. Its fruit has an outer exocarp (thin skin); followed by a mesocarp and an inner endocarp. The mesocarp is processed into palm oil with a by-product - endocarp (palm kernel). The latter is further processed into a low value oil - palm kernel oil. Palm kernel oil is a saturated fat and it is a semi-solid to solid at room temperature. It contains the fatty acids ranging from $\mathrm{C} 6$ to $\mathrm{C} 18$ : lauric, myristic, palmitic, and oleic with lauric being the dominant acid with a composition of $48 \%$. It crystallizes in the beta form at a temperature of $0-25^{\circ} \mathrm{C}$ and has a composition of $\mathrm{C} 6$ (0.3\%), C8 (4.4\%), C10 (3.7\%), C12 (48.3\%), C14 (15.6\%), C16 (7.8\%), C18 (2.0\%), C18:1 (15.1\%), C18:2 (2.7\%) and others (0.2\%) (Chong and Siew, 1994). The unsaturated fats present are oleic and linoleic.

Fatty acids and their mixtures have been evaluated as potential PCMs (Berera 2006). However, mixtures used as PCMs unlike the pure substances which melt/freeze at constant temperatures, 
do melt/freeze over a limited range of temperature. Feldman et al., 1995, reported mixtures of stearic acid (65 wt\%) and palmitic acid (27.5 wt\%)) plus other fatty acids (5.5 wt\%)-emery 420, that melts within the temperature range of $51-56^{\circ} \mathrm{C}$ with an enthalpy value of $180 \mathrm{~kJ} / \mathrm{kg}$. The same authors reported another product (emersol 150) having a composition of stearic acid (83 $\mathrm{wt} \%)$, palmitic acid $(11 \mathrm{wt} \%)$ and other fatty acids $(6 \mathrm{wt} \%)$ melting within the range of $60-66^{\circ} \mathrm{C}$ and an enthalpy value of $206 \mathrm{~kJ} / \mathrm{kg}$. Hasan and Sayigh (1994) also reported the melting range of palmitic acid to be $57.8-61.8^{\circ} \mathrm{C}$ with an enthalpy value of $201 \mathrm{~kJ} / \mathrm{kg}$. Cedeno et al. (2001), and Dimaano and Watanabe (2002) also reported on low enthalpy values of PCMs. Cedeno et al. reported that oleic acid from Merck having $99.9 \mathrm{wt} \%$ composition had enthalpy value of 75.7 $\mathrm{kJ} / \mathrm{kg}$ with a melting value of $-5.3^{\circ} \mathrm{C}$. Similarly, Dimaano and Watanabe reported the enthalpy value of $90 \mathrm{wt} \%$ oleic acid from ED \& L Industries, Inc. as $45.3 \mathrm{~kJ} / \mathrm{kg}$ with the melting temperature as $-5.3^{\circ} \mathrm{C}$. The melting and freezing temperatures of the samples of this study are mixtures and determined to be in a range. For the purpose of this study, temperature range considered as having latent energy will be a difference of $5^{\circ} \mathrm{C}$. Oils from the fruits of the three trees contain mixed fatty acids. Allanblackia oil is a solid at room temperature and shea butter and palm kernel oil are solids to semi-solids at room temperature.

In this study, we report what we believe as the first evaluation of the potential of the oils from Allanblackia spp., shea butter and palm kernel oil as potential environmentally sustainable candidates for PCMs for latent heat storage by the determination of physical properties. The DSC was used to determine change in melting point and latent heat change. Thermal stability of oils were studied using a TGA to show if there was decomposition of the samples during the melting and/or crystallization temperature region (known as the desired temperature range). The FTIR spectroscopy was used to characterize the functional group chemistry of the oils before and after melting/freezing cycles and therefore confirm their thermal stability (Garg et al., 1985). In order to determine the thermo-physical stability and thermal reliability of the oils over a long period of use, a Thermal Cycler was used to subject the oils in a heat/cold cycle for a 1000 times and then re-evaluated to see if they have been physically or chemically impacted. 


\subsection{Materials and Methods:}

\subsubsection{Materials:}

Allanblackia (Allanblackia paviflora) seeds were obtained from Ghana; Shea butter (Bulk Apothecary, Ohio, U.S.A.), Palm kernel oil (Organic Creations, Oregon, U.S.A.), Coffee grinder (Mr. Coffee, USA), meshes of size $0.1 \mathrm{~mm}, 0.25 \mathrm{~mm}, 0.5 \mathrm{~mm}, 0.75 \mathrm{~mm}, 1.0 \mathrm{~mm}$ and $2.0 \mathrm{~mm}$. Hexane (Fisher Scientific, NJ, U.S.A.), soxhlet extractor, filter paper (Whatman International Ltd, Maidstone, England), cellulose extraction thimbles (Whatman-25mm ID x 100mm ED, Whatman International Ltd, Maidstone, England), Buchi rotavapor, R-210/215 (Buchi Labortechnik AG, Flawi, Switzerland), 250ml Erlenmeyer flask, water bath, separating funnel, anhydrous sodium sulfate $\left(\mathrm{Na}_{2} \mathrm{SO}_{4}\right)$ (Fisher Scientific, NJ, U.S.A.), TGA instrument (TA Insturments model Q50, TA instruments, Inc., DE, USA), Platinum pan, DSC instrument (TA Insturments model Q20, TA instruments, Inc., DE, USA), Tzero Aluminium hermetic pans and lids (DSC Consumables Inc., Austin, MN, U.S.A.), PerkinElmer Spectrum 100 FTIR (Waltham, Massachusetts, U.S.A.) with an ATR spectrometer, PTC-100 Programmable Thermal Controller (MJ Research Inc., Watertown, MA, U.S.A.).

\subsubsection{Methods:}

\subsubsection{Sample preparation of Allanblackia seeds}

Seeds of Allanblackia spp. were dried in an oven at $65^{\circ} \mathrm{C}$ for 24 hours. The seeds were then manually de-hulled and then put in plastic bags and stored in the refrigerator until use.

\subsection{Oil extraction from Allanblackia seeds}

Allanblackia spp. seeds that had earlier been de-hulled, were milled into fine particles using a coffee grinder (Mr. Coffee, USA) and passed through meshes of various sizes $(0.1 \mathrm{~mm}, 0.25 \mathrm{~mm}$, $0.5 \mathrm{~mm}, 0.75 \mathrm{~mm}, 1 \mathrm{~mm}$ and $2 \mathrm{~mm}$ ). Five grams of ground seeds were placed in a cellulose extraction thimble (Whatman International, England), capped with a folded filter paper and placed in the extraction chamber of a Soxhlet apparatus. $150 \mathrm{mls}$ of extraction solvent (hexane) was placed in a $250 \mathrm{ml}$ capacity round bottom flask and connected to the extraction chamber. 
The extraction chamber was connected to a reflux system. The heat of the extraction system was turned on and extraction was carried out according to ISO 659-1988E (Garcia-Ayuso and Luque de Castro, 1998) (Fig. 4.1). After extraction, the solvent containing the extracted material was transferred into the round bottom flask of a Buchi rotavapor, (model R-210/215) and the extraction solvent, hexane, recovered by vacuum distillation. The oil remaining in the extraction flask was recovered and dried over nitrogen gas. The resulting extract was placed in a desiccator to attain ambient room temperature conditions and weighed. The percentage yield of the oil was determined according to the formula:

\section{\%Yield $=\underline{\text { Weight of oil extracted }} \times 100$ Weight of Sample}

Similarly, shea butter and palm kernel oil were also extracted with hexane as per the above described protocol.

\subsection{Experimental design}

The experimental design used for this study was a full factorial design with two (2) factors at four (4) levels each. The factors were mesh size and extraction time. The four levels of mesh size were: $0.25 \mathrm{~mm} ; 0.5 \mathrm{~mm} ; 1 \mathrm{~mm}$; and $2 \mathrm{~mm}$ and the extraction times were: $2 \mathrm{hrs}$; $4 \mathrm{hrs}$; $6 \mathrm{hrs}$; and $8 \mathrm{hrs}$. Five grams of ground material was used for each extraction. The experiment was duplicated. 


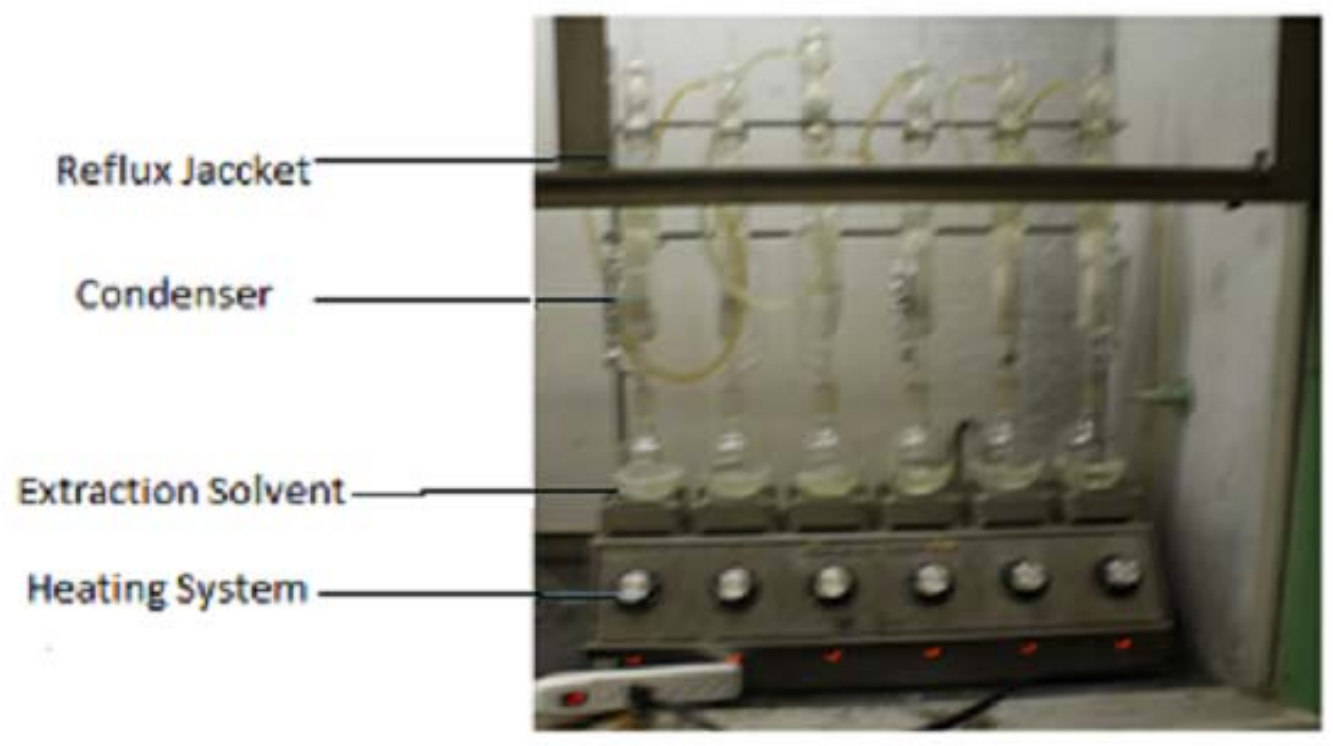

Fig.4.1: Solvent extraction of Allanblackia oil from seeds (Soxhlet Apparatus)

\subsection{Chemical characterization of extracted oils of Allanblackia, shea butter and palm kernel oil}

The functional chemistry of extracted Allanblackia oil, shea butter and palm kernel oil was characterized using Fourier Transform Infrared (FTIR) spectroscopy. The FTIR spectra of each extracted oil was acquired using a PerkinElmer Spectrum 100 spectroscopy instrument with Universal Sampling Accessory at a wave number range of 4000-650 $\mathrm{cm}^{-1}$. Measurements were recorded in Transmittance mode. Four (4) scans were taken per each measurement. Oil sample (about $0.1 \mathrm{~mL}$ ) was placed on the diamond ATR probe aperture, and spectra were recorded at a resolution of $8 \mathrm{~cm}^{-1}$ using 4 scans under 1 minute against air as the background. Mid-IR (FTIR) measurements were recorded for samples before thermal cycling and after thermal cycling.

\subsection{Thermo-physical characterization of oils}

The enthalpies and phase change temperatures of the samples were determined by DSC. The instrument was calibrated with an indium standard. Measurements were taken under a nitrogen 
atmosphere using a heating/cooling/heating cycle at a heating rate of $5^{\circ} \mathrm{C} / \mathrm{min}$, and the same rate for the cooling cycle. These measurements were made in a triplicate and used to calculate the average melting and latent heat values. A programmable thermal controller was used to determine the melting/solidification process for 1000 times to find the thermal reliability and stability of the samples after the thermal cycling. The samples were thermally cycled by heating from $0^{\circ} \mathrm{C}$ to $50^{\circ} \mathrm{C}$ at a rate of $1{ }^{\circ} \mathrm{C} / \mathrm{s}$ and held for $30 \mathrm{~s}$. It is then cooled from $50^{\circ} \mathrm{C}$ to $0^{\circ} \mathrm{C}$ at the same rate of $1{ }^{\circ} \mathrm{C} / \mathrm{s}$, and again held for $30 \mathrm{~s}$. This process was repeated 999 times. This effect impacts the thermal energy storage of the samples as a PCM. The samples were also analyzed thermo-gravimetrically using a TGA instrument. The instrument was calibrated using calcium oxalate in a temperature range of $25-600^{\circ} \mathrm{C}$ at a heating rate of $10^{\circ} \mathrm{C} / \mathrm{min}$ in a nitrogen/compressed air atmosphere (Sari et al., 2011).

\subsection{Results and Discussions}

\subsubsection{Optimum yield of oil extraction from Allanblackia}

The optimum yield of oil extraction from Allanblackia was $70.36 \pm 3.36 \%$ (conditions: minimum mesh size of $0.25 \mathrm{~mm}$ and a time of 4 hours). This yield is high compared with $67.59 \%$ reported by Wilfred et al. (2010) for Allanblackia floribunda seeds. The results show that the smaller mesh size produce a higher yield of oil, and this may be due to a higher surface area of the samples. The statistical model for this extraction using an ANOVA with JMP software gives a $p=0.001$ value at $\alpha=0.05$ significant level and the $R^{2}$ value was 0.57 . The sample size was significant $(\mathrm{p}=0.0001)$ but time was not significant $(\mathrm{p}=0.65)$. Least square mean differences by the Tukey HSD at 0.05 significant level showed significant differences between sample mesh size $0.25 \mathrm{~mm}$ and $1 \mathrm{~mm}$ as well as $0.25 \mathrm{~mm}$ and $2 \mathrm{~mm}$. The mesh size of $0.5 \mathrm{~mm}$ was also significantly different from $2 \mathrm{~mm}$. 
Table 4.1: Results of Allanblackia oil extraction

\begin{tabular}{|c|c|c|c|c|c|c|c|}
\hline Expt \# & $\begin{array}{l}\text { Sample } \\
\text { Size/mm }\end{array}$ & Time/hr & $\begin{array}{l}\text { Sample } \\
\text { wt./g }\end{array}$ & oil wt./g & \%oil wt. & $\begin{array}{l}\text { Av. \%oil } \\
\text { wt. }\end{array}$ & Stdev. \\
\hline 21 & 2 & 8 & 5.0004 & 3.062 & 61.2351 & \multirow[t]{2}{*}{62.07} & \multirow[t]{2}{*}{1.18} \\
\hline 2 & 2 & 8 & 5.0000 & 3.1451 & 62.902 & & \\
\hline 25 & 1 & 8 & 5.0003 & 3.1915 & 63.8262 & \multirow[t]{2}{*}{62.80} & \multirow[t]{2}{*}{1.45} \\
\hline 18 & 1 & 8 & 5.0002 & 3.0889 & 61.7755 & & \\
\hline 27 & 0.5 & 8 & 5.0003 & 3.2946 & 65.888 & \multirow[t]{2}{*}{65.68} & \multirow[t]{2}{*}{0.30} \\
\hline 32 & 0.5 & 8 & 5.0003 & 3.2736 & 65.4681 & & \\
\hline 13 & 0.25 & 8 & 5.0006 & 3.1021 & 62.0346 & \multirow[t]{2}{*}{65.47} & \multirow[t]{2}{*}{4.85} \\
\hline 31 & 0.25 & 8 & 5.0001 & 3.445 & 68.8986 & & \\
\hline 10 & 2 & 6 & 5.0003 & 3.0254 & 60.5044 & \multirow[t]{2}{*}{60.74} & \multirow[t]{2}{*}{0.34} \\
\hline 23 & 2 & 6 & 5.0001 & 3.0493 & 60.9848 & & \\
\hline 30 & 1 & 6 & 5.0006 & 3.2846 & 65.6841 & \multirow[t]{2}{*}{65.11} & \multirow[t]{2}{*}{0.81} \\
\hline 3 & 1 & 6 & 5.0002 & 3.2273 & 64.5434 & & \\
\hline 6 & 0.5 & 6 & 5.0004 & 3.3716 & 67.4266 & \multirow[t]{2}{*}{66.68} & \multirow[t]{2}{*}{1.05} \\
\hline 8 & 0.5 & 6 & 5.0002 & 3.2971 & 65.9394 & & \\
\hline 28 & 0.25 & 6 & 5.0003 & 3.4537 & 69.0699 & \multirow[t]{2}{*}{68.76} & \multirow[t]{2}{*}{0.44} \\
\hline 26 & 0.25 & 6 & 5.0002 & 3.4225 & 68.4473 & & \\
\hline 17 & 2 & 4 & 5.0004 & 3.1257 & 62.509 & \multirow[t]{2}{*}{61.24} & \multirow[t]{2}{*}{1.79} \\
\hline 29 & 2 & 4 & 5 & 2.9989 & 59.978 & & \\
\hline 14 & 1 & 4 & 5.0005 & 3.2458 & 64.9095 & \multirow[t]{2}{*}{64.38} & \multirow[t]{2}{*}{0.75} \\
\hline 22 & 1 & 4 & 5.0001 & 3.1925 & 63.8487 & & \\
\hline 9 & 0.5 & 4 & 5.0003 & 3.1091 & 62.1783 & \multirow[t]{2}{*}{62.08} & \multirow[t]{2}{*}{0.14} \\
\hline 7 & 0.5 & 4 & 5.0002 & 3.0989 & 61.9755 & & \\
\hline 5 & 0.25 & 4 & 5.0003 & 3.3993 & 67.9819 & \multirow[t]{2}{*}{70.36} & \multirow[t]{2}{*}{3.36} \\
\hline 19 & 0.25 & 4 & 5.0003 & 3.6372 & 72.7396 & & \\
\hline 20 & 2 & 2 & 5.0006 & 2.9975 & 59.9428 & \multirow[t]{2}{*}{60.14} & \multirow[t]{2}{*}{0.29} \\
\hline 1 & 2 & 2 & 5.0005 & 3.0176 & 60.346 & & \\
\hline 11 & 1 & 2 & 5.0004 & 3.1985 & 63.9649 & \multirow[t]{2}{*}{64.77} & \multirow[t]{2}{*}{1.14} \\
\hline 4 & 1 & 2 & 5.0002 & 3.2792 & 65.5814 & & \\
\hline 16 & 0.5 & 2 & 5.0004 & 3.1979 & 63.9529 & \multirow[t]{2}{*}{65.47} & 2.15 \\
\hline 15 & 0.5 & 2 & 5 & 3.3494 & 66.988 & & \\
\hline 12 & 0.25 & 2 & 5.0005 & 3.0926 & 61.8458 & 65.63 & 5.36 \\
\hline 24 & 0.25 & 2 & 5.0002 & 3.4713 & 69.4232 & & \\
\hline
\end{tabular}


Since the time was insignificant, the model could not give significant differences to show differences in the means of the treatments. The highest mean of $70.36 \%$ was therefore chosen as the highest extraction yield with the treatment of $0.25 \mathrm{~mm}$ mesh size and a time of $4 \mathrm{hrs}$.

\subsubsection{Differential scanning calorimetric (DSC) analysis of oil samples}

Vegetable oils such as the oils extracted from the fruits of these tropical trees are not pure compounds. They consist of complex mixture of triacylglycerol, (TAG, 96-99\% of esters of glycerol and long chain fatty acids, (Tan and Che Man, 1999)). Hence, they exhibit variable melting and crystallization temperatures, as well as heats of fusion and crystallization due to the great variety of TAGs content. Consequently, these oils melt over a temperature range and exhibit multiple endotherms (Tan and Che Man, 2002). Freezing or crystallization of the oils follows the same pattern. In a thermal analysis by a DSC, the melting and crystallization profile of samples exhibit multiple temperature values. They consist of onset $\left(\mathrm{T}_{\mathrm{o}}\right)$ and offset $\left(\mathrm{T}_{\mathrm{f}}\right)$ temperatures, given by the points where the endotherm/exotherm curves meet the baseline when extrapolated. Various peak temperatures, i.e., the temperature of maximum difference in heat flow between $T_{o}$ and $T_{f}$, are also determined. The temperature ranges of the melting and cooling profiles were determined by the difference between $T_{o}$ and $T_{f}$ (Tan and Che Man, 2000).

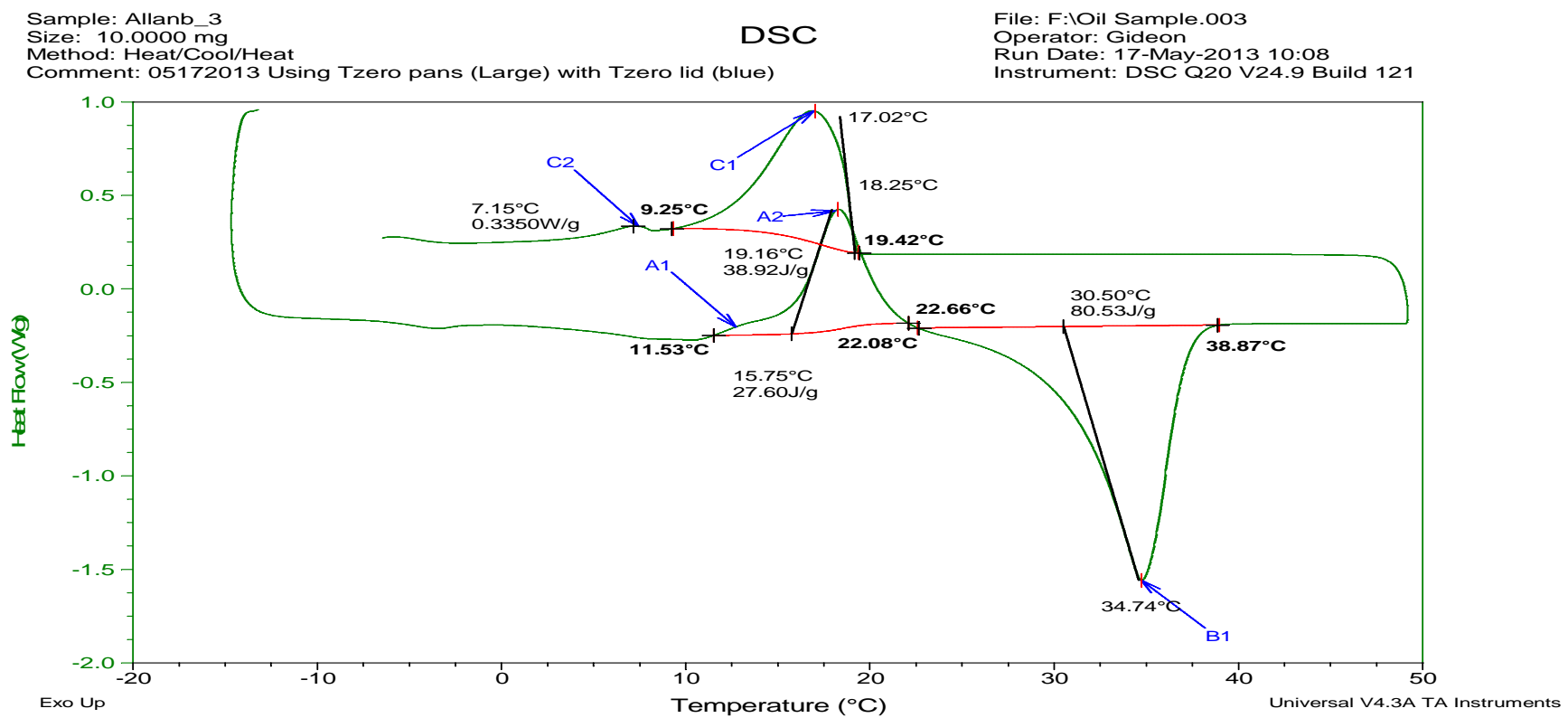

Fig. 4.2: The DSC curve of Allanblackia oil extract. 
The DSC curve of Allanblackia oil (Figure 4.2) exhibited an unusual pattern which indicates heat release (exothermic) in the heating cycle at almost the same temperature range where freezing of the oil occurs during the cooling cycle. This phenomenon occurs before the melting process starts. The exothermic heat of this process is $27.60 \mathrm{~J} / \mathrm{g}$ at a temperature of $18.25^{\circ} \mathrm{C}$ with an extrapolated temperature unto the baseline of $15.75^{\circ} \mathrm{C}$ (which is the onset temperature $\mathrm{T}_{\mathrm{o}}$ ). The full temperature range at which this occurs is $11.53-22.08^{\circ} \mathrm{C}$. After this initial release of heat, the oil then immediately undergoes a heat absorption resulting in the melting of the oil at a peak temperature of $34.74^{\circ} \mathrm{C}$ at $\mathrm{B}_{1}$. The heat absorbed in the process is $80.53 \mathrm{~J} / \mathrm{g}$ with an extrapolated temperature $\left(\mathrm{T}_{\mathrm{o}}\right)$ of $30.50^{\circ} \mathrm{C}$ and the temperature range is $22.66-38.87^{\circ} \mathrm{C}$. The initial release of heat or exothermic peak observed in the Allanblackia melting profile is due to the melting-recrystallization or re-organization of the original fat crystals (Zhang et al., 2013). Berger and Akehurst (1966) reported that oil and fats do not exhibit specific melting and crystallization temperatures but show melting/crystallization profiles. Natural or vegetable oils and fats undergo a process of polymorphism when melted. Polymorphism is a phenomenon whereby the same chemical substance exists in more than one crystalline form and it is strongly dependent on the thermal history of the oil or fat (Berger and Akehurst, 1966). Polymorphic forms can therefore undergo transition to other forms at different temperatures. Before the large peak from the reorganization effect, a small transition peak is seen as a shoulder peak to the larger melting-recrystallization peak observed at $A_{1}$ (Figure 4.2). This shoulder peak overlaps with the main peak at a temperature of $18.25^{\circ} \mathrm{C}$. After the melting process, the melted oil undergoes a cooling cycle where the temperature is gradually reduced. Approximately within the same temperature range where the earlier heat was released, freezing or crystallization of the oil occurs in the range of 19.42-9.25 ${ }^{\circ} \mathrm{C}$ resulting in a freezing peak temperature of $17.02^{\circ} \mathrm{C}$ at $\mathrm{C}_{1}$. When extrapolated from the peak, the onset temperature was $19.16^{\circ} \mathrm{C}$ and the heat released was $38.92 \mathrm{~J} / \mathrm{g}$. A small peak appears in the cooling cycle as a shoulder after the offset temperature of $7.15^{\circ} \mathrm{C}$ at $\mathrm{C}_{2}$. Both the melting and freezing peaks are sharp. The melting process indicates a difference between the melting temperature peak for the main endothermic curve and the onset temperature $T_{0}$, to be about $4^{\circ} \mathrm{C}$. Similarly, the difference between the freezing temperature peak and the onset temperature for the main exothermic curve is about $2^{\circ} \mathrm{C}$. Since the temperature difference between the onset temperature and its melting temperature and also the onset temperature and its freezing temperature are low, the heat absorbed and released respectively represent latent heat. 


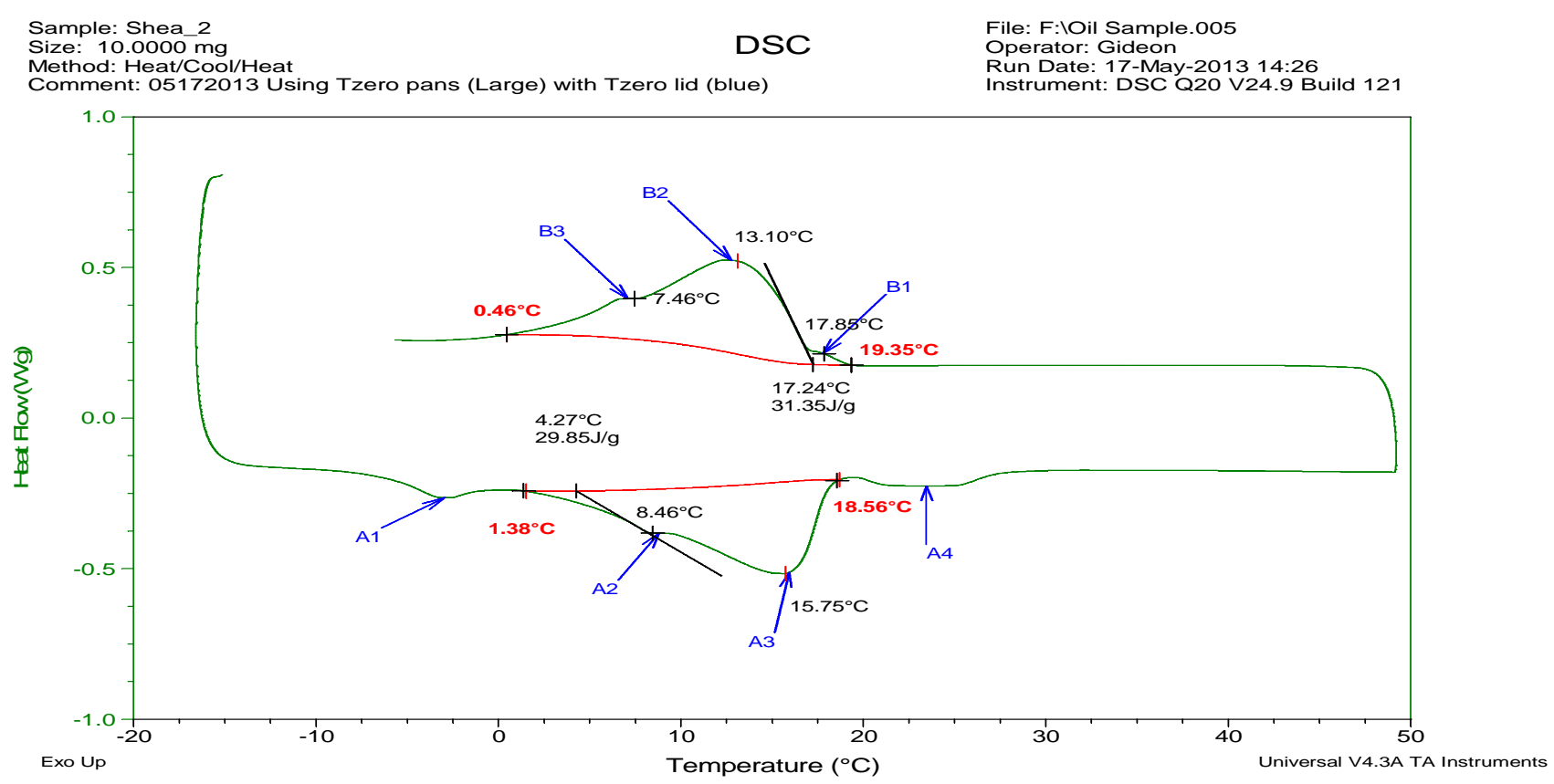

Fig. 4.3: The DSC curve of shea butter

The DSC curves of shea butter show that both the melting and freezing cycles exhibit a broad pattern (Figure 4.3). The curves also exhibit transition temperatures which are due to the polymorphic nature of the oils. There are four such transitional temperature peaks in the heating profile. The main melting peak $\left(\mathrm{A}_{3}\right)$ overlaps with one of the transitional peak $\left(\mathrm{A}_{2}\right)$. Two other transition peaks are separate small peaks $\left(\mathrm{A}_{1}\right.$ and $\left.\mathrm{A}_{4}\right)$ and they are not part of the main melting peak. The first transition peak $\left(A_{1}\right)$ occurs before the major peak starts. A broad transition peak at $\mathrm{A}_{4}$ again is observed after the offset temperature of the main endothermic curve. The onset temperature for the main curve in the heating process occurs at $4.27^{\circ} \mathrm{C}$ and is associated with a melting peak temperature of $15.75^{\circ} \mathrm{C}$. The temperature difference is therefore more than $11^{\circ} \mathrm{C}$ with an unresolved overlapping transitional peak appearing in the main peak. The heat absorbed in the process is $30.07 \mathrm{~J} / \mathrm{g}$, which is low compared to that of the Allanblackia oil and due to the nature of the curve, it is difficult to assign an absolute energy value for such a curve since it is spread over a large temperature range. This therefore cannot be described as latent heat energy. In the case of the freezing process, the energy obtained for the major peak is $29.23 \mathrm{~J} / \mathrm{g}$. There are three peaks involved with two of them being transitional temperature peaks (i.e. $\mathrm{B}_{1}$ and $\mathrm{B}_{3}$ ). The 2 peaks are small and overlap with the main peak. One transition peak appears before the main peak at $\mathrm{B}_{1}$, while the other after it at $\mathrm{B}_{3}$. The energy is lower than that exhibited by Allanblackia 
oil. Polymorphism effect also occurs for both melting and crystallization cycles. The onset temperature is $17.23^{\circ} \mathrm{C}$ and the freezing peak temperature is at $13.12^{\circ} \mathrm{C}$. The temperature difference between the onset temperature and the freezing peak temperature is about $4^{\circ} \mathrm{C}$ which is far lower than the difference in the melting cycle. For the freezing cycle of the shea butter, the difference between the onset temperature $\mathrm{T}_{\mathrm{o}}$ and the peak temperature is $4^{\circ} \mathrm{C}$, which is higher than that for the Allanblackia oil freezing cycle (about $2^{\circ} \mathrm{C}$ ). In this instance, the heat released is latent heat of crystallization even though the magnitude is low compared to the heat released by Allanblackia oil. Li and Ding (2007) prepared a PCM from butanediol di-stearate and obtained an enthalpy value of $181.97 \mathrm{~kJ} / \mathrm{kg}$ at a peak temperature of $51.81^{\circ} \mathrm{C}$ with an onset temperature of $41.80^{\circ} \mathrm{C}$. Comparing the difference between the onset temperature and peak temperature, they obtained a value of $10.01^{\circ} \mathrm{C}$ and this was still considered as latent heat energy. However, considering the crystallization range $19.35-0.46^{\circ} \mathrm{C}$ for shea butter, it is too high to be considered a latent heat. Also, the polymorphism effect is stronger than that of the Allanblackia oil.

The palm kernel oil DSC curve (Figure 4.4) shows a broad melting curve with the maximum melting point peak at $34.14^{\circ} \mathrm{C}$ for peak $\mathrm{A}_{2}$, and the onset temperature at $20.60^{\circ} \mathrm{C}$. The heat absorbed in the process is given by $94.12 \mathrm{~J} / \mathrm{g}$. The melting process exhibits a comparatively large difference of $13^{\circ} \mathrm{C}$ between the onset temperature and the melting peak. The melting enthalpy can therefore not be considered as latent heat since latent heat absorption should be at a constant temperature or the temperature variation should be very small, but the temperature range of 14.07 to $41.43^{\circ} \mathrm{C}$ is too high. Two overlapping transitional temperature peaks which occur at $\mathrm{A}_{1}$ and $\mathrm{A}_{3}$, are all within the major melting peak. In the cooling cycle however, a small shoulder peak occurs at $23.85^{\circ} \mathrm{C}$ just before freezing of the sample (Figure 4.4). The freezing of the sample is very sharp with onset temperature at $20.32^{\circ} \mathrm{C}$ and the freezing temperature at $16.10^{\circ} \mathrm{C}$.

The energy involved in this crystallization process is comparatively high $(95.55 \mathrm{~J} / \mathrm{g})$. In this sample, the endothermic (heating) cycle does not involve latent heat but the exothermic (freezing) cycle involves latent heat because the difference between the onset temperature and the freezing temperature is about $4^{\circ} \mathrm{C}$ even though there is an overlapping shoulder peak before the major peak. The shoulder peak makes the freezing process incongruent (Garg et al., 1985). The crystallization for this sample is simpler and more reproducible than the melting because 
crystallization is influenced only by the chemical composition while the melting is affected by the initial crystalline state of the oil (Tan and Che Man, 1999).

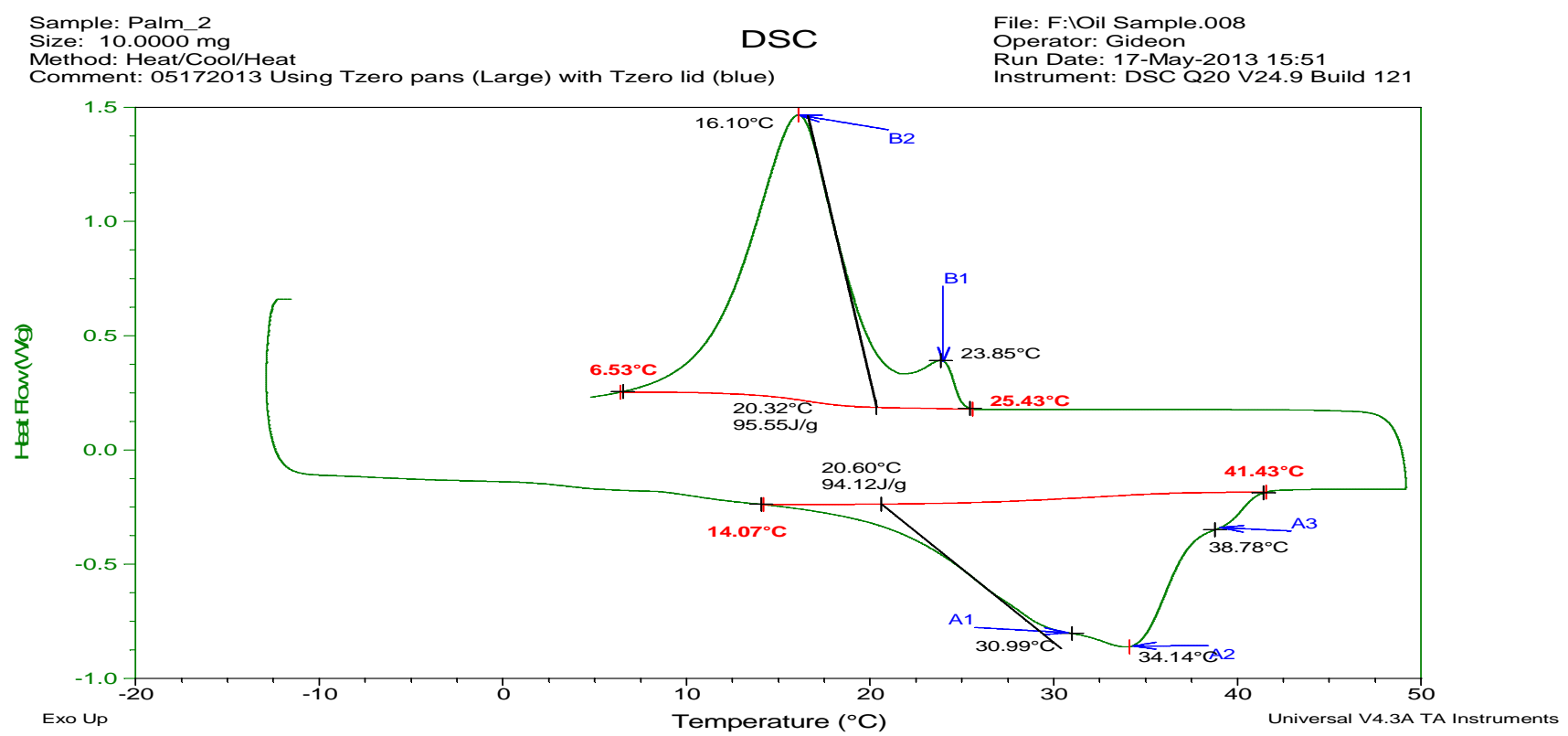

Fig. 4.4: The DSC curve of palm kernel oil

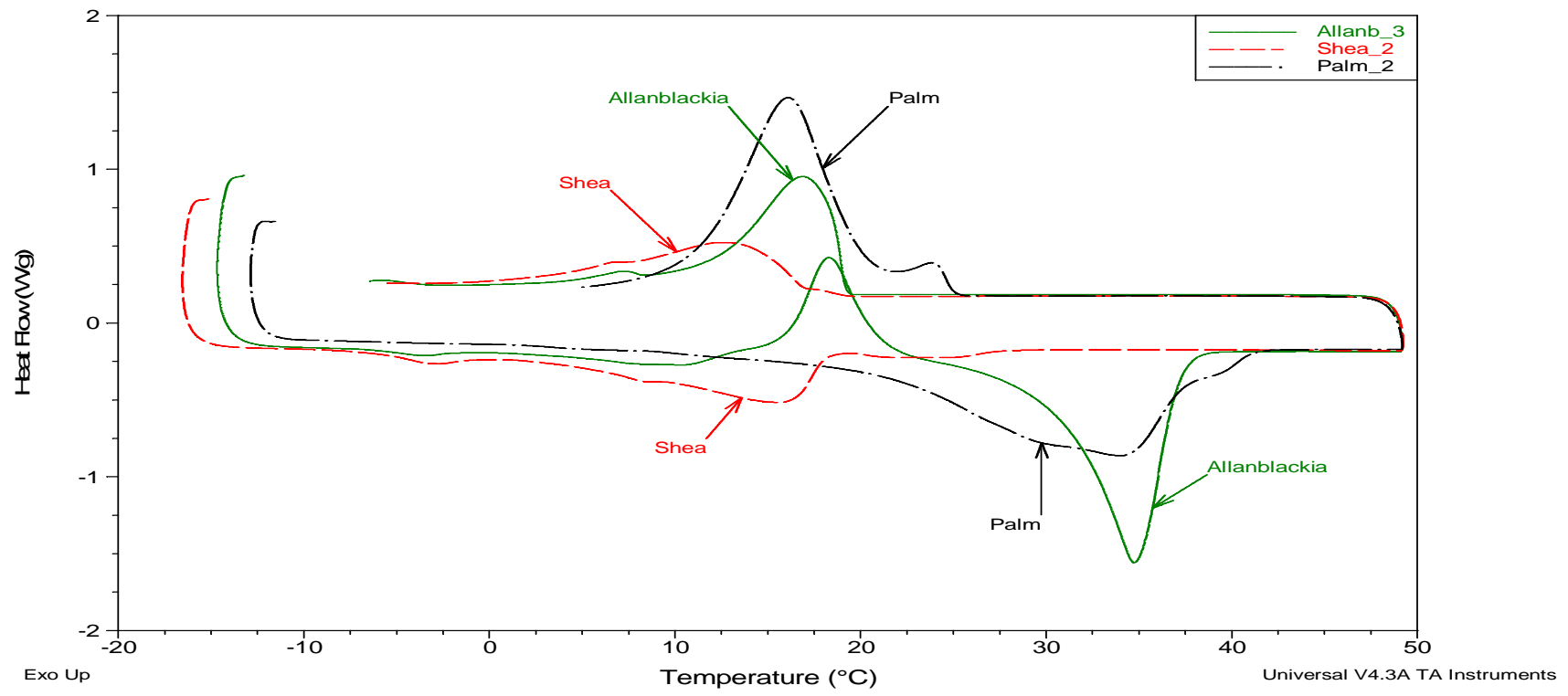

Fig. 4.5: The heating and cooling curves of Allanblackia oil, shea butter and palm kernel oil overlaid on each other. 
Comparing all the curves of the three oils, Allanblackia oil had both melting and the freezing cycles absorbing and releasing latent heats respectively as shown in Figures 4.2 and 4.5. The enthalpies of melting and freezing are high, but not as high as those for palm kernel oil. They are higher than those for shea butter. Even though the palm kernel oil had the highest enthalpy values, its melting enthalpy is not a latent heat because the heating curve is broad. Additionally, it is more polymorphic compared to that of the Allanblackia oil. Only the freezing enthalpy is a latent heat but the melting enthalpy cannot be considered as latent heat but rather sensible heat energy. The shea butter has all of the cycles exhibiting sensible heat instead of latent heat. Both the enthalpy of melting and freezing are not latent heats and the shape of the curve is broad. Shea butter has the lowest enthalpies of the three oils tested and has the lowest melting temperatures. Palm kernel oil has its freezing enthalpy value as the highest and also sharp and is a latent heat (Figures 4.4 and 4.5), but it exhibits a higher polymorphic effect resulting in an incongruent freezing (Garg et al., 1985), than the Allanblackia, whose major crystallization peak is nonpolymorphic. The melting enthalpy of palm kernel oil, even though is high, is too broad and cannot be considered latent heat as shown in Figures 4.4 and 4.5. It is also more polymorphic compared to that of Allanblakia oil.

Based on the thermal profile of the three oils produced by the DSC scans, Allanblackia oil exhibited the greatest potential for use as a PCM for latent energy storage. However, the Allanblackia oil thermal profile is not uniform since it releases energy due to re-organization of the bonds (Zhang et al., 2013), before absorbing energy for melting. Even though palm kernel oil has large enthalpies in both the melting and freezing cycles, it is only the freezing cycle that releases latent heat, while the melting cycle does not absorb latent heat but rather sensible heat because of it being more polymorphic.

\subsubsection{Thermo-gravimetric analysis (TGA) of oil samples}

Thermo-gravimetric analysis is a useful tool for measuring the thermal stability of a material. Thermal stability is an important parameter for determining the suitability of a material for use in thermal energy storage applications (Sari et al., 2011). The thermal stabilities of Allanblackia, shea butter and palm kernel oil, as investigated by TGA analysis are reported in Figures 4.6, 4.7, 4.8 and 4.9 . 
Allanblackia exhibits five different degradation steps (Figure 4.6). This observation confirms that the oil is a mixture of constituents with different chemical properties. The major component in the oil degrades at a temperature between $177.85^{\circ} \mathrm{C}$ and $345.26^{\circ} \mathrm{C}$ with a weight loss of $59.51 \%$. The second step exhibits a weight of $14.86 \%$ within a temperature range of 345.26 $401.11^{\circ} \mathrm{C}$. The third step is associated with a weight loss of $13.01 \%$, the fourth step loses weight of $9.69 \%$, and finally, the fifth step loses weight of $2.88 \%$. As earlier indicated by the DSC scans, Allanblackia oil is polymorphic like most vegetable oils. Therefore, it exhibits multiple chemical properties of its components and gives rise to multiple degradation temperatures in contrast to pure substances. Shea butter exhibits four different degradation steps (Figure 4.7) and the oil has multiple components and cannot be regarded as pure. This oil is polymorphic and it exhibits multiple degradation temperatures. In this oil, the major component degrades at a temperature range of $219.51-349.79^{\circ} \mathrm{C}$ with weight loss of $64.24 \%$. The next degradation occurs at 349.79 to $407.56^{\circ} \mathrm{C}$ with a weight loss of $12.36 \%$. The third degradation occurs with weight loss of $11.02 \%$ at $407.56-467.60^{\circ} \mathrm{C}$. The final degradation occurs at $467.60-549.16^{\circ} \mathrm{C}$ with a weight loss of $12.22 \%$.

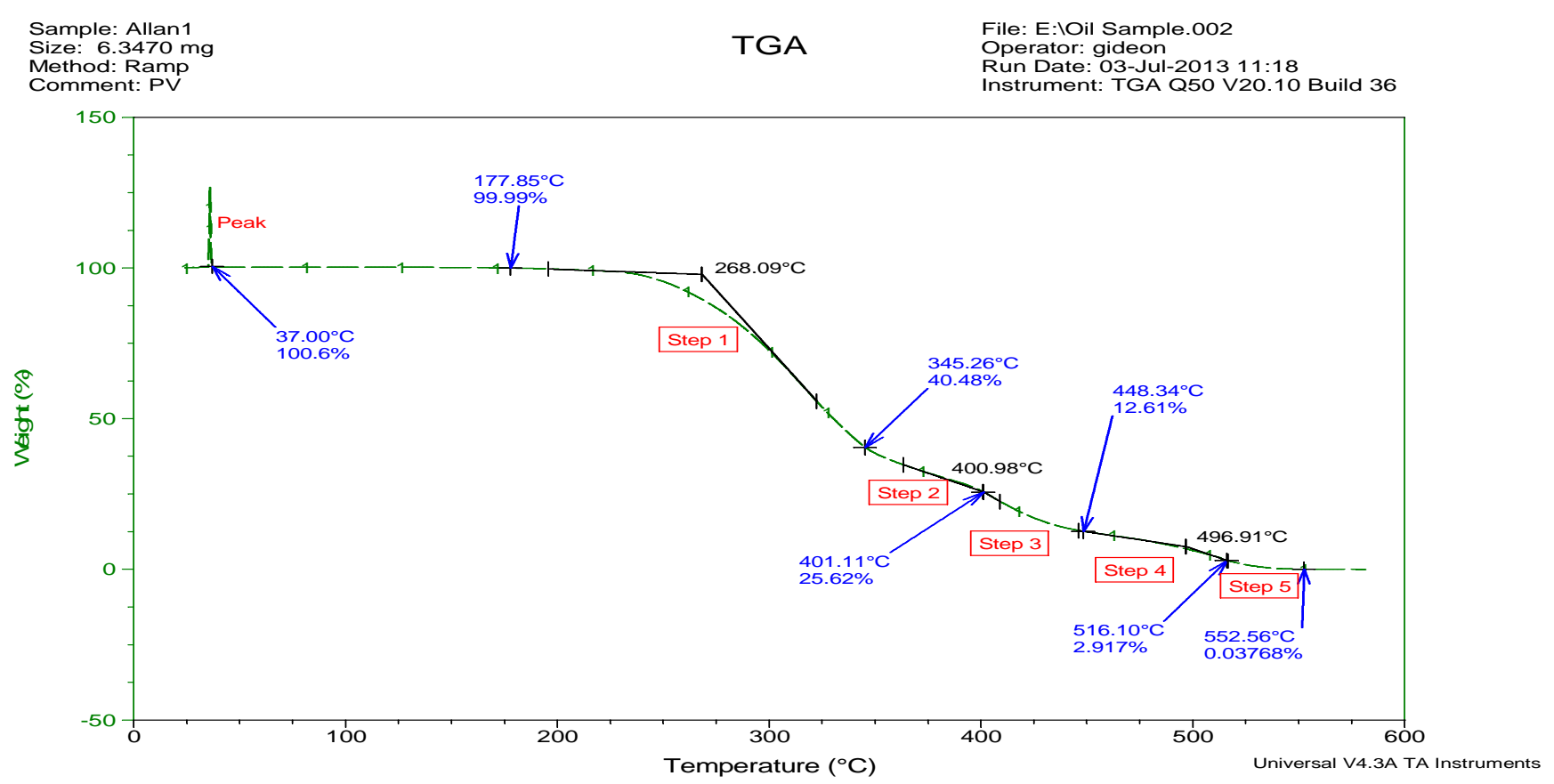

Fig. 4.6: The TGA curve of Allanblackia. 


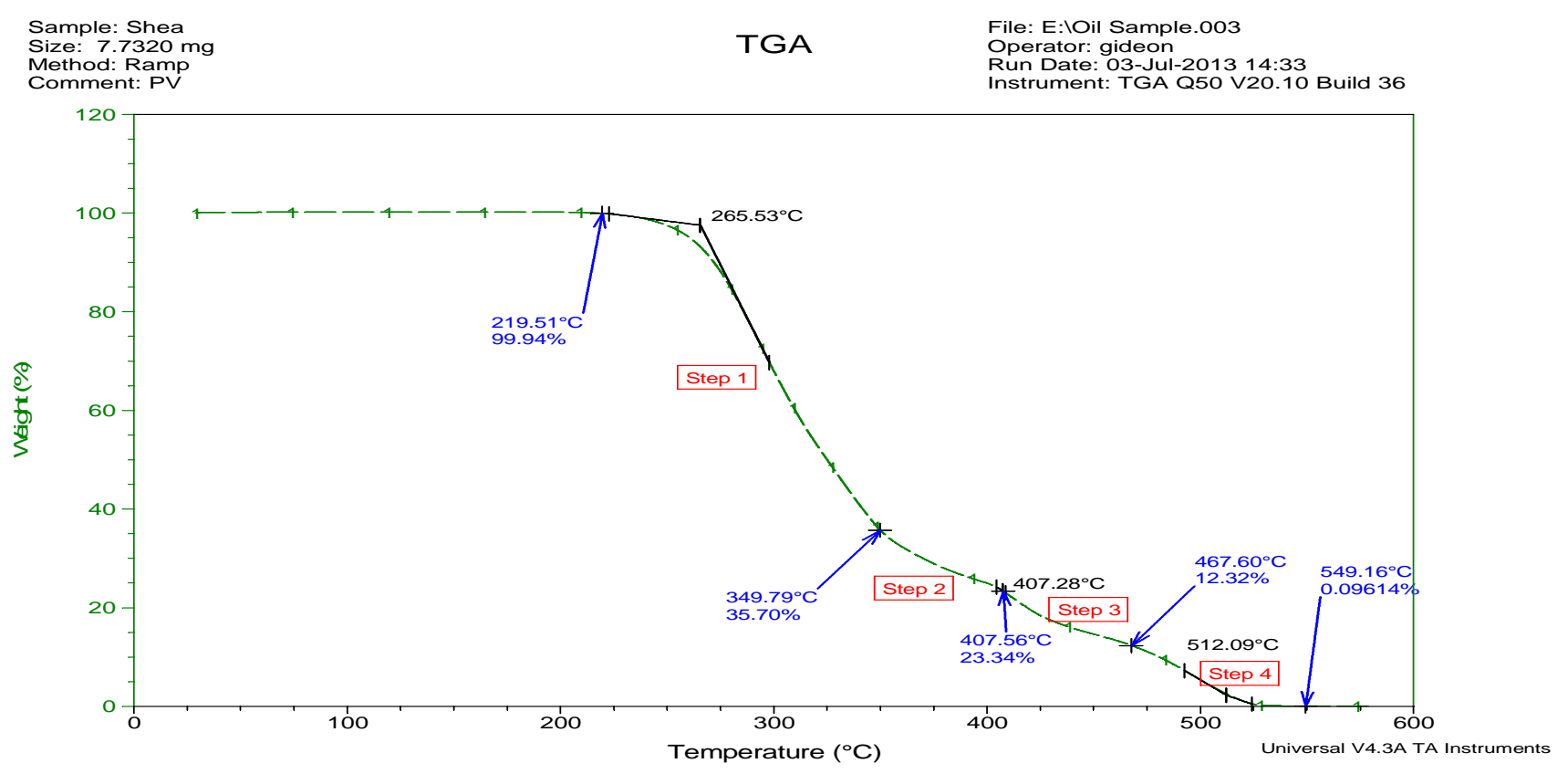

Fig. 4.7: The TGA curve of shea butter

The degradation of palm kernel oil is shown by the TGA thermogram (Figure 4.8). Thermal degradation of palm kernel oil has three levels. Palm kernel oil also exhibits polymorphic properties like the other vegetable oils. The first degradation of palm kernel oil occurs at 226.31 to $315.80^{\circ} \mathrm{C}$ with corresponding weight loss of $72.07 \%$. The second degradation of this oil occurs at 315.80 to $426.82^{\circ} \mathrm{C}$ with a weight loss of $21.77 \%$. The final degradation of this oil occurs at $426.82-533.30^{\circ} \mathrm{C}$ with a weight of $5.98 \%$. 


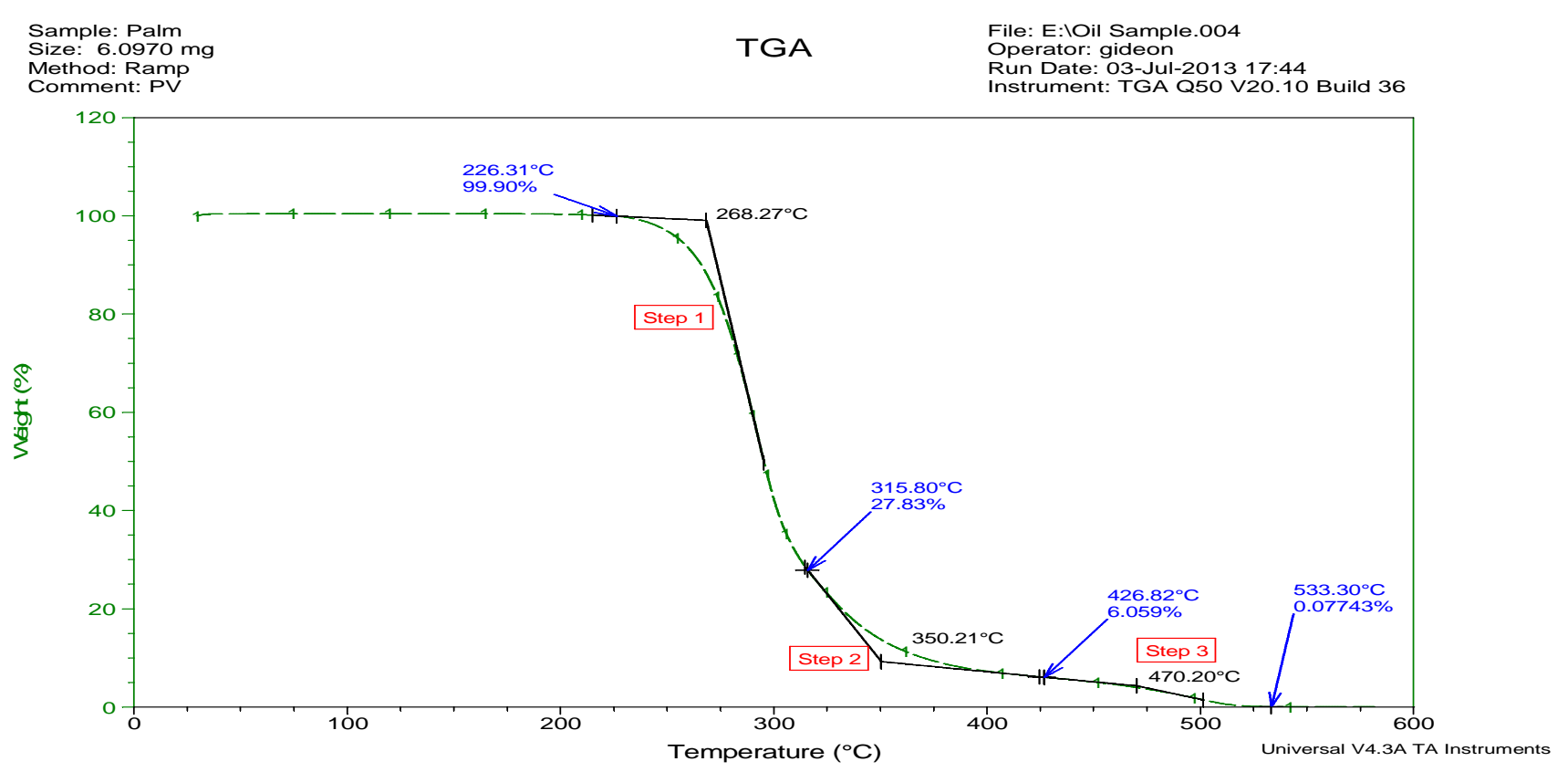

Fig. 4.8: The TGA curve of palm kernel oil.

When the TGA curves of the three oils are overlaid, degradation level 1 of shea butter is faster than that of Allanblackia. Also, the second degradation level of Allanblackia is a little faster than that of shea butter and this is confirmed by their respective weight loss values (Figure 4.6). The degradation at this stage between Allanblackia and shea butter is comparable (Figure 4.9). Palm kernel oil shows a much faster rate of degradation with higher weight percentage loss than both Allanblackia and shea butter in the first and second degradation levels with a total weight loss of 93.84\%. A peak observed for Allanblackia at approximately $37^{\circ} \mathrm{C}$ before degradation of the product may be due to the oxidative instability because it shows a weight gain of the sample (Zhou et al, 2001). This is a unique feature of Allanblackia as it is not exhibited by either shea butter or palm kernel oil. Edible oils (olive oil and milk fat) can take in oxygen during Thermogravimetric Analysis (TGA) with attendant increase in weight (due to oxidation) to show their oxidative instability (Van Aardt et al., 2004). Oils/fats are therefore not very stable at the temperatures where they gain weight during TGA. Shea butter and palm kernel oil did not exhibit any weight gain during melting and/or crystallization during TGA measurement. These oils therefore have oxidative stability within this temperature region. On the other hand, Allanblackia oil shows a sudden spike in peak around $37^{\circ} \mathrm{C}$ and this can be a slight weight gain. 
This may be ascribed to the effect of oxidative instability and/or re-organization of the chemical bonds (Zhang et al., 2013) before melting as described earlier.

Thus, there is no thermal degradation within the melting/crystallization temperature ranges of the oils. Consequently, within the melting/crystallization temperature ranges, all the oils are thermally stable and hence do not decompose or degrade at these temperature ranges, even though there is likelihood that Allanblackia oil may have a slight oxidative instability (Van Aardt et al., 2004) due to a slight weight gain due to the spike in the peak generated in the TGA cycle.

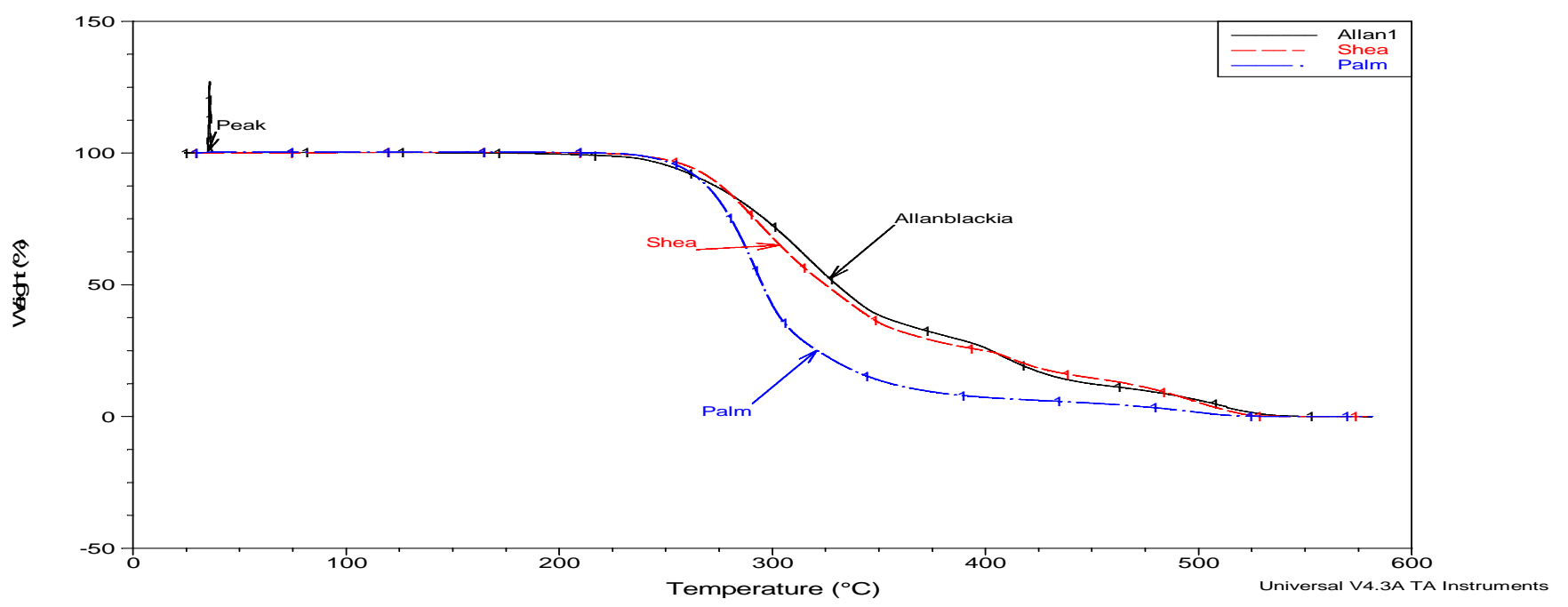

Fig. 4.9: Overlay of the TGA curves of Allanblackia, shea butter and palm kernel oil

\subsubsection{Fourier transform mid-infrared (FTIR) spectroscopy of the raw oil samples}

The FTIR spectra of Allanblackia oil (Table 4.2 and Figure 4.11) shows a medium shoulder peak at $3008 \mathrm{~cm}^{-1}$. This peak is attributed to a $\mathrm{C}-\mathrm{H}$ stretching vibration of cis-double bond $(=\mathrm{C})$. The very strong peaks observed at $2921 \mathrm{~cm}^{-1}$ and $2852 \mathrm{~cm}^{-1}$ are due to asymmetric and symmetric stretching vibrations of aliphatic $\mathrm{CH}_{2}$ groups respectively. The very strong single band at 1744 $\mathrm{cm}^{-1}$ is due to the stretching vibration of the ester carbonyl functional group of the triglyceride oil. The small shoulder peak observed at $1641 \mathrm{~cm}^{-1}$ is also due to the $\mathrm{C}=\mathrm{C}$ stretching vibration of cis olefins. The presence of the shoulder peak at $3008 \mathrm{~cm}^{-1}$ and also the small peak at $1641 \mathrm{~cm}^{-1}$ gives an indication that Allanblackia oil contains cis-olefenic carbons, and hence the oleic, 
linoleic and linolenic fatty acid groups may be present (Vlachos et al., 2006; Guillen and Cabo, 1997).

The sharp medium size peak at $1465 \mathrm{~cm}^{-1}$ is due to the bending (scissoring) vibrations of the $\mathrm{CH}_{2}$ and $\mathrm{CH}_{3}$ aliphatic groups. The weak shoulder band at $1421 \mathrm{~cm}^{-1}$ is attributed to the bending (rocking) vibration of the cis $(=\mathrm{C}-\mathrm{H})$ group. The medium sharp $1377 \mathrm{~cm}^{-1}$ peak is due to the bending vibrations of $\mathrm{CH}_{3}$ groups, while the medium size peak at $1240 \mathrm{~cm}^{-1}$ and the strong peak at $1159 \mathrm{~cm}^{-1}$ are due to the stretching vibrations of the C-O bond of the ester group as well as the bending vibration of the $-\mathrm{CH}_{2}$ group. The various observed peaks at $1116 \mathrm{~cm}^{-1}, 1097 \mathrm{~cm}^{-1}$ and $1026 \mathrm{~cm}^{-1}$, are all due to the presence of the $\mathrm{C}-\mathrm{O}$ stretching bond in the triglyceride of the Allanblackia.

Table 4.2: FTIR spectra of oil samples

\begin{tabular}{|c|c|c|c|}
\hline Sample & Allanblackia & Shea Butter & Palm Kernel Oil \\
\hline Peaks Observed $/ \mathrm{cm}^{-1}$ & $\begin{array}{l}\text { 3008, 2921, 2852, } \\
\text { 1744, 1465, 1421, } \\
\text { 1377, 1260, 1240, } \\
\text { 1159, 1116, 1097, } \\
\mathbf{1 0 2 6 , 8 6 6 , 8 0 3 , 7 2 1}\end{array}$ & $\begin{array}{l}3008,2922,2853, \\
1744,1641,1465, \\
1421,1377,1240, \\
1161,1117,1103, \\
877,721\end{array}$ & $\begin{array}{l}\text { 2953, 2921, 2852, } \\
\text { 1742, 1466, 1421, } \\
\text { 1377, 1229, 1155, } \\
\mathbf{1 1 1 1 , 9 6 5 , 8 8 8 , 7 2 1}\end{array}$ \\
\hline
\end{tabular}

The peak at $721 \mathrm{~cm}^{-1}$ is due to the overlapping of the $\mathrm{CH}_{2}$ rocking vibration and the out-of-plane vibrations of the cis-di-substituted olefins. The absence of a broad band beyond the $3000 \mathrm{~cm}^{-1}$ region indicates the absence of - $\mathrm{OH}$ group in the structure of Allanblackia oil (Guillen and Cabo, 1997; Vlachos et al., 2006; Rothman and Che Man, 2010). The spectra and peaks observed in shea butter are shown in Table 4.2 and figures 4.10-4.13. As observed in the spectra of Allanblackia, the shoulder peak at $3008 \mathrm{~cm}^{-1}$ is due to olefinic $\mathrm{C}-\mathrm{H}$ stretching vibration. The major peaks at $2922 \mathrm{~cm}^{-1}$ and $2853 \mathrm{~cm}^{-1}$ are again due to asymmetric and symmetric $\mathrm{CH}_{2}$ stretching vibrations respectively. Again the very strong sharp $\mathrm{C}=\mathrm{O}$ ester carbonyl peak is observed at $1744 \mathrm{~cm}^{-1}$, while a sharper small shoulder peak is observed at $1641 \mathrm{~cm}^{-1}$ for the $\mathrm{C}=\mathrm{C}$ stretching vibration of the cis-olefin. The presence of the double bond is indicative of the presence of oleic, linoleic or linolenic acid groups in shea butter too. The $1465 \mathrm{~cm}^{-1}$ peak is ascribed to the bending (scissoring) vibrations of the $\mathrm{CH}_{2}$ and $\mathrm{CH}_{3}$ aliphatic groups. Shea butter 
also shows a weak shoulder peak at $1421 \mathrm{~cm}^{-1}$ due to the bending (rocking) vibration of the cis olefinic group, while the peak at $1377 \mathrm{~cm}^{-1}$ is due to bending vibration of the $\mathrm{CH}_{3}$ group. Also, shea butter shows a shoulder peak at $1240 \mathrm{~cm}^{-1}$ and a major peak at $1161 \mathrm{~cm}^{-1}$. These are due to the stretching vibrations of the $\mathrm{C}-\mathrm{O}$ ester bond. The observed peaks at $1117 \mathrm{~cm}^{-1}, 1103 \mathrm{~cm}^{-1}$, are all due to the presence of the $\mathrm{C}-\mathrm{O}$ stretching bond in the triglyceride of the shea butter. $\mathrm{No}-\mathrm{OH}$ group is again observed beyond $3008 \mathrm{~cm}^{-1}$ for the shea butter just like the Allanblackia. However, the $721 \mathrm{~cm}^{-1}$ overlapping $\mathrm{CH}_{2}$ rocking vibration and the out of plane vibration of the cis-di-substituted olefins are observed. The FTIR spectra of palm kernel oil (Table 4.2 and Figures 4.10-4.13) shows no shoulder peak at the $3008 \mathrm{~cm}^{-1}$ position as compared to the spectra of the other two oils. This is due to the absence of the cis olefinic $\mathrm{C}-\mathrm{H}$ stretching vibration bond $(=\mathrm{C}-\mathrm{H})$. The asymmetric and symmetric stretching vibrations of the aliphatic $\mathrm{CH}_{2}$ group are present at $2921 \mathrm{~cm}^{-1}$ and $2852 \mathrm{~cm}^{-1}$ as in the other oil samples.

There is however a small unresolved peak at $2953 \mathrm{~cm}^{-1}$, and this is due to an asymmetric vibration of the aliphatic $\mathrm{CH}_{3}$ group. The single strong carbonyl ester peak occurs at $1742 \mathrm{~cm}^{-1}$, a little lower in wave number shift to that of Allanblackia and shea butter $\left(1744 \mathrm{~cm}^{-1}\right)$. A small peak at $1641 \mathrm{~cm}^{-1}$ for Allanblackia is more intense in shea butter and absent in palm kernel oil. This peak is attributed to olefinic $\mathrm{C}=\mathrm{C}$. The peak at $1466 \mathrm{~cm}^{-1}$ is due to the bending vibrations of the $\mathrm{CH}_{2}$ and $\mathrm{CH}_{3}$ aliphatic groups. The peaks at $1421 \mathrm{~cm}^{-1}$ and $1377 \mathrm{~cm}^{-1}$ are all similar to that in the other oils. The peak seen at $1240 \mathrm{~cm}^{-1}$ for both Allanblackia and shea butter due to stretching vibrations of the C-O ester group is shifted to $1229 \mathrm{~cm}^{-1}$ in palm kernel oil. Similarly, the C-O ester vibration peak at $1155 \mathrm{~cm}^{-1}$ is prominent for palm kernel oil and occurs at higher wavenumbers in Allanblackia $\left(1159 \mathrm{~cm}^{-1}\right)$ and shea butter $\left(1161 \mathrm{~cm}^{-1)}\right.$ respectively. A double peak observed by both Allanblackia $\left(1116 \mathrm{~cm}^{-1}, 1097 \mathrm{~cm}^{-1}\right)$ and shea butter $\left(1117 \mathrm{~cm}^{-1}, 1103 \mathrm{~cm}^{-}\right.$ ${ }^{1}$ ) occurs as a single peak for palm kernel oil at $1111 \mathrm{~cm}^{-1}$. These peaks are ascribed to C-O stretching vibrations. There are other peaks observed at $965 \mathrm{~cm}^{-1}$ and $888 \mathrm{~cm}^{-1}$ (these are due to $-\mathrm{HC}=\mathrm{CH}$-trans out of plane bending vibration). The peak at $721 \mathrm{~cm}^{-1}$ is due to the overlapping of the $\mathrm{CH}_{2}$ rocking vibration (Rothman and Che Man, 2010; Jahangirian et al., 2011). 


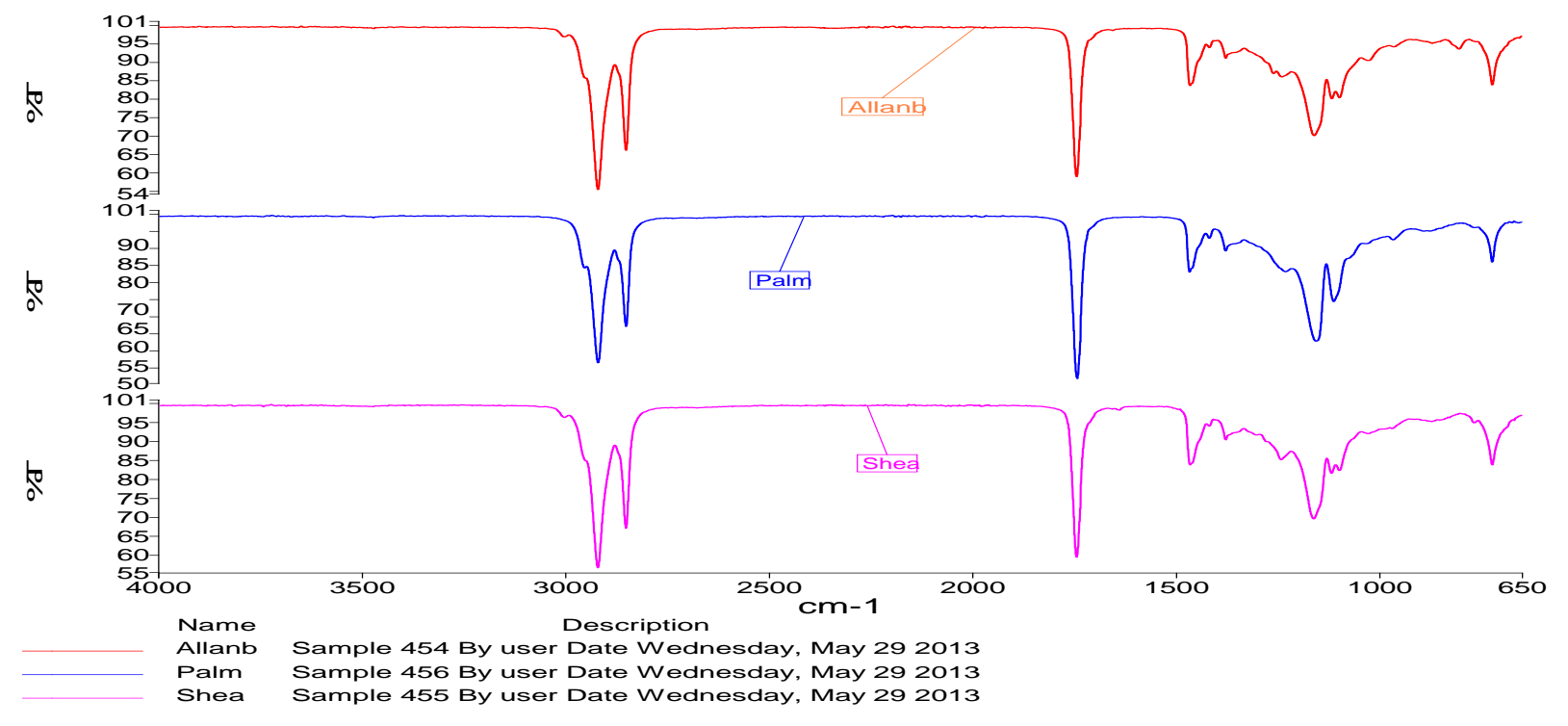

Fig. 4.10: The split spectra of Allanblackia, palm kernel oil and shea butter

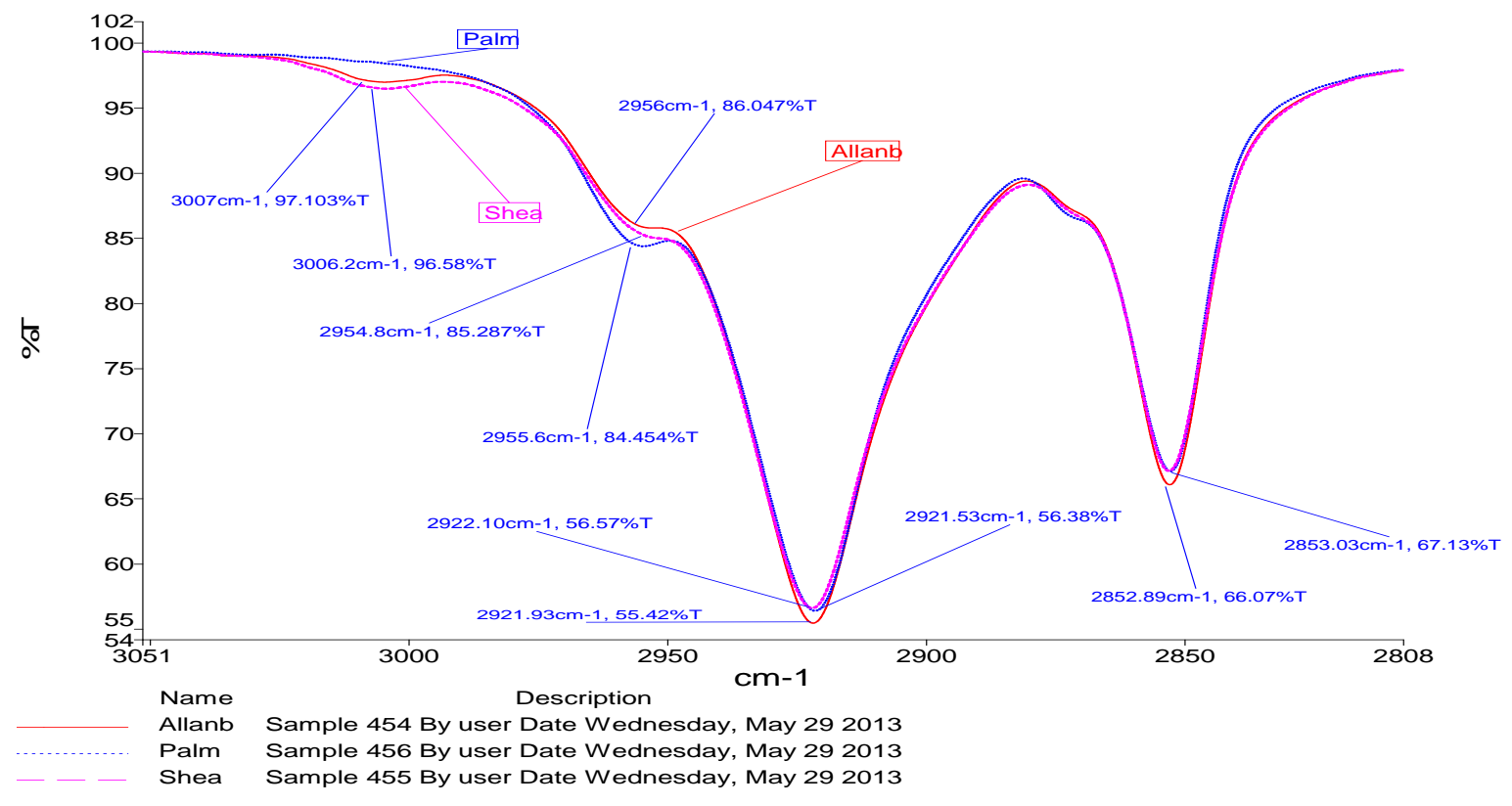

Fig. 4.11: FTIR spectra of oils within the region $2800 \mathrm{~cm}^{-1}$ and $3051 \mathrm{~cm}^{-1}$ 


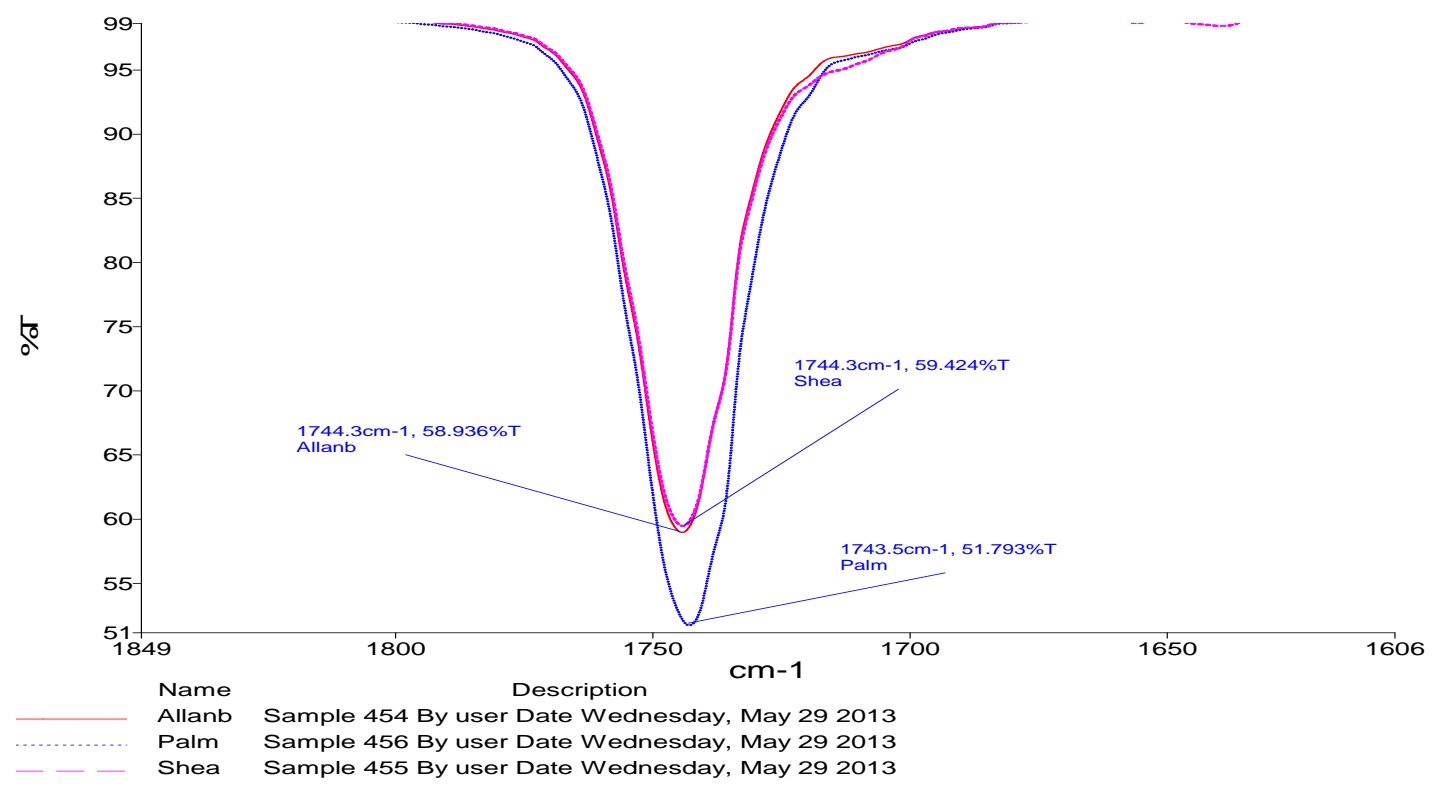

Fig.4.12: FTIR spectra of oils around $1743 \mathrm{~cm}^{-1}$

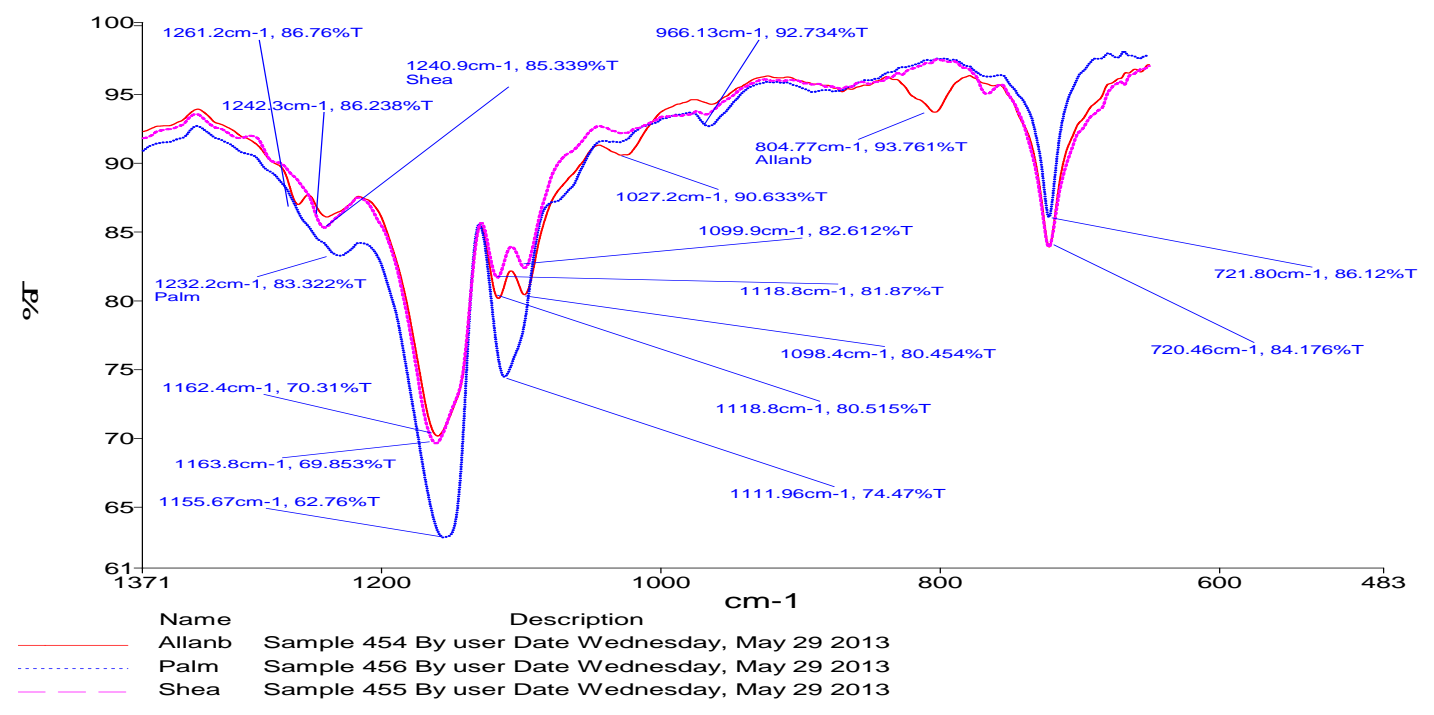

Fig. 4.13: FTIR spectra of oils in the $700-1371 \mathrm{~cm}^{-1}$ region

The absence of peaks around 3004-3008 $\mathrm{cm}^{-1}$ and $1640-1641 \mathrm{~cm}^{-1}$ in palm kernel oil confirms the absence of cis-olefinic double bonds in palm kernel oil. Even though a small peak is observed around $2954 \mathrm{~cm}^{-1}$ for all the oils, palm kernel oil spectra protrudes more than that of Allanblackia and shea butter (Figure 4.11) and is due to an asymmetric vibration shoulder of the aliphatic $\mathrm{CH}_{3}$ group. Again, the absence of the double bond effect may have helped in increasing 
the intensity of the peak for the palm kernel oil. Palm kernel oil peaks at around $1111 \mathrm{~cm}^{-1}, 1155$ $\mathrm{cm}^{-1}$ and $1743 \mathrm{~cm}^{-1}$ (Figures 4.12 and 4.13), all have higher intensities than that for Allanblackia and shea butter.

Table 4.3: Fatty acid characteristics of Allanblackia oil, shea butter and palm kernel oil.

\begin{tabular}{|c|c|c|c|c|c|c|c|c|}
\hline $\begin{array}{l}\text { Fatty Acid } \\
(\%)\end{array}$ & $\begin{array}{l}\text { Arachid } \\
\text { ic Acid } \\
\text { (C20:0) }\end{array}$ & $\begin{array}{l}\text { Steari } \\
\text { c Acid } \\
\text { (C18: } \\
\text { 0) }\end{array}$ & $\begin{array}{l}\text { Oleic } \\
\text { Acid } \\
\text { (C18: } \\
\text { 1) }\end{array}$ & $\begin{array}{l}\text { Linolei } \\
\text { c Acid } \\
\text { (C18:2) }\end{array}$ & $\begin{array}{l}\text { Linoleni } \\
\text { c Acid } \\
\text { (C18:3) }\end{array}$ & $\begin{array}{l}\text { Palmiti } \\
\text { c Acid } \\
\text { (C16:0) }\end{array}$ & $\begin{array}{l}\text { Myristi } \\
\text { c Acid } \\
\text { (C14:0) }\end{array}$ & $\begin{array}{l}\text { Lauri } \\
\text { c Acid } \\
\text { (C12: } \\
\text { 0) }\end{array}$ \\
\hline $\begin{array}{l}\text { Allanblackia } \\
\text { Oil }^{1}\end{array}$ & $<1$ & $45-58$ & $40-51$ & $<1$ & $<1$ & $<2$ & $<1$ & $<1$ \\
\hline Shea Butter ${ }^{2}$ & $<1$ & $20-50$ & $40-60$ & $3-11$ & $<1$ & $2-9$ & $<1$ & $<1$ \\
\hline $\begin{array}{l}\text { Palm Kernel } \\
\text { Oil }^{3}\end{array}$ & $<1$ & $1-3$ & $10-23$ & $<1$ & $<1$ & $7-11$ & $14-20$ & $41-55$ \\
\hline
\end{tabular}

${ }^{1}$ EFSA (2007); ${ }^{2}$ Davrieux et al., 2010; ${ }^{3}$ Adubofour et al., 2013

Table 4.3 gives the fatty acid profile of the oils used in the study. The fatty acids present in the oils and their combinations will greatly affect the melting and crystallization profile of the oil and hence their use as PCMs for energy storage. Allanblackia oil and shea butter have the major fatty acids present in them as stearic and oleic acids. Allanblackia oil seems to have a lot more of stearic acid (45-58\%) than shea butter (20-50\%) while their oleic acid contents are comparable with Allanblackia having a value of 40-51\% and shea butter with 40-60\%. Shea butter melting characteristics will be dully impacted by the presence of linoleic acid, which is unsaturated and has a value of $3-11 \%$ while Allanblackia has less than 1\% linoleic acid. Again, the palmitic acid (which is a saturated fatty acid with a lower molecular weight than stearic acid and oleic acid) content of shea butter is higher (2-9\%) than that of Allanblackia oil $(<2 \%)$. Palm kernel oil has lauric acid as the major fatty acid present in the oil with appreciable amounts of oleic acid (10$23 \%$ ), myristic acid (14-20\%) and palmitic acid (7-11\%) present in it. 


\subsubsection{Thermo-physical and chemical characteristics of oils after Thermal Cycling 4.2.5.1 The DSC spectra of oils after Thermal Cycling}

All the samples were thermally cycled a thousand (1000) times to determine their thermal reliability as well as their chemical stability. Using their DSC values, changes in their enthalpy values and the shape of the curves were determined. From Table 4.4 and Figure 4.14, changes in the DSC spectra of Allanblackia after thermal cycling for a thousand times are observed. The recrystallization peak observed for the oil before the melting of the oil is eliminated after thermal cycling. A small endothermic peak is however observed before the major melting peak. The enthalpy value before thermal cycling was $80.53 \mathrm{~J} / \mathrm{g}$ while that after thermal cycling, was reduced to $66.81 \mathrm{~J} / \mathrm{g}$, i.e., a reduction of $13.72 \mathrm{~J} / \mathrm{g}$. This is consistent with the work of Sharma et al. $(1998 ; 1999 ; 2002)$ who reported that stearic acids melt over a wide range of temperature because they are impure (Zalba et al., 2003). At the same time, the onset temperature increased from $30.50^{\circ} \mathrm{C}$ in the oil before thermal cycling to a value of $32.77^{\circ} \mathrm{C}$ for the oil after thermal cycling. There was also a shift in the peaks toward a higher temperature for the thermally cycled oil to $37.37^{\circ} \mathrm{C}$, while that before thermal cycling was $34.74^{\circ} \mathrm{C}$. Figure 13 also shows that the shape of the exothermic curve did not change much, however, enthalpy values dropped for the thermally cycled Allanblackia oil ( $31.83 \mathrm{~J} / \mathrm{g}$ ) from the original value of $38.92 \mathrm{~J} / \mathrm{g}$. This was shown by Sharma and Sagara (2005) for impure organic compound stearic acid.

Shea butter subjected to thermal cycling also gave some changes in the enthalpy values and the shape of the curves. A broad peak was observed in a range of $-2.03^{\circ} \mathrm{C}$ and $15.64^{\circ} \mathrm{C}$. This was absent or appears as a very small peak in the original sample. The endothermic heat for the major peak in the thermally cycled shea butter increased to $41.56 \mathrm{~J} / \mathrm{g}$ from the value of $29.85 \mathrm{~J} / \mathrm{g}$. Again, this peak is considered to be broad due to the difference in the onset and peak temperature of $7.19^{\circ} \mathrm{C}$, and hence cannot be considered as latent energy. The crystallization curve did not indicate much change in shape even though there was a large difference in enthalpy values. Before thermal cycling, the enthalpy value for the major peak was $31.35 \mathrm{~J} / \mathrm{g}$, and after thermal cycling it increased to $48.21 \mathrm{~J} / \mathrm{g}$. The temperature range was high and hence the peak is broad and again not suitable for latent heat considerations. 
Table 4.4: Table showing the DSC profile of the oil samples before and after Thermally Cycling

\begin{tabular}{|c|c|c|c|c|c|c|}
\hline Sample & $\begin{array}{l}\text { Temp } \\
\text { Range } /{ }^{\circ} \mathrm{C}\end{array}$ & $\begin{array}{l}\text { Onset } \\
\text { Temp } /{ }^{\circ} \mathrm{C}\end{array}$ & $\begin{array}{l}\text { Peak } \\
\text { Temp/ } /{ }^{\circ} \mathrm{C}\end{array}$ & Enthalpy/J/g & Process & $\begin{array}{l}\text { State of } \\
\text { Sample }\end{array}$ \\
\hline \multirow[t]{3}{*}{ Allanblackia } & $11.53-22.08$ & 15.75 & 18.25 & 27.60 & $\begin{array}{l}\mathrm{Re}- \\
\text { crystallization } \\
\text { before melting }\end{array}$ & \multirow{7}{*}{ 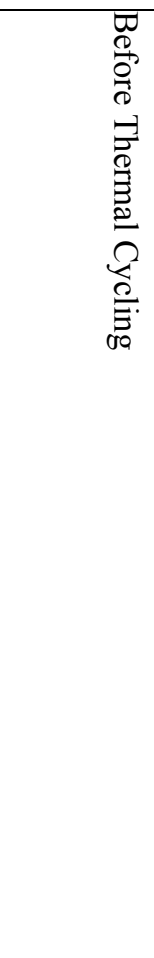 } \\
\hline & $22.66-38.87$ & 30.50 & 34.74 & 80.53 & Melting & \\
\hline & $19.42-9.25$ & 19.16 & $\begin{array}{l}17.02 \\
7.15\end{array}$ & 38.92 & Crystallization & \\
\hline \multirow[t]{2}{*}{ Shea Butter } & $1.38-18.56$ & 4.27 & $\begin{array}{l}15.75 \\
8.46^{\mathrm{a}}\end{array}$ & 29.85 & Melting & \\
\hline & $19.35-0.46$ & 17.24 & $\begin{array}{l}13.10 \\
17.85^{\mathrm{b}} \\
7.46^{\mathrm{c}}\end{array}$ & 31.35 & Crystallization & \\
\hline \multirow[t]{2}{*}{$\begin{array}{l}\text { Palm Kernel } \\
\text { Oil }\end{array}$} & $14.07-41.43$ & 20.60 & $\begin{array}{l}34.14 \\
30.99^{\mathrm{d}} \\
38.78^{\mathrm{e}}\end{array}$ & 94.12 & Melting & \\
\hline & $25.43-6.53$ & 20.32 & $\begin{array}{l}16.10 \\
23.85^{\mathrm{f}}\end{array}$ & 95.55 & Crystallization & \\
\hline & - & - & 22.33 & - & Pre-melting & \multirow{10}{*}{ 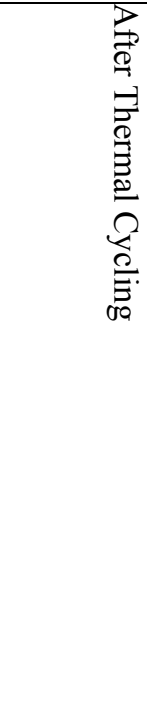 } \\
\hline Аाгапртаска & $26.56-42.99$ & 32.77 & 37.37 & 66.81 & Melting & \\
\hline & $19.00-8.39$ & 19.00 & 16.59 & 31.83 & Crystallization & \\
\hline \multirow{4}{*}{$\begin{array}{l}\text { TC Shea } \\
\text { Butter }\end{array}$} & $(-2.03)-15.64$ & -1.46 & 8.40 & 20.71 & Melting & \\
\hline & $25.89-40.07$ & 28.06 & 35.25 & 41.56 & Melting & \\
\hline & $20.87-(-3.12)$ & 16.26 & 12.64 & 48.21 & Crystallization & \\
\hline & $20.87-16.26$ & - & 18.04 & - & Shoulder Peak & \\
\hline \multirow{3}{*}{$\begin{array}{l}\text { TC Palm } \\
\text { Kernel Oil }\end{array}$} & $27.87-41.56$ & 34.73 & 37.18 & 21.56 & Melting & \\
\hline & $26.44-8.22$ & 19.92 & 16.46 & 35.35 & Crystallization & \\
\hline & $26.44-19.92$ & - & 23.80 & $0.3586 \mathrm{~W} / \mathrm{g}$ & Shoulder Peak & \\
\hline
\end{tabular}

Superscripts: a, b, c, d, e, f are transition peaks that overlap or are apart from the main peaks. 


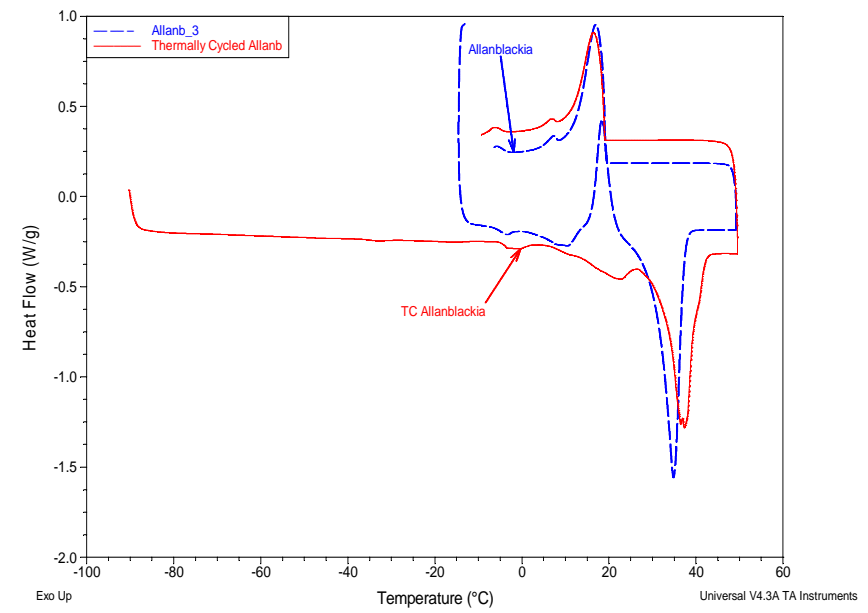

Fig. 4.14: Overlay curve of Allanblackia before and after Thermal Cycling.

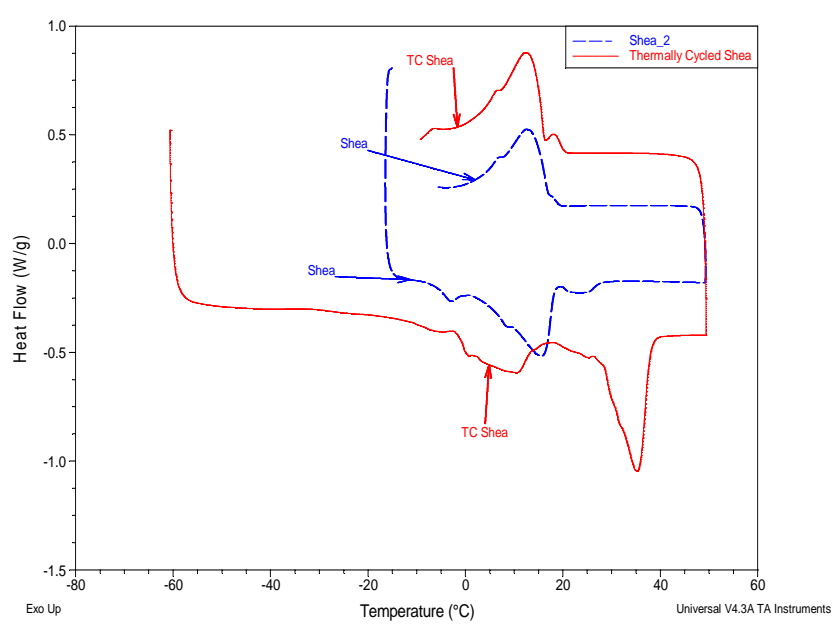

Fig. 4.15: The overlay curve of shea butter before and after Thermal Cycling.

From the curves in Figure 3.16, as well as Tables 4.4, the melting curve for palm kernel oil had a drop in enthalpy value after thermal cycling and it is still not a latent energy. The crystallization curve which was a latent heat before thermal cycling exhibited a drastic drop in enthalpy from $95.55 \mathrm{~J} / \mathrm{g}$ in the sample before thermal cycling to a value of $35.35 \mathrm{~J} / \mathrm{g}$ for the thermally cycled palm kernel oil. Such a large drop in enthalpy value is indicative of the fact that palm kernel oil is thermally unreliable.

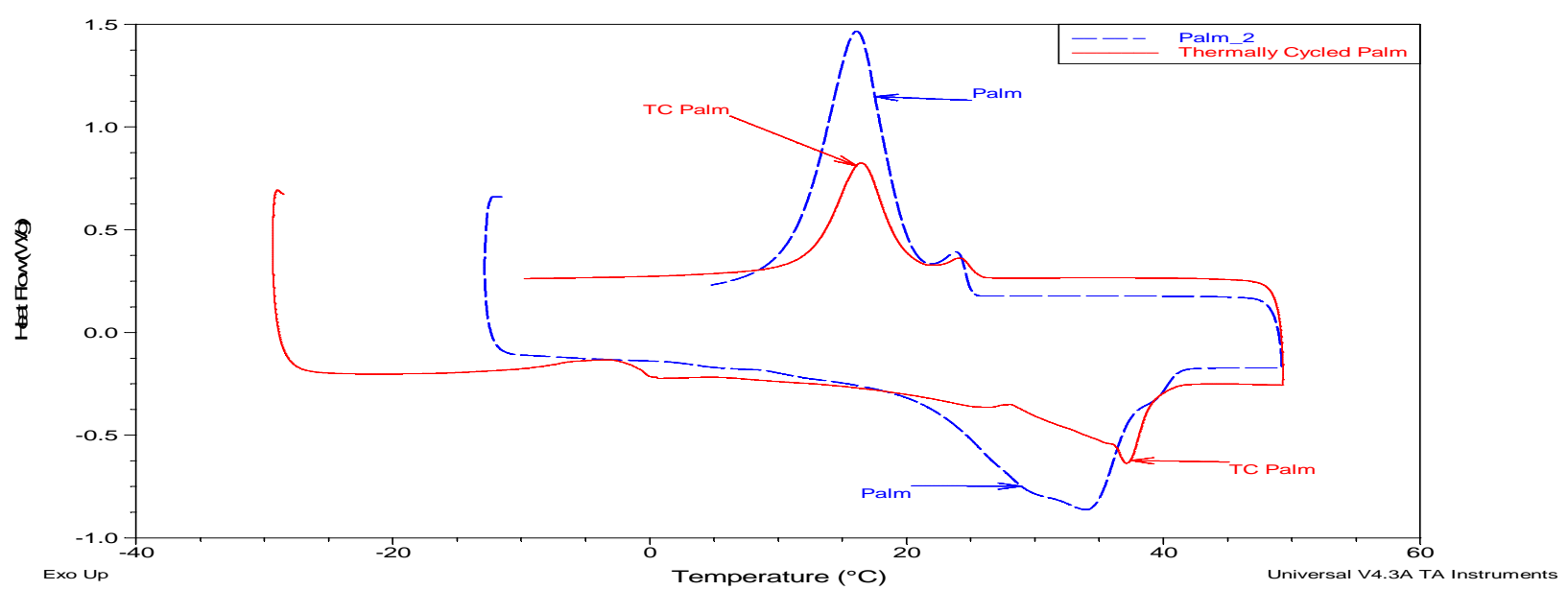

Fig. 4.16: Overlay DSC curve of palm kernel oil before cycling and after Thermal Cycling. 


\subsubsection{The TGA spectra of oils after Thermal Cycling}

Table 4.5: TGA profile of the oil samples before and after Thermally Cycling

\begin{tabular}{|c|c|c|c|c|}
\hline Sample & Degradation Interval $/{ }^{\circ} \mathrm{C}$ & Step & Weight Loss/ \% & $\begin{array}{l}\text { State of } \\
\text { Sample }\end{array}$ \\
\hline \multirow[t]{5}{*}{ Allanblackia } & $177.85-345.26$ & Step 1 & 59.51 & \multirow{12}{*}{ 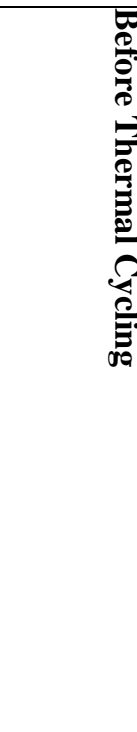 } \\
\hline & $345.26-401.11$ & Step 2 & 14.86 & \\
\hline & $401.11-448.34$ & Step 3 & 13.01 & \\
\hline & $448.34-516.10$ & Step 4 & 9.69 & \\
\hline & $516.10-552.56$ & Step 5 & 2.88 & \\
\hline \multirow[t]{4}{*}{ Shea Butter } & 219.51-349.79 & Step 1 & 64.24 & \\
\hline & $349.79-407.56$ & Step 2 & 12.36 & \\
\hline & $407.56-467.60$ & Step 3 & 11.02 & \\
\hline & $467.60-549.16$ & Step 4 & 12.22 & \\
\hline \multirow[t]{3}{*}{ Palm Kernel Oil } & $226.31-315.80$ & Step 1 & 72.07 & \\
\hline & $315.80-426.82$ & Step 2 & 21.77 & \\
\hline & $426.82-533.30$ & Step 3 & 5.98 & \\
\hline \multirow[t]{4}{*}{ TC Allanblackia } & $200.00-367.03$ & Step 1 & 72.71 & \multirow{11}{*}{ בి } \\
\hline & $367.03-417.79$ & Step 2 & 8.24 & \\
\hline & $417.79-499.63$ & Step 3 & 10.21 & \\
\hline & $499.63-537.13$ & Step 4 & 8.19 & \\
\hline \multirow[t]{4}{*}{ TC Shea Butter } & $220.00-355.73$ & Step 1 & 67.03 & \\
\hline & $355.73-426.06$ & Step 2 & 13.52 & \\
\hline & $426.06-496.99$ & Step 3 & 8.47 & \\
\hline & $496.99-537.79$ & Step 4 & 11.51 & \\
\hline \multirow[t]{3}{*}{ TC Palm Kernel Oil } & $225.00-330.33$ & Step 1 & 70.20 & \\
\hline & $330.33-476.42$ & Step 2 & 25.99 & \\
\hline & $476.42-526.64$ & Step 3 & 4.37 & \\
\hline
\end{tabular}

After thermally cycling the oil samples for a thousand times and taking their TGA spectra, it was shown that Allanblackia had a change in the TGA curve of its thermally cycled oil, which was a little different from the original oil sample. From a temperature of around $180-200^{\circ} \mathrm{C}$, all the samples began to lose weight. Allanblackia showed a change in its TGA thermogram. The original oil sample exhibited five steps in its degradation while the Thermally Cycled oil gave 4 
steps. From Table 4.5 and Figure 4.17, there was a drastic change in the degradation of the first step for Allanblackia oil. The original oil lost 59.51\% of its weight in its first step, whereas in the thermally cycled oil sample, the first step lost $72.71 \%$. It seemed that the first and second steps in the original Allanblackia oil sample, was degraded as just step 1 in the thermally cycled Allanblackia sample. In the case of shea butter, the change in shape after thermal cycling was not much as indicated in Table 4.5 and Figure 4.17, where the same 4-step degradation was seen in the thermally cycled sample. Palm kernel oil changed the least in all the samples. It maintained its shape for the original sample as the thermally cycled sample. Even though there were degradation of the samples accompanying the increase in temperature of the samples during the thermal cycling process, it can be seen that within the temperature of interest (i. e., the temperature at which the samples change phase), there were no weight losses. This means that, the samples did not degrade at the temperature of melting/crystallization, which is the region of concern or interest.

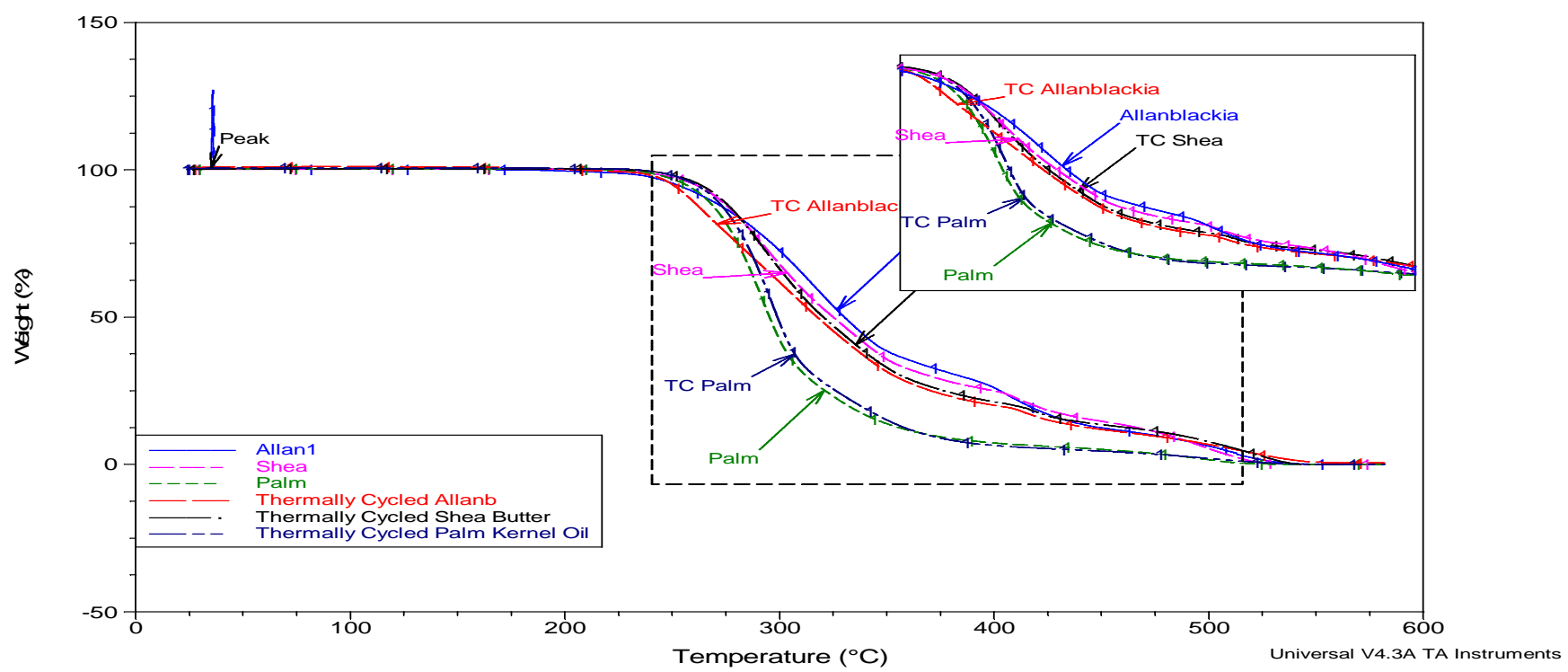

Fig. 4.17: The overlay curve of all the samples shown before and after thermal cycling.

It is therefore evident that at the region of interest, there was no degradation or weight loss of the samples. Even at higher temperatures, the TGA profile changed slightly. All the samples are therefore thermally stable within the desired temperature region of interest. 


\subsubsection{Functional chemistry of oil samples after Thermal Cycling}

Figures 4.18, 4.19 and 4.20 show the FTIR spectra of the oil samples of Allanblackia, shea butter and palm kernel oil which have been combined with their thermally cycled spectra respectively. Both the combined spectra of shea butter and palm kernel oil did not show any changes in their spectra after thermal cycling for 1000 times. This is an indication of their chemical stability. In the case of Allanblackia however, even though the peaks were the same, the intensities of the peaks for the thermally cycled oil within the range of 1404 and $758 \mathrm{~cm}^{-1}$, were reduced. The peaks did not disappear, but were reduced after thermal cycling (Figure 4.18). The affected peaks in Allanblackia are shown at $1261 \mathrm{~cm}^{-1}, 1116 \mathrm{~cm}^{-1}, 1098 \mathrm{~cm}^{-1}, 1023 \mathrm{~cm}^{-1}$ and $803-804 \mathrm{~cm}^{-1}$.

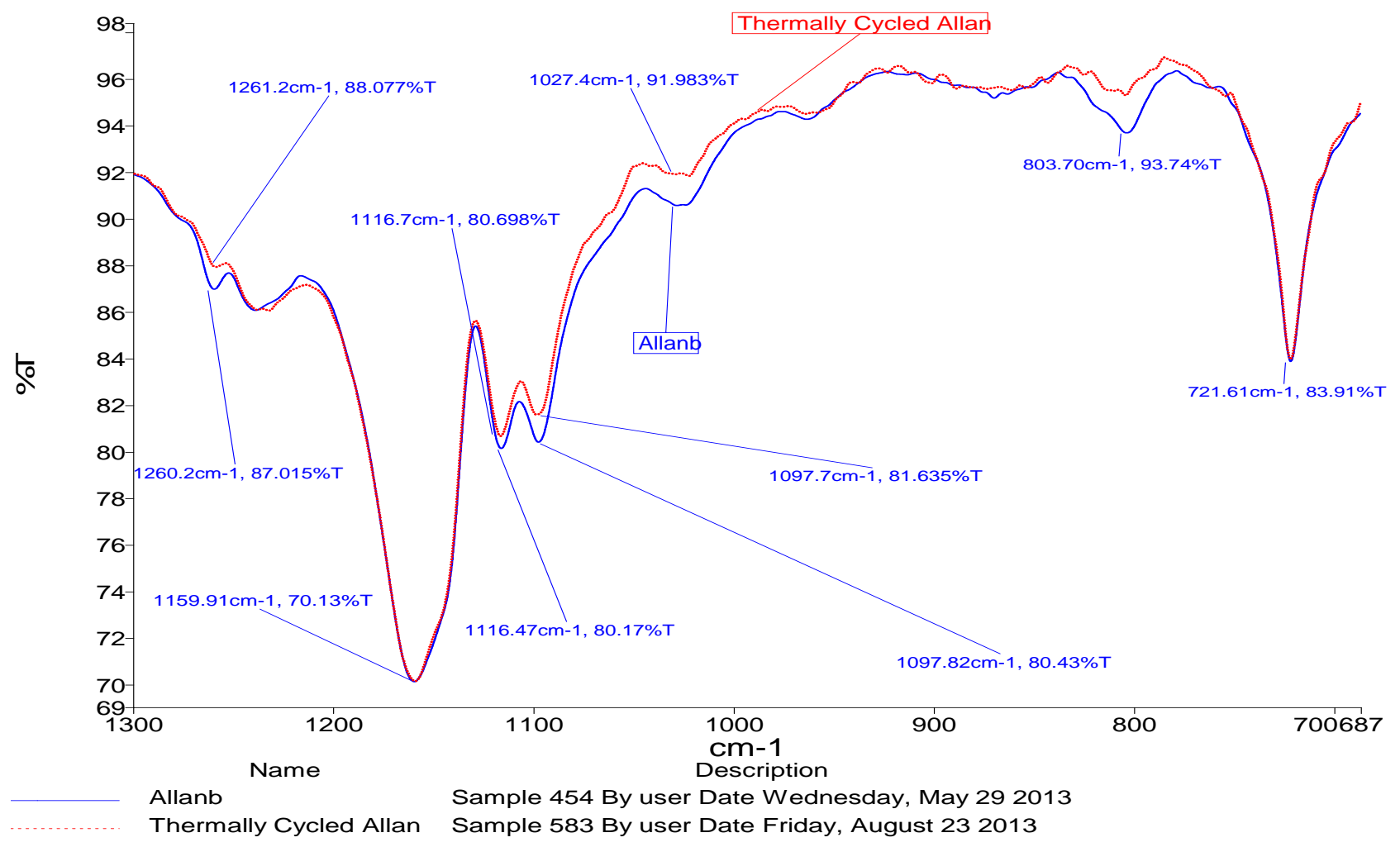

Fig. 4.18: The combined spectra of Allanblackia oil and thermally cycled Allanblackia oil within $1300-687 \mathrm{~cm}^{-1}$ region

The peaks at $1116 \mathrm{~cm}^{-1}, 1098 \mathrm{~cm}^{-1}$ and $1023 \mathrm{~cm}^{-1}$ are all due to the $\mathrm{C}-\mathrm{O}$ ester bond in the triglyceride. Since all the bonds were present but their intensities were reduced, the samples have not been degraded, but rather it seems the bond strength has been affected. Chemical stability 
may be a little affected due to the decrease in intensity of the peak, but not the disappearance of the peaks. However, the continued presence of this bonds despite the reduction in its intensity (since there was no disintegration of the sample, and the shape of the FTIR peaks did not disappear but just reduce), show that the Allanblackia sample is chemically stable but has a slight oxidative instability (Zhou et al., 2001; Van Aardt et al., 2004).

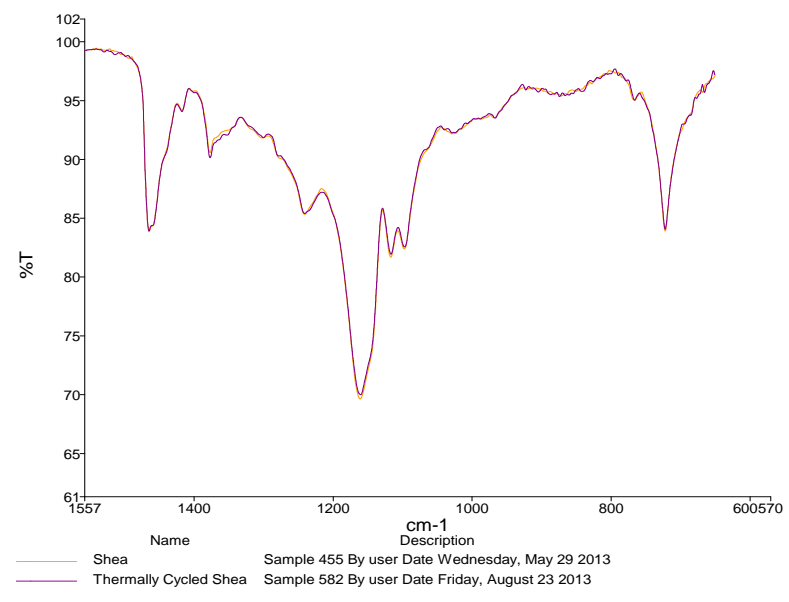

Fig. 4.19: The spectra of shea butter and thermally cycled shea butter within $1557-600 \mathrm{~cm}^{-1}$.

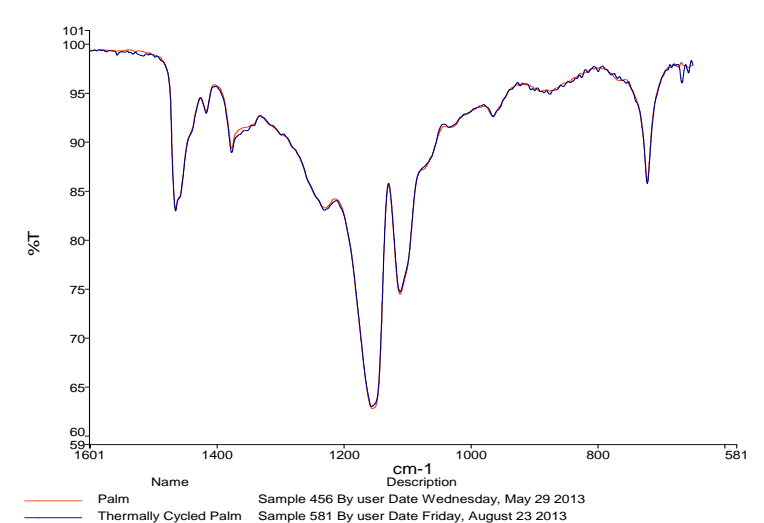

Fig. 4.20: The palm kernel and thermally cycled palm kernel oil within $1601-581 \mathrm{~cm}^{-1}$

\subsection{Conclusion}

The fruit oils of the three tropical trees, Allanblackia (Allanblackia parviflora), shea butter (Vitellaria paradoxa) and palm kernel oil from the palm nut fruit (Elaeis guineensis) were evaluated for potential use as phase change materials (PCM) for thermal energy storage. Their physical and chemical properties were characterized using differential scanning calorimetry (DSC), thermogravimetric analysis (TGA) and infrared spectroscopy (FTIR). The method of TGA was used to determine the thermal stability of these oils. These are also consistent with our results for all the oils. Shea butter and palm kernel oils melt and/or crystallize over too wide a range of temperatures making then non latent enthalpies, exhibit polymorphism and therefore cannot be considered as candidates for PCMs. In contrast, Allanblackia oil exhibits melting and freezing cycles that are indicative of latent heats notwithstanding the decrease in latent heat after 1000 thermal cycles. The sudden increase in weight around the $37^{\circ} \mathrm{C}$ point shown by TGA scans 
of Allanblackia can be ascribed to a slight oxidative instability. There was no degradation of Allanblackia oil within the desired temperature range (which is the melting/freezing temperature regions) and confirms its thermal stability in this temperature range. There was also a slight decrease in the FTIR peaks at $1260 \mathrm{~cm}^{-1}, 1116 \mathrm{~cm}^{-1}, 1097 \mathrm{~cm}^{-1}, 1023 \mathrm{~cm}^{-1}$ and $803 \mathrm{~cm}^{-1}$ (Figure 4.18) which are attributed to $\mathrm{C}-\mathrm{O}$ bonds in the triglyceride. Of all the samples considered, Allanblackia oil has the potential for use as a PCM for latent energy storage. To increase oxidative stability, there is the need to further modify and or process the oil to see if there can be improvement in their properties for use as PCMs for thermal energy storage.

\subsection{References}

Abbiw, D.K., and others (1990). Useful plants of Ghana: West African uses of wild and cultivated plants. (Intermediate Technology Publications and the Royal Botanic Gardens).

Adubofuor, J., Sefah, W., and Oldham, J.H. (2013). Nutrient composition of Allanblackia Paviflora seed kernels and oil compared with some plant fats and oils and application of the oil in soap preparation. Journal of Cereals and Oil Seeds Vol 4, 1-9.

Berea, G. P. 2006. Thermal energy storage systems - stearic/lauric acid mixtures as phase change materials. 3.014 Materials laboratory Module -1. 9pp.

Berger, K.G., and Akehurst, E.E. (1966). Some applications of differential thermal analysis to oils and fats. International Journal of Food Science \& Technology 1, 237-247.

Cedeño, F.O., Prieto, M.M., Espina, A., and García, J.R. (2001). Measurements of temperature and melting heat of some pure fatty acids and their binary and ternary mixtures by differential scanning calorimetry. Thermochimica Acta 369, 39-50.

Chaudhari, V.N., Rathod, M.K., and Chaudhari, K.A. (2013). Stearic Acid as Phase Change Material: Thermal Reliability Test and Compatibility with some Construction Materials. In International Journal of Engineering Research and Technology, (ESRSA Publications),

Chong, C.L., and Siew, W.L. (1994). Chemical and physical properties of palm kernel oil. In Proceedings of the World Conference on Lauric Oils: Sources. Processing and Applications, pp. 79-83.

Chou, K. J. Y. 2008. Phase change materials for energy efficient housing applications. MSE 395. $\mathrm{M}^{\mathrm{c} C o r m i c k}$ Northwestern Engineering.

Davrieux, F., Allal, F., Piombo, G., Kelly, B., Okulo, J.B., Thiam, M., Diallo, O.B., and Bouvet, J.-M. (2010). Near infrared spectroscopy for high-throughput characterization of shea tree (Vitellaria paradoxa) nut fat profiles. Journal of Agricultural and Food Chemistry 58, 78117819 . 
Dimaano, M.N.R., and Watanabe, T. (2002). Performance investigation of the capric and lauric acid mixture as latent heat energy storage for a cooling system. Solar Energy 72, 205-215.

Dincer, I., and Rosen, M. (2002). Thermal energy storage: systems and applications (John Wiley \& Sons).

http://en.wikipedia.org/wiki/Latent heat. Accessed 4/2/2015.

Farid, M.M., Khudhair, A.M., Razack, S.A.K., and Al-Hallaj, S. (2004). A review on phase change energy storage: materials and applications. Energy Conversion and Management 45, $1597-1615$.

Feldman, D., Banu, D., and Hawes, D. (1995). Low chain esters of stearic acid as phase change materials for thermal energy storage in buildings. Solar Energy Materials and Solar Cells 36, $311-322$.

Garcia-Ayuso, L.E., and De Castro, M.L. (1999). A multivariate study of the performance of a microwave-assisted Soxhlet extractor for olive seeds. Analytica Chimica Acta 382, 309-316.

Garg, H.P., Mullick, S.C., and Bhargava, A.K. (1985). Solar thermal energy storage (Springer Science \& Business Media).

Guillén, M.D., and Cabo, N. (1997). Infrared spectroscopy in the study of edible oils and fats. Journal of the Science of Food and Agriculture 75, 1-11.

Hasan, A., and Sayigh, A.A. (1994). Some fatty acids as phase-change thermal energy storage materials. Renewable Energy 4, 69-76.

Hermann, M. (2009). The impact of the European Novel Food Regulation on trade and food innovation based on traditional plant foods from developing countries. Food Policy 34, 499-507.

http://www.superglossary.com/Definition/Chemistry/Eutectic_Mixture.html. Accessed $\underline{03 / 10 / 2013}$.

Jahangirian, H., Haron, M.J., Yusof, N.A., Silong, S., Kassim, A., Rafiee-Moghaddam, R., Peyda, M., and Gharayebi, Y. (2011). Enzymatic synthesis of fatty hydroxamic acid derivatives based on palm kernel oil. Molecules 16, 6634-6644.

Li, W.-D., and Ding, E.-Y. (2007). Preparation and characterization of a novel solid-liquid PCM: Butanediol di-stearate. Materials Letters 61, 1526-1528.

Louppe, D. (2008). Plant Resources of Tropical Africa: Timbers/ed.: D. Louppe; AA OtengAmoako. General ed.: RHMJ Lemmens.... 7. 1 (PROTA).

Mukherjee, S., Mitra, A., and others (2009). Health effects of palm oil. J Hum Ecol 26, 197-203.

Okullo, J.B.L., Omujal, F., Agea, J.G., Vuzi, P.C., Namutebi, A., Okello, J.B.A., and Nyanzi, S.A. (2010). Physico-Chemical characteristics of shea butter (Vitellaria paradoxa CF Gaertn.) oil 
from the Shea district of Uganda. African Journal of Food, Agriculture, Nutrition and Development 10.

Rohman, A., and Che Man, Y. (2010). FTIR spectroscopy combined with chemometrics for analysis of lard in the mixtures with body fats of lamb, cow, and chicken. International Food Research Journal 17, 519-526.

RPT 223 - Food and Drug Administration, 2004. http://www.fda.gov/

Sarı, A., Biçer, A., Lafçı, Ö., and Ceylan, M. (2011). Galactitol hexa stearate and galactitol hexa palmitate as novel solid-liquid phase change materials for thermal energy storage. Solar Energy 85, 2061-2071.

Sharma, A., Sharma, S.D., and Buddhi, D. (2002). Accelerated thermal cycle test of acetamide, stearic acid and paraffin wax for solar thermal latent heat storage applications. Energy Conversion and Management 43, 1923-1930.

Sharma, S.D., and Sagara, K. (2005). Latent heat storage materials and systems: a review. International Journal of Green Energy 2, 1-56.

Sharma, S.D., Buddhi, D., and Sawhney, R.L. (1998). Accelerated thermal cycle tests of industrial grade phase change materials. In Proc. National Solar Energy Convention-97: Towards Commercialization of Clean Energy. Chennai. India. Anna University, pp. 73-77.

Sharma, S.D., Buddhi, D., and Sawhney, R.L. (1999). Accelerated thermal cycle test of latent heat-storage materials. Solar Energy 66, 483-490.

Tan, C.P., and Man, Y.C. (1999). Quantitative differential scanning calorimetric analysis for determining total polar compounds in heated oils. Journal of the American Oil Chemists' Society 76, 1047-1057.

Tan, C.P., and Man, Y.C. (2000). Differential scanning calorimetric analysis of edible oils: comparison of thermal properties and chemical composition. Journal of the American Oil Chemists' Society 77, 143-155.

Tan, C.P., and Man, Y.B. (2002). Comparative differential scanning calorimetric analysis of vegetable oils: I. Effects of heating rate variation. Phytochemical Analysis 13, 129-141.

Tetens, I. (2007). Opinion of the Scientific Panel on Dietetic Products, Nutrition and Allergies on a request from the Commission related to the safety of Allanblackia seed oil for use in yellow fat and cream based spreads: Request $N^{\circ}$ EFSA-Q-2007-059 (European Food Safety Authority).

Van Aardt, M., Duncan, S.E., Long, T.E., O'Keefe, S.F., Marcy, J.E., and Sims, S.R. (2004). Effect of antioxidants on oxidative stability of edible fats and oils: thermogravimetric analysis. Journal of Agricultural and Food Chemistry 52, 587-591. 
Vlachos, N., Skopelitis, Y., Psaroudaki, M., Konstantinidou, V., Chatzilazarou, A., and Tegou, E. (2006). Applications of Fourier transform-infrared spectroscopy to edible oils. Analytica Chimica Acta 573, 459-465.

Wilfred, S., Adubofuor, J., and Oldham, J.H. (2010). Optimum conditions for expression of oil from Allanblackia floribunda seeds and assessing the quality and stability of pressed and solvent extracted oil. African Journal of Food Science 4, 563-570.

Zalba, B., Marín, J.M., Cabeza, L.F., and Mehling, H. (2003). Review on thermal energy storage with phase change: materials, heat transfer analysis and applications. Applied Thermal Engineering 23, 251-283.

Zhang, X., Li, L., Xie, H., Liang, Z., Su, J., Liu, G., and Li, B. (2013). Comparative analysis of thermal behavior, isothermal crystallization kinetics and polymorphism of palm oil fractions. Molecules 18, 1036-1052.

Zhou, W., Ooi, Y.H., Russo, R. a al, Papanek, P., Luzzi, D.E., Fischer, J.E., Bronikowski, M.J., Willis, P.A., and Smalley, R.E. (2001). Structural characterization and diameter-dependent oxidative stability of single wall carbon nanotubes synthesized by the catalytic decomposition of CO. Chemical Physics Letters 350, 6-14.

\section{Appendix}

\section{A.1 Applications of PCMs in Solar Water Heating}
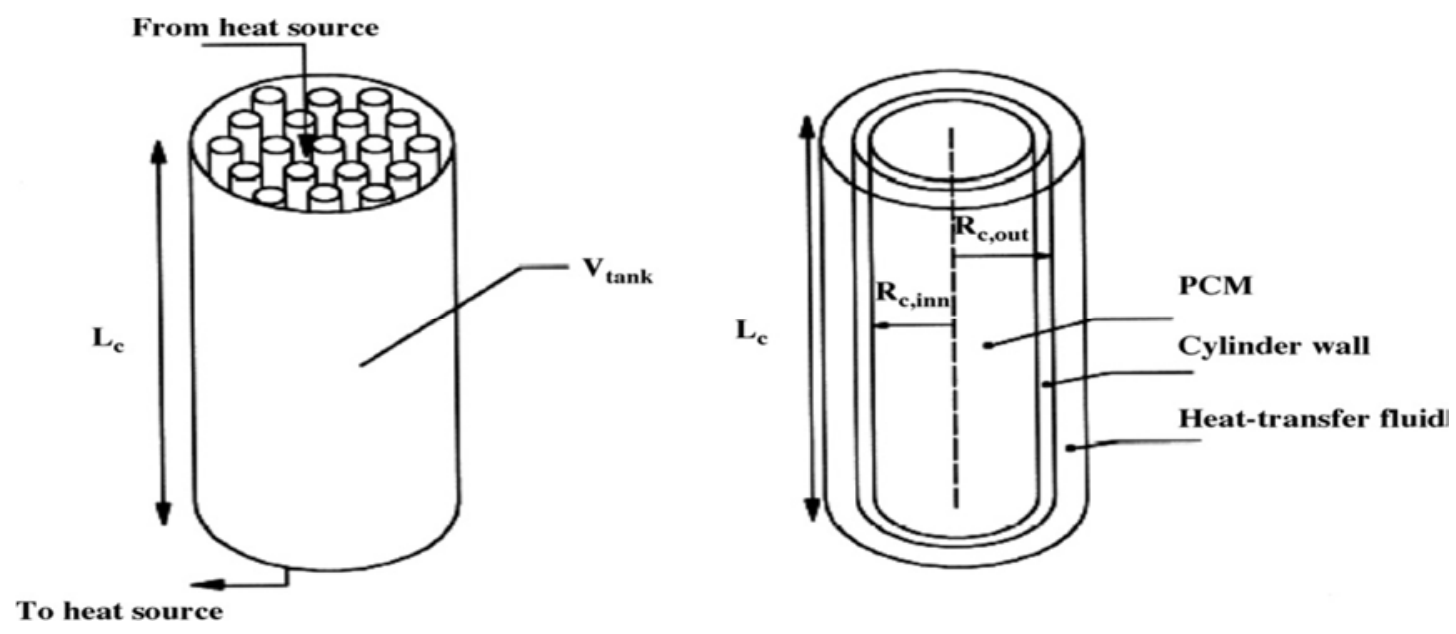

Source: Sharma et al., 2009

Fig. A1. A cylindrical shell with PCM storage. 


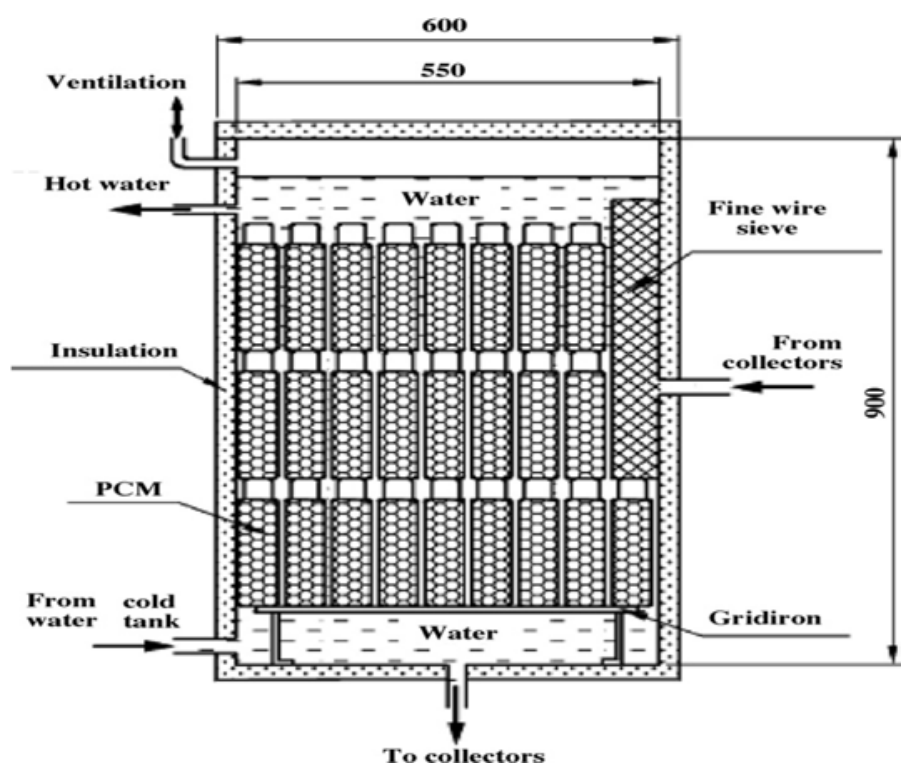

Source: Sharma et al., 2009

Fig. A2. Detailed cross-sectional view of the cylindrical heat storage tank combined with PCM. 


\title{
5 Phase Change Materials for Thermal Energy Storage: Evaluation of Fatty Acids from Tropical Fruit Oils
}

\begin{abstract}
Fatty acids were produced from the oils of Allanblackia, shea butter and palm kernel and subjected to both thermo-physical and chemical analysis using the DSC and TGA for the thermophysical assessment, and FTIR for the chemical analysis. The DSC curves showed that all the fatty acids of the oils were polymorphic indicating that the fatty acids produced were from triglycerides from the oils. Results indicated that fatty acids from Allanblackia oil (AllanFA) has the potential for use as a PCM for thermal energy storage system. The fatty acid from Allanblackia oil was thermally stable within the region of interest and also chemically stable after 1000 thermal cycling. The DSC results gave an enthalpy value of $97.19 \mathrm{~J} / \mathrm{g}$ at a peak temperature of $37.54^{\circ} \mathrm{C}$ for the major peak. However, thermal reliability of AllanFA was a little suspect since the enthalpy value reduced by $37.72 \%$ while the crystallization also reduced by $26.43 \%$. The enthalpy at the end of the thermal cycling was $60.53 \mathrm{~J} / \mathrm{g}$ for melting and $34.71 \mathrm{~J} / \mathrm{g}$ for crystallization, which can be considered as still high enough for thermal energy considerations. The fatty acids produced from both shea butter and palm kernel oil did not have latent heat properties and therefore could not be considered as PCMs for thermal energy storage systems.
\end{abstract}

\subsection{Introduction}

Continuing global volatility in oil prices and negative environmental footprint of the use of oil and other fossil materials to generate energy has necessitated the need to search and develop alternate energy sources. One important aspect of the energy production process is the occasional mis-match between supply and demand. Energy storage is required to overcome these discrepancies (Beckham and Gill, 1984). There are five major energy storage methods: (1) mechanical energy storage, (2) chemical energy storage, (3) Biological energy storage (4) Magnetic energy storage and (5) thermal energy storage (Dincer, I. and Rosen, M. A., 2002).

In this study, we focused only on thermal energy storage. Thermal energy can be stored in three major forms: (1) sensible heat storage (SHS), (2) latent heat storage (LHS) and (3) thermochemical heat storage (THS). Energy storage that causes a material to rise or lower in 
temperature is called sensible heat storage (Dincer and Rosen 2002). The effectiveness of SHS is contingent on the specific heat of the storage material. A common example of SHS is the use of rocks or water as the storage medium. Energy storage by phase change (transition from solid to liquid or from liquid to vapor and vice versa, with no change in temperature) is called latent heat storage. Change in volume if it occurs is very small with an increase in storage density. The important factors for LHS are the specific heat of solidification/fusion or vaporization and the temperature at which the phase change occurs (Dincer and Rosen 2002). Both SHS and LHS may occur in the same storage system. In a THS system, energy is absorbed or released via breaking and forming of molecular bonds in a completely reversible chemical reaction (Lane, 1983).

Latent heat occurs through solid-liquid, solid-gas, liquid-gas, liquid-solid, and solid-solid transformations. However, most practical transformations are the solid-liquid/liquid-solid and the solid-solid transformations (Sharma and Sagara, 2005). Solar energy, off-peak electricity and industrial waste energy can all be stored using phase change materials (PCMs) as latent heat storage materials. These stored energies can be applied in solar cooking, waste heat recovery systems, space heating and cooling, solar water heating and greenhouse applications (Sharma and Sagara, 2005). Phase change materials employed in latent heat storage systems act as a medium that absorbs energy when heated and releases energy when cooled. The first reported application of PCM was in the use for heating and cooling in buildings (Lane, 1983). Telkes at al. (1978) promoted the idea of using PCMs in walls of buildings which are called Trombe walls. There are three main types of PCMs: (1) organic, (2) inorganic and (3) eutectic mixtures. Shukla et al. (2008) evaluated some organic and inorganic acids for use as PCMs. He studied the thermal cycling properties of the inorganic compounds and organic compounds and concluded that the inorganic compounds were not suitable PCM materials for use in LHS. Li and Ding (2007), prepared and characterized butanediol-distearate from stearic acid and 1,4-butanediol and concluded that the ester produced was an excellent energy storing material for use as a PCM. Other examples of organic PCMs are paraffin and non-paraffin material (Garg et al., 1985; Buddhi and Sawhney, 1994; Sharma et al., 1999). All such organic PCMs are from fossil-derived sources. 
Properties of materials that are essential for their use as PCMs in LHS are thermal and chemical stability. The PCMs need to be assessed to determine whether they are thermally stable and reliable before they can be used as latent heat storage materials.

In this study, DSC was used to determine whether the energy absorbed or released was high enough to be used for thermal energy storage and also whether it was a latent heat energy. Differential scanning calorimetry determines both thermal energy storage properties and thermal reliability of the PCMs (Sari et al., 2011). Thermal stability of the fatty acids were studied using a TGA to determine if fatty acids decomposed during the melting and/or fusion temperature region (known as the desired temperature range). The chemical and therefore thermal stability of the oils were determined by FTIR spectroscopy. In this analysis, functional group chemistry of the fatty acids before and after melting/freezing cycles were determined (Garg et al., 1985). The information obtained in the FTIR characterization was used to confirm the thermal stability results obtained via DSC and TGA methods. One important requirement of PCMs is the ability to demonstrate thermal stability over a long continuous period of use (Shukla et al., 2008). Thermal cycling for about 1000 times mimics the continuous use of the PCM in service.

Herein, we report the results of the evaluation of fatty acids derived from three tropical fruit oils as PCMs based on their physical and chemical properties. The method for producing fatty acids from the tropical fruits oils are also described. Also described are the methods used for the characterization of the thermo-physical and chemical properties of the fatty acids. The information obtained on the thermo-physical and chemical properties of these fatty acids were combined and used as the basis for determining the candidacy of the fatty acids as potential PCM materials.

\subsection{Materials and Methods}

\subsubsection{Materials:}

Oil from the seeds of Allanblackia (Allanblackia paviflora) obtained from Ghana had already been extracted (data from the use of oil as PCMs for energy storage); shea butter (Bulk Apothecary, Ohio, U.S.A.), palm kernel oil (Organic Creations, Oregon, U.S.A.), Sulfuric Acid (Fisher Scientific, NJ, U.S.A), Anhydrous Sodium Sulfate (Fisher Scientific, NJ, U.S.A),TGA instrument (TA Instruurments model Q50, TA instruments, Inc., DE, USA), Platinum pan, DSC 
instrument (TA Instruments model Q20, TA instruments, Inc., DE, USA), Tzero Aluminum hermetic pans and lids (DSC Consumables Inc., Austin, MN, U.S.A.), PerkinElmer Spectrum 100 FTIR (Waltham, Massachusetts, U.S.A.) with an ATR spectrometer, PTC-100 Programmable Thermal Controller (MJ Research Inc., Watertown, MA, U.S.A.).

\subsubsection{Methods:}

\subsubsection{Design of experiment}

This is a completely random design.

\subsubsection{Preparation of fatty acids from the oils of Allanblackia, shea butter and palm kernel}

Fatty acids were prepared from the oil samples according to the AOCS Official Method Da 1248. Fifty (50) grams of the oil sample was dissolved in $500 \mathrm{ml}$ of hot water contained in a 1000 $\mathrm{ml}$ beaker. A $100 \mathrm{ml}$ of $30 \%$ (volume/volume, v/v) sulfuric acid $\left(\mathrm{H}_{2} \mathrm{SO}_{4}\right)$ was added to the mixture, and glass beads were added to minimize bumping. The mixture was heated gently until the fatty matter collected in a clear layer on top. This mixture was poured into a separating funnel and the aqueous acid layer (lower layer) was removed. Another $300 \mathrm{ml}$ of hot water was added to the remaining layer and again boiled gently for a few minutes and the aqueous bottom layer is removed. This washing process was repeated three times. The process of acidification and washing was done within the shortest possible time while keeping the beaker and separating funnel covered to prevent oxidation of the fatty acids produced. After the washing process is complete, the fatty acid was allowed to settle for a few minutes and then filtered through a bed of anhydrous sodium sulfate $\left(\mathrm{Na}_{2} \mathrm{SO}_{4}\right)$ to remove all water and again dried in the oven at a temperature of $105 \pm 2^{\circ} \mathrm{C}$ for $45-60$ minutes.

\subsubsection{Physical and chemical properties of fatty acids 5.1.2.3.1 Chemical characterization of the fatty acids}

The functional chemistries of the fatty acids produced from Allanblackia oil, shea butter and palm kernel oil were chemically characterized by Fourier transform infrared (FTIR) spectroscopy. The FTIR spectra were determined using a PerkinElmer Spectrum 100 spectroscopy instrument with Universal Sampling Accessory at a wave number range of 4000- 
$600 \mathrm{~cm}^{-1}$. Measurements were recorded in transmittance mode. Four (4) scans were taken per each measurement. Oil sample (about $0.1 \mathrm{~mL}$ ) was dropped on the diamond ATR probe aperture,

and spectra were recorded at a resolution of $8 \mathrm{~cm}^{-1}$ using 4 scans under 1 minute against air as the background. The FTIR-ATR monitors the chemical components present in the oil sample at any given time. The FTIR measurements were recorded for samples before thermal cycling and after thermal cycling.

\subsubsection{Thermo-physical characterization of fatty acids 5.1.2.4.1 Differential scanning calorimetry (DSC)}

The enthalpies and phase change temperatures of the fatty acids were determined by DSC. The instrument was calibrated with an indium standard. Measurements were taken under a nitrogen atmosphere using a heating/cooling/heating cycle at a heating rate of $5^{\circ} \mathrm{C} / \mathrm{min}$, and the same rate for the cooling cycle.

\subsection{Thermal cycling}

Thermal cycling of fatty acids was determined in triplicate using a programmable thermal controller. The data obtained was used to calculate the average melting and latent heat values. This protocol determined the melting/solidification (1000 times) of the fatty acids. This information was used to compute the thermal reliability and stability of the fatty acids after the thermal cycling. Each fatty acid sample was thermally cycled by heating from $0^{\circ} \mathrm{C}$ to $50^{\circ} \mathrm{C}$ at a rate of $1{ }^{\circ} \mathrm{C} / \mathrm{s}$ and held for $30 \mathrm{~s}$. It was then cooled from $50^{\circ} \mathrm{C}$ to $0^{\circ} \mathrm{C}$ at the same rate of $1{ }^{\circ} \mathrm{C} / \mathrm{s}$, and again held for $30 \mathrm{~s}$. This process was repeated 999 times.

\subsection{Thermo-gravimetric analysis (TGA)}

The thermal stability of the fatty acids were determined thermo-gravimetrically using a TGA instrument. The instrument was calibrated using calcium oxalate. Samples were placed in a platinum pan and subjected to a cycle using a temperature range of $25-600^{\circ} \mathrm{C}$ at a heating rate of $10^{\circ} \mathrm{C} / \mathrm{min}$ in a nitrogen/compressed air atmosphere (Sari et al., 2011).

\subsection{Results and Discussions}

\subsubsection{Differential scanning calorimetric (DSC) analysis of fatty acids}


The DSC profile of the fatty acids of Allanblackia oil (AllanFA) is shown in Figure 5.1. The thermogram of the fatty acid showed an improvement in its thermal properties compared to that of the raw Allanblackia (Figure 5.2). The exothermic peak observed in the DSC curve of raw Allanblackia oil before melting was replaced by a minor endothermic peak at $\mathrm{F}_{2}$ before the major endothermic peak appeared. This minor peak occurred in the $7.97-26.51^{\circ} \mathrm{C}$ range with a peak temperature of $21.07^{\circ} \mathrm{C}$. The onset temperature was $15.43^{\circ} \mathrm{C}$ with the enthalpy of $18.61 \mathrm{~J} / \mathrm{g}$. A major endothermic peak occurred at $37.54^{\circ} \mathrm{C}$ at $\mathrm{F}_{3}$ with an onset temperature of $34.58^{\circ} \mathrm{C}$ and the enthalpy of of $97.19 \mathrm{~J} / \mathrm{g}$ within a range of $26.51-42.99^{\circ} \mathrm{C}$. Also, a major peak occured at $37.54^{\circ} \mathrm{C}$. The freezing cycles exhibited a major peak at $16.66^{\circ} \mathrm{C}$ with an enthalpy of $47.18 \mathrm{~J} / \mathrm{g}$ and an onset temperature of $19.16^{\circ} \mathrm{C}$. For an enthalpy change to be considered to be a latent energy, the energy is delivered at a constant temperature or over a narrow temperature range. These materials are therefore characterized by latent heat of melting/crystallization and their melting point(s). This makes these storage materials very attractive for smaller and lighter storage devices with low storage losses such as packaging materials, clothing, blankets, gloves, astronaut space suits and footwear (Berera, 2006).

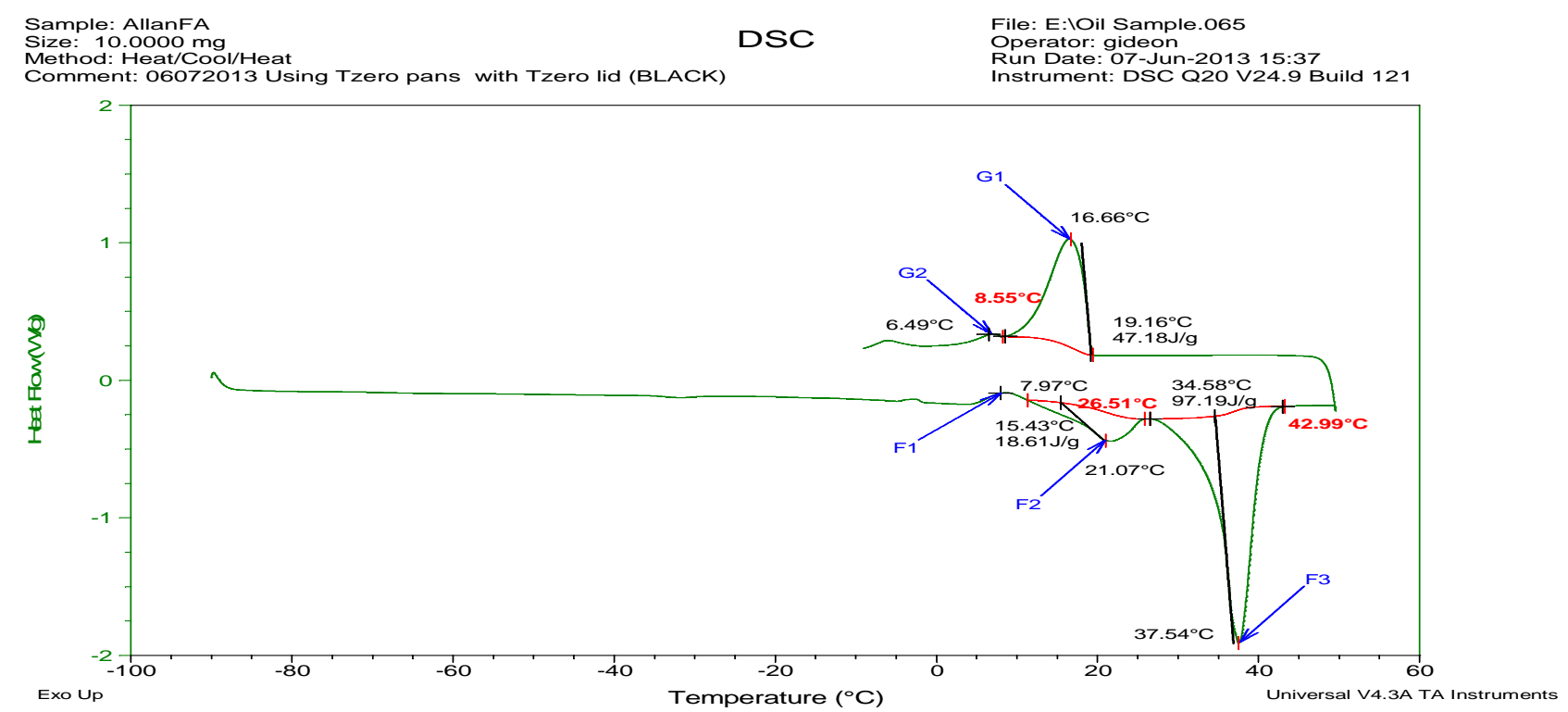

Fig. 5.1: DSC thermogram of fatty acids from Allanblackia oil (AllanFA).

The cooling curve obtained in this study was much simpler and reproducible as those reported by Berger and Akehurst (1966). The major melting and crystallization peaks were sharp enough to 
be considered latent heat energy for PCM. This observation reflects an improvement in the thermo-physical characteristics of the fatty acids compared to the raw Allanblackia oil (Figure 5.2). Additionally, the heat of melting increased. The melting temperature of the fatty acid was higher than the oil. The shape of the thermogram was sharper and exhibited the disappearance of the exothermic peak before melting. This was due to the absence of heat release due to the reorganization of the crystals before melting. The crystallization curve for the raw Allanblackia oil and the AllanFA were approximately the same (Figures 5.1 and 5.2).

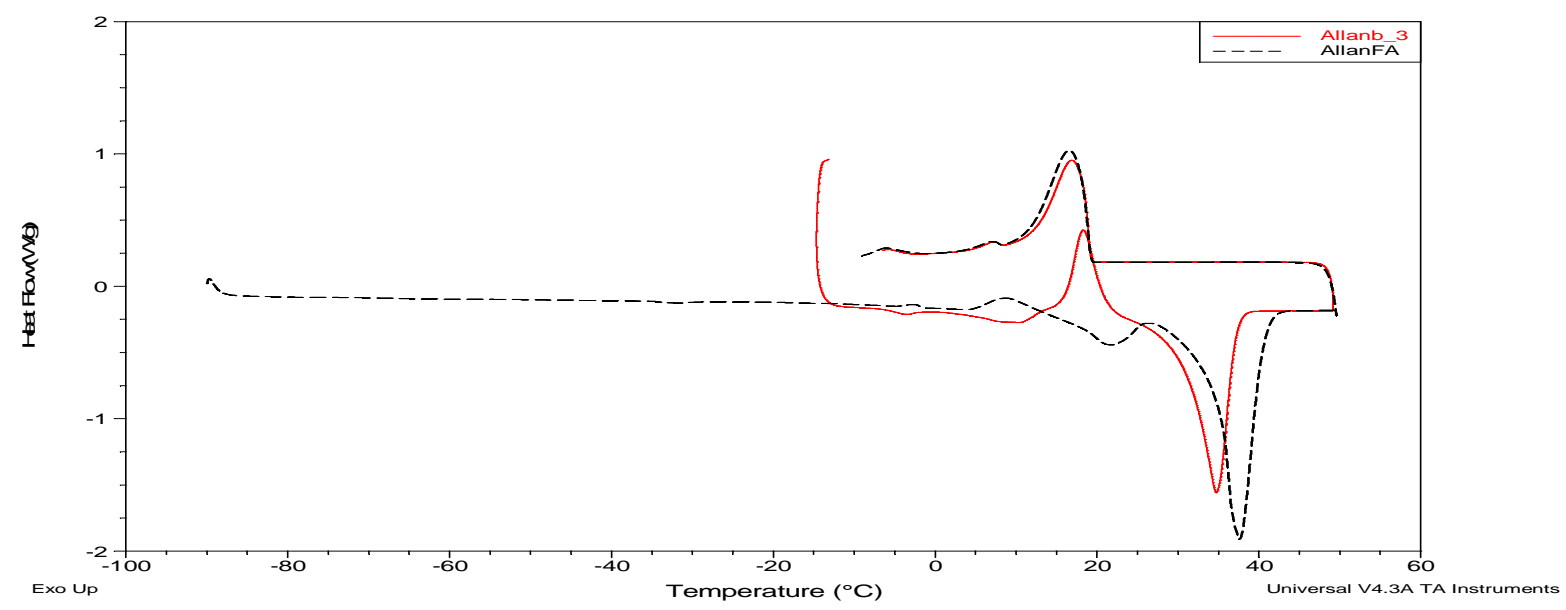

Fig. 5.2: DSC overlaid thermograms of Allanblackia oil and Allanblackia fatty acid. 


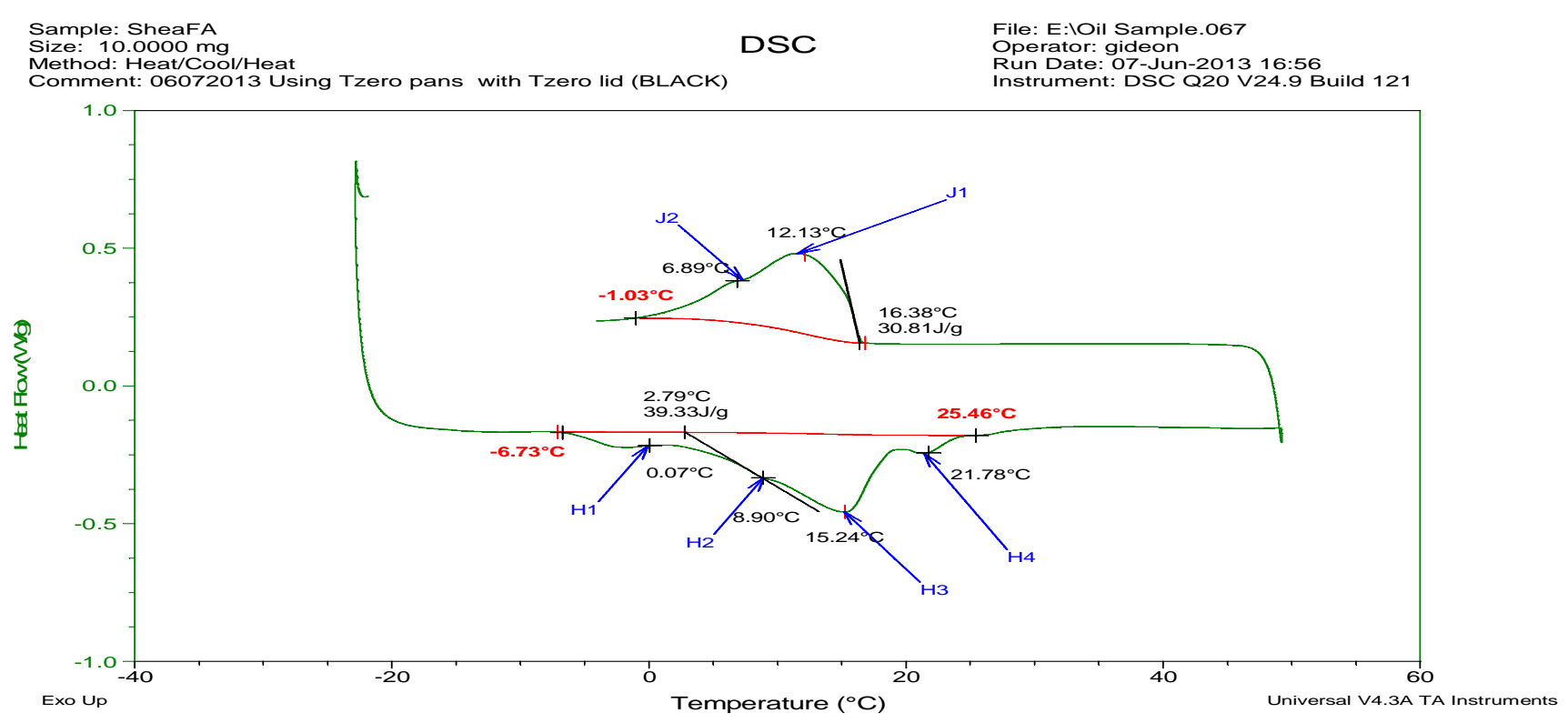

Fig. 5.3: DSC thermogram of the fatty acid of shea butter (SheaFA)

Figure 5.3 shows the DSC thermogram of the fatty acid from shea butter (SheaFA). The melting curve had four transitional peaks at $\mathrm{H}_{1}, \mathrm{H}_{2}$, and $\mathrm{H}_{4}$. All the transitional peaks overlapped with the major peak at $\mathrm{H}_{3}\left(15.24^{\circ} \mathrm{C}\right)$. The enthalpy was $39.33 \mathrm{~J} / \mathrm{g}$ at an onset temperature of $2.79^{\circ} \mathrm{C}$. The melting temperature range was $6.73-25.46^{\circ} \mathrm{C}$. This range was too broad to be considered suitable for use as a PCM material in latent heat energy storage because latent heat energy should occur at a constant temperature or with a small change in temperature (Abhat, 1983; Lane, 1983). The major peak for the crystallization curve was at $\mathrm{J}_{1}\left(12.13^{\circ} \mathrm{C}\right)$ and exhibited an overlapping transition temperature at $\mathrm{J}_{2}\left(6.89^{\circ} \mathrm{C}\right)$. 


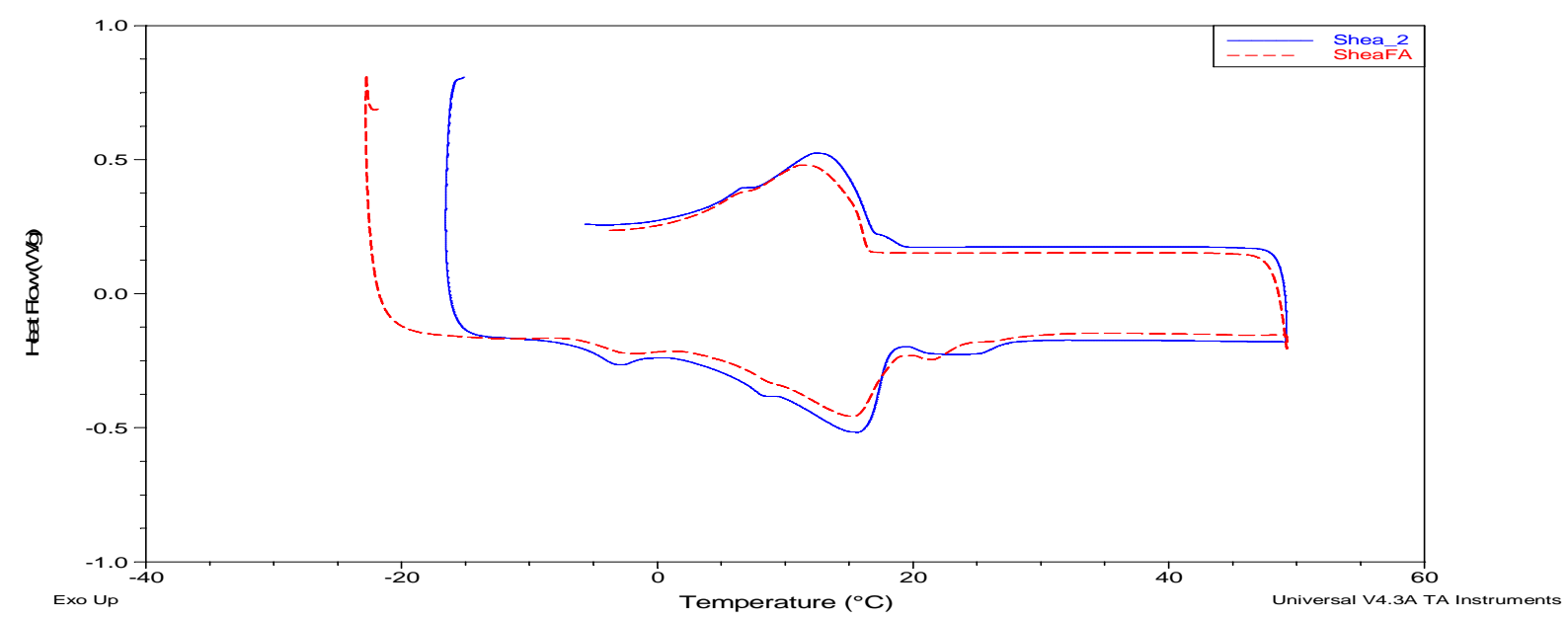

Fig. 5.4: DSC thermogram of overlaid shea butter and its fatty acid.

Figure 5.4 shows the overlaid melting and crystallization thermograms of raw shea butter and its fatty acid. There was no marked difference between the DSC thermograms of shea butter and its fatty acid (Figure 5.4).

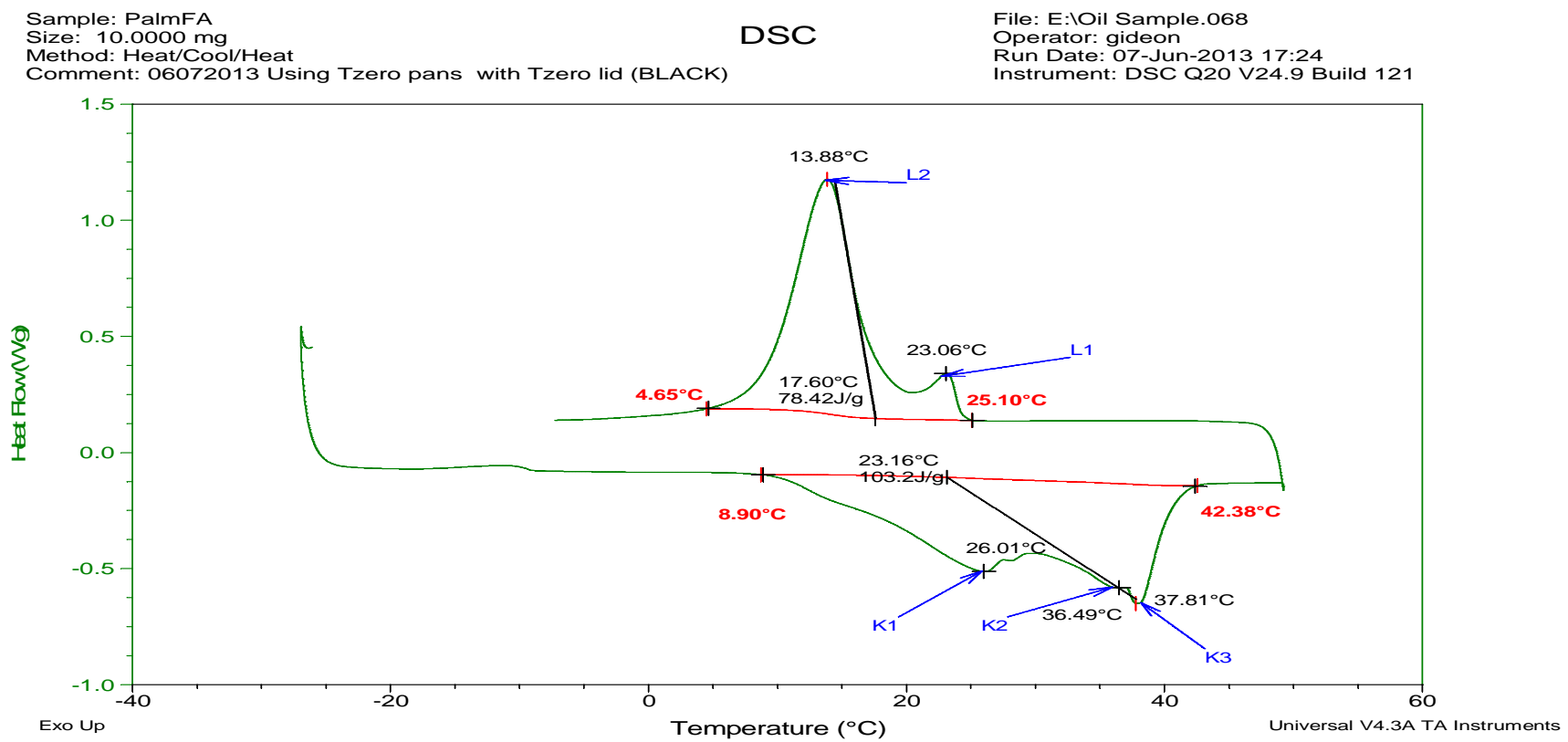

Fig. 5.5: DSC thermogram of fatty acid of palm kernel oil (PalmFA) 
Figure 5.5 shows the DSC curve of the fatty acid derived from palm kernel oil (PalmFA). The melting curve showed a very complex profile with multiple unresolved peaks within the same range. The minor, transitional and major peaks $\left(\mathrm{K}_{1}, \mathrm{~K}_{2}\right.$ and $\mathrm{K}_{3}$ respectively) were all within the same region $\left(8.90\right.$ and $\left.42.38^{\circ} \mathrm{C}\right)$.

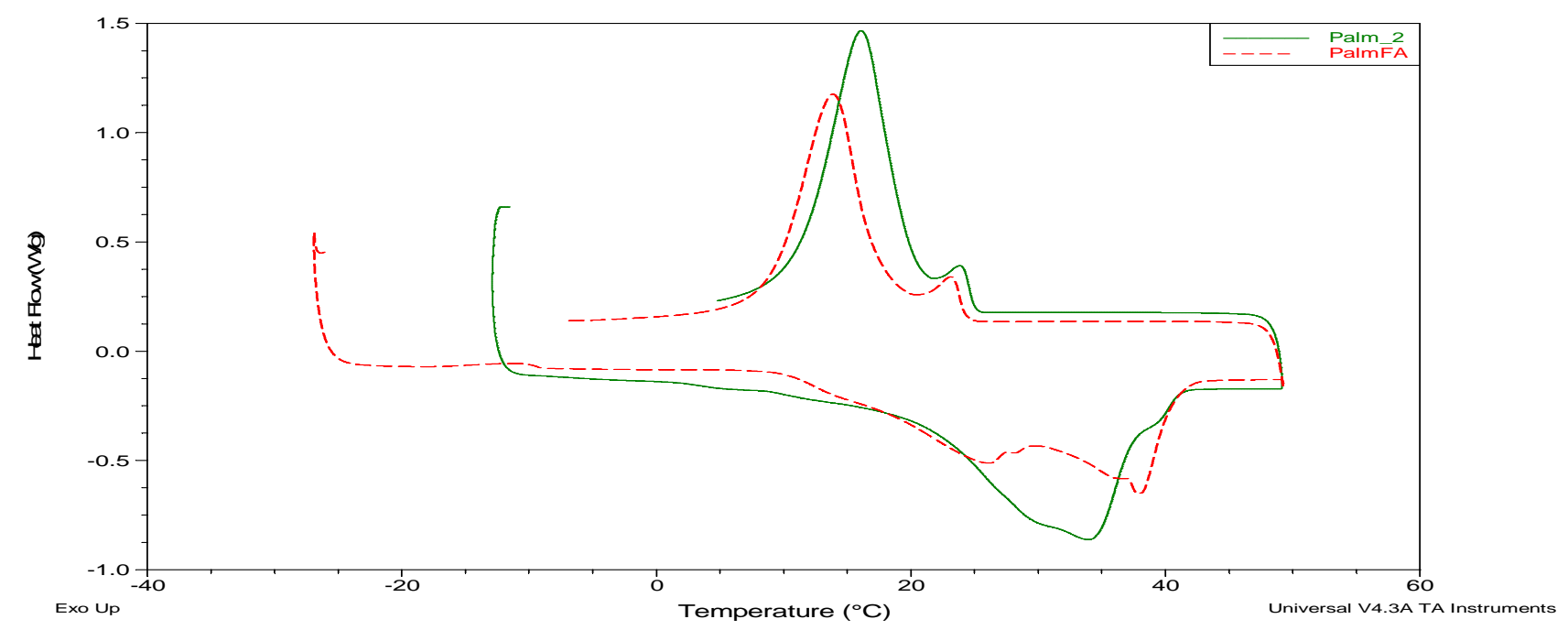

Fig. 5.6: Overlaid DSC thermograms of palm kernel oil and its fatty acid.

An enthalpy value of $103.2 \mathrm{~J} / \mathrm{g}$ could not be assigned to one particular peak because the melting profile was very complex and too broad to be considered as a measure of latent heat energy. This could be ascribed to incongruent melting (Sharma and Sagara, 2005). The crystallization curve had an overlapping minor peak at $23.06^{\circ} \mathrm{C}$ with the major peak occurring at $13.88^{\circ} \mathrm{C}$. The enthalpy involved was $78.42 \mathrm{~J} / \mathrm{g}$ at an onset temperature of $17.60^{\circ} \mathrm{C}$. Figure 5.6 shows the overlaid curves of palm kernel oil and the derived fatty acid. The fatty acid of the palm kernel oil exhibited a more complex melting profile than the palm kernel oil. The melting profile of PalmFA therefore was complex while the enthalpy value of crystallization was greatly reduced (Figure 5.6). 
Fatty acids of oil samples overlaid on each other

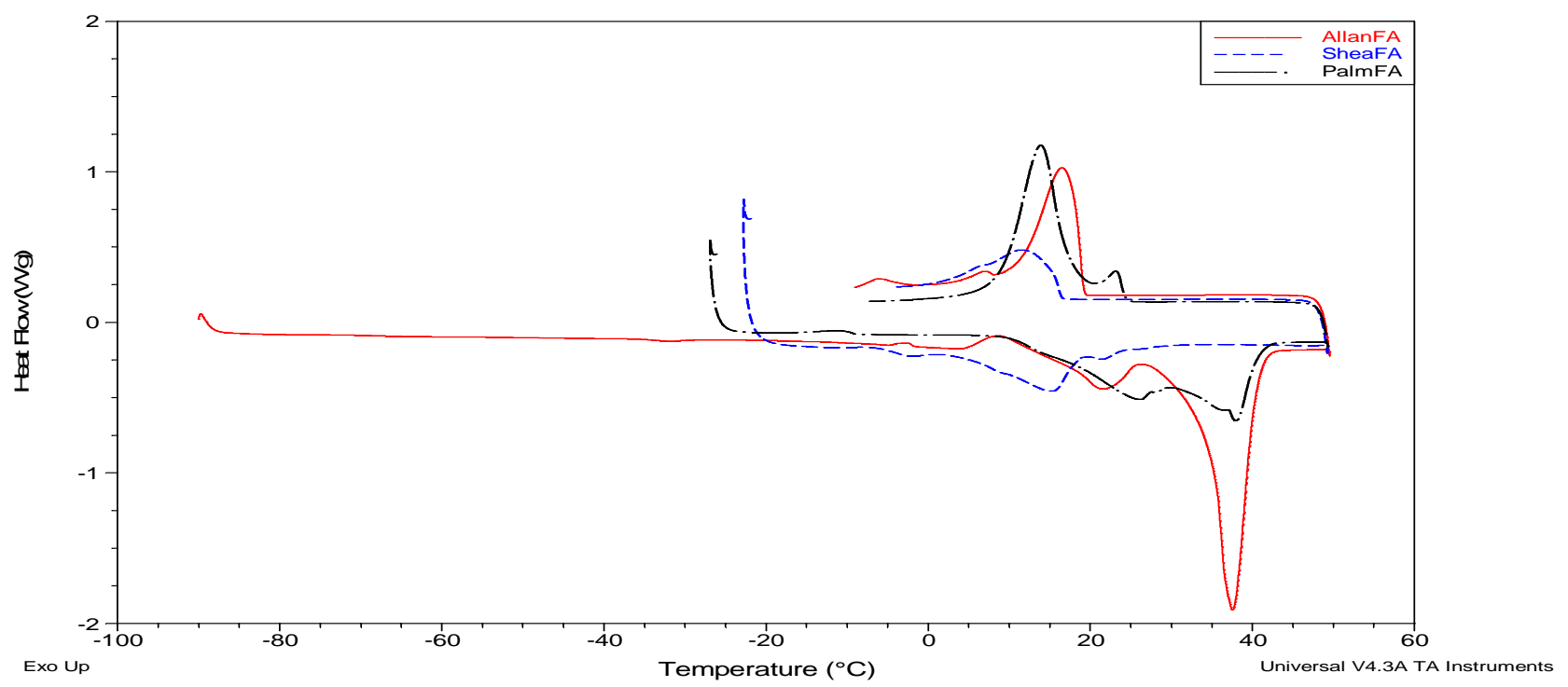

Fig. 5.7: DSC thermogram of overlaid AllanFA, SheaFA and PalmFA.

Therefore, this fatty acid could not be used as a PCM for thermal energy storage. The associated heat of fusion is shown in Figure 5.5. Judging from Figure 5.7, AllanFA is the candidate material for use as PCM in thermal energy storage because it is sharper; has little overlap in the major peaks and a large enthalpy value. Both SheaFA and PalmFA did not exhibit latent energy properties suitable for use as PCMs for thermal energy storage based on the DSC thermogram.

\subsubsection{DSC profile of thermally cycled fatty acids}

The DSC curve of the thermally cycled AllanFA (TC AllanFA) is shown in Figure 5.8 and Table 5.1. The curve shows that the pre-crystallization observed in the Allanblackia oil curve (Figure 5.2) but is absent from fatty acid curve (Figure 5.1), showed up after thermal cycling with an exothermic enthalpy value of $17.01 \mathrm{~J} / \mathrm{g}$ at $\mathrm{L}_{1}$ corresponding to the temperature range where the crystallization occurred. 


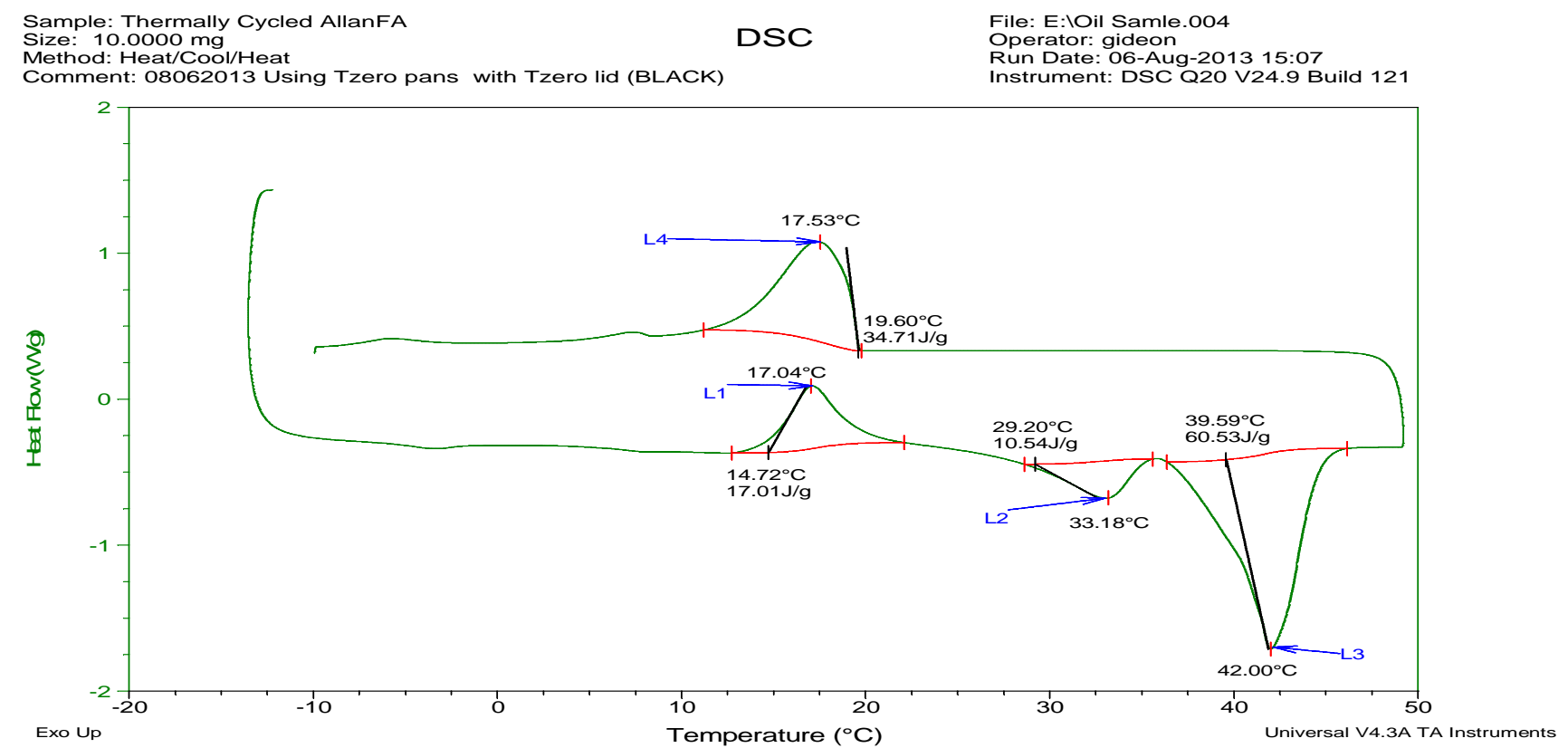

Fig. 5.8: DSC thermogram of AllanFA after Thermal Cycling

The DSC curve of AllanFA after thermal cycling (Figure 5.8), showed that both the minor ( $\left.\mathrm{L}_{2}\right)$ and major $\left(\mathrm{L}_{3}\right)$ peaks were still present, however, the major peak enthalpy decreased from 97.19 $\mathrm{J} / \mathrm{g}$ to $60.53 \mathrm{~J} / \mathrm{g}$ (37.72\% reduction).This is consistent with the work reported by Shukla et al. (2008). The latter authors demonstrated in their study that thermal cycling reduced the enthalpy of organic PCM, paraffin wax (A), by $28 \mathrm{~kJ} / \mathrm{kg}$ and the melting temperatures by $3^{\circ} \mathrm{C}$. The crystallization peak ( $\mathrm{L}_{4}$ ) enthalpy was also reduced from $47.18 \mathrm{~J} / \mathrm{g}$ to $34.71 \mathrm{~J} / \mathrm{g}$. This represented a reduction of $26.43 \%$. The same authors also reported a decrease of $35-40 \mathrm{~kJ} / \mathrm{kg}$ for the latent heat of fusion for erythritol with a corresponding decrease of $9-10^{\circ} \mathrm{C}$ in temperature for a 500 1000 thermal cycling. These enthalpy reductions are very significant and will affect the thermal stability of the fatty acid from Allanblackia oil. However, Sari et al. (2003, 2003) studied the thermal reliability of stearic acid, palmitic acid, myristic acid and lauric acid for use as latent heat storage materials. These authors concluded that even though there was a melting change of $0.07-7.87^{\circ} \mathrm{C}$ and a change in the latent heat of fusion by $1-27 \%$ with respect to thermal cycling, the PCMs exhibited good thermal reliability in the long term. The temperature difference for the crystallization cycle between the onset temperature and the peak temperature before and after thermal cycling were all below $3^{\circ} \mathrm{C}$ and hence low enough to be considered latent energies. 
Table 5.1: DSC profile of oils and their fatty acids

\begin{tabular}{|c|c|c|c|c|}
\hline$\underline{\text { Sample }}$ & Process & Enthalpy/J/g & $\begin{array}{l}\text { Melting } \\
\text { Range } /{ }^{\circ} \mathrm{C}\end{array}$ & $\begin{array}{l}\text { Temp. } \\
\underline{\text { Diff. } /{ }^{\circ} \mathrm{C}}\end{array}$ \\
\hline \multirow[t]{2}{*}{ Allanblackia Oil } & Melting & 80.53 & $30.50-34.74$ & 4.24 \\
\hline & Crystallization & 38.59 & $19.16-17.02$ & 2.14 \\
\hline \multirow[t]{2}{*}{ Allanblackia FA } & Melting & 97.19 & $34.58-37.54$ & 2.96 \\
\hline & Crystallization & 47.18 & $19.16-16.66$ & 2.50 \\
\hline \multirow[t]{2}{*}{ TC Allanblackia Oil } & Melting & 65.74 & $32.85-37.40$ & 4.55 \\
\hline & Crystallization & 31.83 & $19.00-16.59$ & 2.41 \\
\hline \multirow[t]{2}{*}{ TC Allanblackia FA } & Melting & 60.53 & $39.59-42.00$ & 2.41 \\
\hline & Crystallization & 34.71 & $19.60-17.53$ & 2.07 \\
\hline \multirow[t]{2}{*}{ Shea Butter } & Melting & 29.85 & $4.27-15.75$ & 11.48 \\
\hline & Crystallization & 31.35 & $17.24-13.10$ & 4.14 \\
\hline \multirow[t]{2}{*}{ Shea Butter FA } & Melting & 39.33 & $2.79-15.24$ & 12.45 \\
\hline & Crystallization & 30.81 & $16.38-12.13$ & 4.25 \\
\hline \multirow[t]{2}{*}{ TC Shea Butter } & Melting & 49.15 & $27.64-35.23$ & 7.59 \\
\hline & Crystallization & 44.51 & $16.27-12.74$ & 3.53 \\
\hline \multirow[t]{2}{*}{ TC Shea Butter FA } & Melting & 22.15 & $6.29-16.51$ & 10.22 \\
\hline & Crystallization & 29.51 & $16.83-13.17$ & 3.66 \\
\hline \multirow[t]{2}{*}{ Palm Kernel Oil } & Melting & 94.12 & $20.60-34.14$ & 13.54 \\
\hline & Crystallization & 95.55 & $20.32-16.10$ & 4.22 \\
\hline \multirow[t]{2}{*}{ Palm Kernel FA } & Melting & 103.20 & $23.16-37.81$ & 14.65 \\
\hline & Crystallization & 78.42 & $17.6-13.88$ & 3.72 \\
\hline \multirow[t]{2}{*}{ TC Palm Kernel Oil } & Melting & 21.57 & $34.73-37.18$ & 2.45 \\
\hline & Crystallization & 34.59 & $19.95-16.51$ & 3.44 \\
\hline \multirow[t]{2}{*}{ TC Palm Kernel FA } & Melting & 81.23 & $18.19-27.55$ & 9.36 \\
\hline & Crystallization & 85.37 & $17.53-14.67$ & 2.86 \\
\hline
\end{tabular}

The thermogram in Figure 5.9 shows the combined DSC curve for Allanblackia and AllanFA and also their thermally cycled products. It is evident from the curves that even though AllanFA 
had improved thermal properties, their properties were negatively affected after thermal cycling to some extent, in that an exothermic peak due to re-organization of the fatty acid crystals did appear after thermal cycling, even though it was absent before the thermal cycling. However, latent heat energy values indicated that it could be used for thermal energy storage provided it is thermally stable.

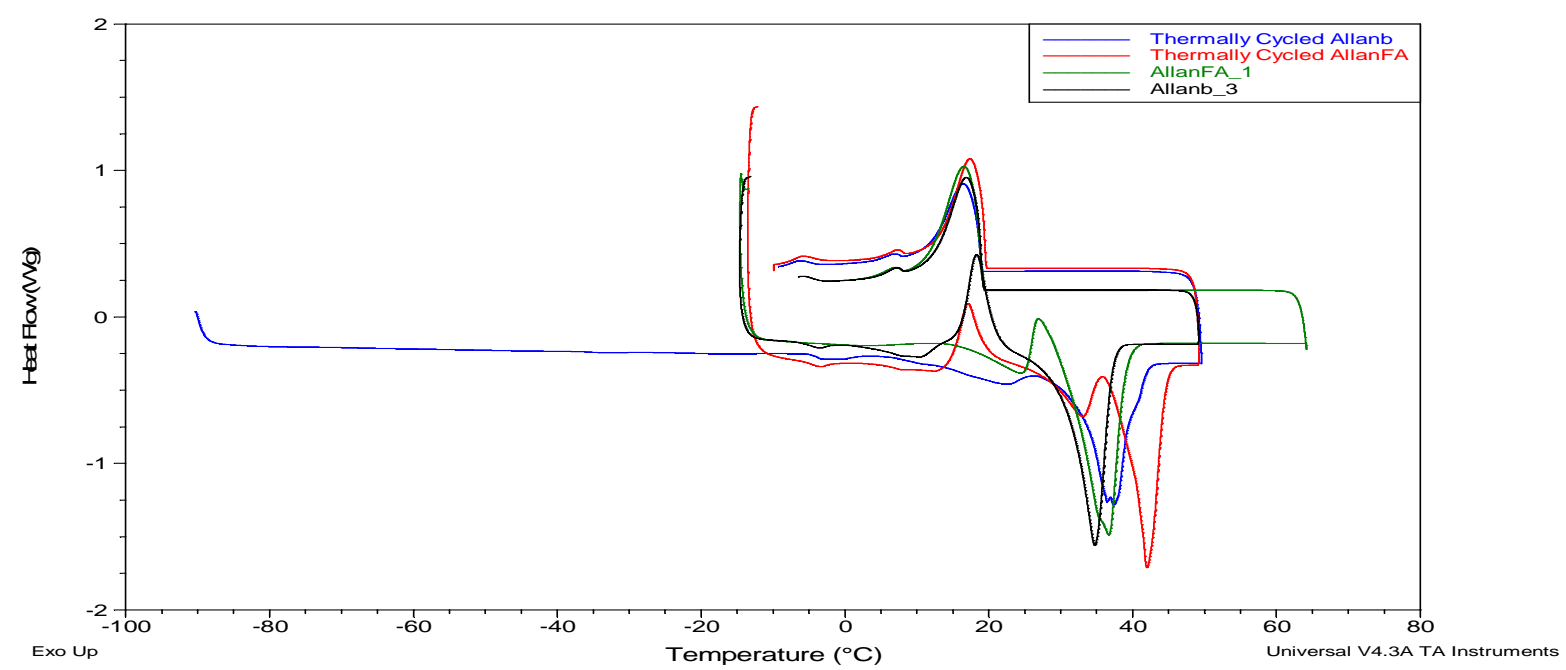

Fig. 5.9: Overlaid DSC thermograms of Allanblackia, Allanblackia fatty acid, thermally cycled Allanblackia and thermally cycled Allanblackia fatty acid.

Thermally cycled shea butter fatty acid (TC SheaFA, Figure 5.10) has an enthalpy value of 22.15 $\mathrm{J} / \mathrm{g}$ with the peak temperature at $16.51^{\circ} \mathrm{C}$ at $\mathrm{L}_{1}$. The temperature difference between the onset temperature and the peak temperature is $10.22^{\circ} \mathrm{C}$. This is too big to be considered latent because as described earlier, latent heat must be delivered at a constant temperature or over a narrow temperature range (Berera, 2006). Like the SheaFA before thermal cycling, there was not much change in latent energy properties after thermal cycling. 


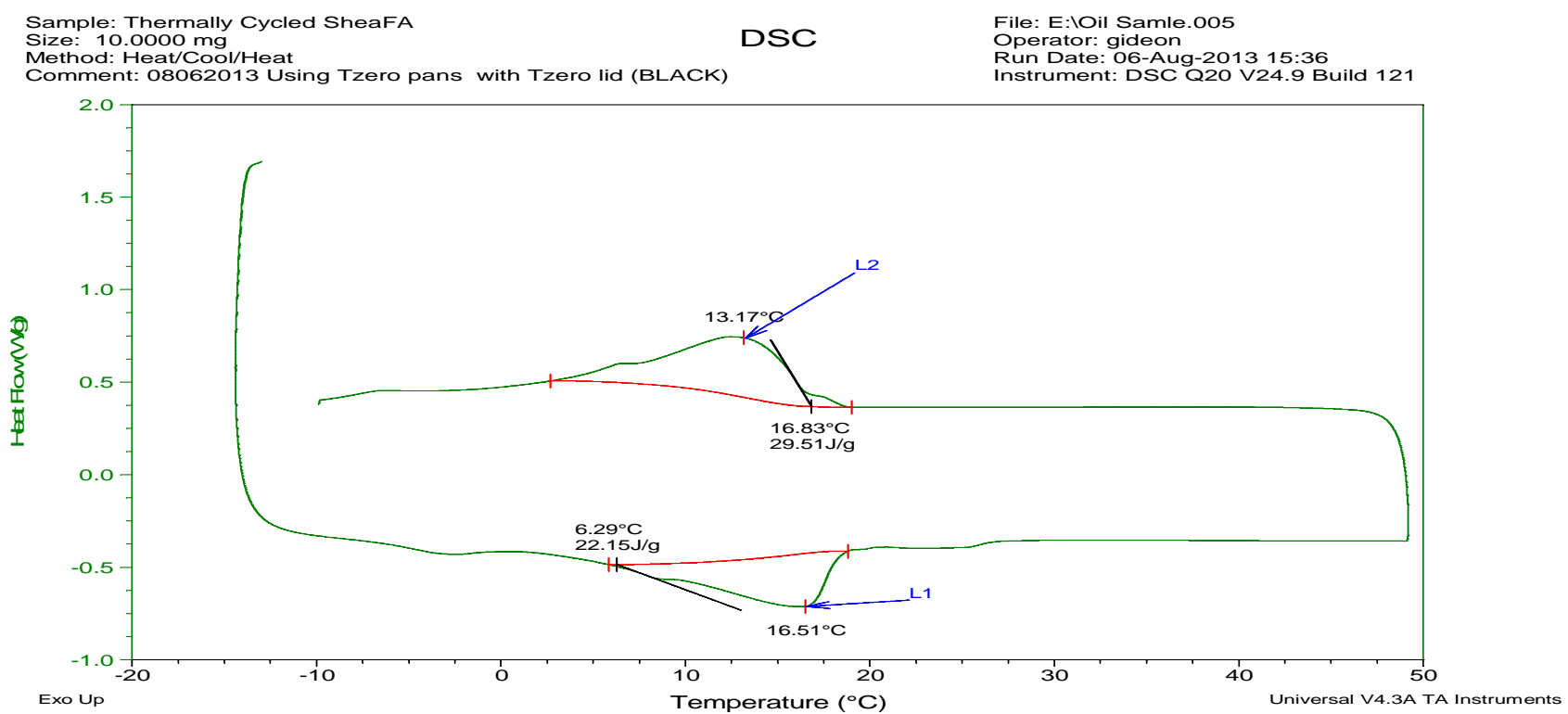

Figure 5.10: DSC thermogram of fatty acid of shea butter after thermal cycling

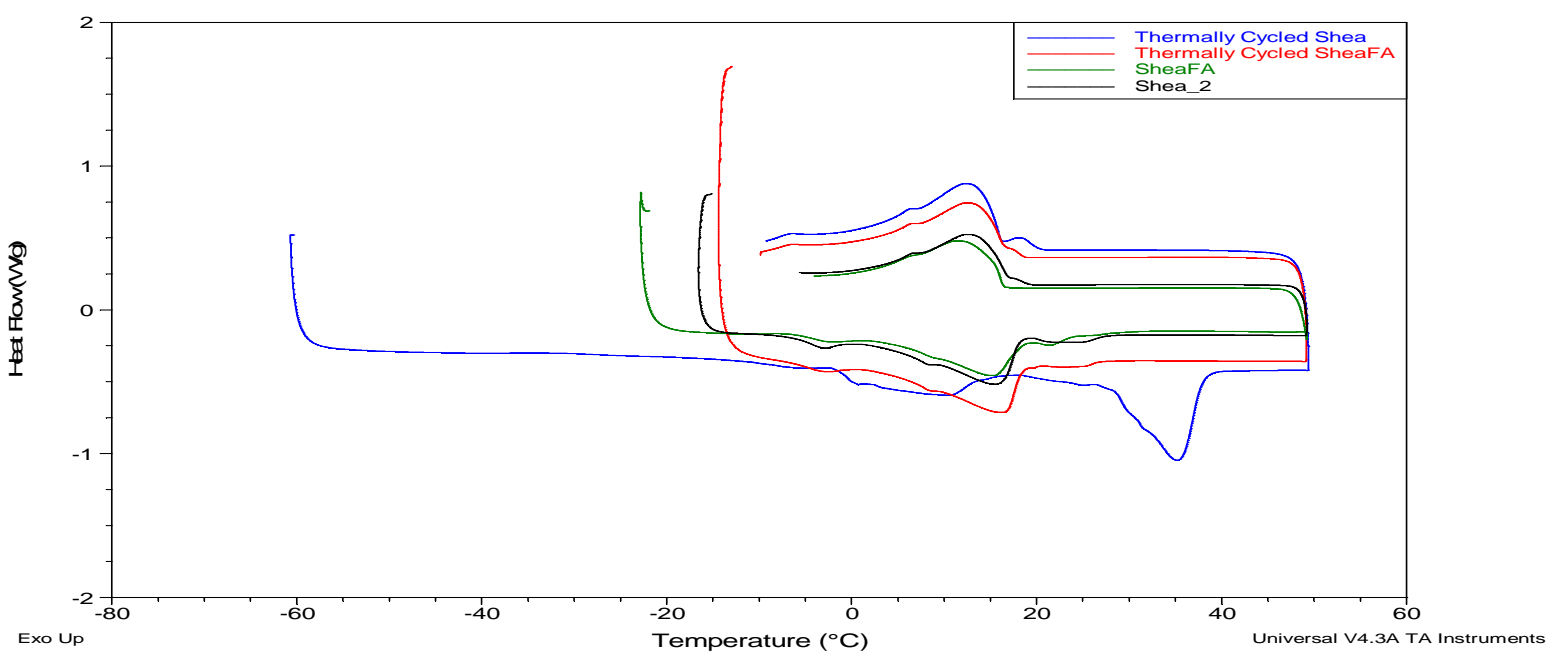

Figure 5.11: Overlaid DSC curves of non- and thermally cycled shea butter and SheaFA

The DSC heating curve (Figure 5.8 and 5.10) showed a reduction in enthalpy from $39.33 \mathrm{~J} / \mathrm{g}$ to $22.15 \mathrm{~J} / \mathrm{g}$ (a reduction of 43-37\%) and this was in agreement with the studies of Shukla et al. (2008). The cooling curve after thermal cycling exhibited a change in enthalpy values from 30.81 $\mathrm{J} / \mathrm{g}$ to $29.51 \mathrm{~J} / \mathrm{g}$ (reduction of $4.22 \%$ ). The crystallization curve is latent (Berera, 2006) with a temperature difference of $3.66^{\circ} \mathrm{C}$ after thermal cycling, even though the cooling curve exhibited 
a drop in latent heat energy values after thermal cycling. So whilst the crystallization process can be considered latent with little loss in latent heat energy value, the melting process is not latent and hence the overall cycle is not a latent heat energy for PCM considerations because it is expected that for latent heat energy considerations, both the melting and crystallization curves have to be taken into consideration for a material to be used as a PCM. Figure 5.11 indicates that apart from the thermally cycled shea butter, there was not much difference in the properties for the SheaFA and thermally cycled SheaFA. And, since SheaFA has been shown to exhibit no latent energy, it could not be considered for use as PCM for latent heat energy storage.

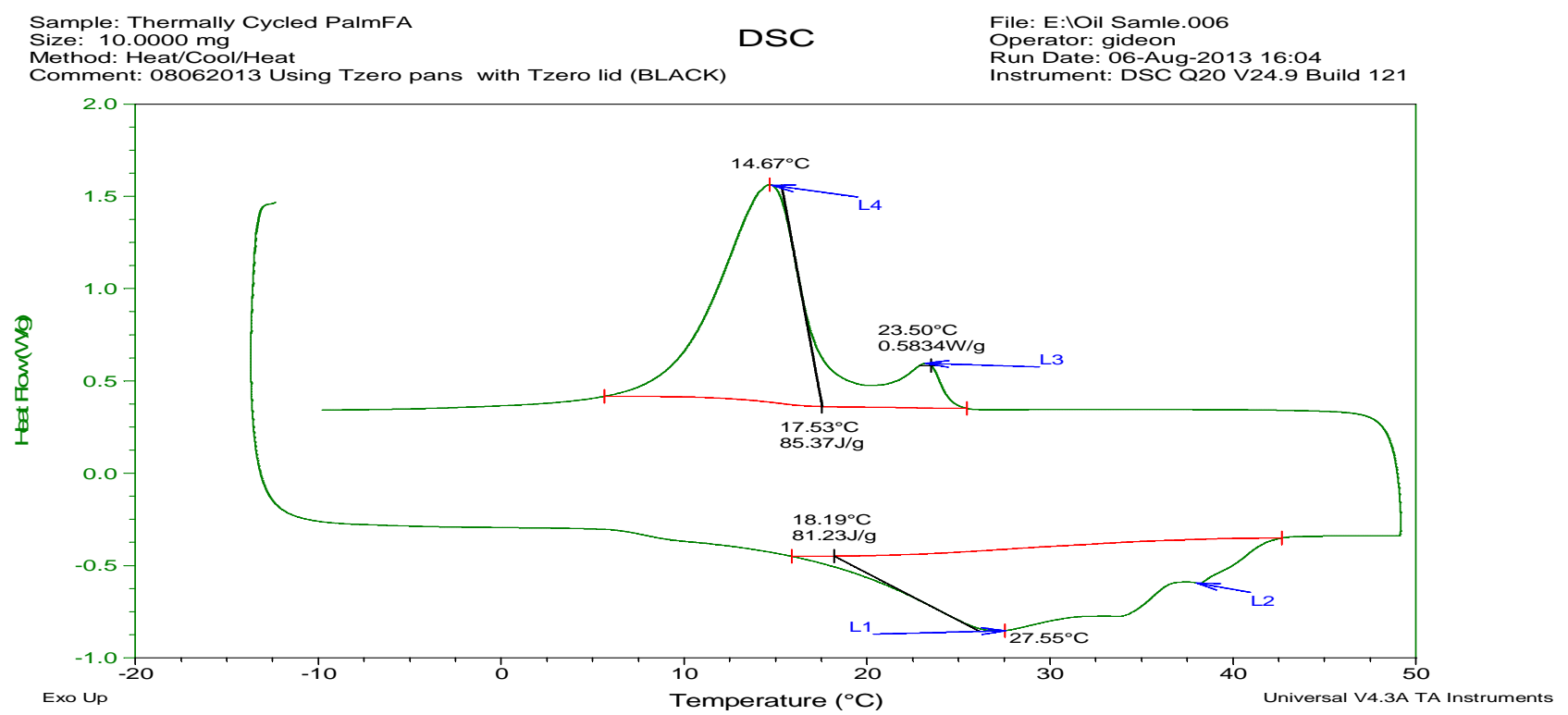

Figure 5.12: DSC thermogram of fatty acid of palm kernel oil after thermal cycling

Figure 5.12 indicates that after thermal cycling of PalmFA, the heating curve was not latent because it exhibits multiple transition peaks and the curve was very broad and complex. Thus, PalmFA cannot be considered as being latent (Berera, 2006), and hence, the results after thermal cycling cannot change its properties. 


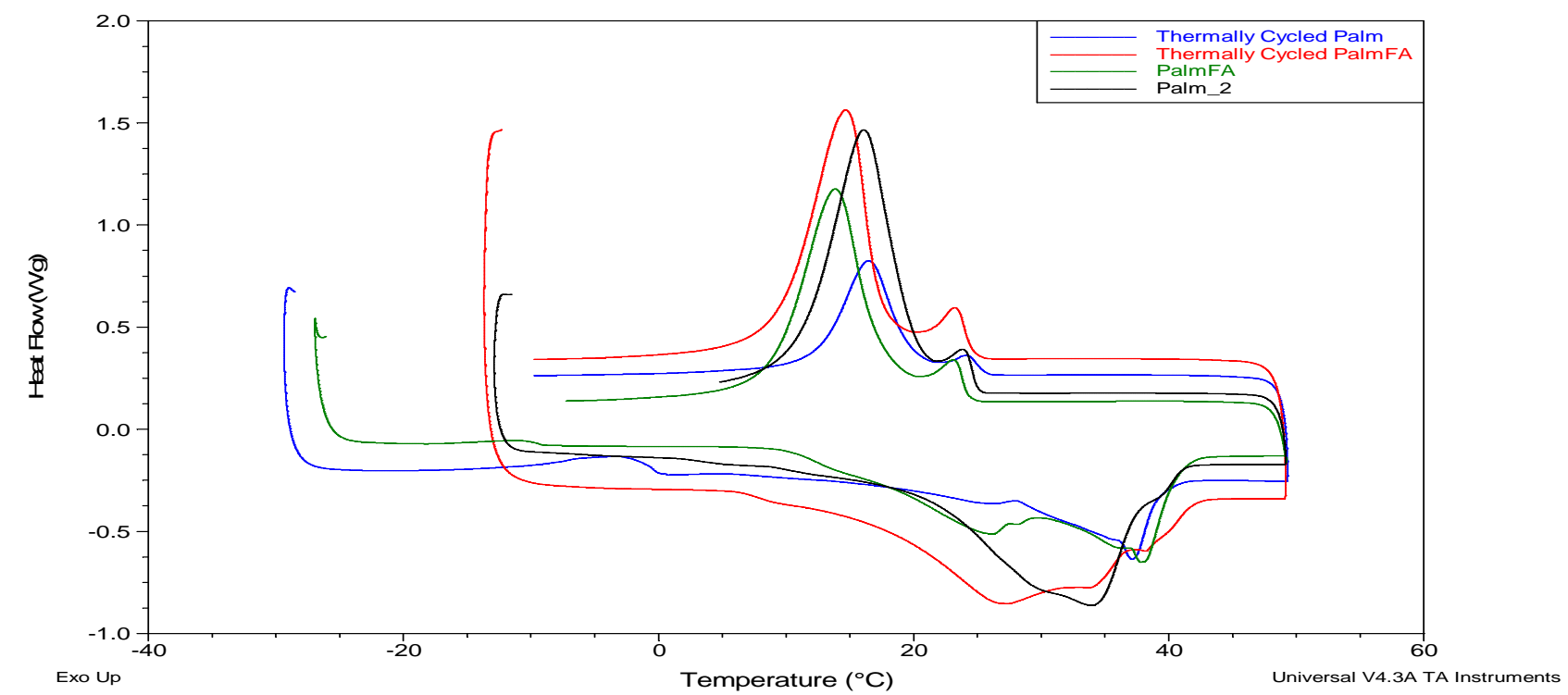

Figure 5.13: Overlaid DSC curves of non- and thermally cycled palm kernel oil, palm kernel fatty acid

The crystallization curve in Figure 5.12 and 5.13 for PalmFA showed that the major peak after thermal cycling increased from $78.42 \mathrm{~J} / \mathrm{g}$ to $85.37 \mathrm{~J} / \mathrm{g}$ (an increase of $8.14 \%$ ). This effect was opposite to that of AllanFA and SheaFA. Again the crystallization curve was more latent for PalmFA as explained earlier. In comparison to the thermogram of AllanFA, the whole cycle (i. e. melting and crystallization) for AllanFA could be considered as latent energy. The curve in Figure 5.13 shows the combined thermograms for the palm kernel oil and PalmFA, as well as their thermally cycled curves. Even though thermal cycling did not negatively impact the physico-thermal properties of the PalmFA, in that their enthalpy values did rather increase and not decrease, the initial fatty acid was not latent for PCM considerations because the melting profile did not give latent energy properties.

\subsubsection{Thermo-gravimetric analysis (TGA) of fatty acids}

Thermo-gravimetric analysis (TGA) was used to determine the thermal stability of the fatty acids derived from the three oils and to assess whether they were good candidates for use in thermal energy storage applications (Sari et al., 2011). Thermal stability of oils were studied using a 
Thermo-gravimetric Analysis (TGA) to show if there was decomposition of the samples during the melting and/or crystallization temperature region (known as the desired temperature range) (Sari et al., 2011). The degradation data of these fatty acids are reported in Figures 5.14-5.23. Allanblackia fatty acid curve is shown in Figure 5.14. The AllanFA exhibited four different degradation steps. The first step occurred within a temperature range of approximately $200^{\circ} \mathrm{C}$ to $334.59^{\circ} \mathrm{C}$ with $61.86 \%$ weight loss. The second step occurred with a weight loss of $27.72 \%$; the third step with a weight loss of $18.36 \%$, and finally the fourth step exhibited a weight loss of $0.42 \%$ at a final temperature of $550^{\circ} \mathrm{C}$. Overall, AllanFA did not degrade in the region of interest (the region where melting and crystallization of the sample occurs, Figure 5.14).

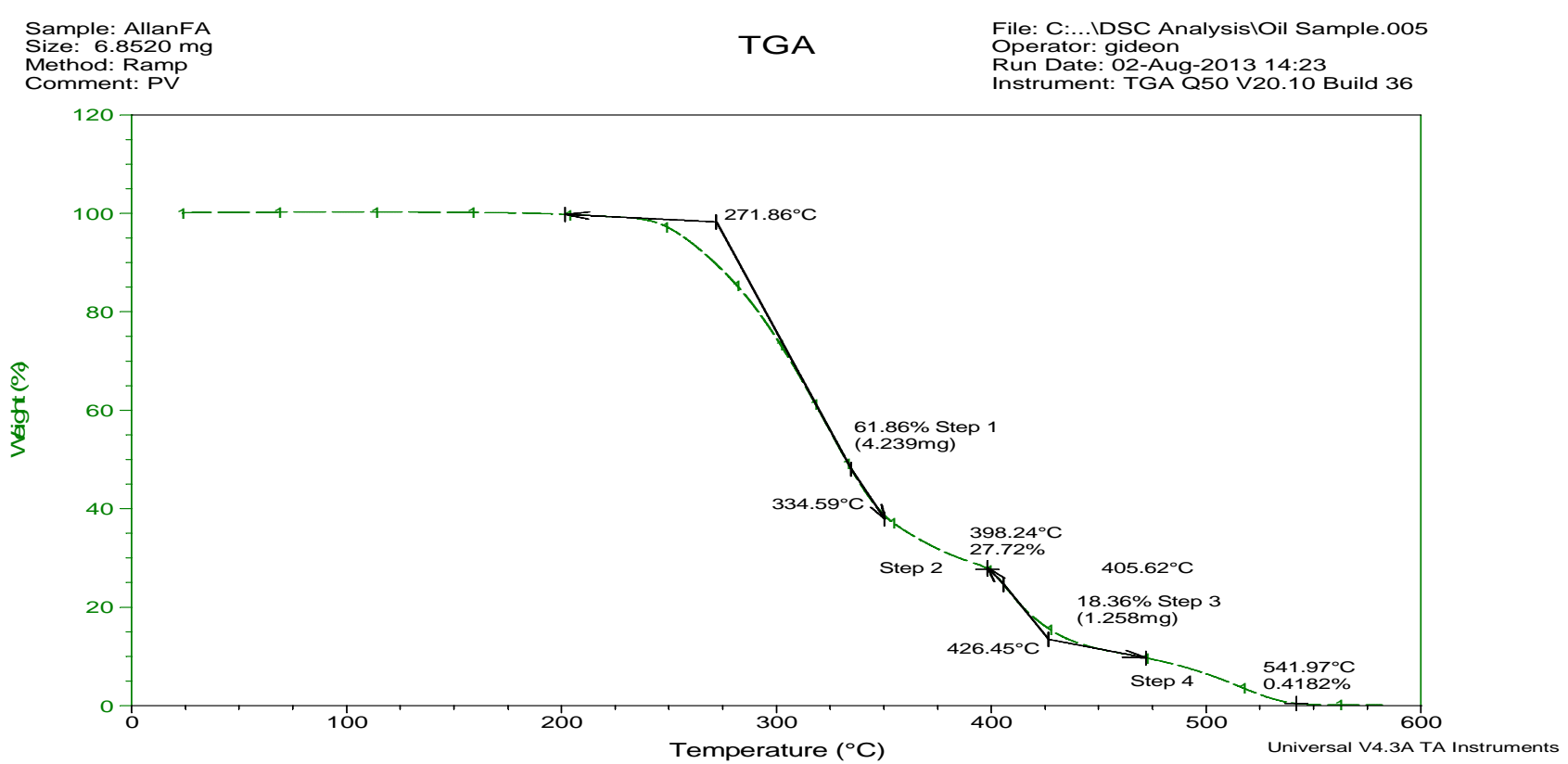

Fig. 5.14: TGA thermogram of AllanFA

The AllanFA was polymorphic because it contained multiple fatty acids and therefore exhibited multiple degradation steps. From the TGA, it is clear that within the temperature region of interest (melting/crystallization), AllanFA was thermally stable because there was no degradation of the sample. 


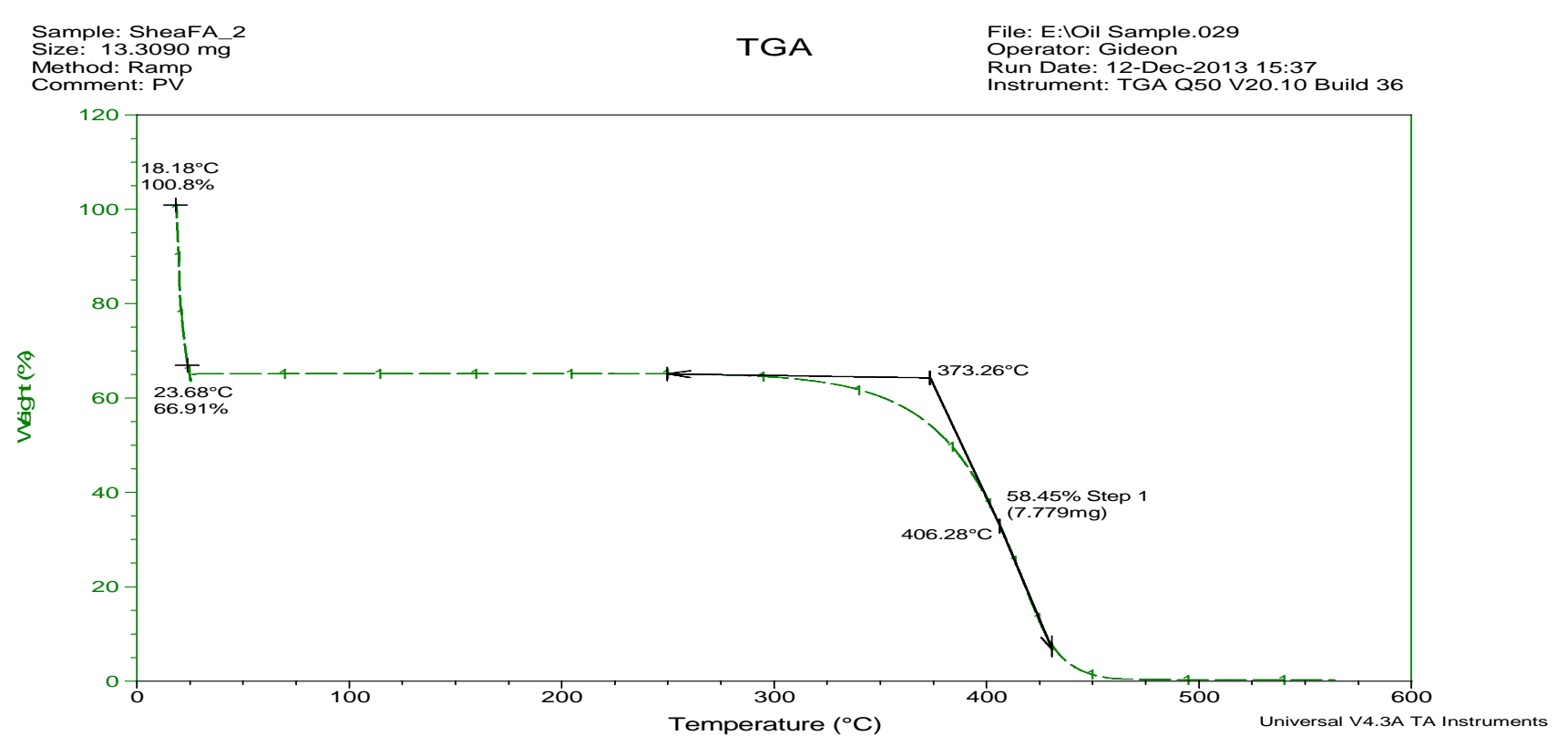

Fig. 5.15: The TGA thermogram of SheaFA

Figure 5.15 shows the TGA thermogram for the fatty acid derived from shea butter (SheaFA). The degradation of SheaFA was unique and was characterized by two degradation steps. The first degradation step occurred within the region of interest $\left(18.18\right.$ and $23.68^{\circ} \mathrm{C}$ ) (Sari et al., 2011). Within this temperature range, the sample degraded $100 \%$ to $66.91 \%$. The second degradation step occurred in the temperature range of $300-475^{\circ} \mathrm{C}$. It is important to note that SheaFA was not thermally stable since it degraded within the desired temperature of melting or crystallization, which is the temperature of interest in this case. The DSC thermogram (Figure 5.3) showed that SheaFA exhibited four transition peaks and the peak temperature for the major peak was at $15.24^{\circ} \mathrm{C}$ within a range of $2.79-25.4^{\circ} \mathrm{C}$. Thus, the TGA results confirmed that SheaFA degraded within the temperature of interest which is the melting crystallization region. 


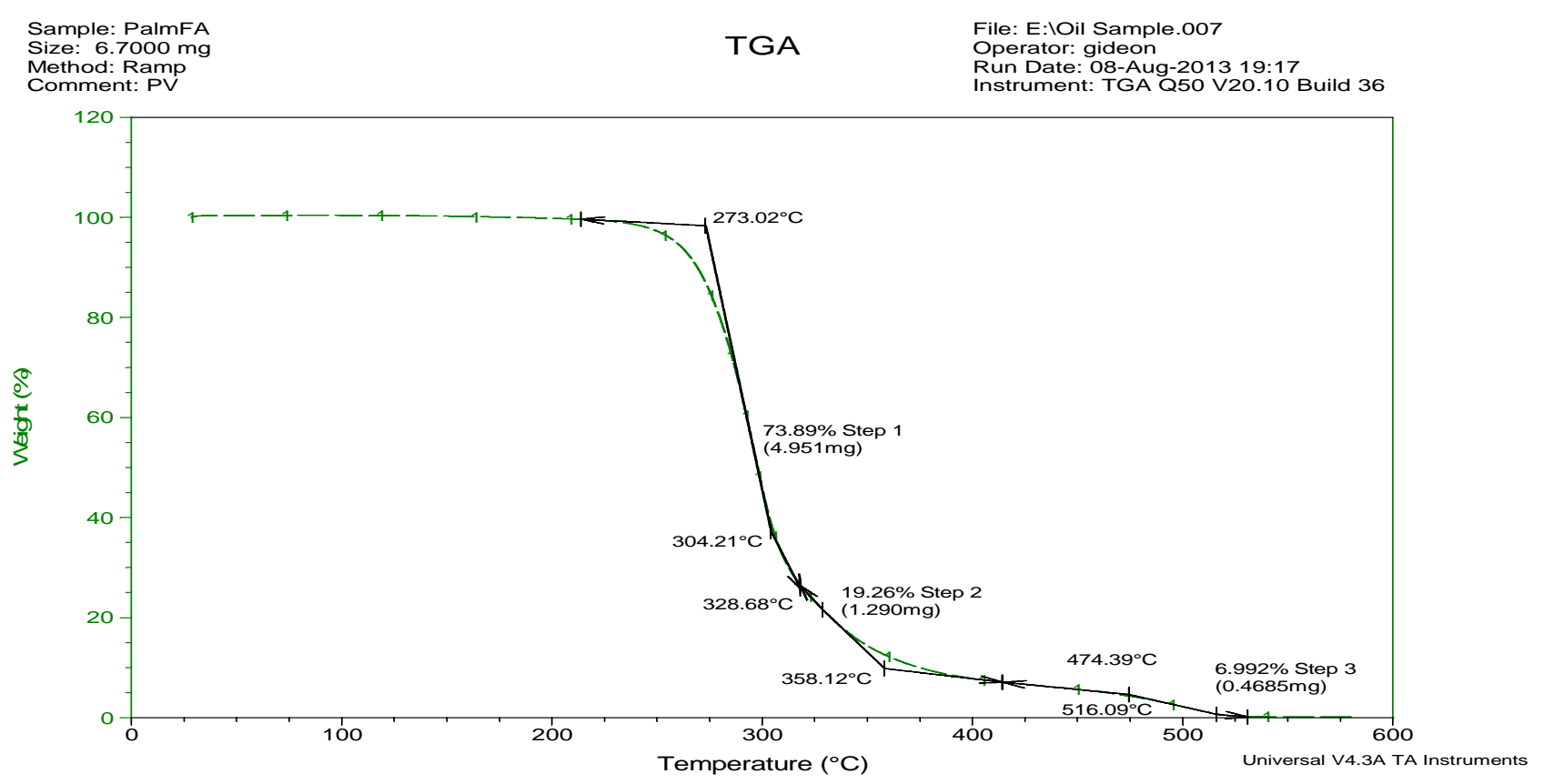

Figure 5.16: TGA thermogram of PalmFA

Figure 5.16 represents the TGA thermogram for the fatty acid derived from palm kernel oil (PalmFA). The PalmFA degradation exhibited three thermal degradation steps. The first degradation step occurred within a temperature range of $250-328.68^{\circ} \mathrm{C}$ with a $73.89 \%$ degradation. The second degradation step occurred between 328.68 and $420^{\circ} \mathrm{C}$ with a $19.26 \%$ degradation. The final $7 \%$ of the sample was degraded in the temperature range of 420 and $550^{\circ} \mathrm{C}$. Again, it was evident that PalmFA did not show any degradation within the temperature of interest, and hence was thermally stable within the temperature of interest.

Figure 5.17 shows that SheaFA was thermally unstable and disintegrated within the desired temperature region of interest and therefore it was not suitable for use as a PCM for thermal energy storage. On the other hand, AllanFA and PalmFA were all thermally stable within their regions of interest. They did not degrade or lose weight within that region. But Figure 5.17 shows that both AllanFA and PalmFA began to lose weight around the same temperature, but PalmFA lost weight faster than AllanFA. Again, while PalmFA lost weight in three steps, AllanFA lost weight in four steps depending on the type and number of fatty acids present in each sample. 


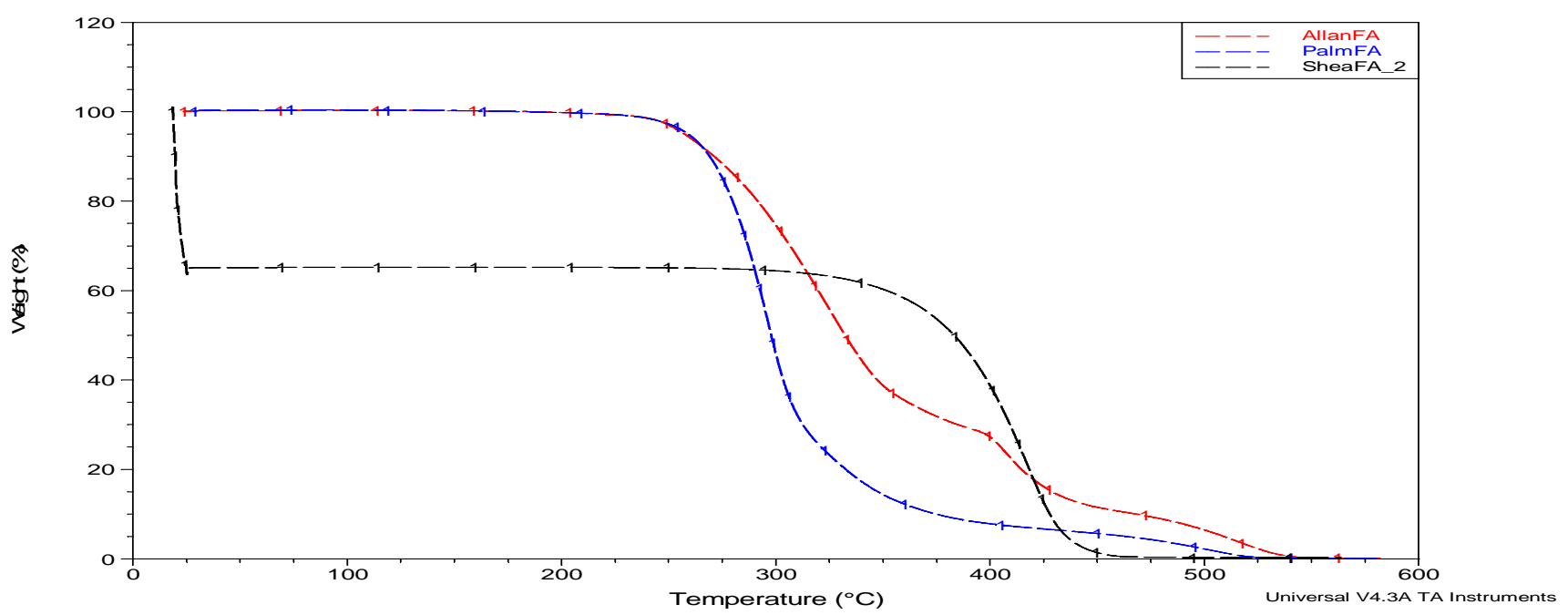

Fig. 5.17: TGA thermogram of the overlaid AllanFA, SheaFA, and PalmFA.

\subsubsection{Thermo-gravimetric analysis of fatty acids after Thermal Cycling}

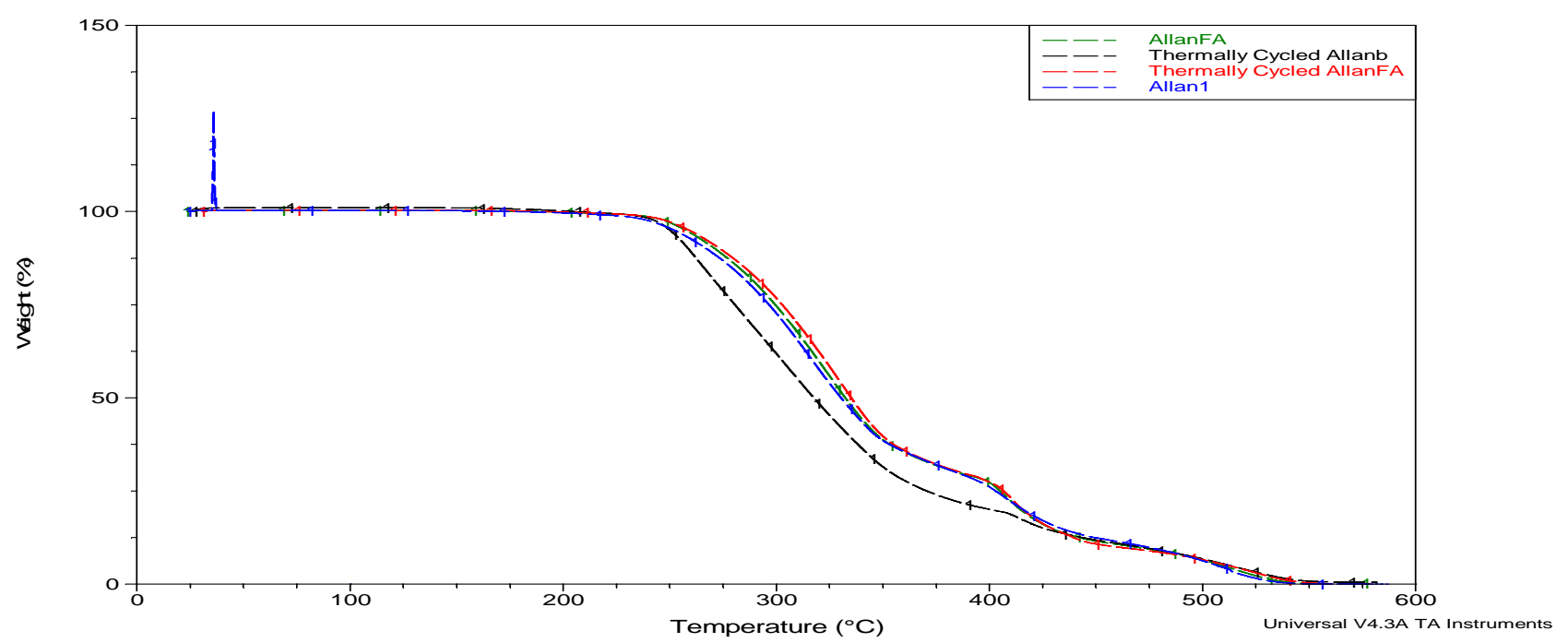

Figure 5.18: TGA curve of the overlaid Allanblackia, AllanFA, TC Allanblackia, and TC AllanFA (Data from earlier paper on the use of fruit seed oils as PCMs). 
Figure 5.18 shows the overlaid TGA thermogram of Allanblackia oil and AllanFA, and their samples after thermal cycling. It was evident that after thermal cycling, there were no loss in weight of all the samples within their desired temperature regions of interest. Consequently, they were thermally reliable. However, AllanFA showed more resilience than the Allanblackia oil which lost weight faster but beyond the region of interest. Also, the gain in weight shown by the Allanblackia oil and which was due to oxidative instability was not observed in the AllanFA.

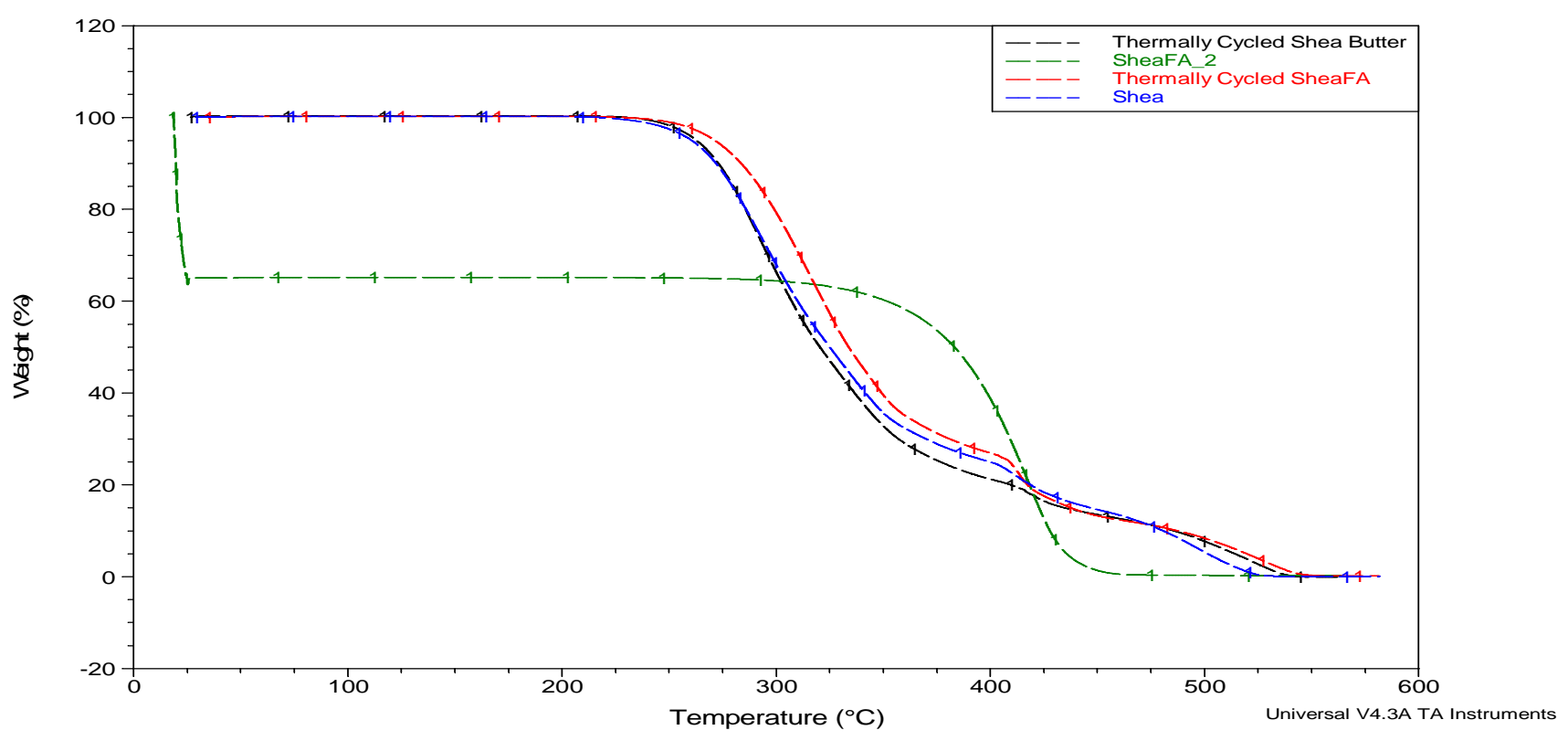

Figure 5.19: TGA curve of the overlaid shea Butter, SheaFA, TC Shea Butter, and TC SheaFA (Data from earlier paper on the use of fruit seed oils as PCMs).

Figure 5.19 also showed the overlaid TGA thermograms of shea butter, SheaFA and their thermally cycled samples. Even though the SheaFA was not stable because it lost weight within the desired temperature range of interest, the thermally cycled sample did not exhibit that phenomenon. Shea butter itself did not show much variation after thermal cycling. However, thermal stability data obtained via TGA showed that shea butter exhibited greater thermal stability than its fatty acid.

Figure 5.20 shows that the TGA thermograms of non- and thermally cycled palm kernel oil and PalmFA exhibited the same pattern. Therefore, it can be concluded that palm kernel oil and 
PalmFA are all thermally stable for use as PCMs for thermal energy storage based on TGA considerations.

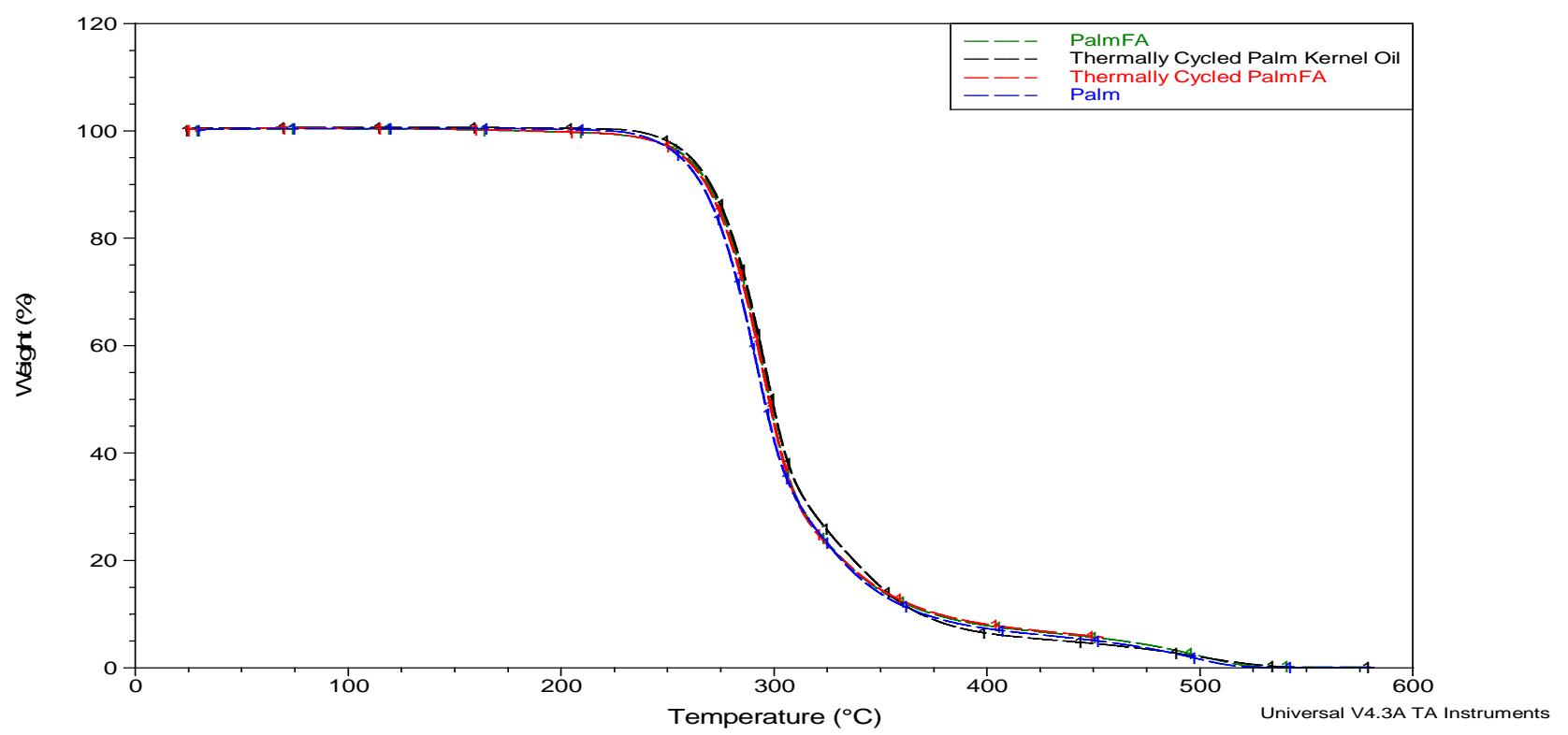

Figure 5.20: TGA curve of the overlaid palm kernel oil, PalmFA, TC palm kernel, and TC PalmFA (Data from earlier paper on the use of fruit seed oils as PCMs).

\subsubsection{Fourier Transform Infrared (FTIR) Spectroscopy of Fatty Acids}

The FTIR spectroscopy was used to study the functional group chemistry and consequently the thermal stability of the non- and thermally cycled fatty acids derived from the three oils. A change in the functional group chemistry of the non- and thermally cycled fatty acids indicated chemical instability. Figure 5.21 gives the overlaid thermograms of fatty acids derived from Allanblackia (AllanFA) and the thermally cycled AllanFA. After 1000 times thermal cycling, no major difference could be observed in their FTIR spectra (Figure 5.21). The fatty acid derived from Allanblackia could therefore be considered as being thermally stable and suitable for use as a PCM for thermal energy storage system. Figure 5.22 also shows no change in the chemistry of the SheaFA after being thermally cycled for a 1000 times. 


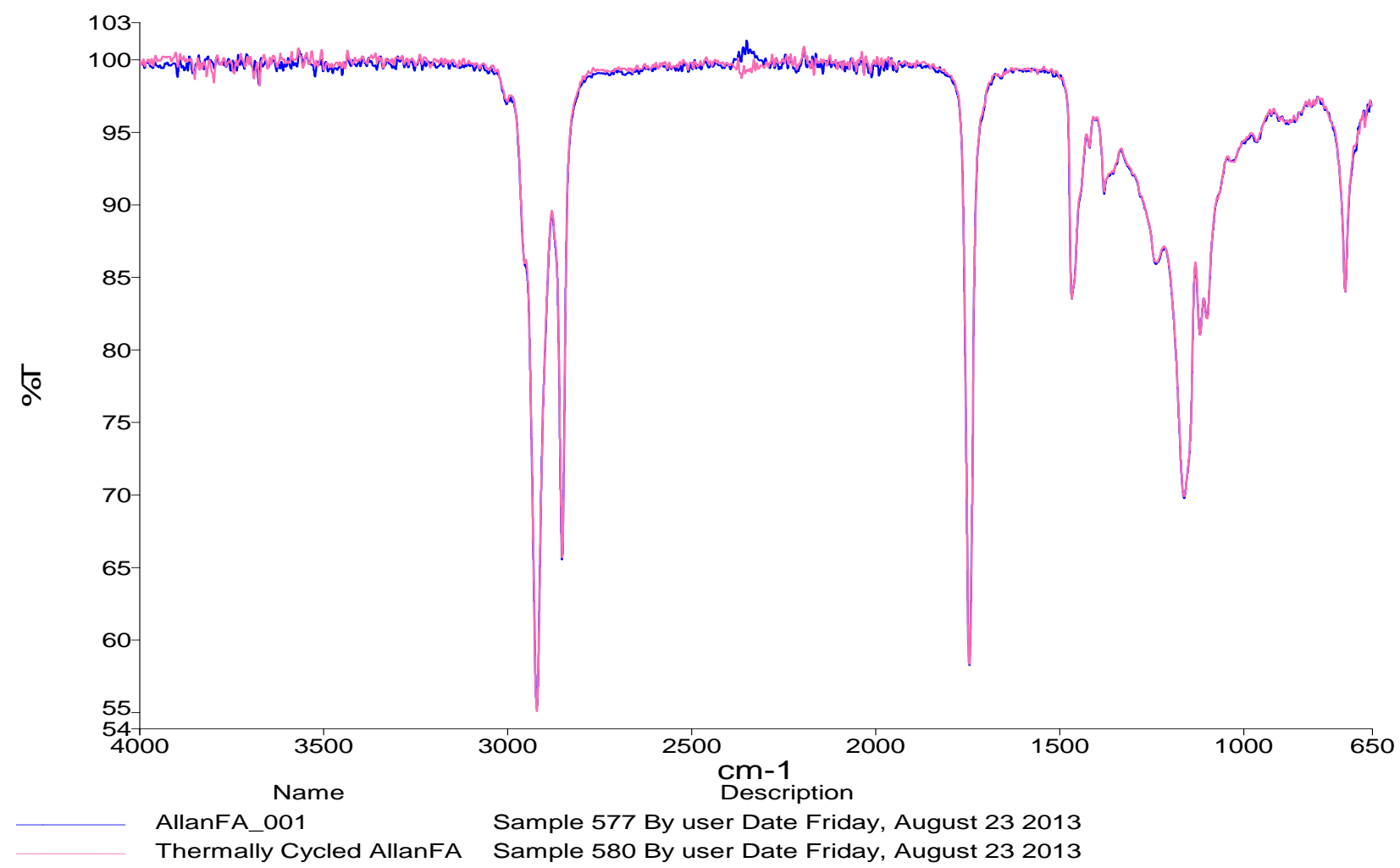

Figure 5.21: FTIR spectra of the overlaid curves of AllanFA and Thermally Cycled AllanFA.

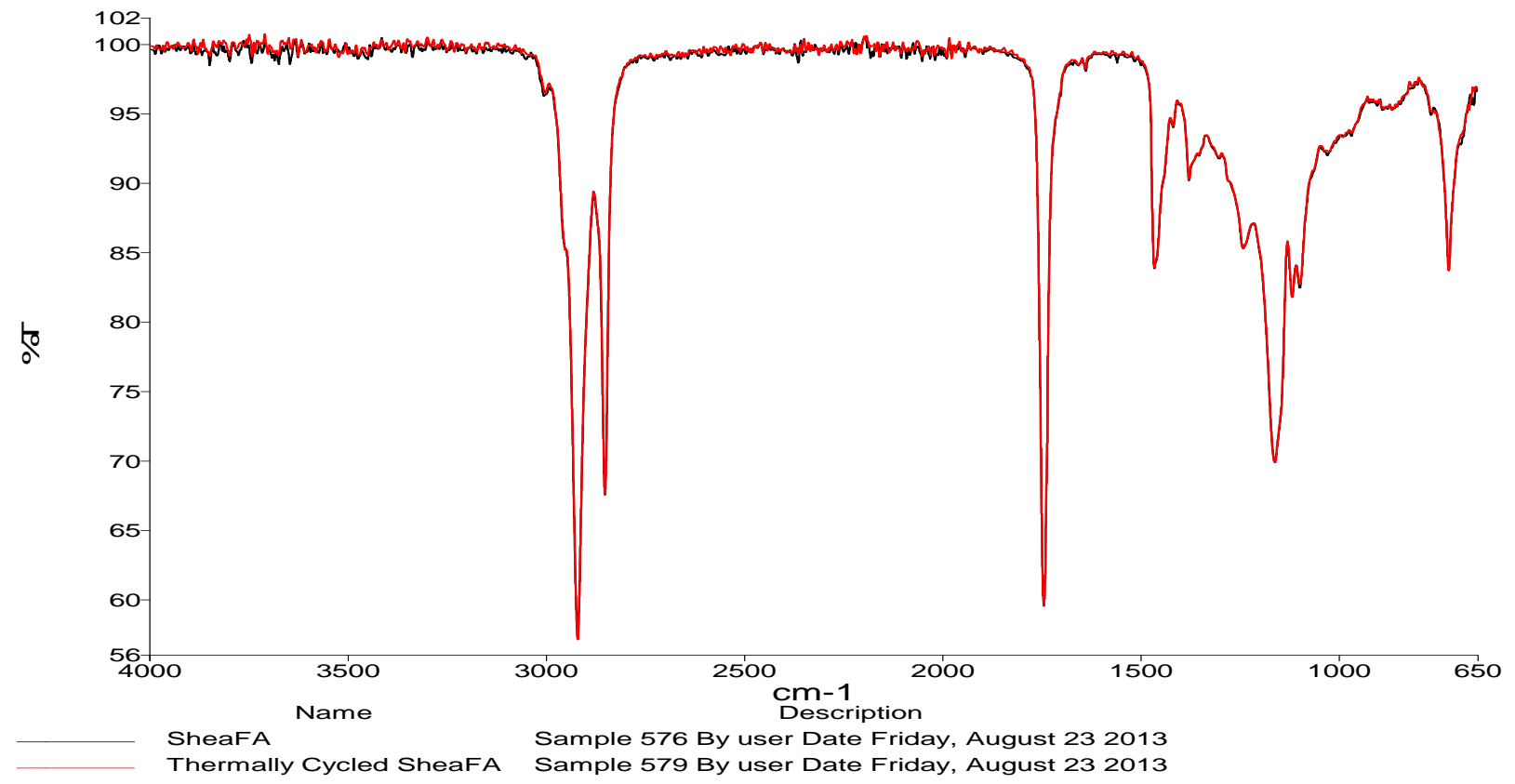

Fig. 5.22: FTIR Spectra of the overlaid curves of SheaFA and Thermally Cycled SheaFA. 
The FTIR spectra of SheaFA and the thermally cycled SheaFA are all the same and did not depict any changes in its functional groups chemistry. Therefore, fatty acids derived from shea butter was thermally stable for use as a PCM in thermal energy storage systems reference to their functional group chemistry. Figure 5.23 shows the spectra of the overlaid thermograms of the produced fatty acid of palm kernel oil (PalmFA) and the Thermally Cycled PalmFA. Similarly, FTIR spectra of non- and thermally cycled fatty acids derived from palm kernel oil were similar and therefore thermally stable for use as a PCM for thermal energy storage system.

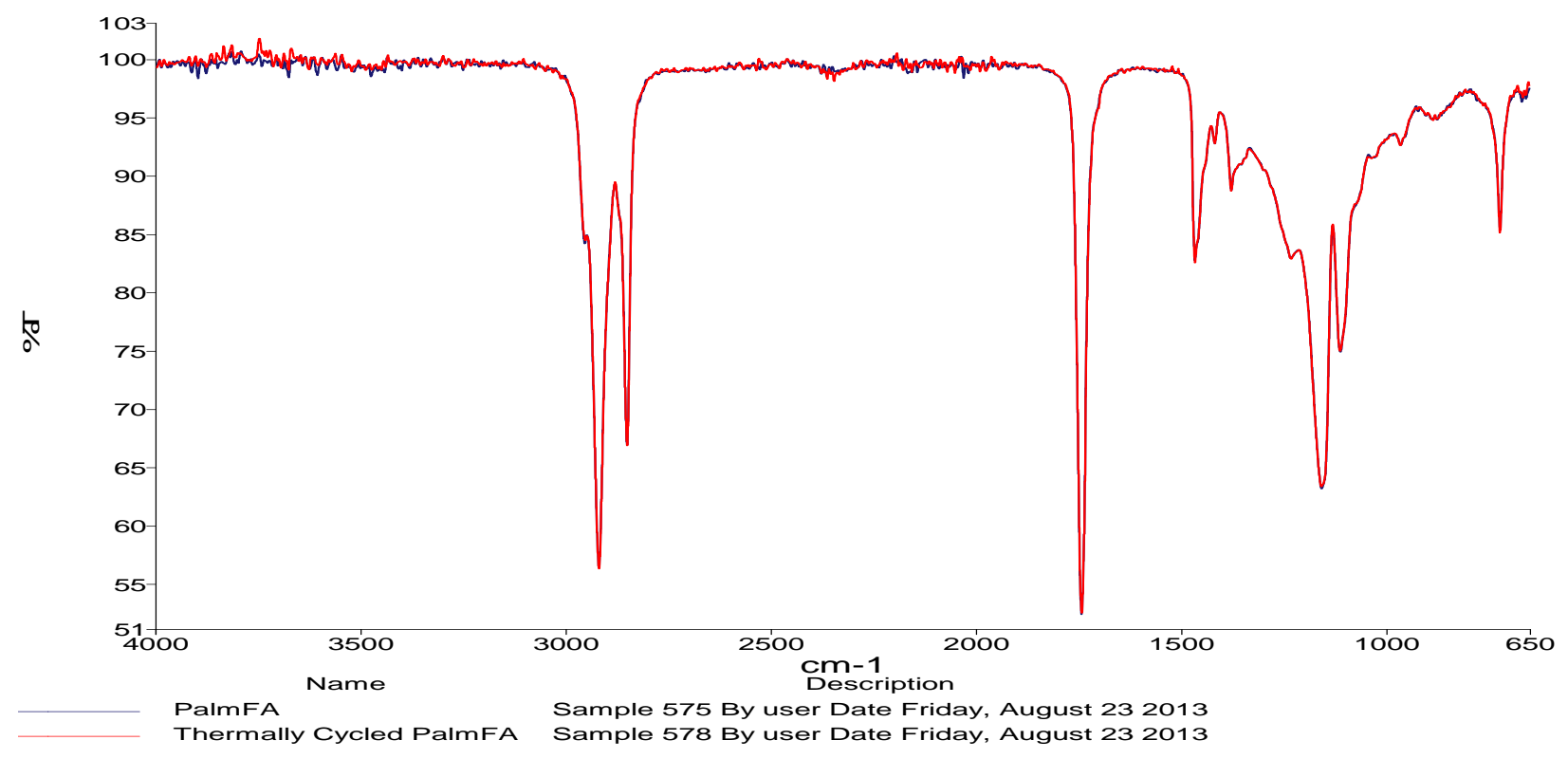

Figure 5.23: FTIR spectra of the overlaid curve of PalmFA and Thermally Cycled PalmFA.

\subsection{Conclusions}

Considering the use of the fatty acids of Allanblackia, shea butter and palm kernel oil for use as PCMs for thermal energy storage systems, DSC studies showed that AllanFA had an enthalpy value of $97.19 \mathrm{~J} / \mathrm{g}$ at a peak temperature of $37.54^{\circ} \mathrm{C}$ for the major endothermic peak. Crystallization enthalpy was also high with a value of $47.18 \mathrm{~J} / \mathrm{g}$ at a major peak temperature of $16.66^{\circ} \mathrm{C}$. The energy involved was a latent heat energy for AllanFA. The thermal reliability was not clear since there was a decrease in enthalpy after thermal cycling from 97.19-60.53 J/g and also an exothermic peak appeared after the thermal cycling process. However, AllanFA could still be used as a PCM after a reduction of $37.72 \%$ for the heating cycle and also a reduction of $26.43 \%$ for the cooling cycle (from $47.18-34.71 \mathrm{~J} / \mathrm{g}$ ), because the final enthalpy value could be 
considered still high enough for use for thermal energy storage. AllanFA was thermally stable within the desired region of interest where there was no degradation of the sample. The infrared data showed that AllanFA was thermally stable and the sample did not decompose after thermal cycling. The DSC curves of SheaFA and PalmFA showed that their melting cycle did not indicate exhibition of latent heat energies even though their crystallization curves gave latent heats. They melted over a very wide range and showed too many transition peaks. Furthermore, the TGA of SheaFA showed that it was thermally unstable. The infrared spectra of both the SheaFA and the PalmFA showed that they are all chemically stable after thermal cycling.

In conclusion, the fatty acids of Allanblackia oil showed that they could be considered as a potential PCM for thermal energy storage systems while both the SheaFA and PalmFA did not.

\subsection{References}

Abhat, A. (1983). Low temperature latent heat thermal energy storage: heat storage materials. Solar Energy 30, 313-332.

AOCS Official Method Da 12-48.

Beckham, G. and Gill, P. V., 1984. Thermal energy storage. Springer-Verlag, Austria. 230.

Berera, G. P. 2006. Thermal energy storage systems - stearic/lauric acid mixtures as phase change materials. 3.014 Materials laboratory Module -1.9

Berger, K.G., and Akehurst, E.E. (1966). Some applications of differential thermal analysis to oils and fats. International Journal of Food Science \& Technology 1, 237-247.

Buddhi, D., and Sawhney, R.L. (1994). Proceeding of thermal energy storage and energy conversion. School of Energy and Environmental Studies. Devi Ahilya University, Indore, India.

Dincer, I., and Rosen, M. (2002). Thermal energy storage: systems and applications (John Wiley \& Sons).

Garg, H.P., Mullick, S.C., and Bhargava, A.K. (1985). Solar thermal energy storage (Springer Science \& Business Media).

Lane, G.A. (1983). Solar heat storage: latent heat materials.

Li, W.-D., and Ding, E.-Y. (2007). Preparation and characterization of a novel solid-liquid PCM: Butanediol di-stearate. Materials Letters 61, 1526-1528.

Sarı, A. (2003). Thermal characteristics of a eutectic mixture of myristic and palmitic acids as phase change material for heating applications. Applied Thermal Engineering 23, 1005-1017. 
Sar1, A. (2003). Thermal reliability test of some fatty acids as PCMs used for solar thermal latent heat storage applications. Energy Conversion and Management 44, 2277-2287.

Sarı, A., Biçer, A., Lafçı, Ö., and Ceylan, M. (2011). Galactitol hexa stearate and galactitol hexa palmitate as novel solid-liquid phase change materials for thermal energy storage. Solar Energy 85, 2061-2071.

Sharma, S.D., and Sagara, K. (2005). Latent heat storage materials and systems: a review. International Journal of Green Energy 2, 1-56.

Sharma, S.D., Buddhi, D., and Sawhney, R.L. (1999). Accelerated thermal cycle test of latent heat-storage materials. Solar Energy 66, 483-490.

Shukla, A., Buddhi, D., and Sawhney, R.L. (2008). Thermal cycling test of few selected inorganic and organic phase change materials. Renewable Energy 33, 2606-2614.

Telkes, M. (1978). Trombe wall with phase change storage material. In Proceedings of the 2nd National Passive Solar Conference, Philadelphia, PA, 


\title{
6 Evaluation of methyl and butyl esters of Tropical fruit oils as Phase Change Materials for Thermal Energy Storage
}

\begin{abstract}
Methyl and butyl esters were synthesized from the oils of Allanblackia, shea butter and palm kernel using the transesterification method. These esters were subjected to both thermo-physical assessment using DSC and TGA methods, and chemical analysis using the FTIR method respectively. The TGA curve and data showed that all the esters were stable within the desired temperature of operation or interest. They did not degrade within the temperature of melting and crystallization, even though at higher temperatures they exhibited various stabilities. The methyl esters gave multiple degradation steps, an indication of their polymorphism, while the butyl esters gave a single degradation step. The FTIR method showed that all the esters were chemically stable except palm kernel methyl ester. The DSC curves showed that the methyl esters of all the oils did not show latent energy properties and lack thermal reliability while the butyl esters of Allanblackia and shea butter have a good reliability. Allanblackia butyl ester and shea butter butyl ester are therefore the best candidates to be considered as PCMs for thermal energy storage systems.
\end{abstract}

\subsection{Introduction}

Phase change materials (PCMs) because of their high energy storage density are effective latent heat medium for use as thermal energy storage (TES). Renewable energies reduce carbon dioxide emissions as compared to that from fossil fuels. Solar energy as a renewable energy is a potential replacement to fossil fuels in domestic applications, industrial uses, agricultural uses, etc. However, renewable energy sources such as solar energy is intermittent in its production and supply of energy. There is therefore the need to store the energy produced from solar sources during the day and used in the night when needed (Sharma and Sagara, 2005). Latent heat storage has some problems which need resolution. These are low thermal conductivity, subcooling, phase segregation, change in volume, cost, and change in the thermo-physical properties over a long period of cycling of the PCM (Sharma and Sagara, 2005). Different PCMs can be employed in different applications such as solar water heating, greenhouse application, waste heat recovery systems, space cooling and heating, pizza transportation systems, organ 
transport systems, solar cooking, etc. Phase change materials used in latent energy storage undergo phase transformations in the form of solid-solid transformation, solid-liquid transformation, solid-gas transformations and liquid-gas transformation. Solid-solid transformation has the advantage of smaller volume change in the phase change process, longer lifespan, no leakage, smaller erosion to the device, etc. They however have the disadvantage of smaller latent heat and higher temperature during phase transformation (Wang et al., 2000). Solid-gas and liquid-gas transformations have high latent heat but are associated with very large changes in volume resulting in problems of containment making the transitions too complex and uneconomical. Solid-liquid transformation has the greatest potential for thermal energy storage due to less than $10 \%$ change in volume with adequate comparable latent heat energy (Sharma and Sagara, 2005).

Phase change materials can be classified into organic, inorganic and eutectic mixtures. Organic PCMs are paraffins and non-paraffins, inorganics include salt hydrates and metallic oxides, while the eutectics are made up of mixtures of inorganic-inorganic compounds, inorganic-organic compounds or organic-organic compounds (Garg et al., 1985; Sharma et al., 2009). Fatty acids and fatty acid esters have been classified as non-paraffin organic PCMs. Sari (2003) studied fatty acids such as stearic acid, palmitic acid, myristic acid and lauric acid, to determine their thermal reliability for use as latent heat storage materials. The study concluded that the thermal reliability of fatty acids are good enough for use as thermal energy storage materials because of their latent heat of fusion and melting temperature with respect to thermal cycling. Sari et al. (2009) synthesized a series of esters from stearic acid and n-butyl alcohol, isopropyl alcohol and glycerol. Fourier transform infrared and ${ }^{1} \mathrm{H}$ NMR were used for chemical characterization; DSC for determination of latent heat and melting temperature; thermal cycling for thermal reliability; and thermal conductivity to see if the esters could be used for PCMs. It was concluded that synthesized esters had satisfactory thermal properties, good thermal reliability and thermal conductivities suitable for use as PCMs for thermal energy storage. Sari et al. (2010) again synthesized fatty acid esters from glycerol and myristic acid, palmitic acid and stearic acid. Their studies concluded that the synthesized esters had adequate thermal stability, chemical stability, thermal reliability and thermal conductivity for use as PCMs for thermal energy storage. For a PCM to be used in thermal storage systems, it should have the aforementioned desirable thermophysical, kinetics and chemical properties (Garg et al., 1985). 
Vegetable oils can be converted into esters via transesterification reaction indicated below:

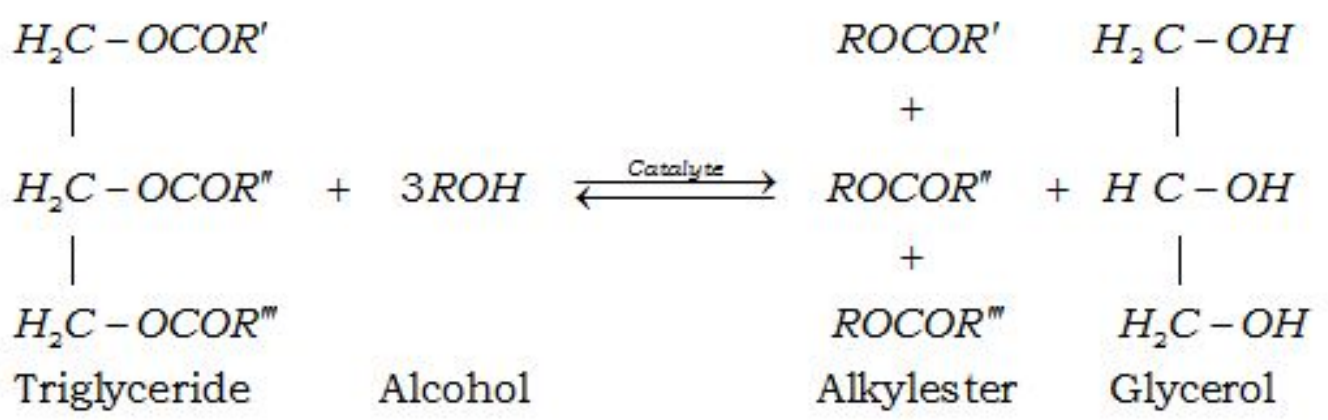

Source: http://www.biomassenergy.gr/en/articles/technology/biodiesel/505-biodiesel-productionand-the-transesterification-process

where R ', R" and R"' are long chains containing carbon and hydrogen atoms (chain of fatty acids).

Nimcevic et al. (2000) studied transesterification of rapseed oil using butanol with both basic and acidic catalysts and showed that potassium hydroxide $(\mathrm{KOH})$ catalyst produced a yield (butyl esters) of $15.4 \%$ while sulfuric acid $\left(\mathrm{H}_{2} \mathrm{SO}_{4}\right)$ catalyst gave a yield of $97.5 \%$ in 3 hours.

To date, synthesized esters that have been characterized and assessed for use as PCMs have been derived from fossil fuel sources. The overarching objectives of this study is to evaluate potential precursors from renewable and sustainable sources for the production of esters of fatty acids and evaluation for their use as PCMs in thermal energy storage. Oils from tropical tree fruits of Allanblackia, shea butter and palm kernel were used as precursors. Specifically, in this study, fatty acid ester were synthesized from these oils and characterized by thermo-physical and chemical methods to determine their suitability for use as PCMs for thermal energy storage.

\subsection{Materials and Methods:}

\subsubsection{Materials:}

Oil from the seeds of Allanblackia (Allanblackia paviflora) obtained from Ghana had already been extracted (data from the use of oil as PCMs for energy storage); Shea butter (Bulk Apothecary, Ohio, U.S.A.), Palm kernel oil (Organic Creations, Oregon, U.S.A.), Sulfuric Acid (Fisher Scientific, NJ, U.S.A), Anhydrous Sodium Sulfate (Fisher Scientific, NJ, U.S.A), TGA instrument (TA Insturments model Q50, TA instruments, Inc., DE, USA), Platinum pan, DSC 
instrument (TA Insturments model Q20, TA instruments, Inc., DE, USA), Tzero Aluminium hermetic pans and lids (DSC Consumables Inc., Austin, MN, U.S.A.), PerkinElmer Spectrum 100 FTIR (Waltham, Massachusetts, U.S.A.) with an ATR spectrometer, PTC-100 Programmable Thermal Controller (MJ Research Inc., Watertown, MA, U.S.A.), Buchi Rotavapor, R-210/215 (Flawil, Switzerland), vacuum pump.

\subsubsection{Methods:}

\subsubsection{Experimental design}

The experimental design here is a completely randomized design.

\subsubsection{Preparation of methyl esters from Allanblackia, shea butter and palm kernel oil}

Methyl esters of the oils of Allanblackia, shea butter and palm kernel were prepared by transesterifcation via the protocol of Mahamuni and Adewuyi (2009). Lang et al. (2001) have shown that a base catalyst, $\mathrm{KOH}$, was an excellent catalyst for methyl ester preparation. Oil samples were reacted with methanol using a ratio of methanol to oil as 6:1 under reflux at a temperature of $65^{\circ} \mathrm{C}$ for about 3 hours with stirring at $1000 \mathrm{rpm}$. The oil sample was heated on a water bath to $65{ }^{\circ} \mathrm{C}$ and $1 \%$ (weight/volume, wt/v) potassium hydroxide $(\mathrm{KOH})$ of the oil was dissolved in the methanol and added to the heated oil. The reaction started when the reaction mixture attained $65^{\circ} \mathrm{C}$. At the end of the reaction, the mixture was poured into a separating funnel and two layers separated out. The upper and bottom layers represented the ester and glycerin layers respectively. The glycerin layer was separated from the ester layer by decantation using gravity. The upper methyl ester layer was heated in a rotavapor (Buch Rotavapor) under vacuum to extract excess methanol. The remaining product was poured into a separating funnel and washed several times with warm water and then dried over anhydrous sodium sulfate $\left(\mathrm{Na}_{2} \mathrm{SO}_{4}\right)$.

\subsubsection{Preparation of butyl esters from Allanblackia, shea butter and palm kernel oils}

Butyl esters of the oils of Allanblackia, shea butter and palm kernel were prepared via tranesterification (Nimcevic et al. 2000). Nimcevic et al., 2000, have shown that an acid catalyst gave a higher yield with butanol than a base catalyst. About $10 \mathrm{~g}$ of oil was measured into a 125 
$\mathrm{ml}$ conical flask and heated on an oil bath to $117^{\circ} \mathrm{C}$. A $1.5 \%$ (volume/volume, $\mathrm{v} / \mathrm{v}$ ) sulfuric acid $\left(\mathrm{H}_{2} \mathrm{SO}_{4}\right)$ as catalyst was added to butanol at a molar ratio of 9:1 (butanol to oil). The alcohol mixture was added to the heated oil at the $117^{\circ} \mathrm{C}$ under reflux. The reaction commenced with the introduction of the butanol-catalyst mixture and ran for 3 hours with stirring (1000 rpm). At the end of reaction, the reaction mixture was poured into a separating funnel and the lower glycerin phase decanted. The upper phase containing the produced ester was heated in a rotary evaporator (Buchi Rotavapor) under vacuum to remove excess alcohol. The ester remaining was washed several times with warm water and finally dried over anhydrous $\mathrm{Na}_{2} \mathrm{SO}_{4}$.

\subsection{Chemical characterization of methyl and butyl esters of Allanblackia, shea butter and palm kernel oils}

Fourier transform infrared spectroscopy was used to characterize the functional group chemistry of both methyl and butyl esters. The FTIR spectra were acquired using a PerkinElmer Spectrum 100 instrument with Universal Sampling Accessory within a wavenumber range of 4000-600 $\mathrm{cm}^{-}$ 1. Measurements were taken in transmittance mode with four scans per measurement. A $0.1 \mathrm{~mL}$ ester sample was warmed on a water bath to a temperature of $40^{\circ} \mathrm{C}$ and dropped on a diamond ATR probe aperture. Spectra were taken at a resolution of $8 \mathrm{~cm}^{-1}$ under 1 minute against air as the background. FTIR spectra of samples were taken before and after thermal cycling of the esters.

\subsection{Thermo-physical characterization of esters}

The phase change temperatures and enthalpies of esters were determined by thermo-physical methods of DSC and TGA. Heat or energy involved in melting and crystallization as well as the temperature at which these transitions take place is given by DSC measurements and the degradation profile of the esters by TGA.

\subsection{Differential scanning calorimetry (DSC) of esters}

Differential scanning calorimeter (TA Instruments model Q20, TA instruments, Inc., DE, USA) was used to determine heat/energy involved in melting/crystallization and the temperatures at which these transitions occurred. Nitrogen (99.999\% purity) was used as the purge gas at a flow rate of $\sim 20 \mathrm{~mL} / \mathrm{min}$. The instrument was calibrated with indium (m.pt. $156.6^{\circ} \mathrm{C}, \Delta H_{f}=28.45 \mathrm{~J} / \mathrm{g}$ ) 
and $n$-dodecane (m.p. $-9.65^{\circ} \mathrm{C}, \Delta H_{f}=216.73 \mathrm{~J} / \mathrm{g}$ ). Samples of $c a .6-12 \mathrm{mg}$ were weighed into Tzero Aluminium hermetic pans (DSC Consumables Inc., Austin, MN, U.S.A.) to the nearest 0.1 mg, and lids were hermetically sealed. An empty, Tzero Aluminium hermetic pan was used as reference. Prior to analysis of samples, the baseline was obtained with an empty Tzero hermetically sealed aluminum pan. Measurements were taken under nitrogen atmosphere using a heating/cooling/heating cycle at $5^{\circ} \mathrm{C} / \mathrm{min}$. The onset temperature $\left(T_{o}\right)$, the offset temperature $\left(T_{f}\right)$ (points where the extrapolated leading edge of the endotherm/exotherm intersects with the baseline), and peak temperatures (temperatures of maximum different heat flow) between $T_{o}$ and $T_{f}$ were determined. The melting and cooling temperature ranges were obtained from the difference between $T_{o}$ and $T_{f}$. All DSC values reported as average of three scans (Tan and Che Man, 2000).

\subsection{Thermal cycling of esters}

To determine the thermal reliability and stability of the methyl and butyl esters, their samples were thermally cycled 1000 times (melting/solidification) using a programmable thermal cycler. Thermal cycling of samples was effected by heating them from $0^{\circ} \mathrm{C}$ to $50^{\circ} \mathrm{C}$ at a rate of $1{ }^{\circ} \mathrm{C} / \mathrm{s}$ and held for $30 \mathrm{~s}$; cooled from $50^{\circ} \mathrm{C}$ to $0^{\circ} \mathrm{C}$ at the same rate of $1{ }^{\circ} \mathrm{C} / \mathrm{s}$, and again held for $30 \mathrm{~s}$. This process was repeated 999 times.

\subsection{Thermo-gravimetric analysis (TGA) of esters}

Thermal degradation of the esters were determined using a thermo-gravimetric analyzer (TA Insturments model Q50, TA instruments, Inc., DE, USA). The instrument was calibrated using calcium oxalate. Samples were placed in a platinum pan and subjected to cycling using a temperature range of $25-600^{\circ} \mathrm{C}$ at a heating rate of $10^{\circ} \mathrm{C} / \mathrm{min}$ in a nitrogen $/$ compressed air atmosphere (Sari et al., 2011). 


\subsection{Results and Discussions:}

\subsubsection{Differential scanning calorimetric (DSC) analysis of methyl and butyl esters produced from oils of Allanblackia, shea butter and palm kernel}

For an enthalpy change to be considered to be a latent energy, the energy is delivered at a constant temperature or over a narrow temperature range. These materials are therefore characterized by latent heat of melting/crystallization and their melting point(s) (Berera, 2006). The DSC profile of the methyl ester from Allanblackia oil (Allan Methyl Ester) is shown in Figure 6.1. The first heating process gave an enthalpy value of $38.44 \mathrm{~J} / \mathrm{g}$ extrapolated to a temperature value of $39.2^{\circ} \mathrm{C}$ at a peak temperature of $41.81^{\circ} \mathrm{C}$. On cooling, a small exothermic peak appeared at a peak temperature of $44.96^{\circ} \mathrm{C}$ with an enthalpy value of $2.152 \mathrm{~J} / \mathrm{g}$. The main enthalpy of crystallization appeared further away from the small exothermic peak at a peak temperature of $17.16^{\circ} \mathrm{C}$ with an enthalpy value of $12.06 \mathrm{~J} / \mathrm{g}$ and an extrapolated temperature of $18.85^{\circ} \mathrm{C}$. In the final heating cycle of the ester, an exothermic temperature occurred at the main crystallization peak region at a peak temperature of $17.71{ }^{\circ} \mathrm{C}$ with an enthalpy value of $13.01 \mathrm{~J} / \mathrm{g}$ and an extrapolated temperature of $15.19^{\circ} \mathrm{C}$. This phenomenon was attributed to the melting-recrystallization or re-organization of the fat or ester crystals (Berger and Akehurst, 1966), known as polymorphism (Tan and Che Man, 2002). Tan and Che Man (2002) attributed this to the fact that when the sample is heated, the less stable polymorph melted as the more stable ones rearranged and melted at a higher temperature. This feature of the Allanblackia oil and its methyl ester was due to the polymorphic solid-to-solid transformation on heating resulting in the exothermic heat evolution, before the melting process at a higher temperature. 


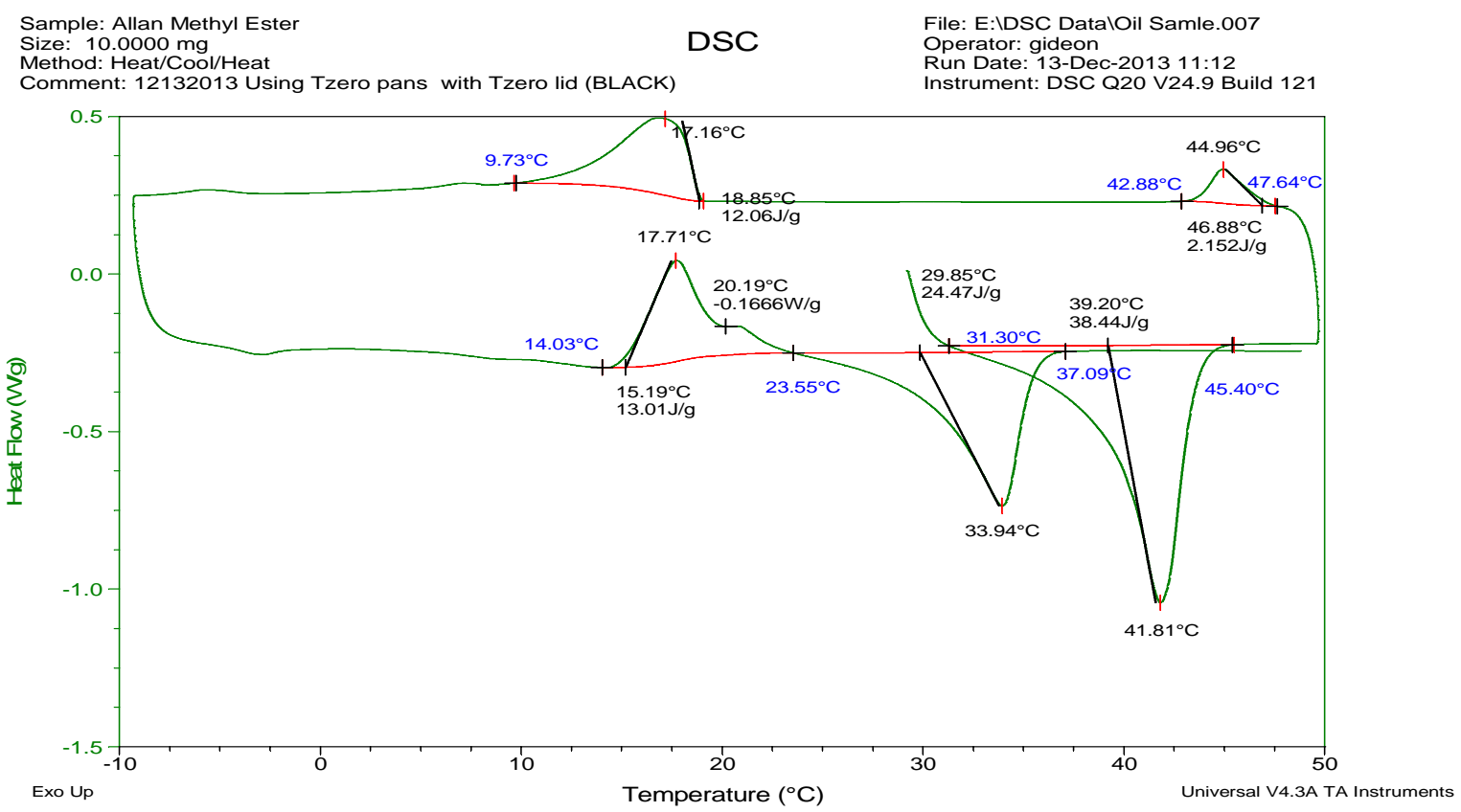

Fig. 6.1: The DSC curve of Allanblackia methyl ester

This solid-to-solid transformation or re-organization, uniquely occurred at the crystallization temperature range. Continuing the heating process generated a new main endothermic enthalpy value of $24.47 \mathrm{~J} / \mathrm{g}$ at a reduced extrapolated temperature of $29.85^{\circ} \mathrm{C}$ with a peak temperature of $33.94^{\circ} \mathrm{C}$. The peak temperature of the second heating was reduced from the first heating by $7.87^{\circ} \mathrm{C}$, while the enthalpy value was also reduced by $13.97 \mathrm{~J} / \mathrm{g}$. Again this property was unique to Allanblackia methyl ester where the enthalpy change was not reproducible after initial melting of the ester. It is also clear from Figure 6.1 that the first heating did not produce exothermic heat because the temperature for the exothermic heat occurred in the range of $14-24^{\circ} \mathrm{C}$ while the heating process started around $29^{\circ} \mathrm{C}$ and hence it could not be observed. 


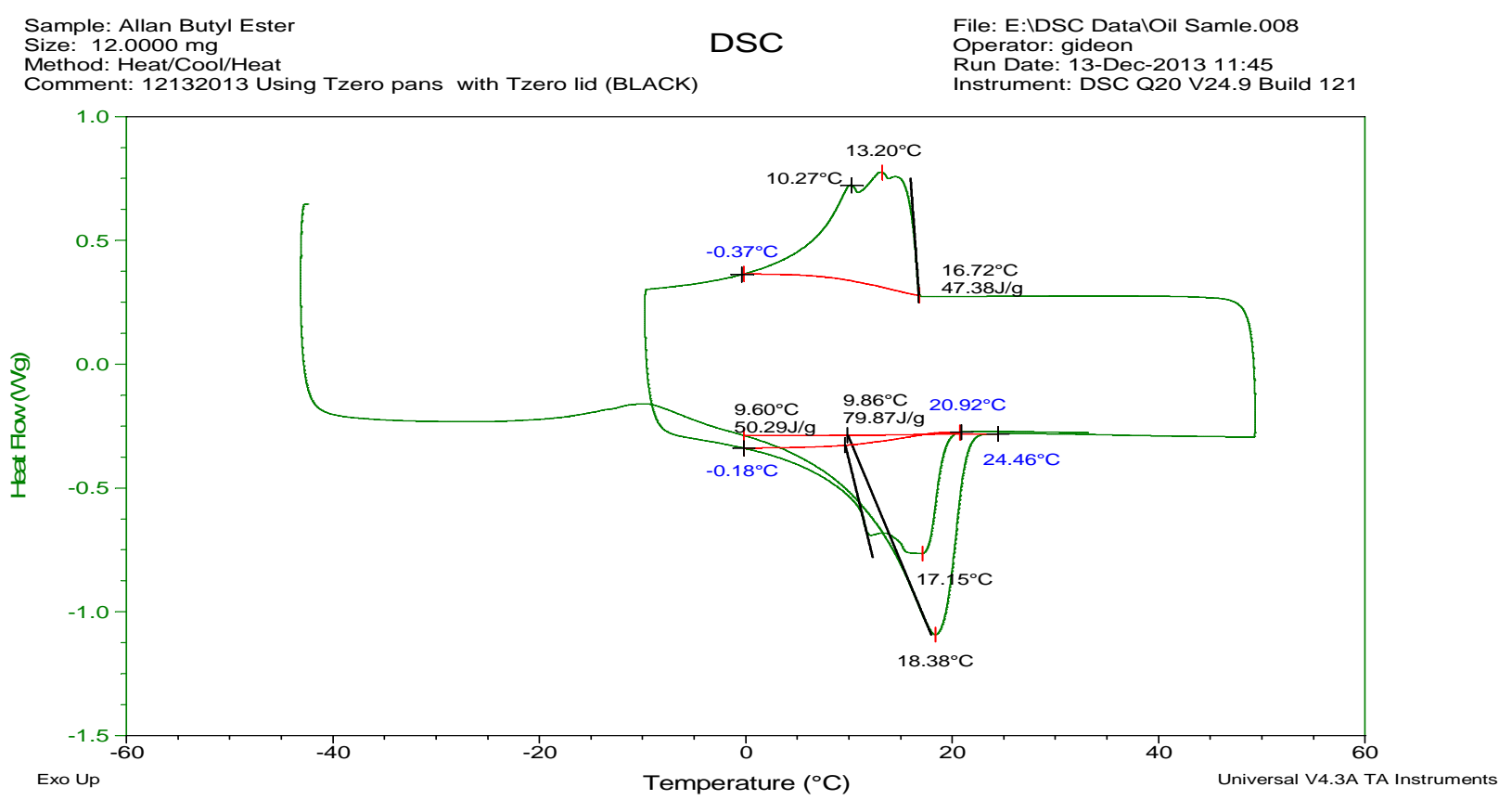

Fig. 6.2: The DSC curve of Allanblackia butyl ester

The DSC profile of Allanblackia butyl ester is shown in Figure 6.2. The first heating process produced endothermic heat with a value of $79.87 \mathrm{~J} / \mathrm{g}$ at an extrapolated temperature of $9.86^{\circ} \mathrm{C}$. The peak temperature for this curve occurred at $18.38^{\circ} \mathrm{C}$. On cooling, the sample crystallized and released a heat of $47.38 \mathrm{~J} / \mathrm{g}$ at an extrapolated temperature of $16.72^{\circ} \mathrm{C}$ with a peak temperature of $13.2^{\circ} \mathrm{C}$. The curve had a transition peak at $10.27^{\circ} \mathrm{C}$ which overlapped with the main crystallization curve. The second heating for the program gave a much broader peak with a transition overlapping peak with the major peak occurring at $17.15^{\circ} \mathrm{C}$ and produced an enthalpy of $50.29 \mathrm{~J} / \mathrm{g}$ at an extrapolated temperature of $9.6^{\circ} \mathrm{C}$. The second heating produced a broader peak with a reduced enthalpy and also had a transitional peak within the main peak. The major peak for the second heating did occur in the same region as the first heating. However, the enthalpy value was reduced while the curve gave multiple peaks and was broader. There was not much separation in the region of melting and crystallization. The exothermic heat release before the melting due to re-organization of the crystals in the Allanblackia methyl ester profile was absent in the Allanblackia butyl ester profile. The enthalpy associated with the butyl ester was much larger than that of the methyl ester. However, the butyl ester peaks appeared at much lower temperatures. 
The DSC profile of shea butter methyl ester is shown in Figure 6.3. The first heating process coincided with the second heating process giving an enthalpy value of $48.07 \mathrm{~J} / \mathrm{g}$ at a peak temperature of $17.28^{\circ} \mathrm{C}$ extrapolated to a temperature of $10.34^{\circ} \mathrm{C}$.

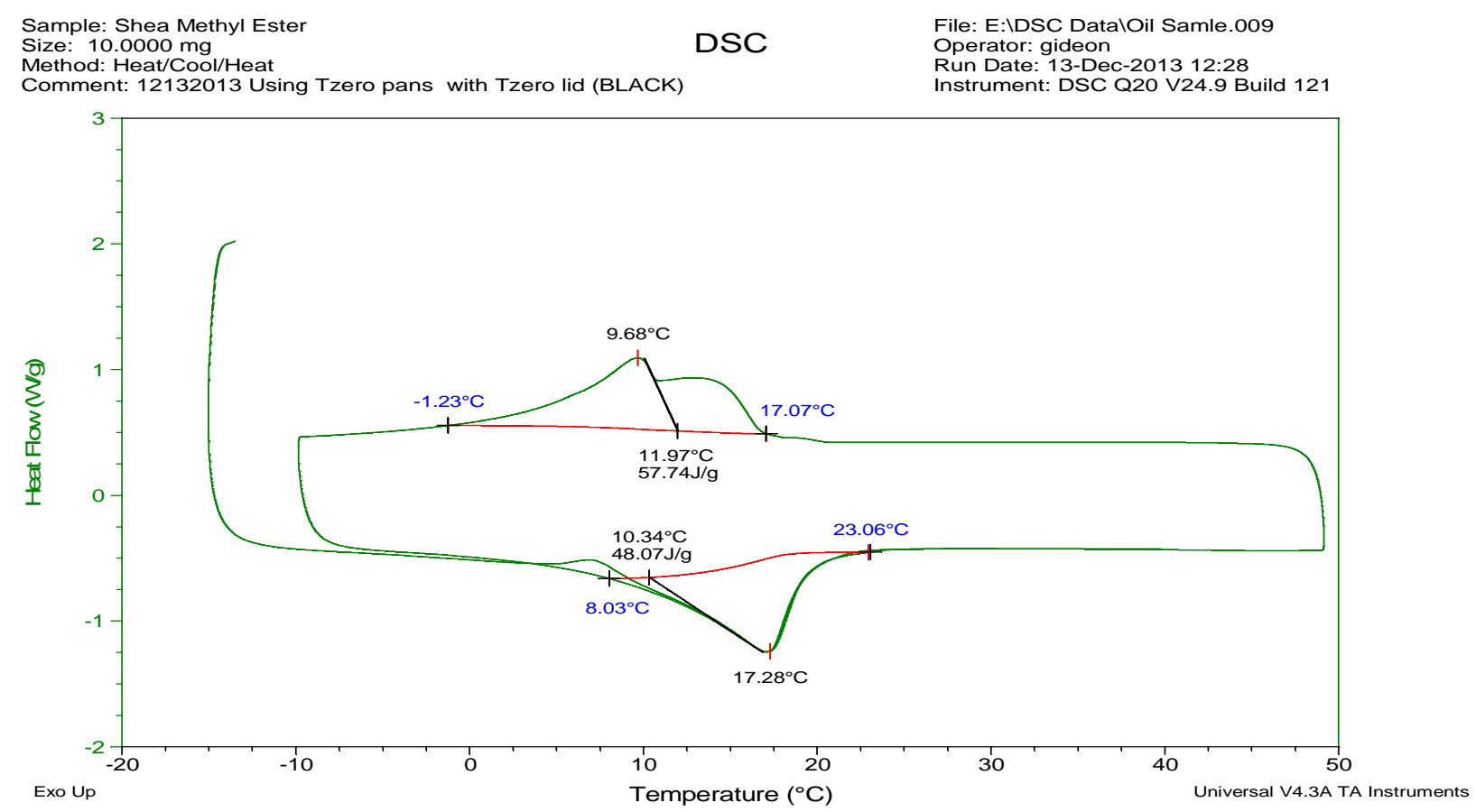

Fig. 6.3: The DSC curve of shea butter methyl ester

The crystallization process in this case was more polymorphic showing a much broader peak in overlap with the major peak at a peak temperature of $9.68^{\circ} \mathrm{C}$. The enthalpy value involved was $57.74 \mathrm{~J} / \mathrm{g}$. This cannot be considered latent heat due to the broad nature of the curve as well as the polymorphic nature shown.

Figure 6.4 is the DSC curve for butyl ester of shea butter. The curve was more reproducible since the second heating coincided with the first heating. 


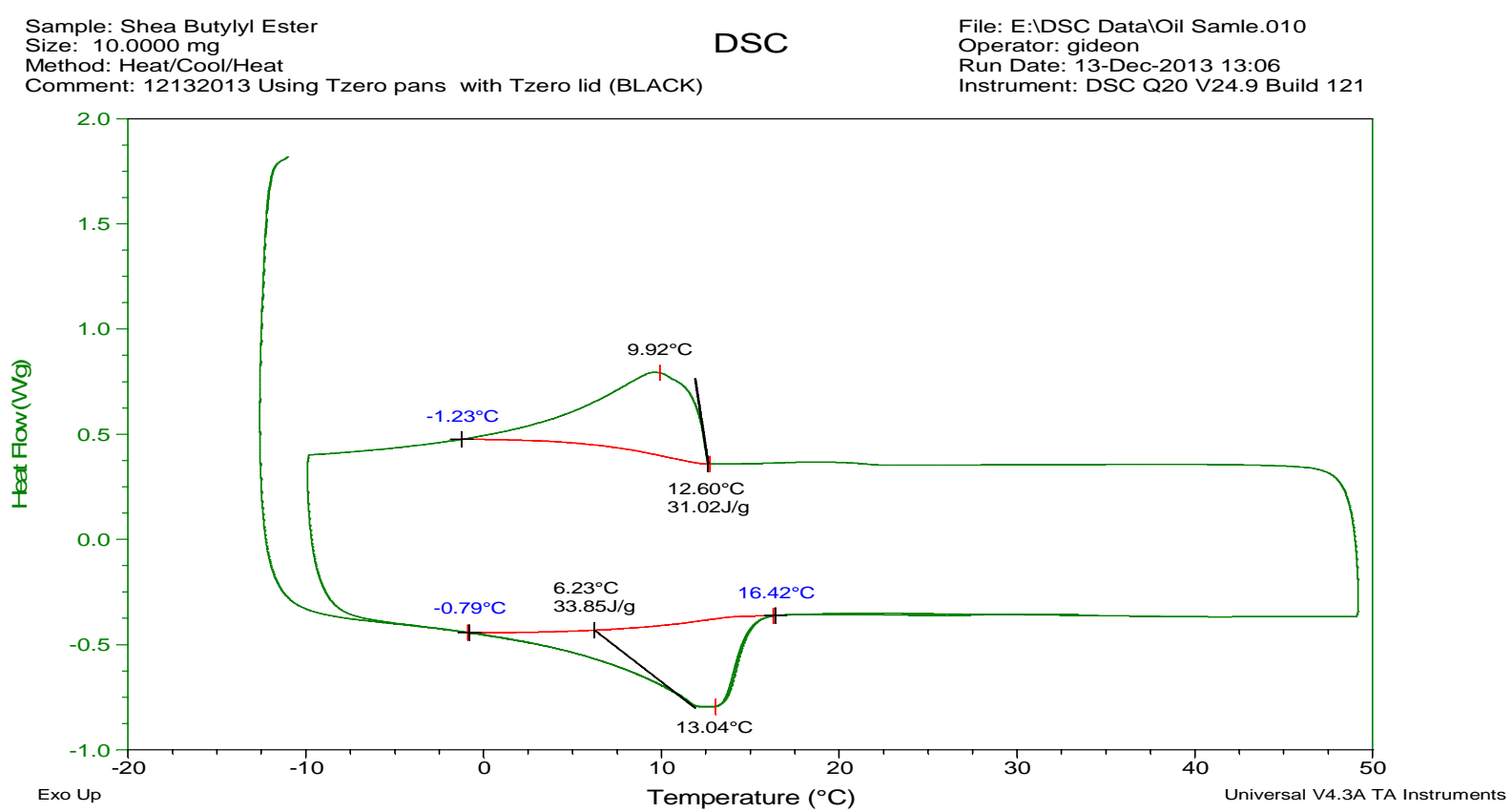

Fig. 6.4: The DSC curve of shea butter butyl ester

Also, the heating and crystallization regions coincided. The enthalpy of heating was $33.85 \mathrm{~J} / \mathrm{g}$ at a peak temperature of $13.04^{\circ} \mathrm{C}$ extrapolated to $6.23^{\circ} \mathrm{C}$. The crystallization process produced a much smoother curve than the methyl ester with an enthalpy value of $31.02 \mathrm{~J} / \mathrm{g}$ at a peak temperature of $9.92^{\circ} \mathrm{C}$ extrapolated to a temperature of $12.6^{\circ} \mathrm{C}$. It was evident that the methyl ester had a higher enthalpy than the butyl ester but the butyl ester curve was smoother and more reproducible and latent, as discussed earlier, and melting or crystallization must occur at a constant temperature or with a small temperature difference (Berera, 2006; Sharma and Sagara, 2005). Hence the butyl ester is better than the methyl ester in this regard.

The DSC profile of palm kernel methyl ester is depicted in Figure 6.5. The curve did not show any peaks over the whole heating and crystallization process. No inferences could be made since the DSC curve did not produce any peaks. This meant that the ester formed was a semi-solid and so did not change phase much on heating. So the heat involved did not involve a phase change and it is minimal and could be considered sensible heat (SH) instead. 


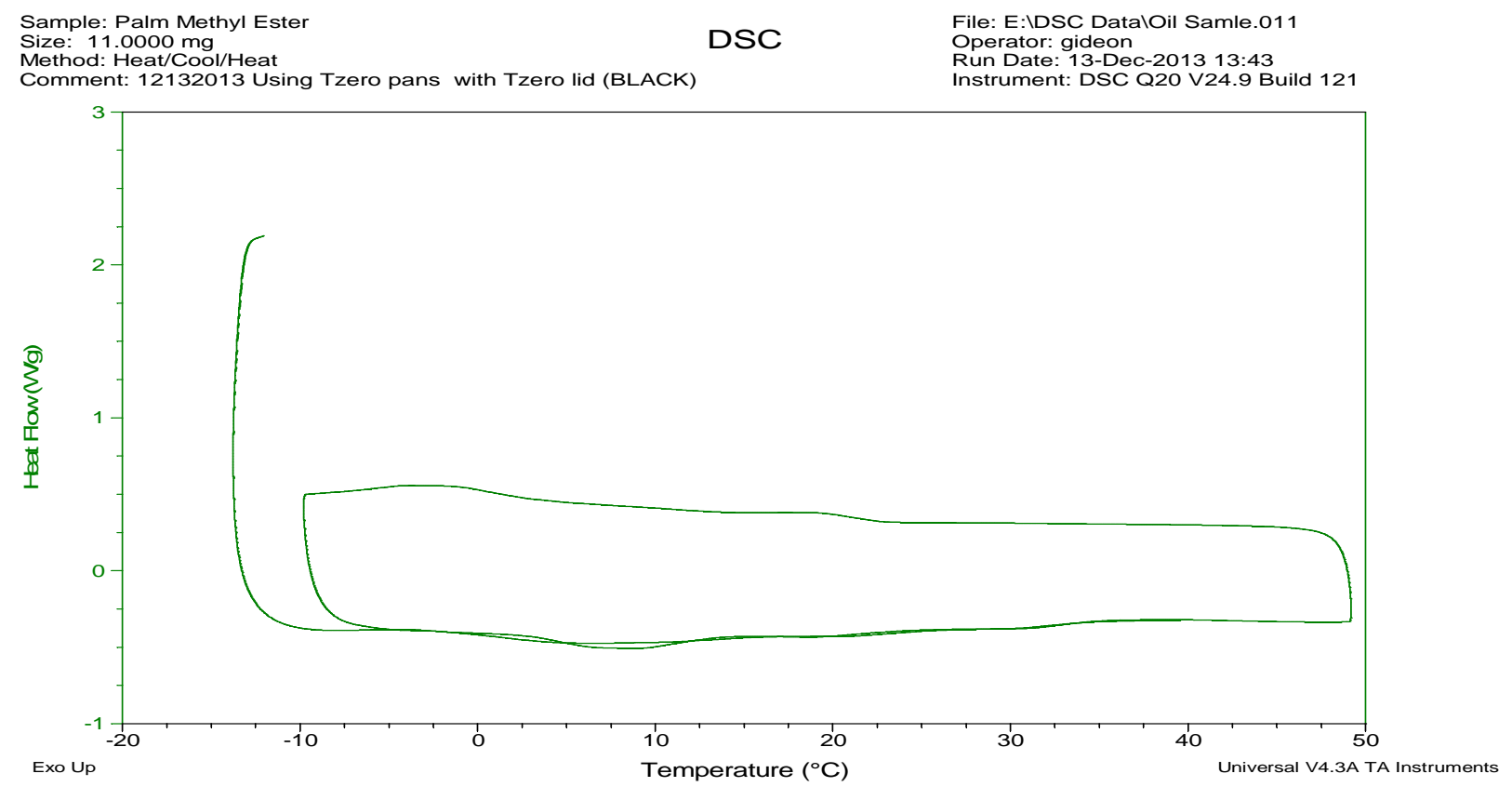

Fig. 6.5: The DSC curve of palm kernel oil methyl ester

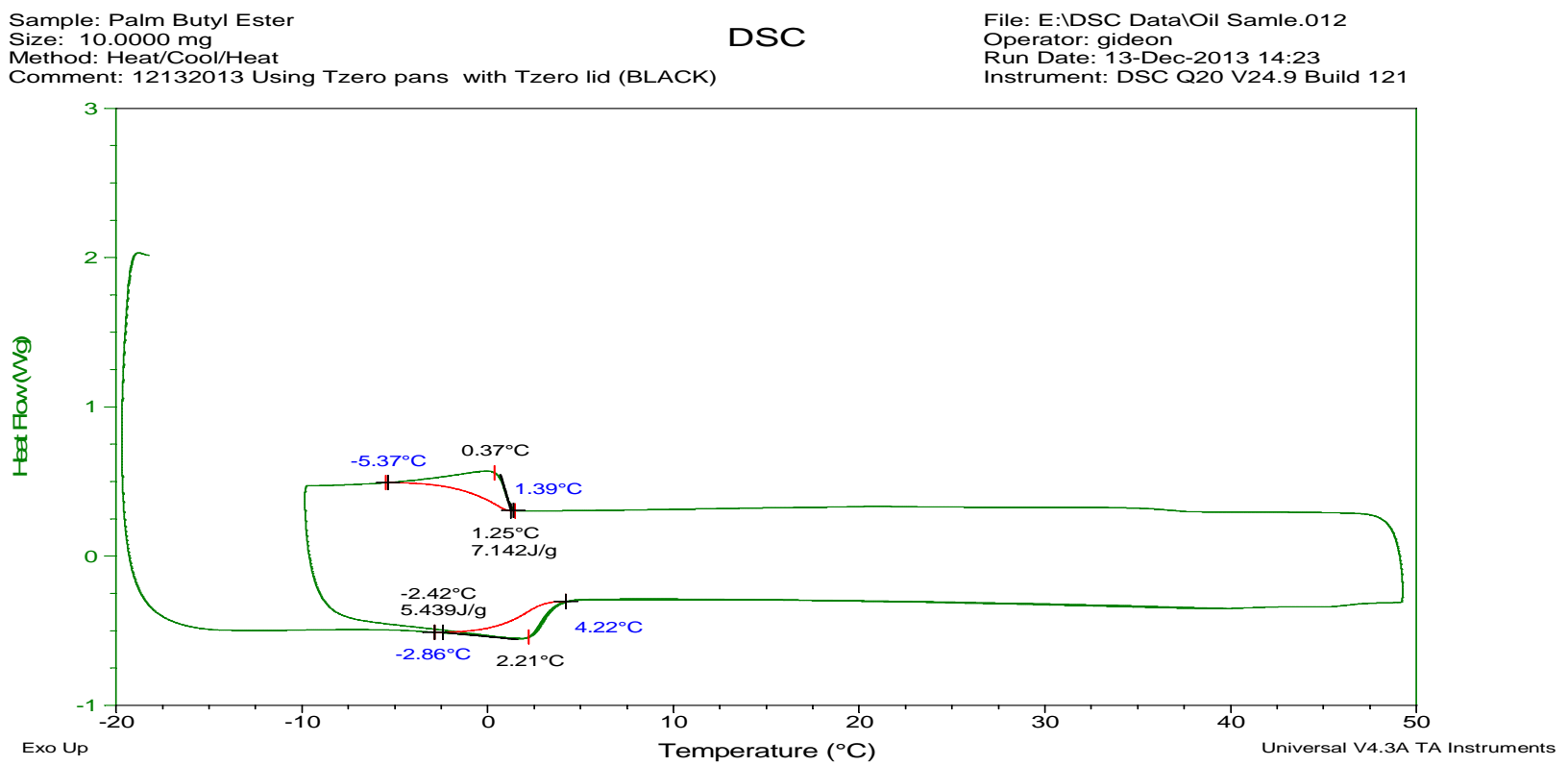

Fig. 6.6: The DSC curve of palm kernel oil butyl ester

The DSC profile of palm kernel butyl ester is shown in Figure 6.6. Both the heating and crystallization processes occurred in the same temperature regions. The enthalpies involved were 
very small but curves were much smoother and the first heating coincided with the second heating process. The temperatures involved were also low within the $0^{\circ} \mathrm{C}$ region.

DSC profile of Allanblackia methyl ester after 1000 thermal cycles is shown in Figure 6.7. Although the curve profile did not change, the thermal properties did improve after thermal cycling. The exothermic heat released after thermal cycling increased from $13.01 \mathrm{~J} / \mathrm{g}$ to 21.02 $\mathrm{J} / \mathrm{g}$. Similarly, first heat absorbed an enthalpy of $56.65 \mathrm{~J} / \mathrm{g}$ at a peak temperature of $42.22^{\circ} \mathrm{C}$ from a value of $38.44 \mathrm{~J} / \mathrm{g}$ at a peak temperature of $41.81^{\circ} \mathrm{C}$ before thermal cycling. In the second heating the enthalpy value after thermal cycling was $39.89 \mathrm{~J} / \mathrm{g}$ at a peak temperature of $34.56^{\circ} \mathrm{C}$. However, before thermal cycling, the enthalpy value was $24.47 \mathrm{~J} / \mathrm{g}$ at a peak temperature of $33.94^{\circ} \mathrm{C}$. The thermal cycling process appear to have increased both the enthalpy value as well as the temperature, which was contrary to the study reported by Shukla et al. (2008) and Sari et al. (2003, 2003). The same phenomenon was observed for the crystallization process. After thermal cycling, the enthalpy of crystallization was $21.04 \mathrm{~J} / \mathrm{g}$ at a peak temperature of $16.5^{\circ} \mathrm{C}$, while before thermal cycling, the enthalpy value was $12.06 \mathrm{~J} / \mathrm{g}$ at a peak temperature of 17.16 $\mathrm{J} / \mathrm{g}$. The small minor exothermic peak observed for the crystallization process was absent after thermal cycling.

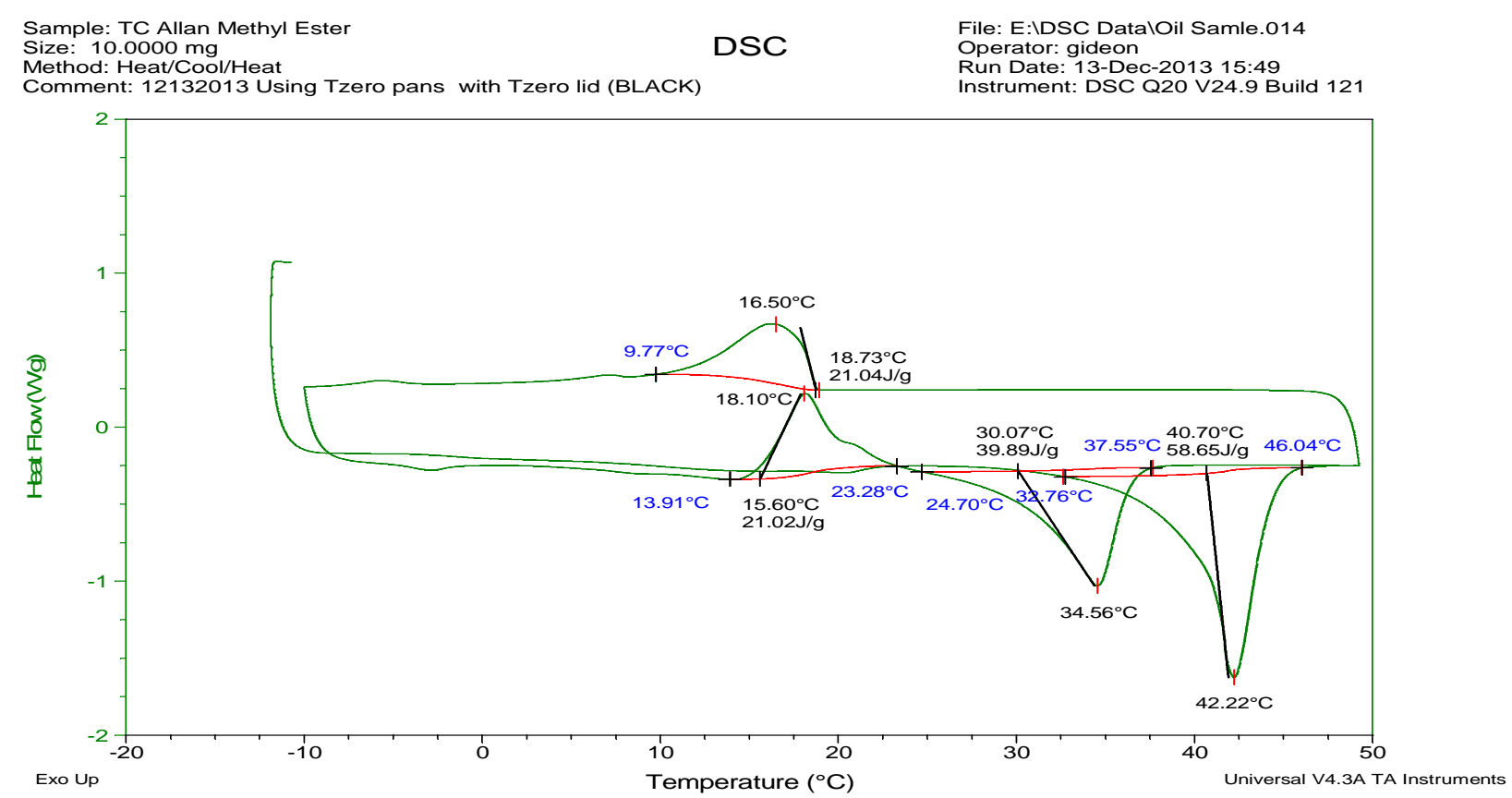

Fig. 6.7: The DSC curve of Thermally Cycled (TC) Allanblackia methyl ester 
Figure 6.8 shows the DSC profile of the thermally cycled Allanblackia butyl ester. The shape of the curve showed that the thermal cycling did not impact the properties of the butyl ester since the first and second heating curves were similar (coincide broadly). However, the enthalpy values were less than those before the thermal cycling as expected. Also, crystallization was more defined (sharper curve) than before the thermal cycling. With respect to the second heating, enthalpy changed from $50.29 \mathrm{~J} / \mathrm{g}$ to a value of $42.94 \mathrm{~J} / \mathrm{g}$ after thermal cycling. Before the thermal cycling, the enthalpy of the first heating for Allanblackia butyl ester was $79.87 \mathrm{~J} / \mathrm{g}$ while the second heating was $50.29 \mathrm{~J} / \mathrm{g}$. After thermal cycling, the curve were coincident. This was attributed to the re-organization of the crystals associated with Allanblackia and its products. This was because after several cycles of melting and crystallizing, that property diminished as shown in the thermally cycled Allanblackia butyl ester heating curve (Figures 6.2 and 6.8).

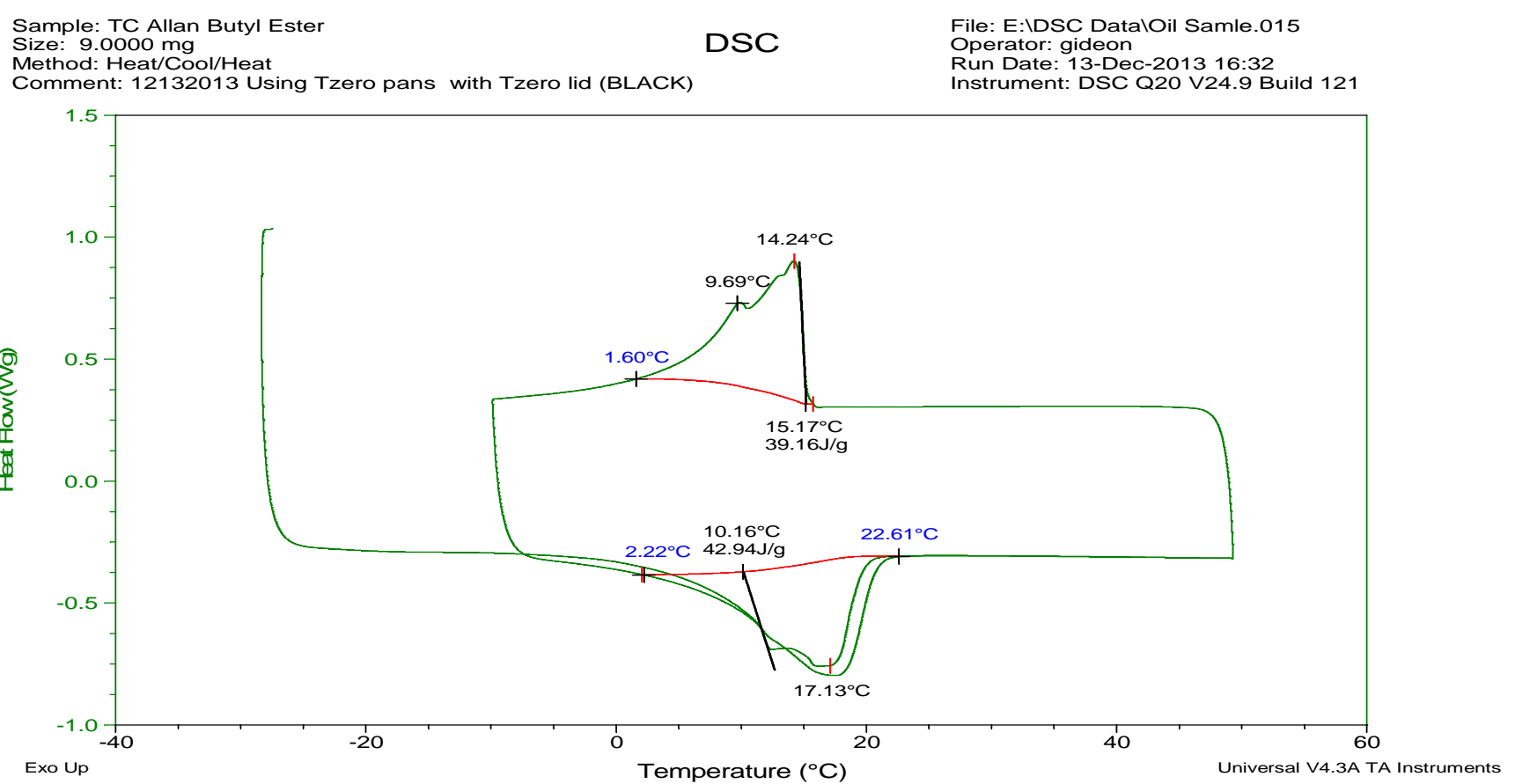

Fig. 6.8: The DSC curve of Thermally Cycled (TC) Allanblackia butyl ester 


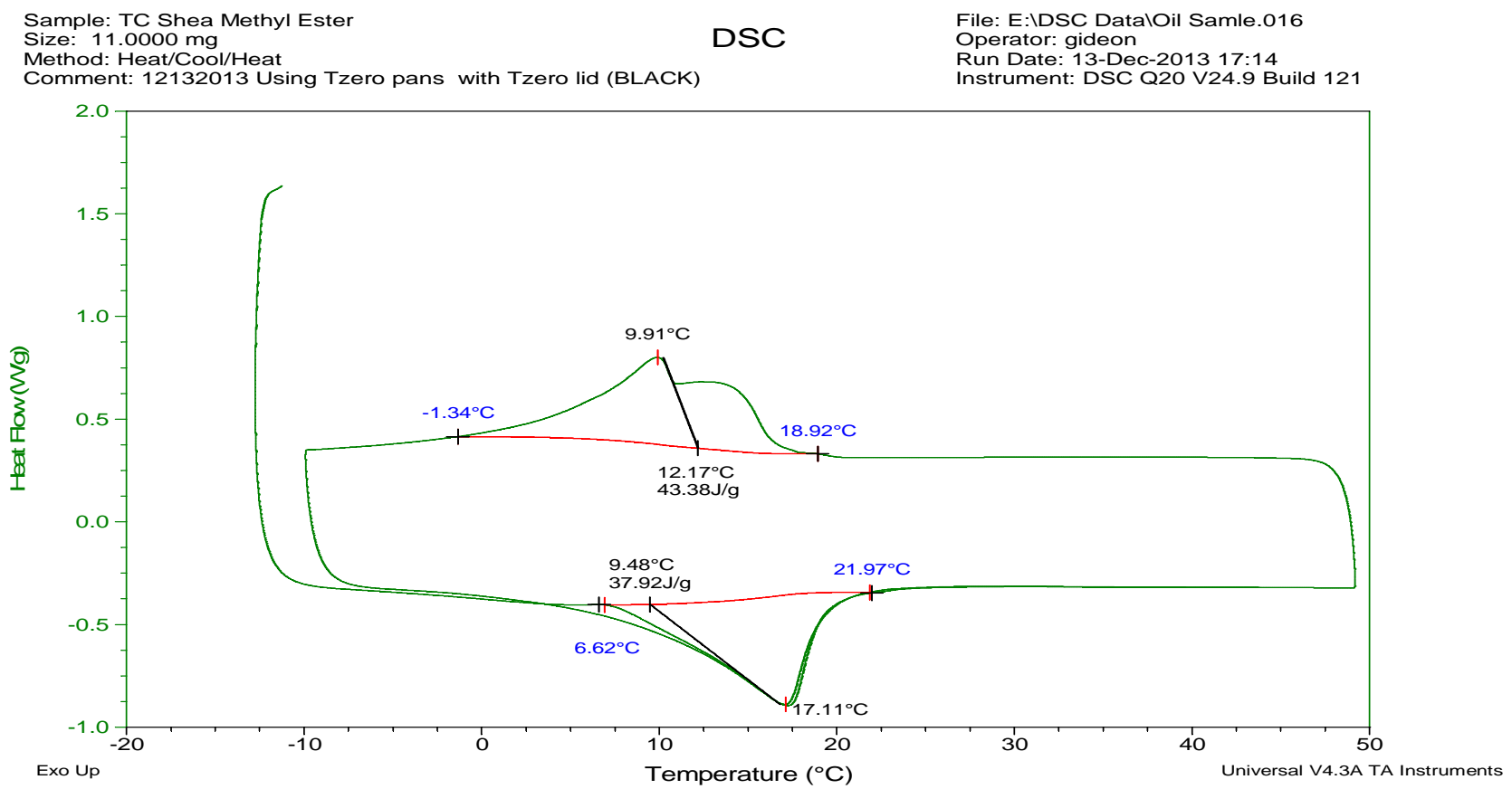

Fig. 6.9: The DSC curve of Thermally Cycled (TC) shea butter methyl ester

The DSC curve of thermally cycled shea methyl ester is shown in Figure 6.9. The shapes of curves in Figures 6.9 and 6.3 were similar. Peaks for both the melting and crystallization were similar. Also, the profiles of the first and second heating cycles were similar. The enthalpies for both fusion and crystallization were lower after thermal cycling.

The DSC curve of the thermally cycled shea butyl ester is shown in Figure 6.10. Figure 6.4 represents the DCS curve for the same sample before thermal cycling. The shape of the DSC curves in Figures 6.4 and 6.10 including their peaks for melting and crystallization were similar. The first and second heating curves did coincide with each other. This was an indication that the sample did not thermally change. Consequently, their enthalpies were reduced to reflect thermal cycling effect. 


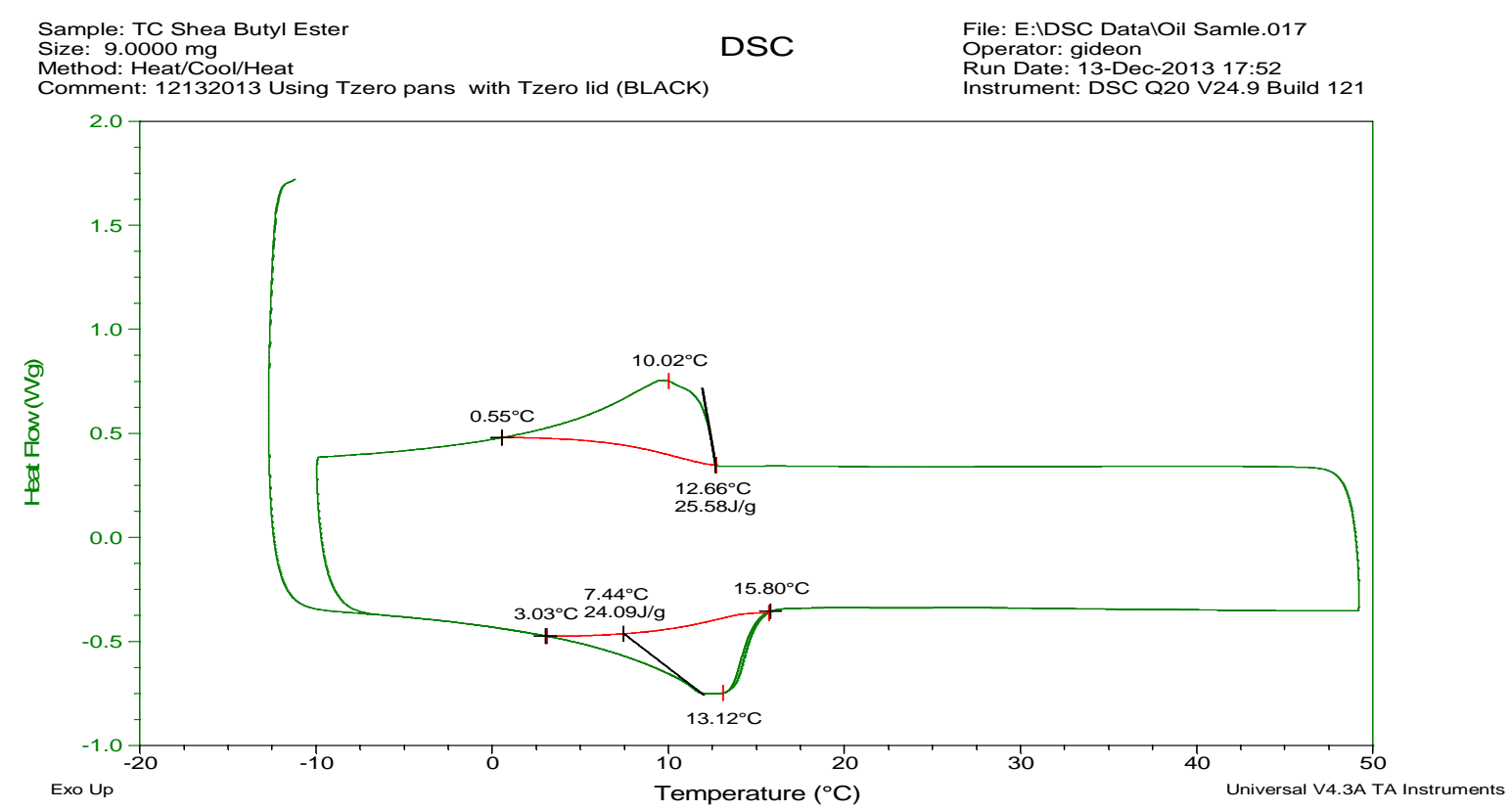

Fig. 6.10: The DSC curve of thermally cycled (TC) shea butter butyl ester

The DSC curve of thermally cycled palm oil methyl esters is shown in Figure 6.11. The shape of the curve was more complex with broad peaks difficult to identify. The first and second heating did coincide eliminating the crystal reorganization phenomenon. As compared to the curve before the thermal cycling in Figure 6.5 which looked a lot smoother, the peaks were too broad to be identified or to be considered latent energies. 


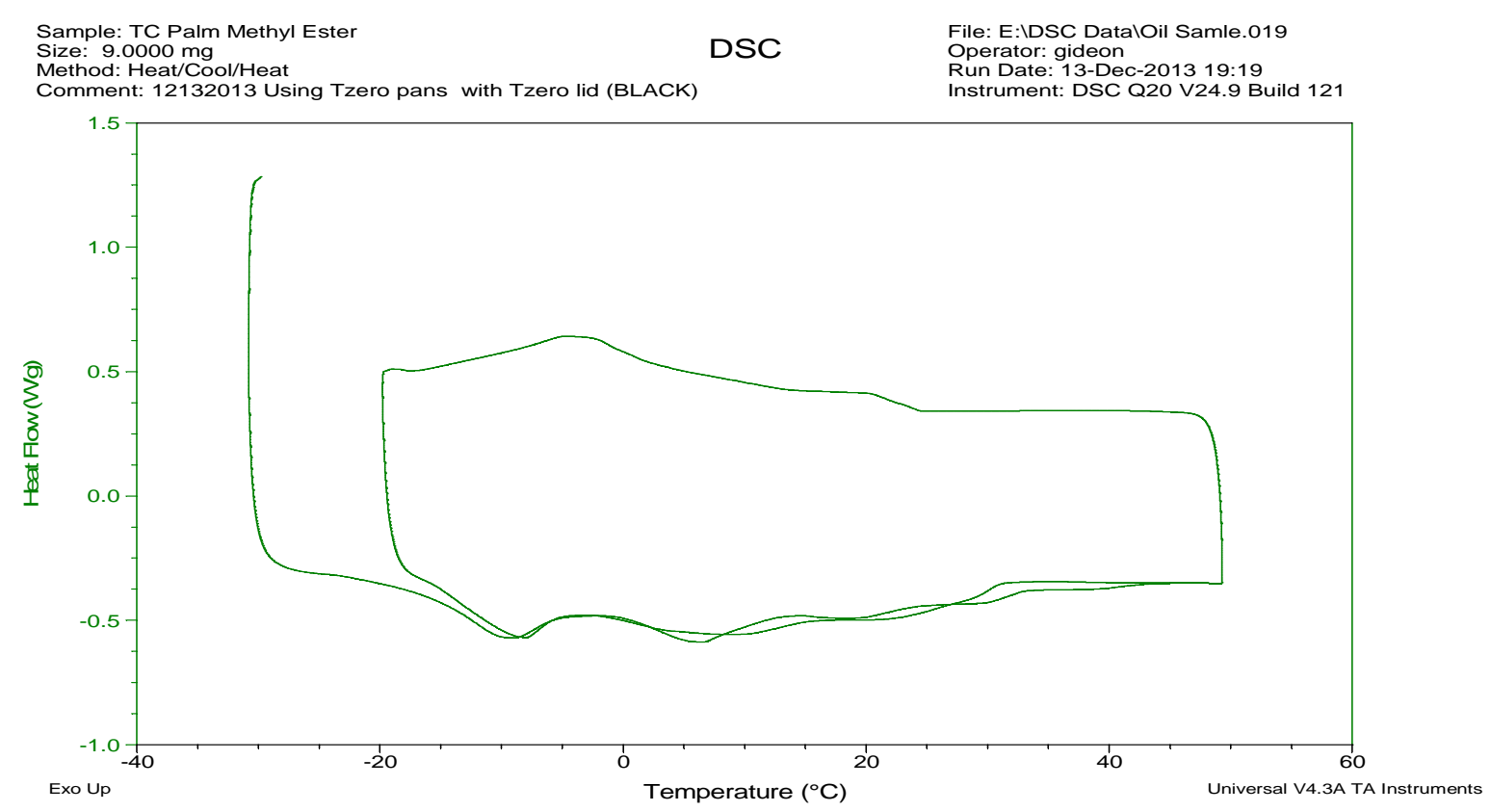

Fig. 6.11: The DSC curve of thermally cycled (TC) palm kernel methyl ester

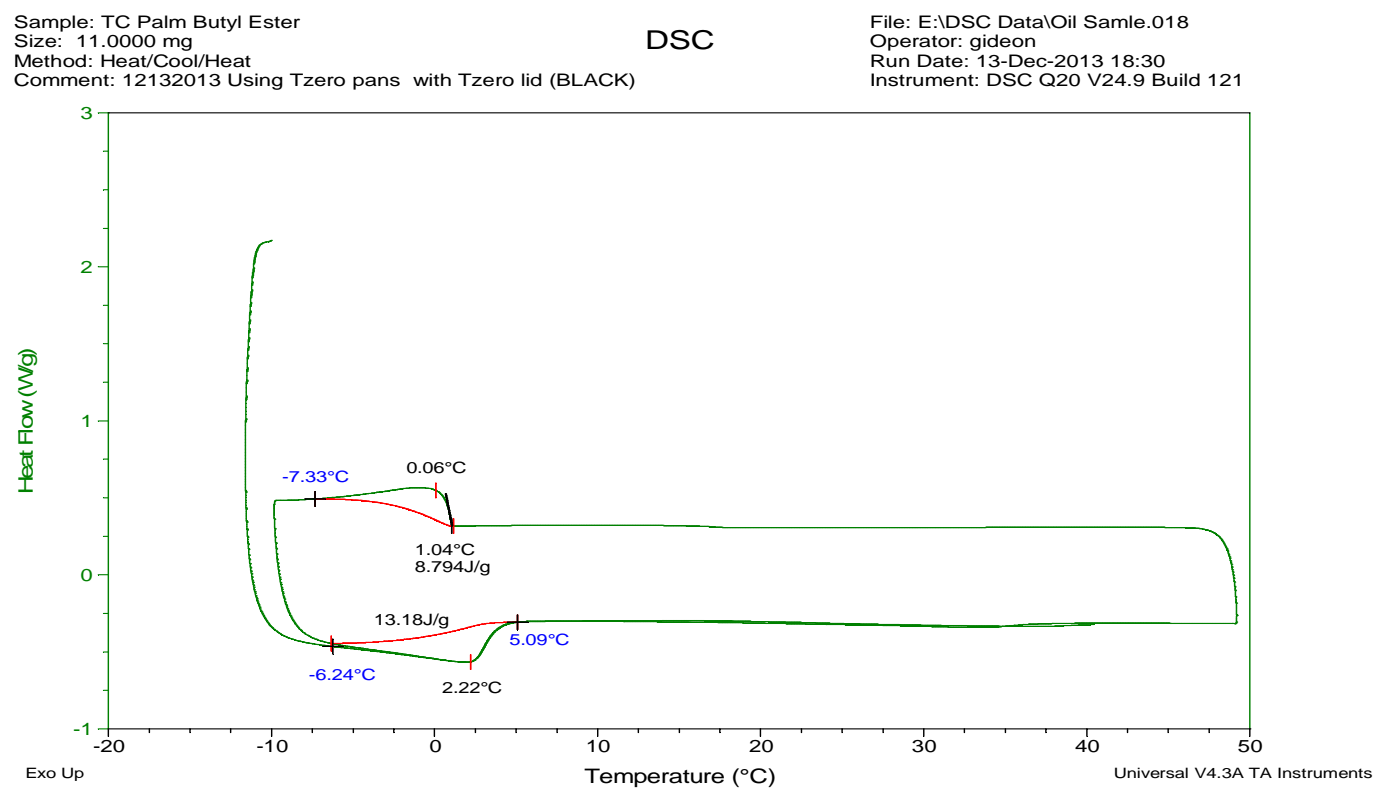

Fig. 6.12: The DSC curve of thermally cycled (TC) palm kernel butyl ester 
Butyl esters of palm kernel oil before and after thermal cycling showed some stability even though their enthalpy values were too small and in the low temperature region (Figures 6.6 and 6.12). Although the shape of their curves indicated thermal reliability, their enthalpies were reduced after thermal cycling.

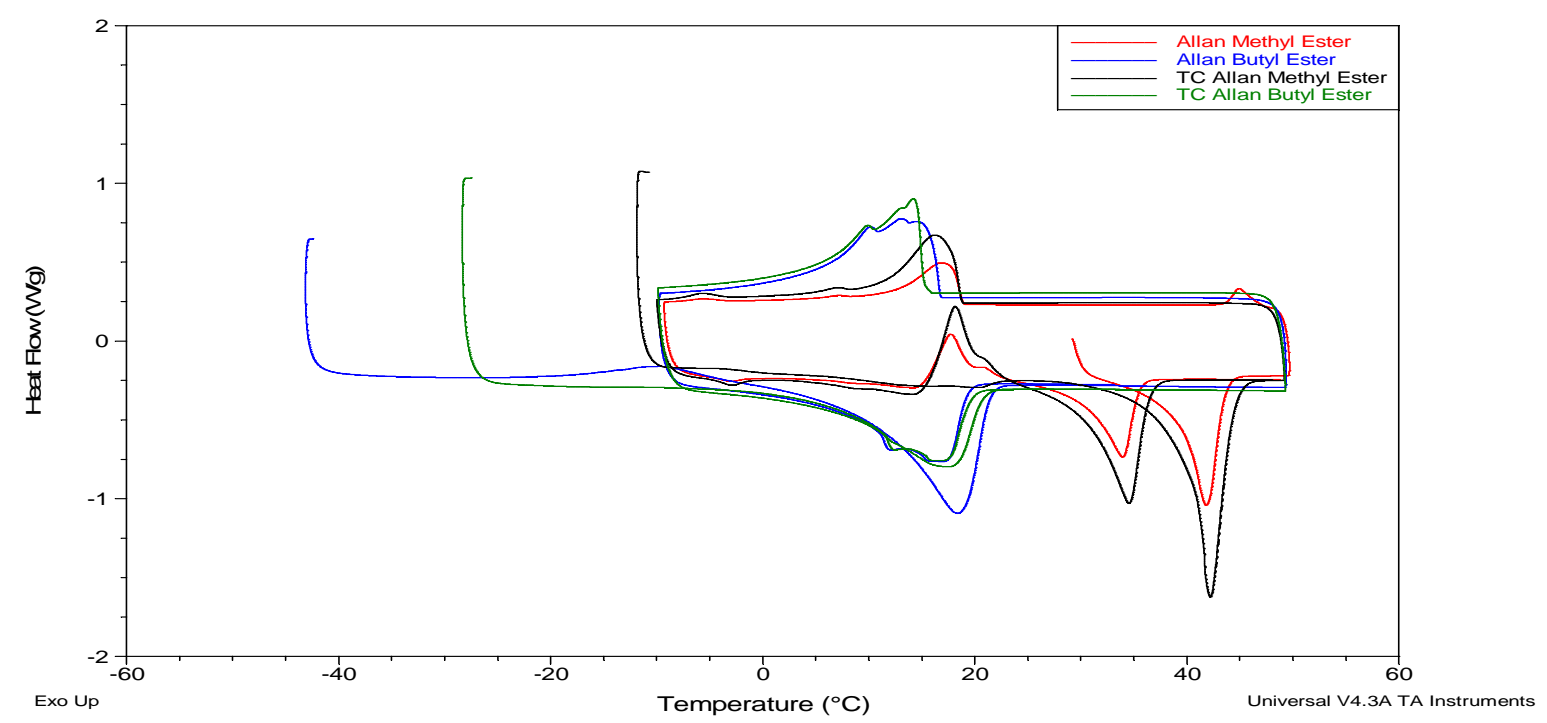

Fig. 6.13: The overlaid curve of the methyl and butyl esters of Allanblackia and their thermally cycled products.

Figure 6.13 shows the DSC scans of all the esters of Allanblackia before and after thermal cycling. The methyl ester gave higher enthalpies after thermal cycling. The first and second heating programs did not coincide. For the butyl ester, the first and second heating before thermal cycling appeared within the same temperature range but did not coincide. After thermal cycling, the first and the second heating were more coincident and sharper but with reduced enthalpy values. 


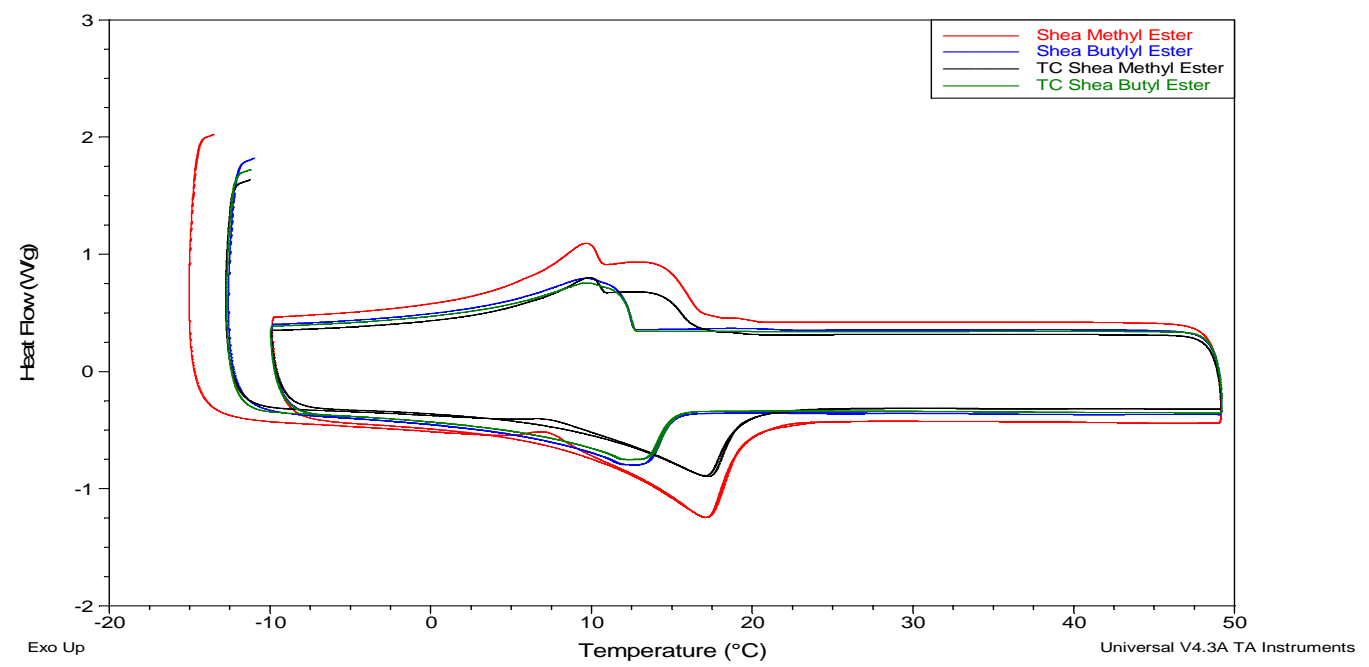

Fig. 6.14: The overlaid curve of the methyl and butyl esters of shea butter and their thermally cycled products

From the overlaid curves of the esters of shea butter in Figure 6.14, it was evident that shea methyl ester showed a large drop in enthalpy as well as the peak values after thermal cycling. The butyl ester of shea butter was more stable after thermal cycling than the methyl ester of shea butter.

The overlaid DSC scans of palm kernel oil esters are shown in Figure 6.15. The methyl esters did not exhibit any clearly discernable properties while the butyl ester showed good thermal stability. However, their enthalpy values were small and the phase change occurred at lower temperatures. 


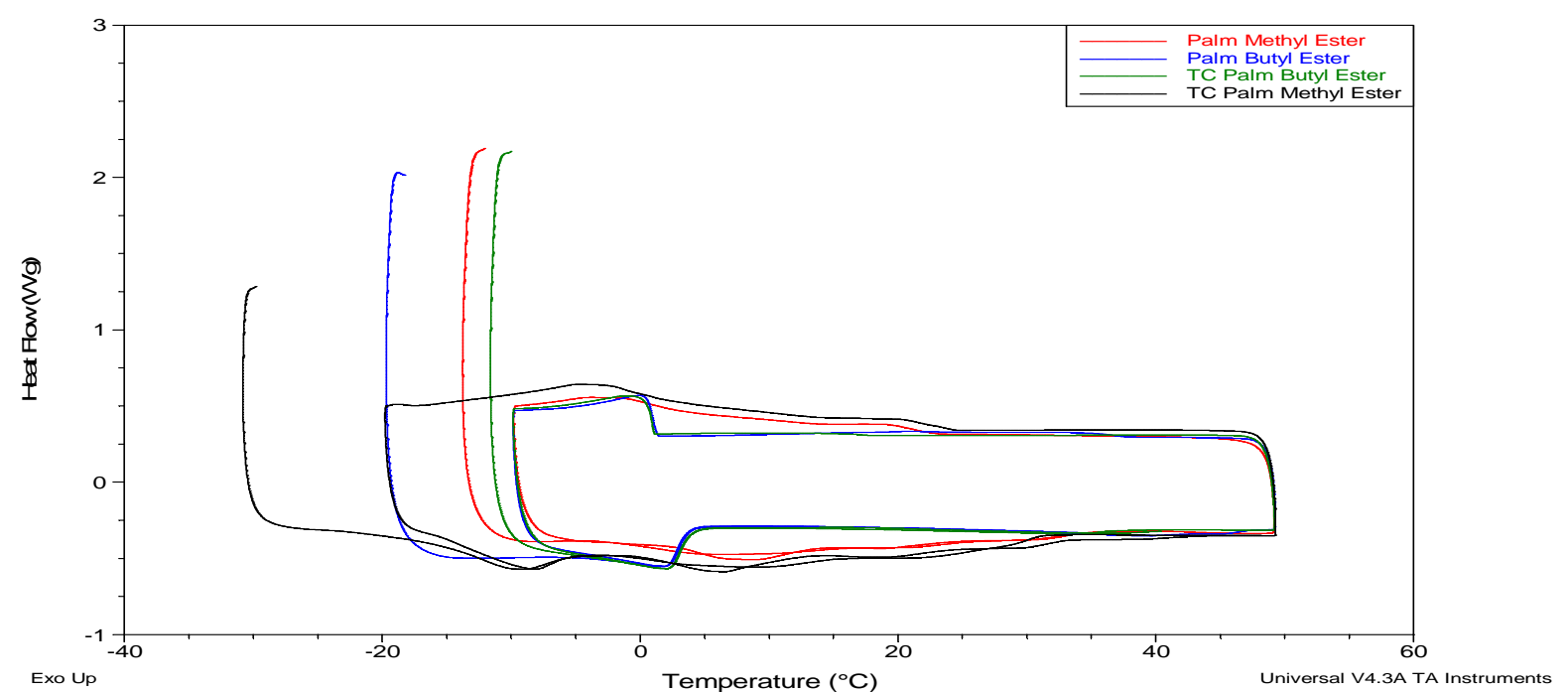

Fig. 6.15: Overlaid curve of the methyl and butyl esters of palm kernel and their thermally cycled products

\subsubsection{Thermo-gravimetric analysis (TGA) of esters produced from the oils of Allanblackia oil, shea butter and palm kernel oil}

Thermo-gravimetric analysis was used to determine the thermal stability of the esters derived from the oils of Allanblackia, shea butter and palm kernel. The thermal stability of the oils were a measure of their suitability as good candidates for use as PCMs for thermal energy storage applications (Sari et al. 2011). The degradation steps in the TGA analysis is shown in Table 6.1. This table showed that the methyl esters underwent multiple degradation steps while the butyl esters all underwent one single degradation step. Degradation of methyl esters started from point $\mathrm{B}$ at $208.41^{\circ} \mathrm{C}$ (point B, Figure 6.16, Table 6.1) while the butyl esters commenced degradation at $126.1^{\circ} \mathrm{C}$ (point A, Figure 6.16, Table 6.1). Separation of the curves was observed at point $\mathrm{C}$ (Figure 6.16) for Allanblackia methyl ester and the thermally cycled Allanblackia methyl ester. In the TGA scan (Figure 6.16), point $\mathrm{C}$ occurred at $258.48^{\circ} \mathrm{C}$ after a degradation of $4.83 \%$. 
Table 6.1: Table showing the thermal degradation of the esters of Allanblackia, shea butter and palm kernel oil.

\begin{tabular}{|l|l|l|l|}
\hline \multirow{2}{*}{ Sample } & \multicolumn{2}{|l|}{ \% Degradation } & \multicolumn{2}{l|}{} \\
\cline { 2 - 4 } & Step 1 & Step 2 & Step 3 \\
\hline Allan Methyl Ester & 61.40 & 8.50 & 25.06 \\
\hline TC Allan Methyl Ester & 65.40 & 11.93 & 22.67 \\
\hline Allan Butyl Ester & 100.00 & - & - \\
\hline TC Allan Butyl Ester & 99.87 & - & - \\
\hline Shea Methyl Ester & 53.81 & 35.27 & 10.92 \\
\hline TC Shea Methyl Ester & 54.73 & 33.43 & 11.84 \\
\hline Shea Butyl Ester & 100.00 & - & - \\
\hline TC Shea Butyl Ester & 99.85 & - & - \\
\hline Palm Methyl Ester & 51.44 & 32.03 & 16.53 \\
\hline TC Palm Methyl Ester & 52.79 & 34.02 & 13.19 \\
\hline Palm Butyl Ester & 100.00 & - & - \\
\hline TC Palm Butyl ESter & 100.00 & - & \\
\hline
\end{tabular}

Final degradation occurred at $418.02^{\circ} \mathrm{C}$ (point E) with $21.84 \%$ of both samples not degraded and the curves fuse together again for the final degradation step. The final degradation occurred at $575^{\circ} \mathrm{C}$. After 1000 thermal cycles, methyl esters did not degrade in the desired temperature region of interest (region of melting and crystallization of the esters $-15-42^{\circ} \mathrm{C}$, Figures 6.1 and 6.7). Thus, Allanblackia methyl ester was thermally stable within the desired temperature of interest. 
Figure 6.16 shows that Allanblackia butyl esters degrade in a single step. At point D, there was a very slight separation of the scans of Allanblackia butyl ester and the thermally cycled Allanblackia butyl ester. However, the scan patterns remained the same and complete degradation occurred at $275^{\circ} \mathrm{C}$. The butyl ester degraded at a faster rate than the methyl ester. The single degradation step indicated a higher purity of the butyl ester than the methyl ester. Again, within the temperature of interest, there was no degradation of the butyl ester of Allanblackia oil.

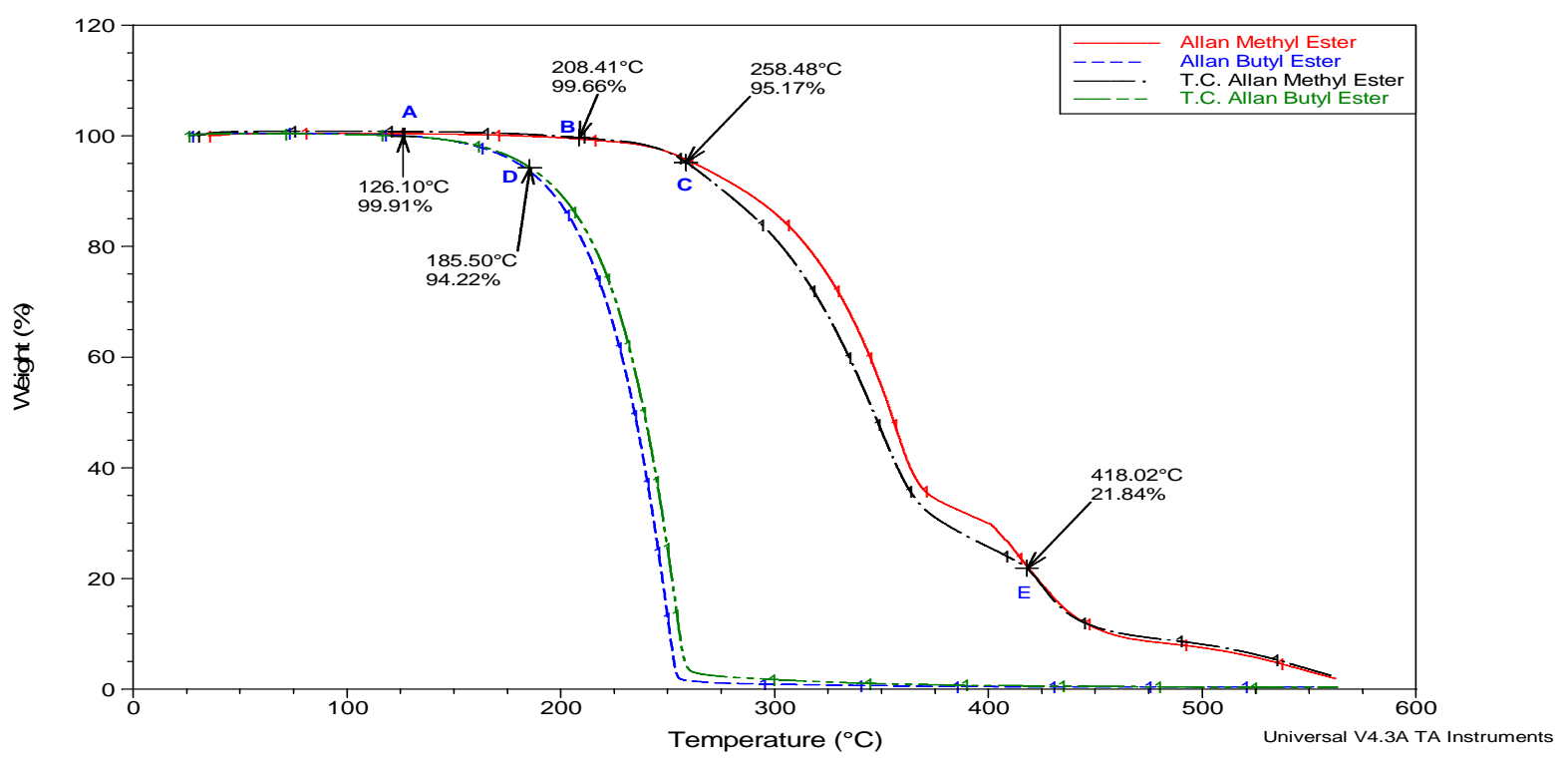

Fig. 6.16: Overlaid TGA curves of the esters of Allanblackia and their thermally cycled products

The curve in Figure 6.17 shows the degradation of the esters of shea butter and their thermally cycled products. Shea butyl esters exhibited the highest stability at the highest temperature. Shea butyl ester separated itself from the other three DSC scan at $154.95^{\circ} \mathrm{C}$ (point G) after $1.92 \%$ degradation for all samples. The other three samples (shea methyl ester, TC shea methyl ester and TC shea butyl ester) commence and degraded faster but the DSC scans separated at $198.23^{\circ} \mathrm{C}$ (point $\mathrm{H}$ ) with $87.16 \%$ of the samples undegraded. At $\mathrm{H}$, thermally cycled shea butyl ester degraded as a single step degradation while the methyl esters exhibited multiple steps. A slight difference in the degradation of the shea methyl ester and the thermally cycled shea methyl ester was observed between $198.23^{\circ} \mathrm{C}$ and $360.32^{\circ} \mathrm{C}$ with the thermally cycled product showing a 
slightly lower degradation rate than non-thermally cycled shea methyl ester. Shea butyl ester, which showed a higher stability at the initial stage of the degradation process however, degraded at a much higher temperature but a higher rate in a single step (Figure 6.17). The butyl esters completely degraded at $375^{\circ} \mathrm{C}$ while the methyl esters exhibited multiples steps and $100 \%$ degradation at $565^{\circ} \mathrm{C}$.

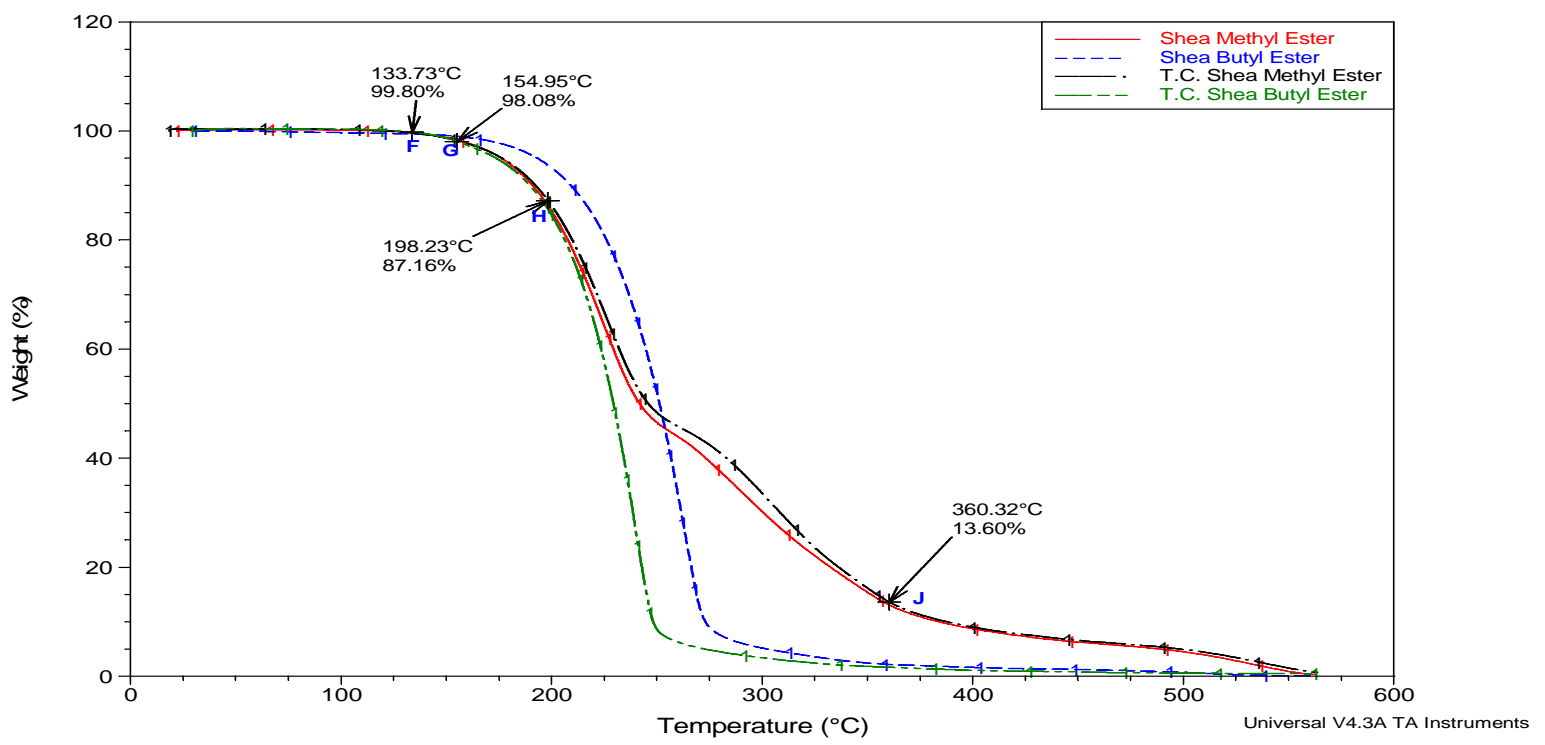

Fig. 6.17: Overlaid TGA curves of the esters of shea butter and their thermally cycled products.

The DSC scans of esters of shea butter, showed melting and crystallization for both non- and thermally cycled methyl and butyl esters below $25^{\circ} \mathrm{C}$ (desired temperature region of interest). Thus, within the desired temperature of interest, both methyl and butyl esters of shea butter are all stable for use as a thermal energy storage system. 


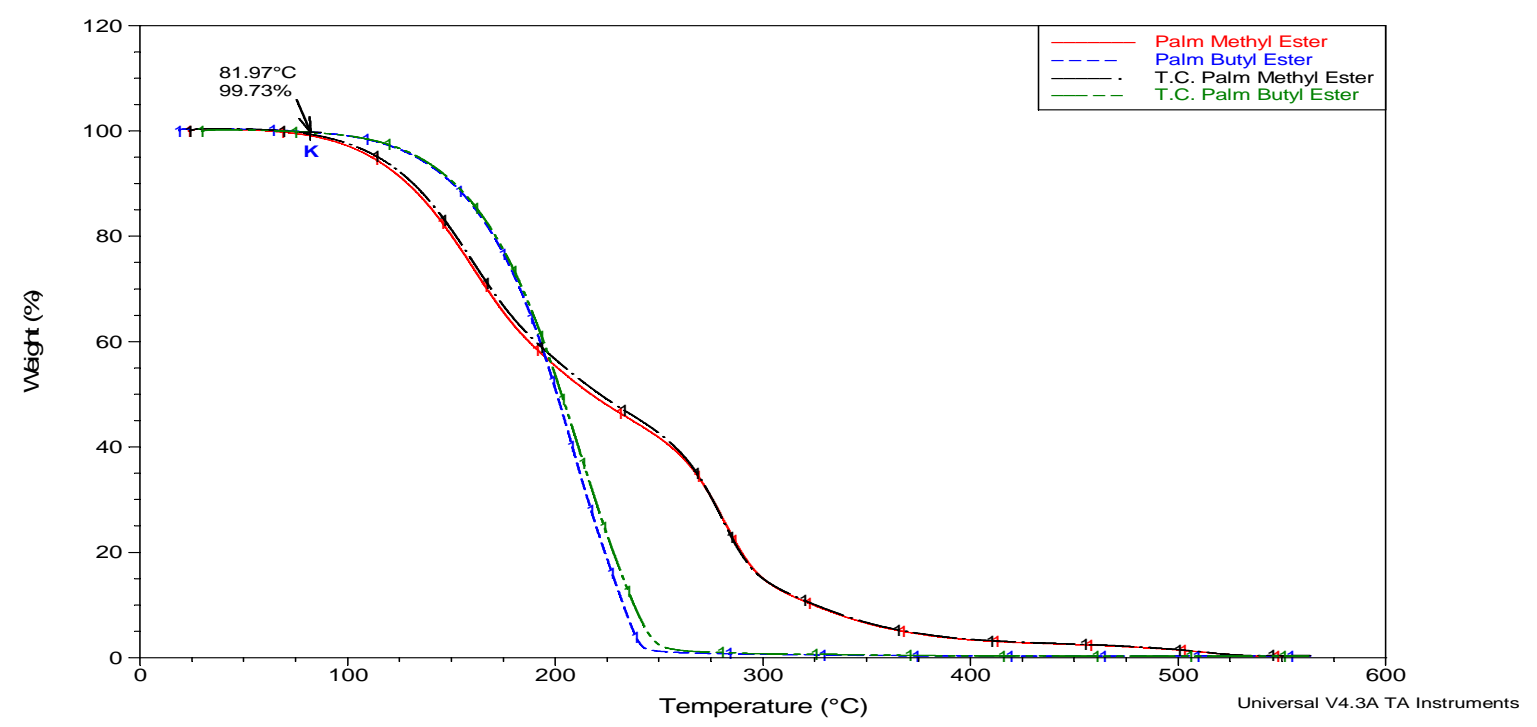

Fig. 6.18: Overlaid TGA curves of the esters of palm kernel oil and their thermally cycled products

Figure 6.18 gives the overlaid TGA scans for methyl and butyl esters of non- and thermally cycled palm kernel oil. It was clearly evident that the methyl esters degraded at the same rate in multiple steps. All samples began to degrade at $81.97^{\circ} \mathrm{C}$ (point K) with $99.73 \%$ of sample undegraded. The rate of degradation in the first step for the methyl esters was faster than that of butyl esters. However, rate of degradation of methyl esters in the second step was slower than that of butyl esters. Although the butyl esters degraded within a single step, they initially exhibited more stability than the methyl esters (Figure 6.18). The butyl esters degraded completely at $275^{\circ} \mathrm{C}$ while the methyl esters degraded at $525^{\circ} \mathrm{C}$. From the DSC scans in Figures 6.5, 6.6, 6.11, 6.12 and 6.15, the melting point of the esters of palm kernel oil occurred below $4^{\circ} \mathrm{C}$. Thus, if degradation commenced at $81.97^{\circ} \mathrm{C}$, then the samples did not degrade within the temperature of interest, and hence TGA results demonstrated their thermal stability for use as thermal energy storage system.

The TGA scan in Figure 6.19 compares the TGA curves of the methyl esters of Allanblackia, shea butter and palm kernel oil. All the methyl esters thermally degraded in multiple steps. 
Evidently, Allanblackia methyl ester was the most stable since it degraded at the highest temperature followed by shea butter methyl ester and palm kernel methyl ester.

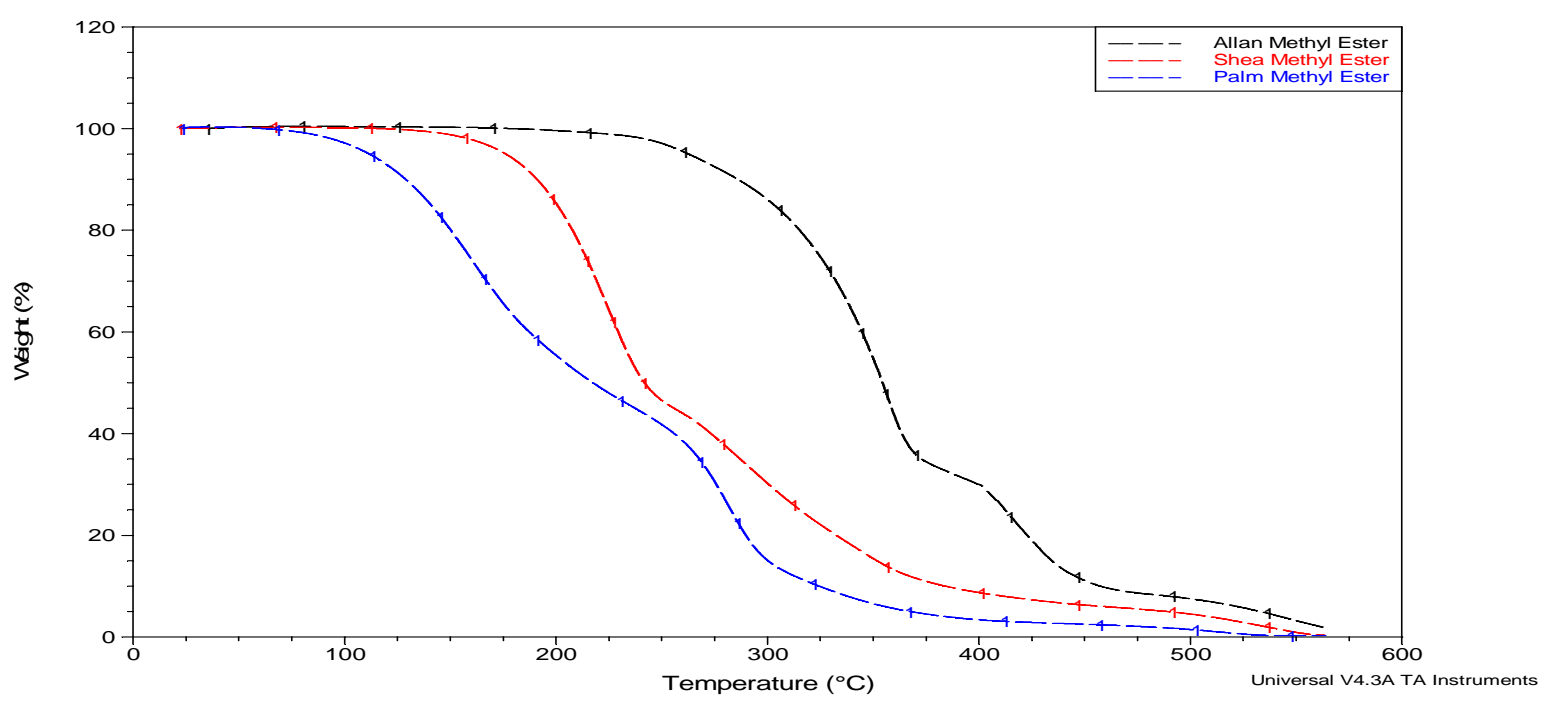

Fig. 6.19: Overlaid curves of the methyl esters of Allanblackia, shea butter and palm kernel oil

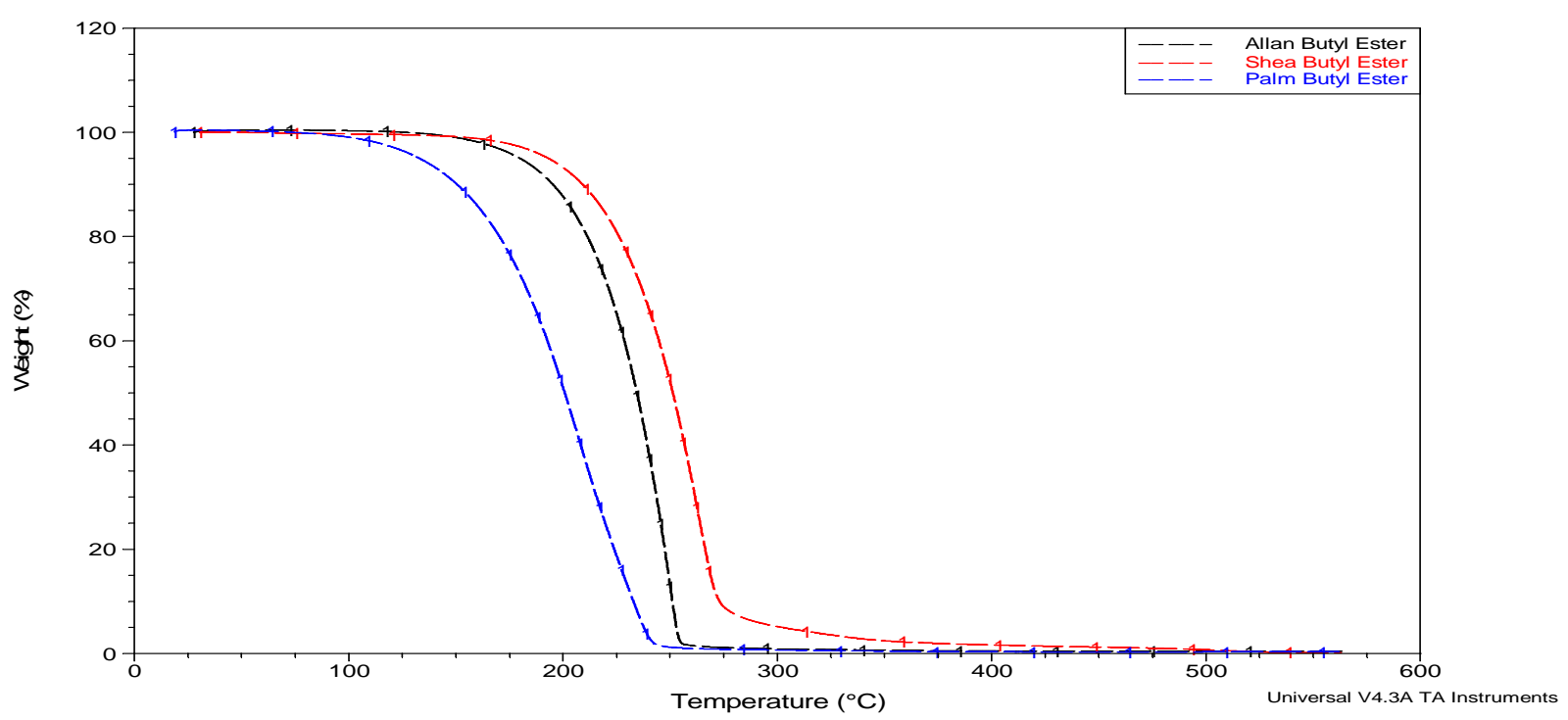

Fig. 6.20: Overlaid TGA curves of the butyl esters of Allanblackia, shea butter and palm kernel oil 
The butyl esters in Figure 6.20 shows that the most stable is shea butter, followed by Allanblackia and palm kernel butyl ester. The butyl esters degraded in a single step and they were stable within the desired temperature of interest.

\subsubsection{FTIR spectral analysis}

Table 6.2: Table showing observed peaks in FTIR spectra of esters of oil samples.

\begin{tabular}{|c|c|}
\hline Sample & Observed Peaks/cm' \\
\hline Allanblackia Methyl Ester & $\begin{array}{l}3007,2921,2853,1744,1463,1429,1375,1238,1159, \\
1116,721\end{array}$ \\
\hline TC Allanblackia Methyl Ester & $33007,2921,2853,1744,1463,1375,1238,1159,1116,721$ \\
\hline Allanblackia Butyl Ester & $\begin{array}{l}3007,2958,2923,2853,1738,1463,1376,1243,1172, \\
1117,1066,1023,956,840,722\end{array}$ \\
\hline TC Allanblackia Butyl Ester & $\begin{array}{l}3007,2958,2923,2853,1738,1463,1375,1243,1172, \\
1117,1066,1023,953,840,722\end{array}$ \\
\hline Shea Butter Methyl Ester & $\begin{array}{l}3007,2922,2853,1743,1463,1375,1244,1168,1117, \\
1017,857,721\end{array}$ \\
\hline TC Shea Butter Methyl Ester & $\begin{array}{l}3007,2922,2853,1743,1463,1375,1238,1167,1117, \\
1017,857,721\end{array}$ \\
\hline Shea Butter Butyl Ester & $\begin{array}{l}3007,2958,2923,2853,1738,1463,1376,1243,1172, \\
1118,1061,1023,968,840,722\end{array}$ \\
\hline TC Shea Butter Butyl Ester & $\begin{array}{l}3007,2958,2923,2853,1738,1463,1376,1243,1172, \\
1118,1067,1023,967,840,722\end{array}$ \\
\hline Palm Kernel Methyl Ester & $\begin{array}{l}2922,2853,1742,1463,1375,1249,1166,1113,1017,879, \\
722\end{array}$ \\
\hline
\end{tabular}




\begin{tabular}{|l|l|}
\hline TC Palm Kernel Methyl Ester & $\begin{array}{l}3309,2920,2852,1742,1466,1375,1249,1168,1112, \\
1047,879,721\end{array}$ \\
\hline Palm Kernel Butyl Ester & $\begin{array}{l}\text { 2957, 2923, 2854, 1738, 1463, 1376, 1238, 1171, 1114, } \\
1065,1023,962,840,722\end{array}$ \\
\hline TC Palm Kernel Butyl Ester & $\begin{array}{l}\text { 2957, 2923, 2854, 1738, 1463, 1376, 1244, 1171, 1114, } \\
1065,1023,962,840,722\end{array}$ \\
\hline
\end{tabular}

The mid-infrared spectroscopic analysis (FTIR) was used in characterizing the functional group chemistry of the non- and thermally cycled esters of Allanblackia, shea butter and palm kernel oil. Table 6.2 gives the wavenumbers of observed infrared peaks of the esters before and after thermal cycling. The spectra in Figure 6.21 showed that esters of Allanblackia oil absorbed within 3051 and $2820 \mathrm{~cm}^{-1}$ range. The spectra of all methyl and butyl esters followed the same pattern before and after thermal cycling. The shoulder peak around $2958 \mathrm{~cm}^{-1}$ was more characteristic of the butyl esters and was unresolved for the methyl esters. The absorption peak at $2921 \mathrm{~cm}^{-1}$ for methyl esters was more prominent with higher intensity than for the butyl esters at $2923 \mathrm{~cm}^{-1}$.

At the wavenumber of $2853 \mathrm{~cm}^{-1}$, the methyl esters are more prominent than the butyl esters. It is clear that these peaks have not been affected by the thermal cycling process. Figure 6.22 represents the FTIR spectra in the $1815 \mathrm{~cm}^{-1}$ to $1612 \mathrm{~cm}^{-1}$ range and differences in absorption peaks were observed for methyl and butyl esters. 


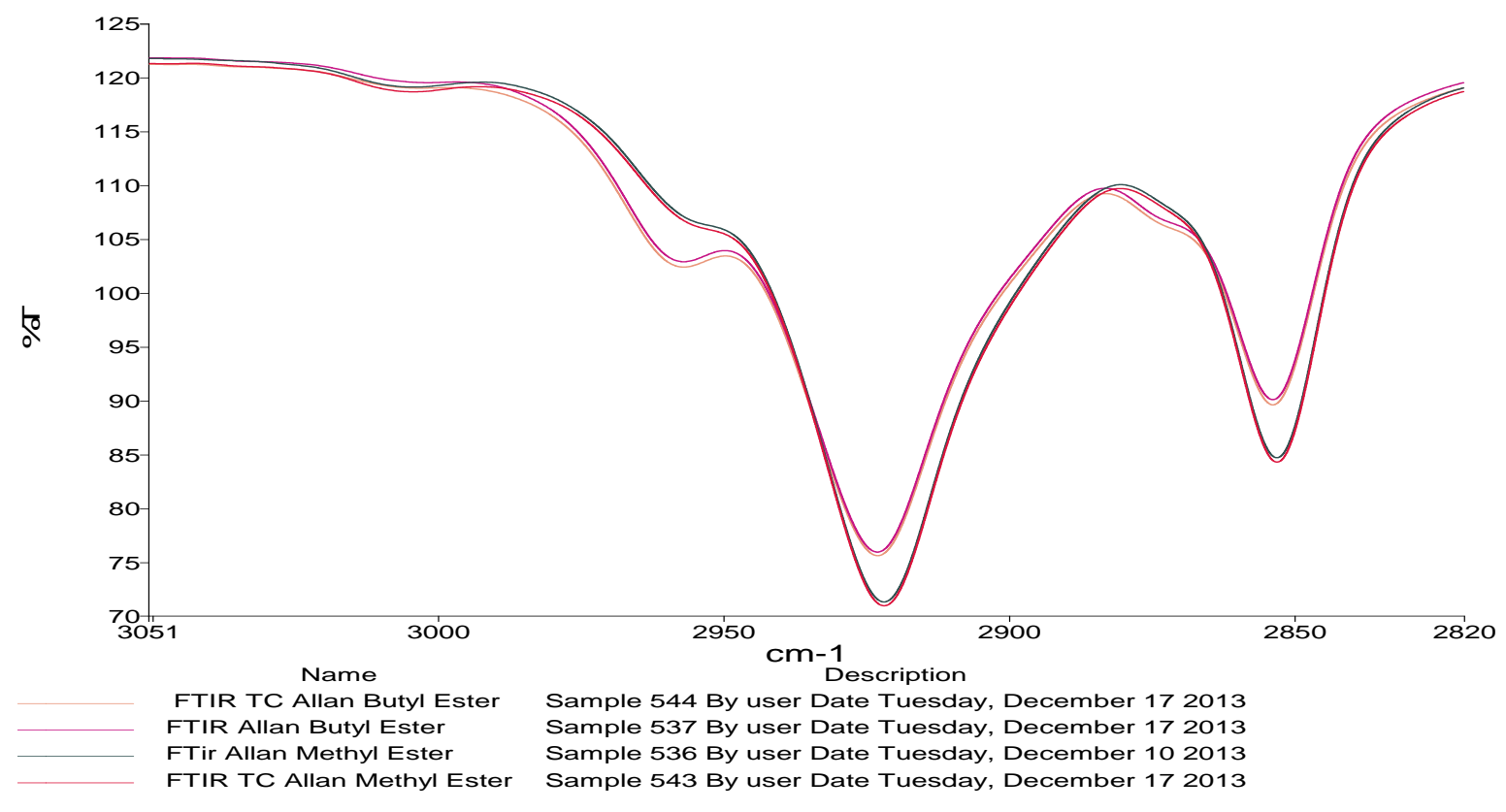

Fig. 6.21: Overlaid FTIR curves of the esters of Allanblackia oil and their thermally cycled products within $3051-2820 \mathrm{~cm}^{-1}$ region.

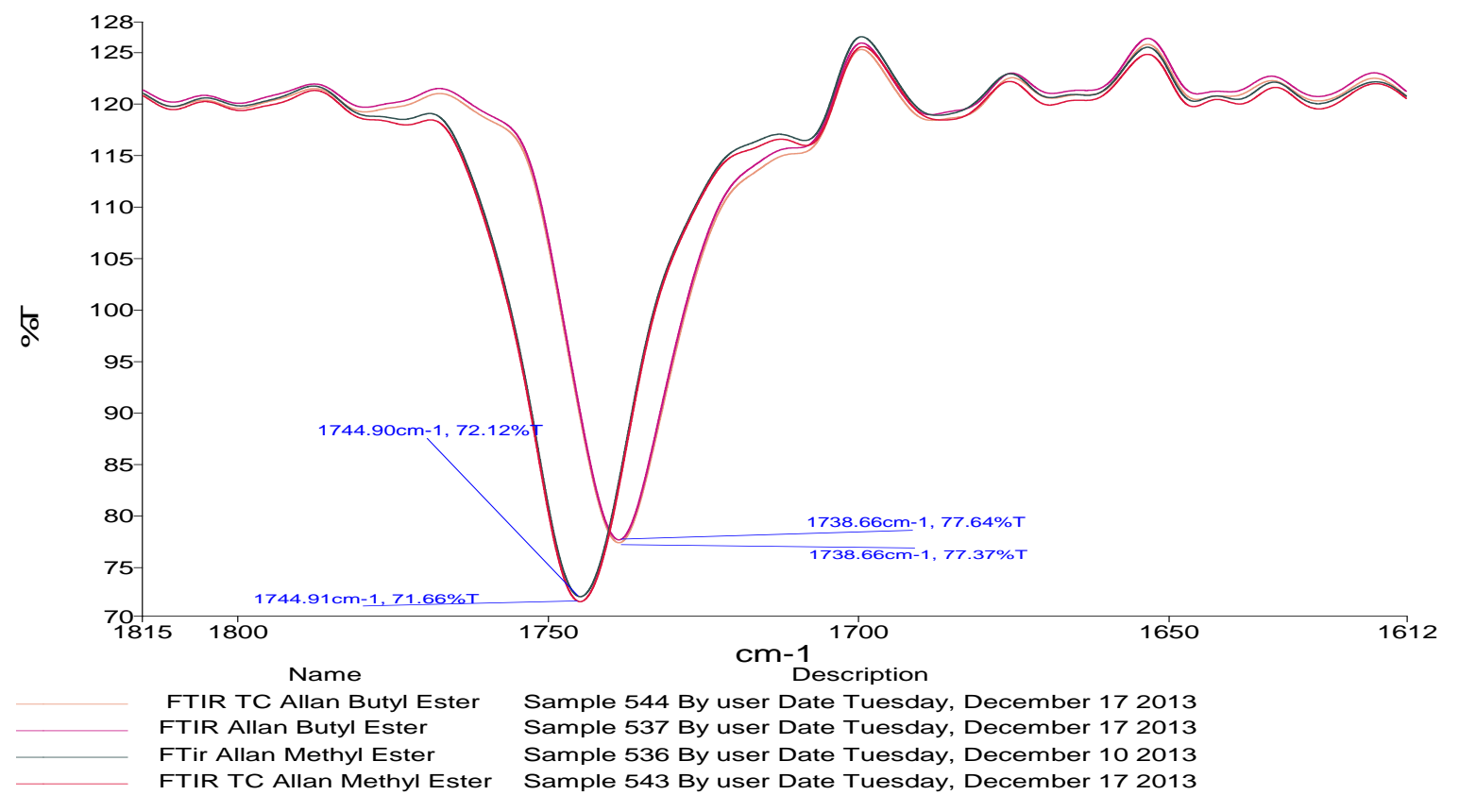

Fig. 6.22: Overlaid FTIR curves of non- and thermally cycled esters of Allanblackia oil in the $1815-1612 \mathrm{~cm}^{-1}$ region. 
The methyl ester peaks appeared at $1744 \mathrm{~cm}^{-1}$ for the ester carbonyl peak of methyl ester of Allanblackia while the butyl ester peak(s) for the same oil appeared at $1738 \mathrm{~cm}^{-1}$ for the ester carbonyl peaks of the butyl esters. Both non- and thermally cycled methyl and butyl esters exhibited similarly absorption peaks respectively. For butyl esters, both non- and thermally cycled samples exhibited similar absorption peaks. In the $1700 \mathrm{~cm}^{-1}-1600 \mathrm{~cm}^{-1}$ region, both methyl and butyl esters showed similar spectra. Marked difference in absorption peaks between methyl esters and butyl esters is shown in Figures 6.23 and Table 6.2. Absorption peaks at 1172, $1066,1023,956$ and $840 \mathrm{~cm}^{-1}$ for butyl esters are absent in the spectra of methyl ester curves. The intensities of the absorption peaks for methyl esters were higher than the butyl esters (Figure 6.23). Since the FTIR spectra of non- and thermally cycled methyl and butyl esters respectively were similar, no degradation of esters occurred, clear indication of their chemical stability. This is also confirmed by the TGA degradation curves.

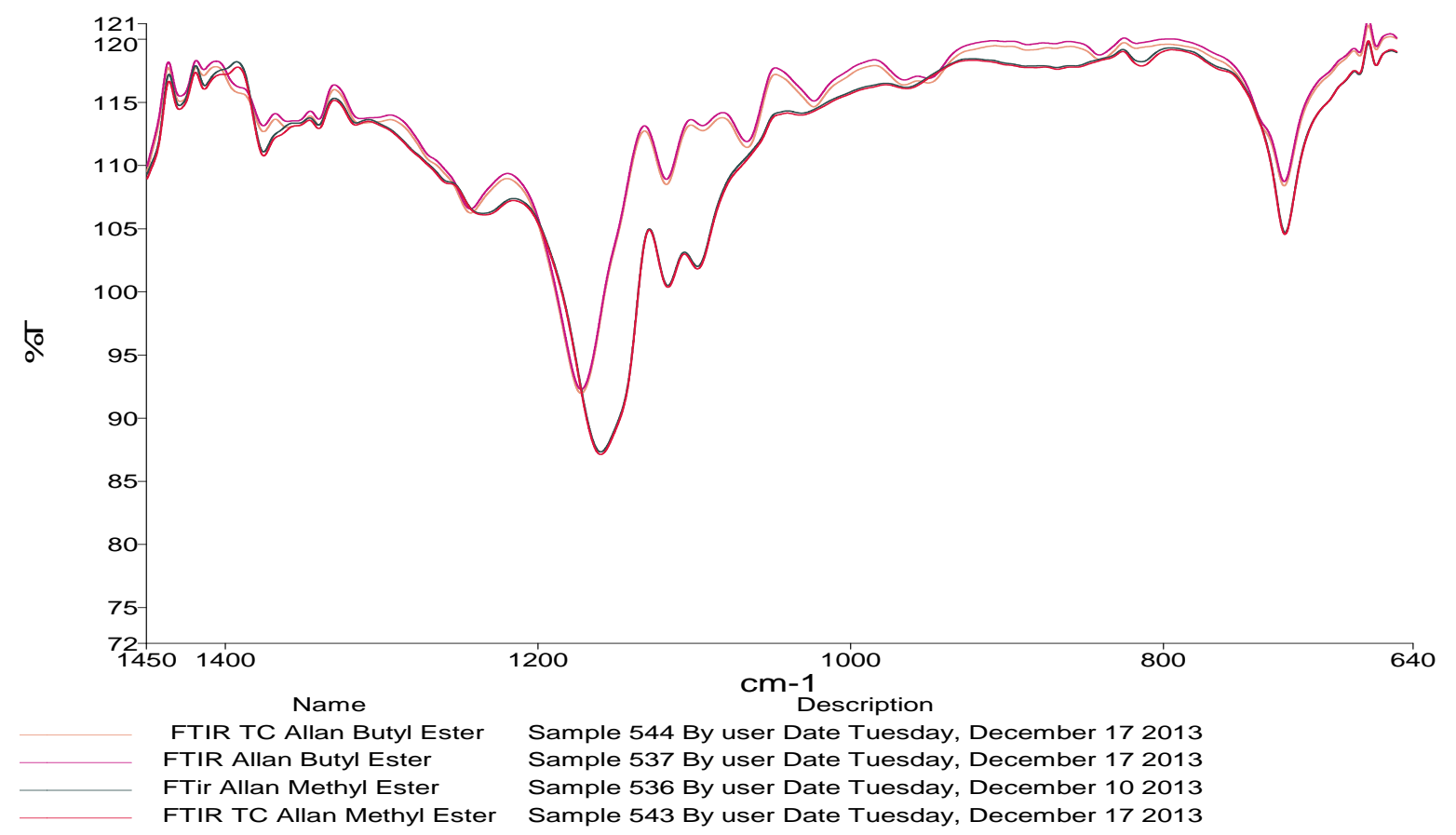

Fig. 6.23: Overlaid FTIR spectra of non- and thermally cycled esters of Allanblackia oil in the 1450 and $640 \mathrm{~cm}^{-1}$ region.

The full FTIR absorption spectra range of non- and thermally cycled esters of shea butter is shown in Figure 6.24. Butyl esters exhibited a shoulder peak at $2958 \mathrm{~cm}^{-1}$ but this peak is absent 
in methyl esters (Figures 6.24 and 6.25). The intensities of the absorption peaks at 2922 or 2923 $\mathrm{cm}^{-1}$ and $2853 \mathrm{~cm}^{-1}$ were higher for the methyl esters than the butyl esters.

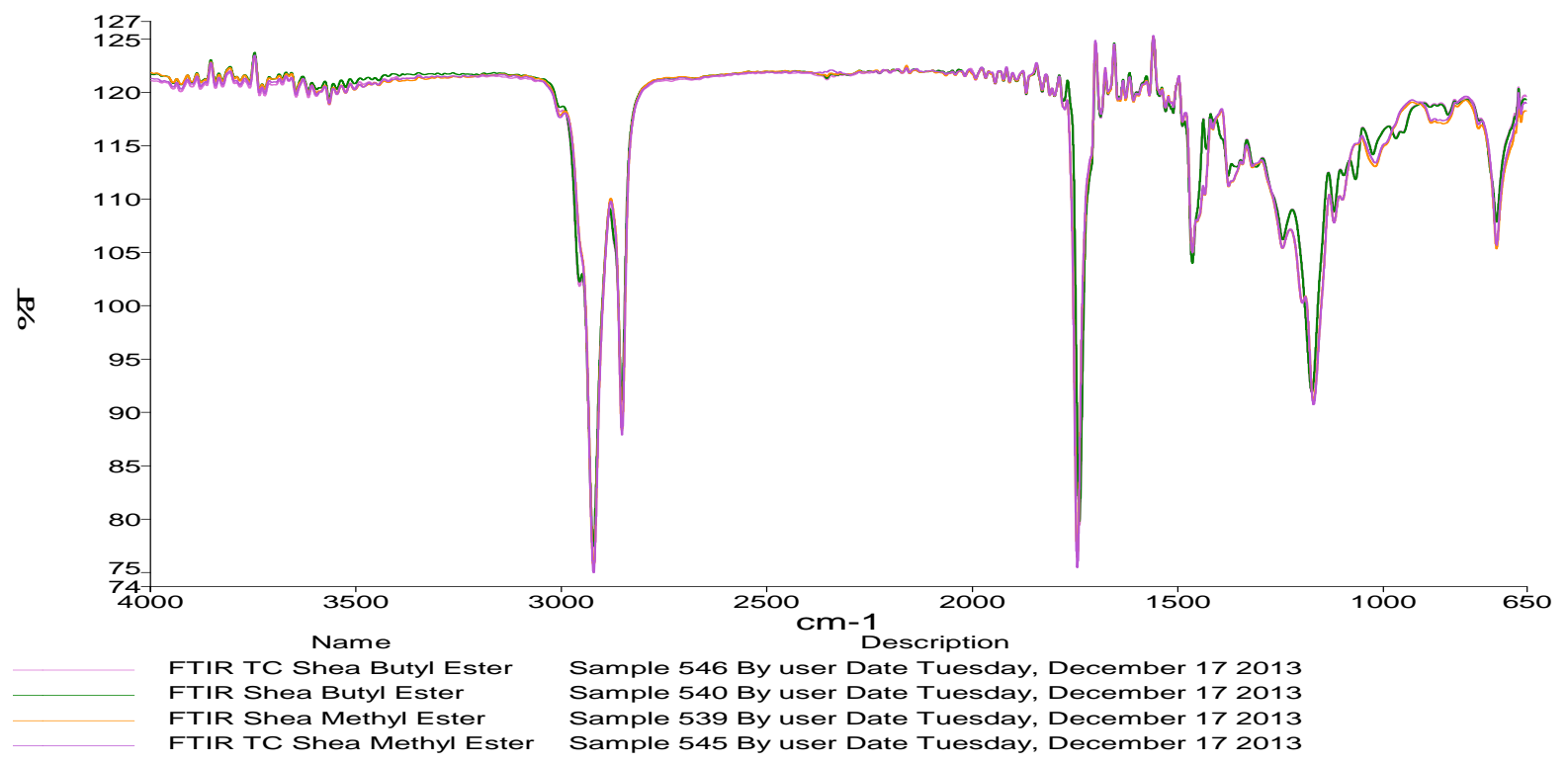

Figure 6.24: Overlaid FTIR curves of non- and thermally cycled esters of shea butter in the 4000 and $650 \mathrm{~cm}^{-1}$ region.

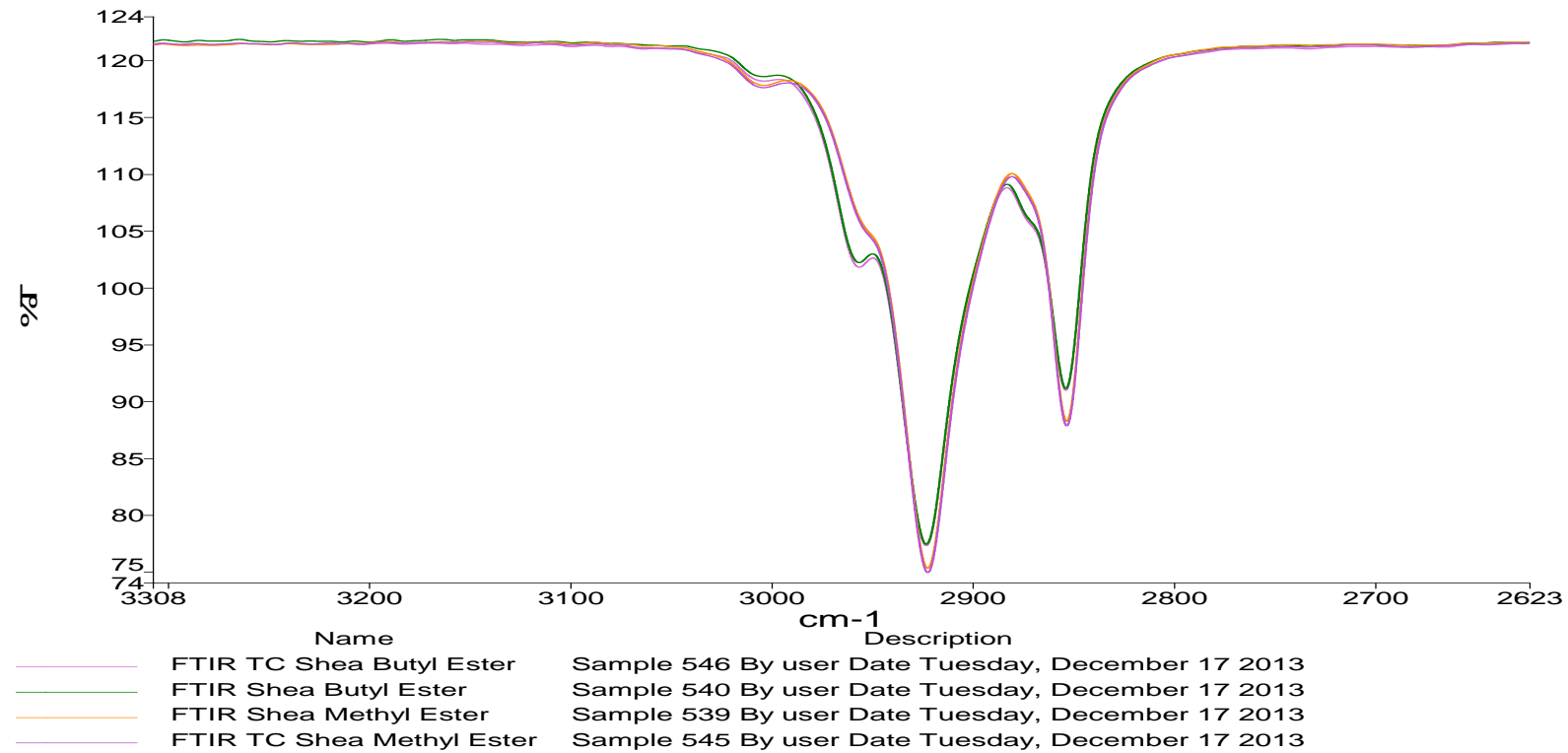

Figure 6.25: Overlaid FTIR curves of non- and thermally cycled esters of shea butter in the 3300 and $2623 \mathrm{~cm}^{-1}$ region. 
The carbonyl ester peaks for the butyl esters shifted to a lower wavenumber region at $1738 \mathrm{~cm}^{-1}$ and were coincident (i. e. shea butyl ester and TC shea butyl ester). The carbonyl ester peak for the methyl esters occurred at $1743 \mathrm{~cm}^{-1}$. Thermally cycled shea methyl esters gave a slightly higher intensity than the non-thermally cycled methyl ester.

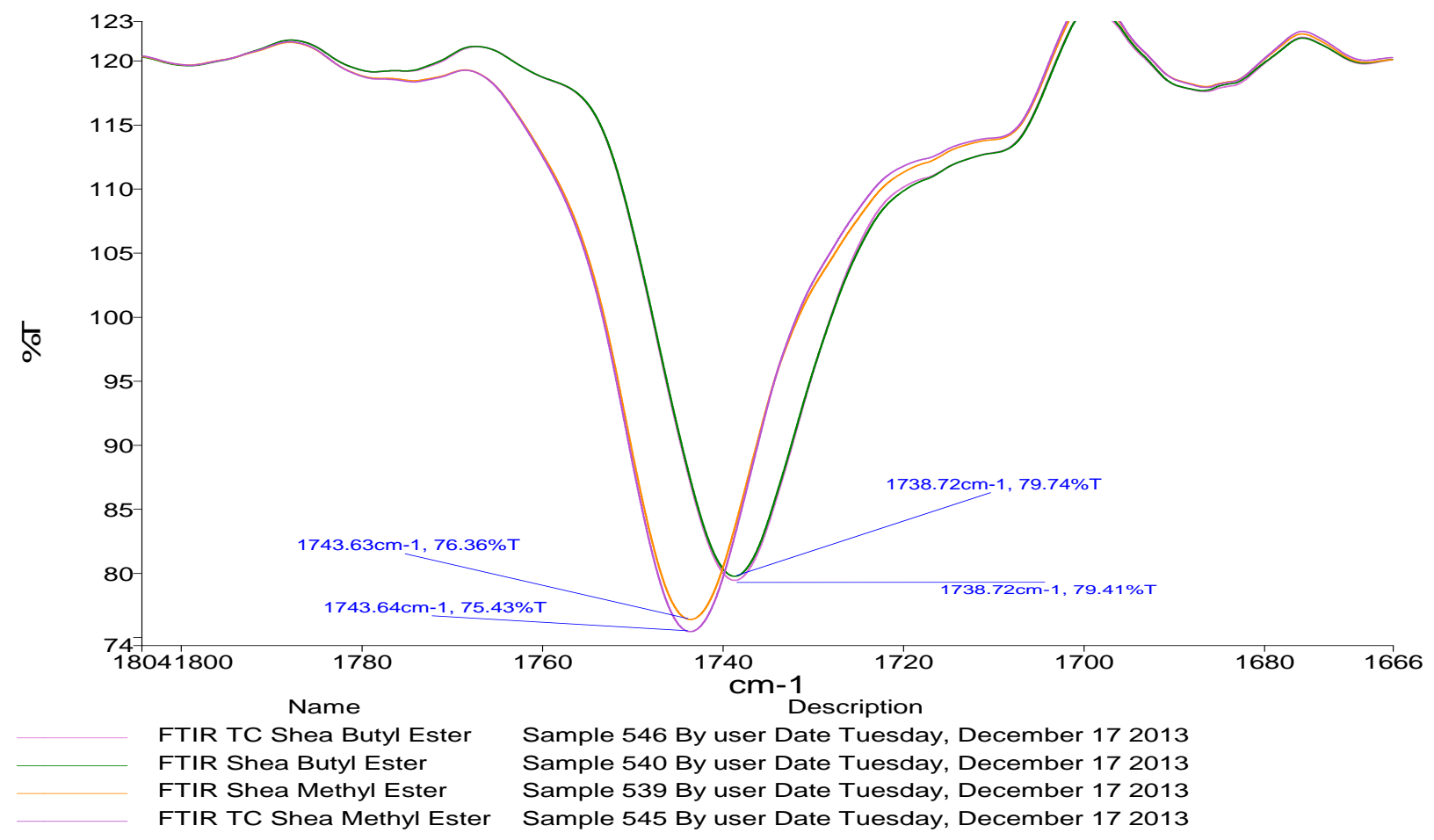

Fig. 6.26: Overlaid FTIR spectra of non- and thermally cycled esters of shea butter in 1804 and $1666 \mathrm{~cm}^{-1}$ region.

The FTIR spectra in the $1483 \mathrm{~cm}^{-1}$ and $650 \mathrm{~cm}^{-1}$ region, shows differences between the methyl and butyl esters. Of the non- and thermally cycled shea butter methyl and butyl esters respectively, no differences were observed in the spectra. These esters did not chemically disintegrate after thermally cycling them for a 1000 times within the desired temperature range. They are therefore thermally stable as also confirmed by TGA. 


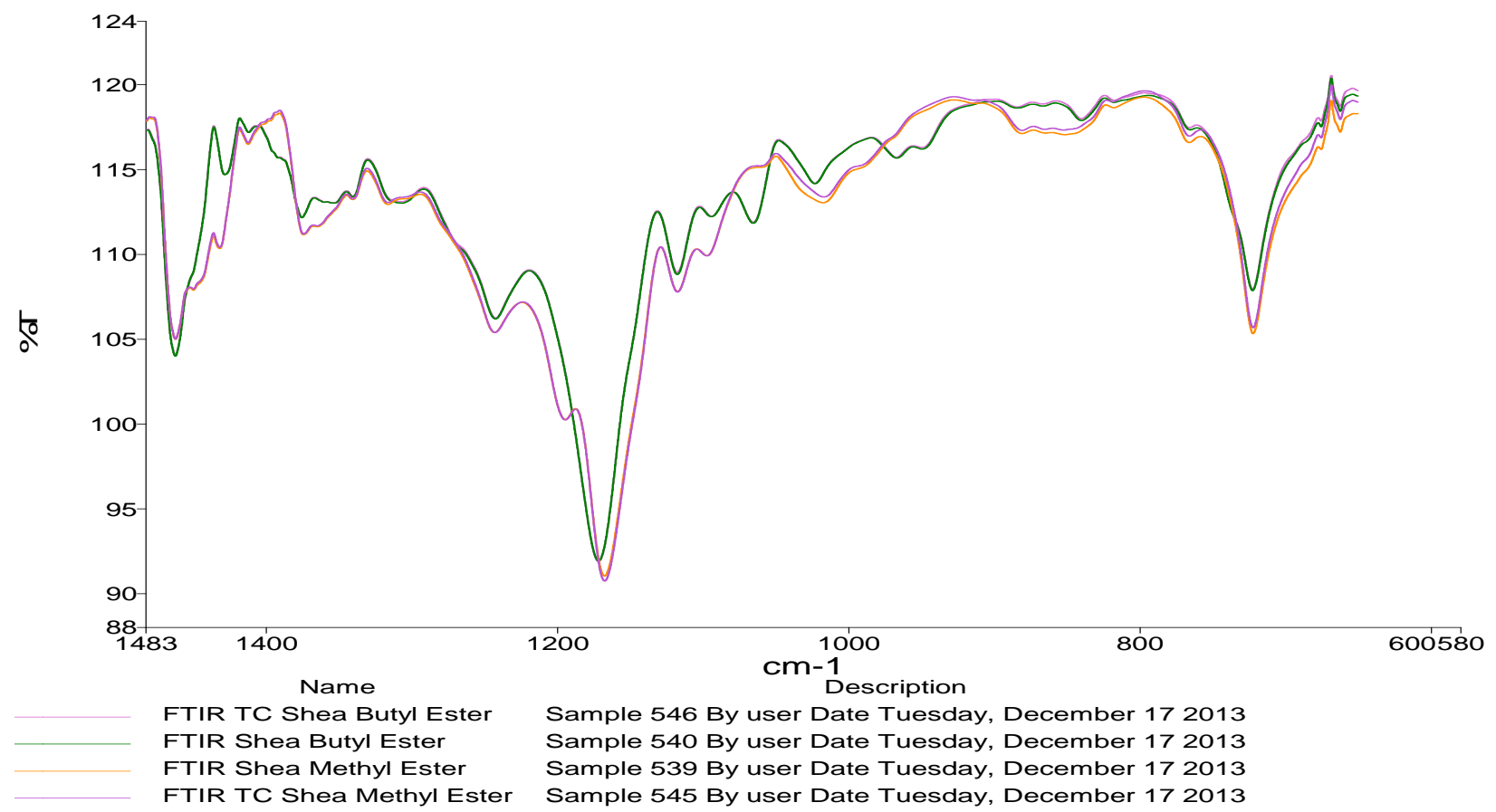

Fig. 6.27: Overlaid FTIR spectra of non- and thermally cycled esters of shea butter in 1483 and $650 \mathrm{~cm}^{-1}$ region.

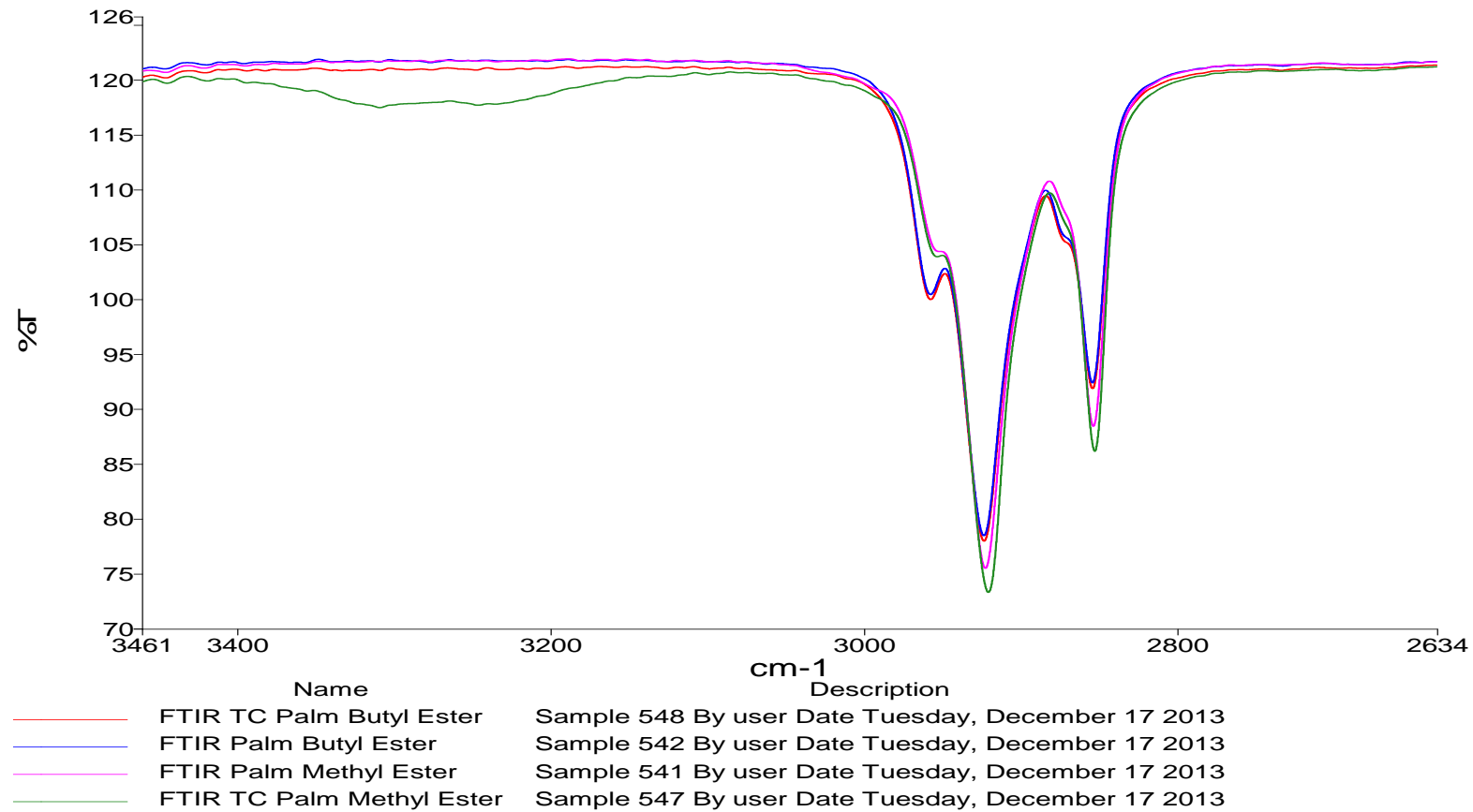

Fig. 6.28: Overlaid FTIR curves of non- and thermally cycled esters of palm kernel oil in 3461 and $2634 \mathrm{~cm}^{-1}$ region. 
The FTIR spectra of non- and thermally (1000 times) cycled methyl and butyl esters of palm kernel oil is shown respectively at 3461 and $2634 \mathrm{~cm}^{-1}$ region in Figure 6.28. The FTIR spectra of non- and thermally cycled methyl ester were slightly different. A broad peak at $3309 \mathrm{~cm}^{-1}$ was attributed to $\mathrm{OH}$ absorption. This absorption peak is absent in the non-thermally cycled sample. They also exhibited different intensities at $2922 \mathrm{~cm}^{-1}$. While the FTIR spectra of non- and thermally cycled butyl esters of palm kernel oil showed no difference, the spectra for non- and thermally cycled methyl ester exhibited some difference. This indicated a change in chemistry of the palm kernel methyl ester produced and hence an effect on the thermal stability of the ester.

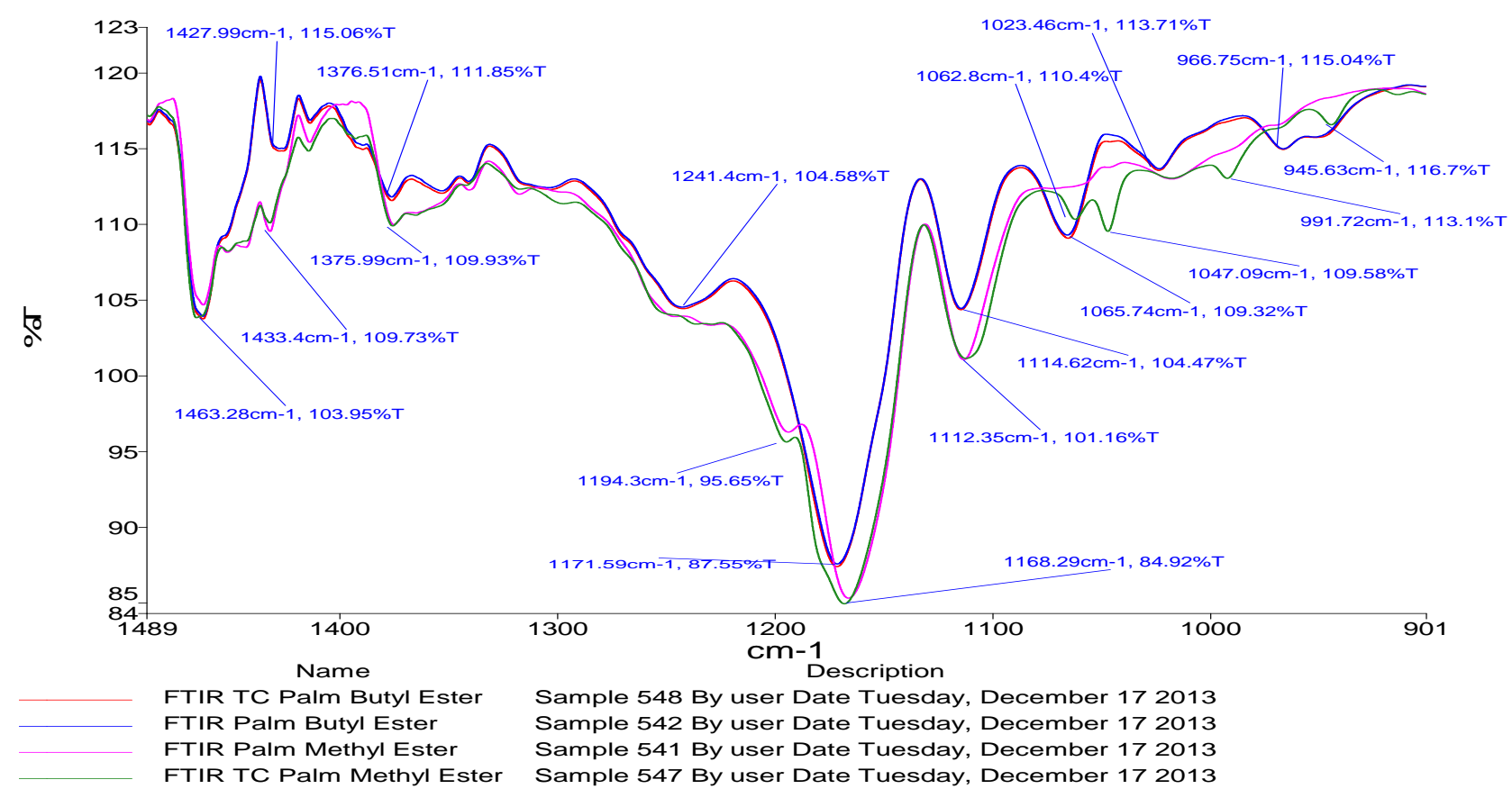

Fig. 6.29: Overlaid FTIR curves of non- and thermally cycled esters of palm kernel oil in 1489 and $901 \mathrm{~cm}^{-1}$ region.

\subsection{Conclusion}

It was clear by DSC measurement that Allanblackia methyl ester displayed a lot of polymorphic changes after just one cycle with peak temperature reducing by $7.87^{\circ} \mathrm{C}$ and enthalpy value also decreasing by as much as $13.97 \mathrm{~J} / \mathrm{g}$. Again the enthalpy values involved were low with melting being $38.44 \mathrm{~J} / \mathrm{g}$ reducing to $24.47 \mathrm{~J} / \mathrm{g}$ and crystallization shown to be $12.06 \mathrm{~J} / \mathrm{g}$. After thermal cycling for 1000 times, the same polymorphic properties showed up but unexpectedly, the 
enthalpy values increased for both melting and crystallization. Allanblackia methyl ester could therefore not be considered as a good candidate for PCM for latent heat storage considerations due to unreliable characteristics. The butyl ester from Allanblackia looked more coincident than the methyl ester. Again there were enthalpy differences between first and second heating. Multiple overlapping peaks were observed for the second heating as well as the crystallization. After thermal cycling, the properties again improved but the enthalpy values were smaller for both melting and crystallization. The enthalpy values for the butyl esters were larger than the methyl ester. The latent heat energy properties of the butyl ester could be considered for PCM storage but at low temperature applications. Differential scanning calorimetry showed that the curves of shea butter methyl ester for the first and second heating process were more coincident. The heating curves showed a single peak while the crystallization gave multiple peaks with the two peaks overlapping. The crystallization curve was too broad for it to be considered latent while the melting was more coincident. After thermal cycling, there was a change in the enthalpy values which was expected. Shea butter methyl ester could therefore not be suitable as a PCM for thermal latent energy storage systems. Shea butter butyl ester first and second heating were coincident and were more latent in nature. After thermal cycling, the shape did not alter even though enthalpy values were reduced due to the expected thermal cycling effect. Peak temperatures were also reduced. Shea butter butyl esters looked more promising as a PCM with better properties. However, the enthalpy values were small. Palm kernel methyl esters were not suitable as a PCM since it could not produce any discernible peaks. Palm kernel butyl esters did show consistent peaks but they were too small and the temperatures involved were low and could be considered as a PCM.

TGA data and thermograms of Allanblackia methyl and butyl esters were both stable within the temperature of interest. Allanblackia methyl esters were more stable at higher temperatures than their butyl esters counterpart, but the methyl ester was more polymorphic and degraded in multiple steps in comparison to the butyl ester. For shea butter, the methyl and butyl esters were stable within the temperature of interest. The methyl ester at higher temperatures exhibited multiple degradation steps. However, the thermal stability of butyl esters after thermal cycling was reduced significantly, even though they exhibited the same single degradation step. Within the temperature of interest, both the methyl and butyl esters of palm kernel oil were thermally stable. They however degraded at a much lower temperature $\left(81^{\circ} \mathrm{C}\right)$. Initially, the butyl esters 
showed more thermal stability than the methyl esters while the methyl esters degraded in multiple steps. The first degradation step for the butyl esters was more thermally stable than the methyl esters, but their second and third degradation steps for the methyl ester was more stable than the butyl ester. The thermal stability order at higher temperatures for butyl esters were: shea butter $>$ Allanblackia $>$ palm kernel, and they all degraded in a single step. However, within the temperature of interest, they were thermally stable.

Allanblackia methyl and butyl esters were all chemically (and therefore) stable since FTIR spectra before and after thermal cycling showed no change in their functional group chemistry. The esters of shea butter exhibited no difference in their FTIR spectra before and after thermal cycling and consequently in their functional group chemistry. This reflected the chemical (and therefore thermal) stability of the esters of shea butter. The butyl esters of palm kernel oil were chemically and thermally stable as no changes in their functional group chemistry after thermal cycling were observed. However, the methyl ester showed changes in their FTIR spectra after thermal cycling. This indicated thermal degradation of the original product before thermal cycling, and hence a confirmation of thermal instability.

In conclusion, both the thermo-physical and chemical properties of the esters showed that butyl esters of Allanblackia and shea butter were good candidates for use as PCMs for thermal energy storage systems.

\subsection{References}

Berera, G. P. 2006. Thermal energy storage systems - stearic/lauric acid mixtures as phase change materials. 3.014 Materials laboratory Module -1. 9.

Berger, K.G., and Akehurst, E.E. (1966). Some applications of differential thermal analysis to oils and fats. International Journal of Food Science \& Technology 1, 237-247.

Garg, H.P., Mullick, S.C., and Bhargava, A.K. (1985). Solar thermal energy storage (Springer Science \& Business Media).

http://www.biomassenergy.gr/en/articles/technology/biodiesel/505-biodiesel-production-and-thetransesterification-process. Accessed on 08/18/2014.

Lang, X., Dalai, A.K., Bakhshi, N.N., Reaney, M.J., and Hertz, P.B. (2001). Preparation and characterization of bio-diesels from various bio-oils. Bioresource Technology 80, 53-62. 
Mahamuni, N.N., and Adewuyi, Y.G. (2009). Fourier transform infrared spectroscopy (FTIR) method to monitor soy biodiesel and soybean oil in transesterification reactions, petrodieselbiodiesel blends, and blend adulteration with soy oil. Energy \& Fuels 23, 3773-3782.

Nimcevic, D., Puntigam, R., Wörgetter, M., and Gapes, J.R. (2000). Preparation of rapeseed oil esters of lower aliphatic alcohols. Journal of the American Oil Chemists' Society 77, 275-280.

Sar1, A. (2003). Thermal characteristics of a eutectic mixture of myristic and palmitic acids as phase change material for heating applications. Applied Thermal Engineering 23, 1005-1017.

Sarı, A. (2003). Thermal reliability test of some fatty acids as PCMs used for solar thermal latent heat storage applications. Energy Conversion and Management 44, 2277-2287.

Sarı, A., Biçer, A., and Karaipekli, A. (2009). Synthesis, characterization, thermal properties of a series of stearic acid esters as novel solid-liquid phase change materials. Materials Letters 63, $1213-1216$.

Sarı, A., Biçer, A., Karaipekli, A., Alkan, C., and Karadag, A. (2010). Synthesis, thermal energy storage properties and thermal reliability of some fatty acid esters with glycerol as novel solidliquid phase change materials. Solar Energy Materials and Solar Cells 94, 1711-1715.

Sarı, A., Biçer, A., Lafçı, Ö., and Ceylan, M. (2011). Galactitol hexa stearate and galactitol hexa palmitate as novel solid-liquid phase change materials for thermal energy storage. Solar Energy 85, 2061-2071.

Sharma, A., Tyagi, V.V., Chen, C.R., and Buddhi, D. (2009). Review on thermal energy storage with phase change materials and applications. Renewable and Sustainable Energy Reviews 13, $318-345$.

Sharma, S.D., and Sagara, K. (2005). Latent heat storage materials and systems: a review. International Journal of Green Energy 2, 1-56.

Shukla, A., Buddhi, D., and Sawhney, R.L. (2008). Thermal cycling test of few selected inorganic and organic phase change materials. Renewable Energy 33, 2606-2614.

Tan, C.P., and Man, Y.B. (2002). Comparative differential scanning calorimetric analysis of vegetable oils: I. Effects of heating rate variation. Phytochemical Analysis 13, 129-141.

Tan, C.P., and Man, Y.C. (2000). Differential scanning calorimetric analysis of edible oils: comparison of thermal properties and chemical composition. Journal of the American Oil Chemists' Society 77, 143-155.

Wang, X., Lu, E., Lin, W., Liu, T., Shi, Z., Tang, R., and Wang, C. (2000). Heat storage performance of the binary systems neopentyl glycol/pentaerythritol and neopentyl glycol/trihydroxy methyl-aminomethane as solid-solid phase change materials. Energy Conversion and Management 41, 129-134. 


\section{GENERAL CONCLUSIONS}

In the biodiesel production using homogeneous as well as heterogeneous catalysis. The homogeneous catalysis gave the highest optimum yield of $94.72 \%$ with the reaction conditions of the TOFA to methanol molar ratio of $15: 1$ at a temperature of $75^{\circ} \mathrm{C}$ with a catalyst concentration of $0.5 \mathrm{wt} \%$ of the TOFA weight and a time of 60 minutes $(1 \mathrm{hr})$. The spectra from FTIR was in agreement with this reaction condition. The acid value obtained for the homogeneous catalysis was higher than the prescribed ASTM standard value even though the kinematic viscosity value was within the ASTM standards. In the heterogeneous catalysis, the temperature was kept constant at $75-80^{\circ} \mathrm{C}$ and the predicted optimum operating conditions gave a yield of $93.12 \%$ at a TOFA to methanol molar ratio of $21.7: 1$, a catalyst concentration of $23.4 \%$ at a reaction time of 4.7 hours. The optimum condition obtained for the heterogeneous catalysis was outside the design parameters and hence could not be compared with the FTIR spectra obtained. The acid value for the heterogeneous catalysis was however, lower than that for the homogeneous catalysis and within the ASTM standard. The solid catalyst could however be recycled four times without loss in activity of the catalyst.

In the thermal energy studies, the pure oils showed that the energies absorbed or released by the shea butter and palm kernel oil were not latent heat energies because they melt and freeze over too wide a temperature range and were also too polymorphic. Allanblackia oil showed a decrease in latent energies after 1000 thermal cycling. They could however, still be relied on to operate at that reduced enthalpy. Allanblackia oil also showed some oxidative instability and FTIR indicated little reduction in the same FTIR spectral peaks, thus showing chemical stability even though the peaks reduced slightly. The TGA thermogram showed thermal stability within the temperature of interest.

Upon hydrolysis of the oils to their respective fatty acids, Allanblackia fatty acid improved its enthalpy value for both the melting and crystallization process and the energy involved was latent energy. Thermal cycling for 1000 times showed a $37.72 \%$ decrease in energy for the melting process and a $26.43 \%$ decrease in energy for the crystallization process. However, the final energy can still be considered high after thermal cycling. Fatty acid of Allanblackia, AllanFA is also thermally stable and chemically stable. The fatty acids produced from the shea butter and the palm kernel oil did not produce latent energies because they melted over a wide 
range of temperature with too many transition peaks. SheaFA showed that it is thermally unstable since it decomposes within the temperature of interest.

Considering the methyl and butyl esters produced from the respective fatty acids, all the esters are chemically stable except palm kernel methyl ester which showed chemical disintegration after thermal cycling. The methyl esters degraded at higher temperatures than the butyl esters, but the methyl esters degraded with multiple degradation steps than the butyl esters which degraded with single steps even though they all degraded outside the temperature of interest. Hence, all the methyl as well as the butyl esters showed thermal stability. Allanblackia methyl ester showed loss in enthalpy even after a single cycle while the butyl ester is more resilient and shows more reliability. The butyl esters for Allanblackia oil and shea butter gave enthalpy values at reduced temperatures but can be considered as potential for use as PCMs for thermal energy storage while palm kernel butyl ester is not suitable as a PCM because the enthalpies are too small and the temperature involved is too low. All the methyl esters are unsuitable for use as PCMs for thermal energy storage. So, in effect, the potential esters for PCMs are Allanblackia butyl ester and shea butter butyl ester. 


\section{FUTURE RECOMMENDATIONS}

The work on the use of TOFA as a feedstock for biodiesel production has been experimented upon by other researchers using different parameters. One of the main hurdles is how to reduce the high acid content to acceptable levels to make the biodiesel useable which could be achieved by the heterogeneous catalysis. The results obtained from this study can however, be improved by future studies.

1. Further work on the use of the heterogeneous catalyst, Amberlyst BD 20 should be done under pressure in order to increase yield and also the predicted conditions actually measured.

2. Also, instead of a batch process, a continuous process should be experimented on.

3. Cost analysis on the use of TOFA should be done to ensure cost effectiveness.

The use of fruit oils as PCMs for latent energy considerations in thermal energy storage systems has not been experimented upon. This is however, a new study and so further studies are needed to ascertain their complete viability and eligibility for their use as PCMs.

1. The oil samples should be purified in order to remove all impurities in them.

2. The use of environmentally friendly additives to increase energy content should be addressed.

3. There are a large number of tropical oil producing plants whose oils can be assessed and experimented upon to see if they have thermo-physical and chemical properties for use as potential PCMs.

4. The thermal conductivity of the samples experimented upon should be determined to complete eligibility studies.

5. The eligible products should be experimented on actual systems like solar water heaters.

6. Mixed pure oils can be hydrolyzed or esterified to see what products turn out since the mixed raw oils produced too main multiple unresolved peaks in the process. 